FINAL REPORT

FHWA/IN/JTRP-2002/34

\title{
CONSTRUCTION WORK ZONE SAFETY
}

\author{
By \\ Christopher Ryan Huebschman \\ Graduate Research Assistant \\ Camilo Garcia \\ Graduate Research Assistant \\ Darcy M. Bullock \\ Professor \\ Dulcy M. Abraham \\ Associate Professor \\ School of Civil Engineering \\ Purdue University \\ Joint Transportation Research Program \\ Project No: C-36-59FF \\ File No: 8-5-32 \\ SPR- 2496 \\ Conducted in Cooperation with the \\ Indiana Department of Transportation and the \\ U.S. Department of Transportation \\ Federal Highway Administration
}

The contents of this report reflect the views of the authors, who are responsible for the facts and the accuracy of the data presented herein. The contents do not necessarily reflect the official views or policies of the Indiana Department of Transportation or the Federal Highway Administration at the time of publication. The report does not constitute a standard, specification, or regulation.

\footnotetext{
Purdue University

West Lafayette, IN 47907

June 2003
} 


\section{TECHNICAL Summary}

Technology Transfer and Project Implementation Information

INDOT Research

TRB Subject Code:51-8 Work Zone Safety

Publication No.: FHWA/IN/JTRP-2002/34, SPR-2496

June 2003

Final Report

\section{Construction Work Zone Safety}

\section{Introduction}

The segment of road where construction activities takes place is commonly defined as a work zone. Work zones on interstates are most of the times unexpected by the traveling public, increasing the likelihood of accidents occurrences. The natural aging of the highway infrastructure has led to an increase in the number of work zones on interstates. As evidenced in recent years, the attention has been shifted to perform less new construction and instead conduct more rehabilitation and/or reconstruction of existing highway facilities. Therefore, the work is being performed with high exposure to traffic. Maintaining safety of both the traveling public and construction workers performing the work are difficult tasks faced by transportation officials.

Several statistics revealed alarming number of fatalities and accidents during periods of construction work on highways. The statistics have been increasing throughout years, unveiling even more the need for measures to improve safety during periods of work. Several states including Indiana have had the misfortune of experiencing fatalities and accidents during construction work on interstates. During the period of April to May of 2001, a bridge rehabilitation project on I-65 in Lafayette was the site of several fatalities and accidents.

The need of maintaining safety of motorists and workers during periods of construction activities on interstates has prompted the Indiana Department of Transportation (INDOT) to initiate a study aiming to improve the safety in work zones on rural interstates. The two main objectives of the project consisted in 1) determining if active warning devices or improved signing have an impact in work zone safety and 2) to determining if it is appropriate to consider temporary roads and bridges during construction activity on interstates in an effort to maintain two lanes open at all times.

\section{Findings}

An extensive evaluation was conducted to investigate the features of several traffic management technologies currently available. The systems analyzed have been designed to inform the traveling public of the changing conditions during periods of construction work on interstates. These technologies have been proven effective as dissemination tools for informing motorists of the conditions that lie ahead. However, these systems have not been found to be associated with an improvement of safety on interstate work zones. The spacing between sensors and the limitation in communications influences the information that is being displayed to motorists. The benefits of these systems can sometimes be outweighed by their costs, if such systems are not deployed appropriately.

The number of accidents and fatalities is expected to increase during periods of work zones. However, the increase in these numbers was not quantified in the past. Data from sixteen (16) interstate projects in the state of Indiana was analyzed in an effort to quantify the increment of these occurrences during periods of work. Data was analyzed for the period of construction and the same period one year prior to the construction period when there was no construction in the particular section of the highway. Based on the findings, the accident rate was found to increase by twenty seven and one 
half percent $(27.5 \%)$. The high consistency of the regression value $(0.995)$ obtained, showed high confidence on the results obtained.

To inform drivers well in advance of the work zone of the construction activities taking place, a pilot project was initiated in the I-65/US-30 interchange reconstruction project near Merrillville, IN. The deployment of experimental signs consisted of fixed panel signs and Variable Message Signs (VMS) prior to entering the work zone. The panel signs used included a combination of signs presently used by INDOT. The VMS displayed the number of traffic citations issued to date in the work zone. The installation of the panel signs had a significant reduction in the average speeds only at the US-30 interchange. The results also indicated that displaying the number of tickets issued to date did not have a significant impact on the average speeds of motorists throughout the study area. Although a significant reduction in the average speed was observed at the US-30 interchange (heart of work zone), this speed reduction was associated with the installation of the fixed panel signs, rather than with the installation of the Variable Message Signs displaying the number of tickets.

An enforcement study was also conducted in the I-65/US-30 project to evaluate the effectiveness of Indiana State Police (ISP) patrols in advance and though the work zone. Results of the evaluation showed a reduction in the speeds of vehicles traveling the work zone when enforcement was present. The study indicated that a significant speed reduction (greater than 5 mph) occurred on I-65 adjacent to the trooper. This significant speed reduction remained in effect 1.2 miles downstream of the trooper, but was not present 2.4 miles downstream of the trooper.

A travel time study was conducted with the use of a GPS device has been presented. This study showed the benefits of utilizing such systems to document and reference conditions throughout the life of the work zone. The benefits of using GPS systems include the possibility of linking a type of lane restriction to its impact on traffic flow and to use this knowledge in future construction seasons.

An economic model was developed to determine the feasibility of maintaining two lanes open at all times during work zones. This model was developed in terms of the costs of shoulder strengthening, temporary bridges, accidents and fatalities. This model provides INDOT with a preliminary tool for deciding if two lanes open should be maintained in a particular project. The model was validated by using one project located on I-65 near the Tippecanoe/White county border in the state of Indiana.

\section{Implementation}

Improving safety of both motorists and construction workers has led departments of transportation to implement several alternatives in an effort to minimize the occurrences of accidents and fatalities during periods of work on interstates. Changes in traveling conditions typically associated with work zones increase the likelihood of accident occurrences. It is therefore important to inform the traveling public well in advance of the work zone of the changing conditions that lie ahead.

The Indiana Department of Transportation has initiated this study in an effort to find mechanisms to improve the safety on rural interstate work zones in the state of Indiana. The most important findings of this evaluation:

- The benefits associated with deploying traffic management technologies were found to be outweighed by their costs.
- Accident rates on rural interstates can be expected to increase approximately thirty percent during periods of construction.

- Fixed panel signs result in isolated speed reduction in the work zone. This may be of some safety benefit to the construction workers in the immediate construction area.

- Neither the fixed signs nor the variable message signs advising motorists of the enforcing activity appeared to have an impact on upstream speeds. Since high speed rear end collisions are the most significant motorist safety problem, it is not clear these signs will reduce fatal accidents resulting from approaching 
the workzone traffic queue at prevalent speeds.

- Enforcement activity was found to significantly reduce speeds (greater than $5 \mathrm{mph}$ ) at the location adjacent to the trooper. However, the effect of the trooper diminishes as the motorists increase their distance from the trooper.

- GPS systems provide the capability of linking a type of lane restriction to its impact on traffic flow and use this knowledge in future construction seasons.

- The decision to maintain two operational lanes per direction in a particular project can be evaluated using the economic model provided in the report.

\section{Contacts}

For more information:

Prof. Darcy M. Bullock

Principal Investigator

School of Civil Engineering

Purdue University

West Lafayette IN 47907

Phone: (765) 494-2226

Fax: (765) 496-1105

\section{Prof. Dulcy M. Abraham}

Principal Investigator

School of Civil Engineering

Purdue University

West Lafayette IN 47907

Phone: (765) 494-2239

Fax: (765) 494-0644
Indiana Department of Transportation

Division of Research

1205 Montgomery Street

P.O. Box 2279

West Lafayette, IN 47906

Phone: (765) 463-1521

Fax: (765) 497-1665

\section{Purdue University}

Joint Transportation Research Program

School of Civil Engineering

West Lafayette, IN 47907-1284

Phone: (765) 494-9310

Fax: (765) 496-1105 
TECHNICAL REPORT STANDARD TITLE PAGE

\begin{tabular}{|c|c|c|}
\hline $\begin{array}{l}\text { 1. Report No. } \\
\text { FHWA/IN/JTRP-2002/34 }\end{array}$ & 2. Government Accession No. & 3. Recipient's Catalog No. \\
\hline \multirow{2}{*}{\multicolumn{2}{|c|}{$\begin{array}{l}\text { 4. Title and Subtitle } \\
\text { Construction Work Zone Safety }\end{array}$}} & $\begin{array}{l}\text { 5. Report Date } \\
\text { June } 2003\end{array}$ \\
\hline & & 6. Performing Organization Code \\
\hline \multicolumn{2}{|l|}{$\begin{array}{l}\text { 9. Performing Organization Name and Address } \\
\text { Joint Transportation Research Program } \\
1284 \text { Civil Engineering Building } \\
\text { Purdue University } \\
\text { West Lafayette, IN 47907-1284 }\end{array}$} & 10. Work Unit No. \\
\hline \multicolumn{2}{|l|}{$\begin{array}{l}\text { 12. Sponsoring Agency Name and Address } \\
\text { Indiana Department of Transportation } \\
\text { State Office Building } \\
100 \text { North Senate Avenue } \\
\text { Indianapolis, IN } 46204\end{array}$} & 14. Sponsoring Agency Code \\
\hline \multicolumn{3}{|l|}{ 15. Supplementary Notes } \\
\hline
\end{tabular}

\section{Abstract}

The need of maintaining safety of motorists and workers during periods of construction activities on interstates has prompted the Indiana Department of Transportation (INDOT) to initiate a study aimed at improving the safety in work zones on rural interstates. The two main objectives of the project are 1) determine if active warning devices or improved signing have an impact in work zone safety and 2) determine if it is appropriate to consider temporary roads and bridges during construction activity on interstates in an effort to maintain two lanes open at all times.

This report describes the methods used to meet the objectives set forth by INDOT. The report has been subdivided into four major parts. A review of current work zone practices was conducted in neighboring states and abroad, and is presented in the first part of the report. An evaluation of several traffic management technologies that are currently available for interstate work zones was performed. The goal of the evaluation was to determine the benefit INDOT would gain from using a technology of this type. The third part of the report presents the experimentation and testing conducted during the research project. This part discusses the accident data evaluation conducted in several interstate work zone projects in the state of Indiana. This portion of the report also presents the description of the test pilot project that included the deployment and evaluation of a series of fixed signs in conjunction with variable message signs in the I-65/US-30 reconstruction project near Merrillville, IN. The fourth part of the report covers the evaluation conducted to determine the feasibility of maintaining two lanes open at all times during work zones on interstates. An economic model was developed to provide INDOT with a preliminary tool for deciding if two lanes open should be maintained in a particular project. Along with the model is a case study that provides INDOT with an example of the staging required to complete the highway project in several seasons.

\section{Key Words}

work zones, work zone practices, traffic management technologies, accidents, work zone signs, speed study, travel time study, economic model, work zone capacity

\begin{tabular}{|c|c|c|c|}
\hline 19. Security Classif. (of this report) & 20. Security Classif. (of this page) & 21. No. of Pages & 22. Price \\
Unclassified & Unclassified & 269 & \\
\hline
\end{tabular}

18. Distribution Statement

No restrictions. This document is available to the public through the National Technical Information Service, Springfield, VA 22161 
TABLE OF CONTENTS

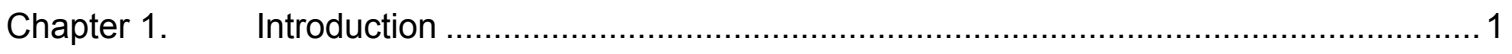

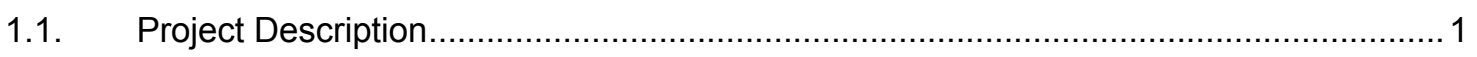

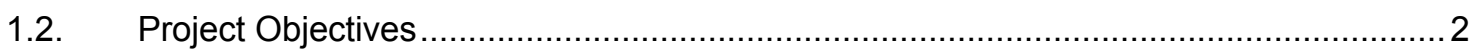

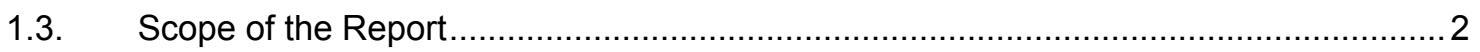

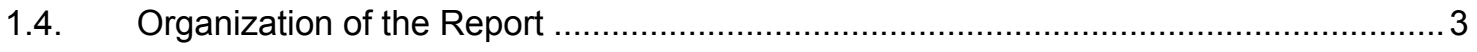

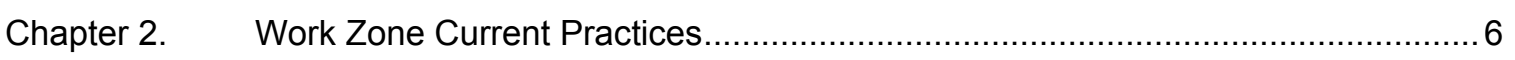

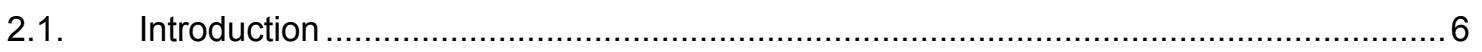

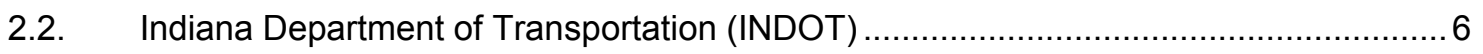

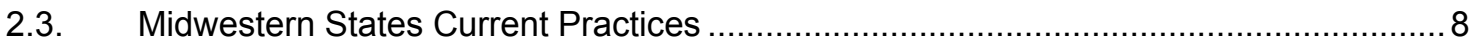

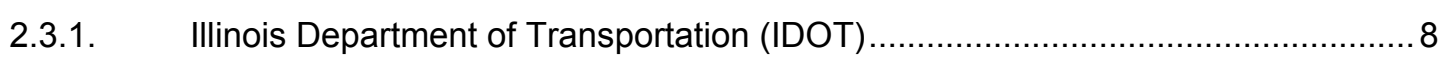

2.3.2. Kentucky Transportation Cabinet................................................................... 13

2.3.3. Michigan Department of Transportation (MDOT) …........................................ 14

2.3.4. Ohio Department of Transportation (ODOT) ….............................................. 15

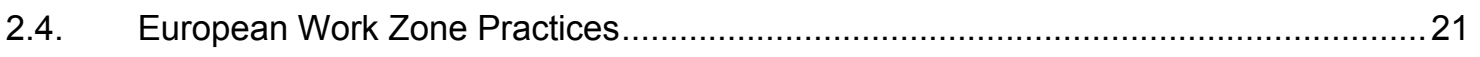

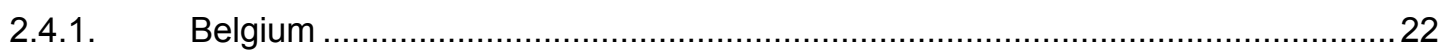

2.4.1.1. Construction and Traffic Operations ...................................................... 22

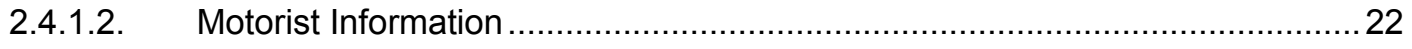

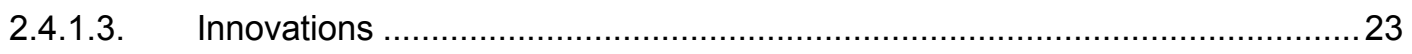

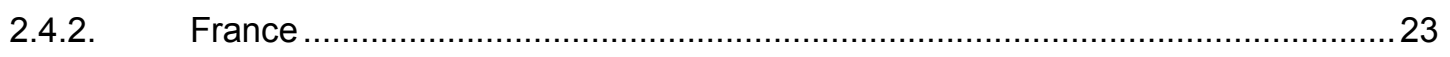

2.4.2.1. Construction and Traffic Operations .......................................................... 23

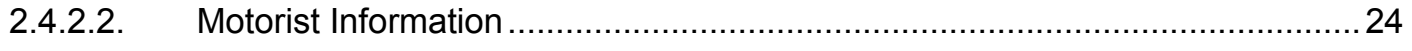

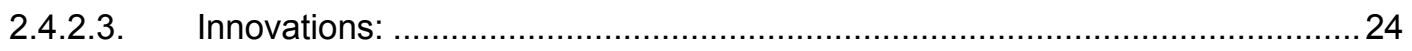

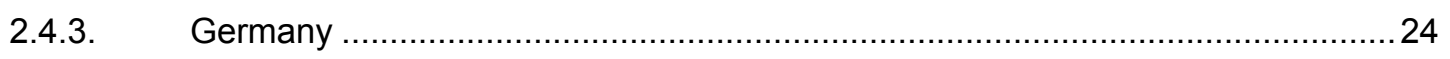

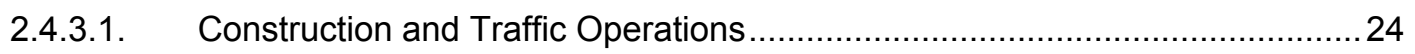

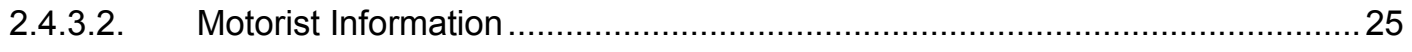

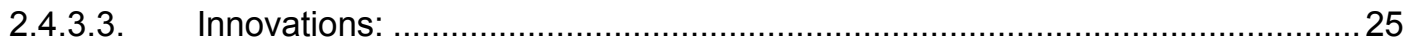

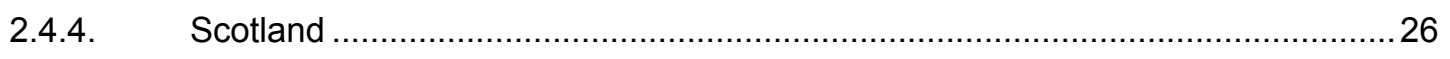

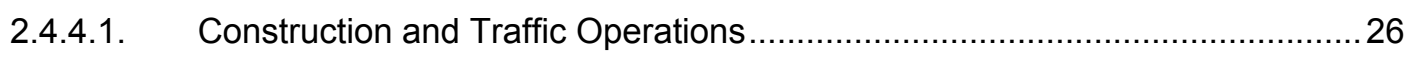

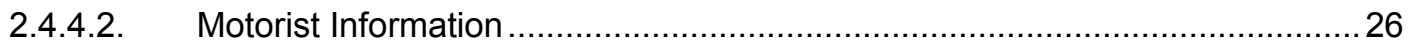




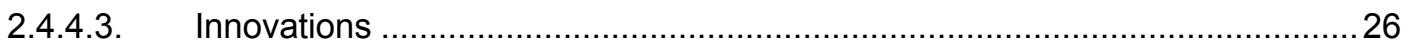

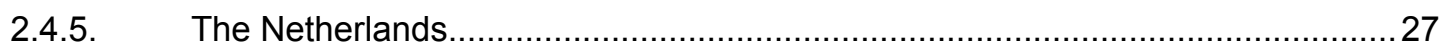

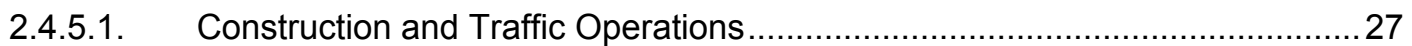

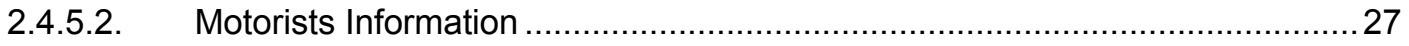

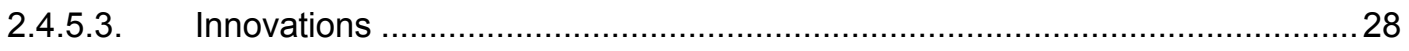

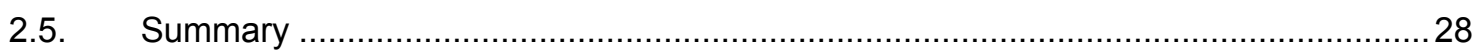

Chapter 3. Traffic Management Technologies.............................................................. 31

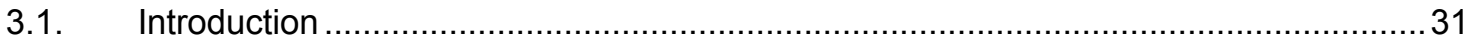

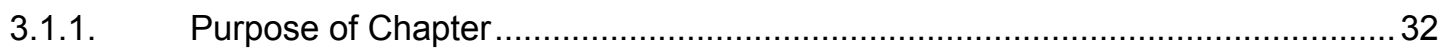

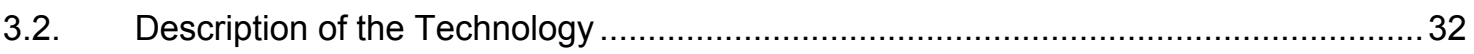

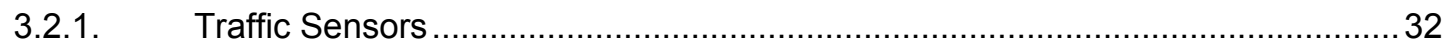

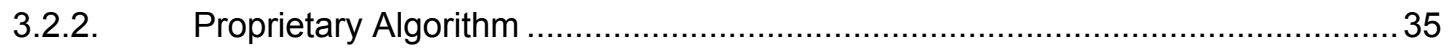

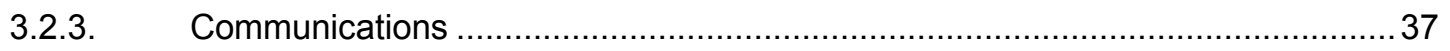

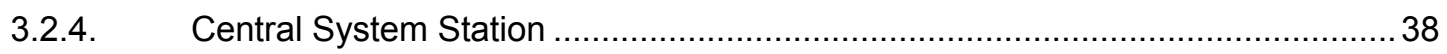

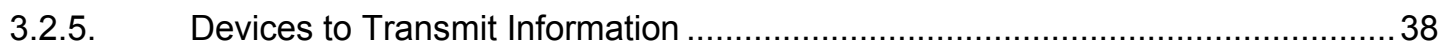

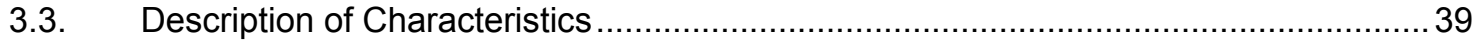

3.4. Advance Speed Information System (ASIS) .................................................... 40

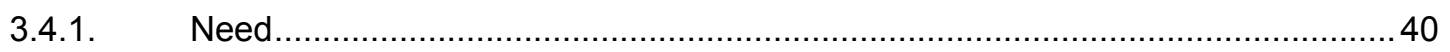

3.4.2. Methods to Transmit Information ............................................................... 40

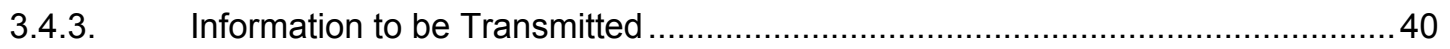

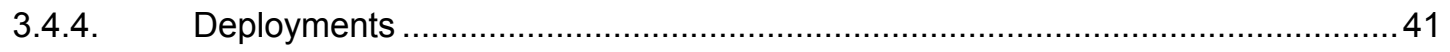

3.5. Automated Data Acquisition and Processing of Traffic Information in Real-time

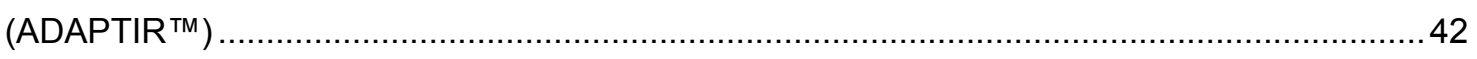

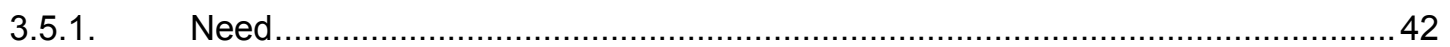

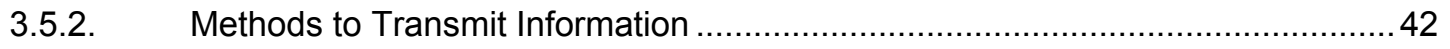

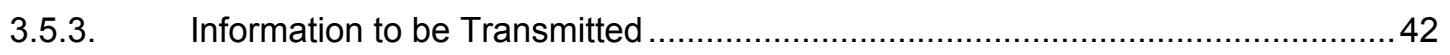

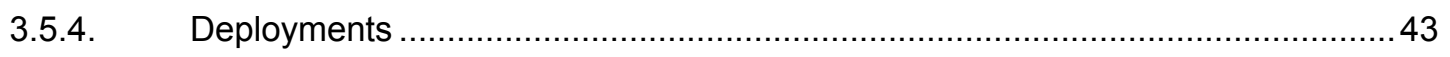

3.6. Automated Information Management System (A.I.M.S.) ......................................... 44

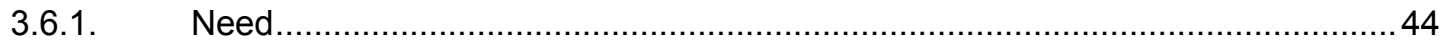

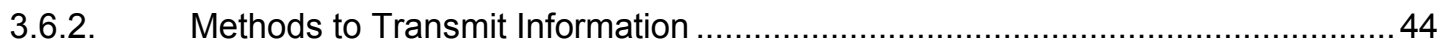

3.6.3. Information to be Transmitted ...................................................................... 45

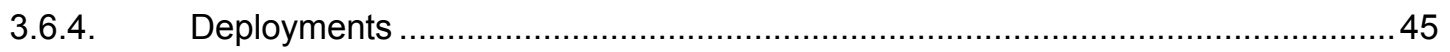

3.7. Computerized Highway Information Processing System (CHIPS ${ }^{\mathrm{TM}}$ ) .........................46

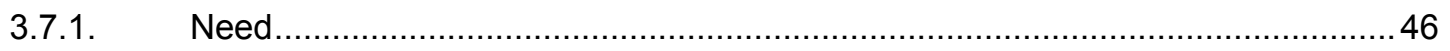

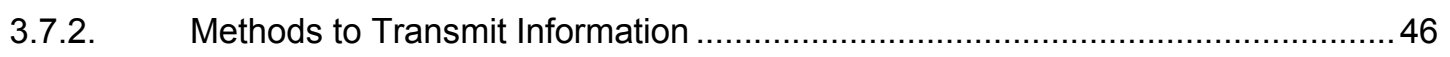

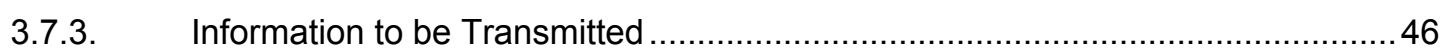




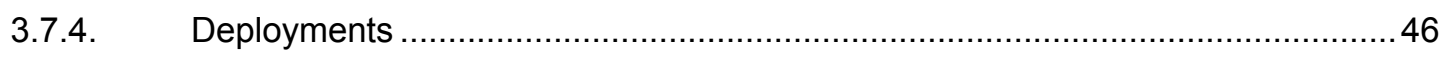

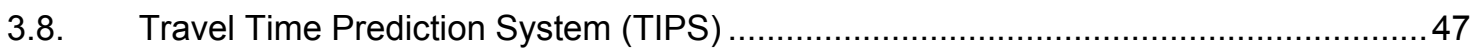

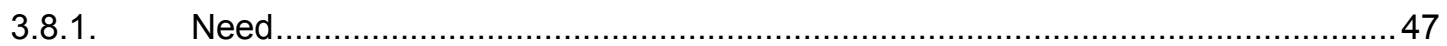

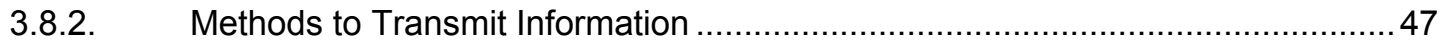

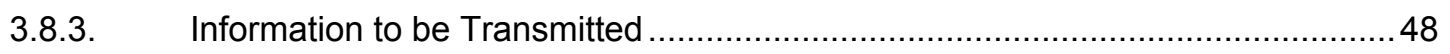

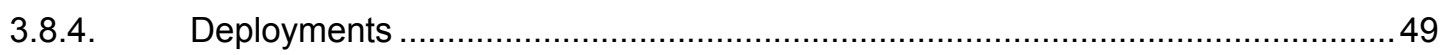

3.9. Work Zone Alert and Information Radio (WIZARD) .............................................. 49

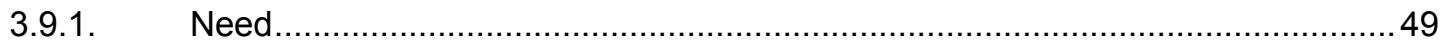

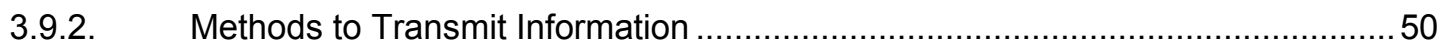

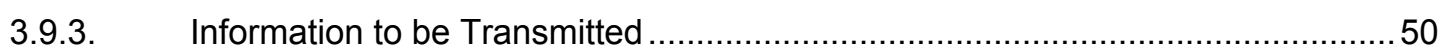

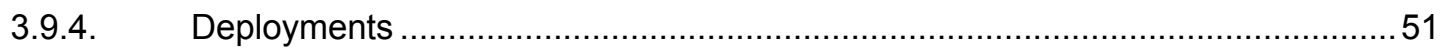

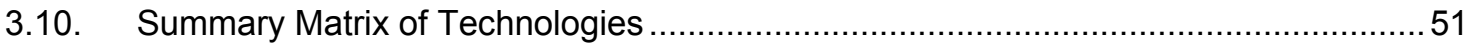

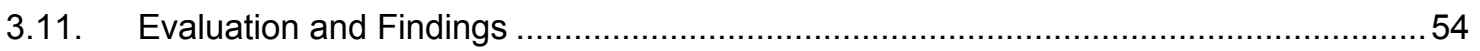

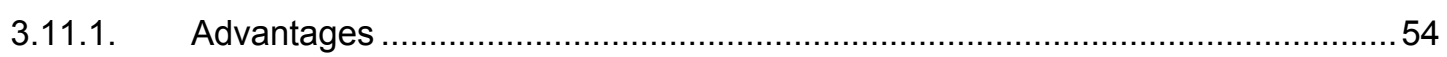

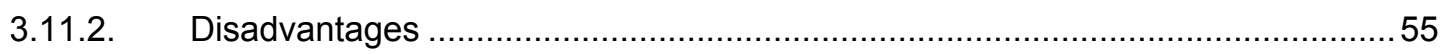

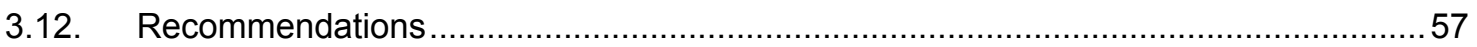

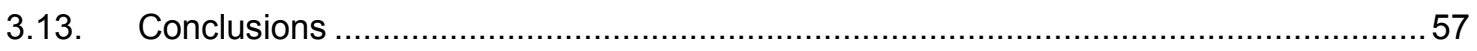

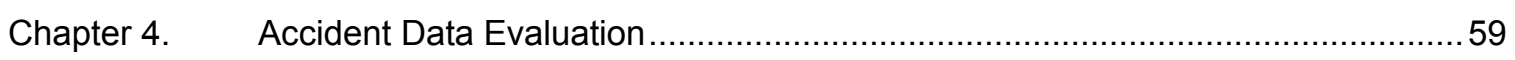

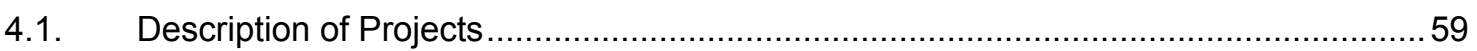

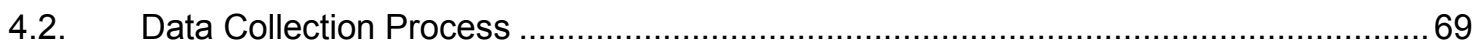

4.2.1. Zone 1: I-65/SR 25 Interchange Reconstruction Project ................................. 71

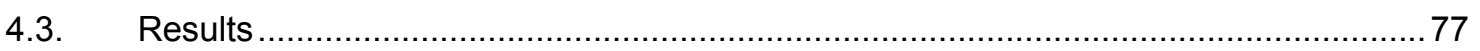

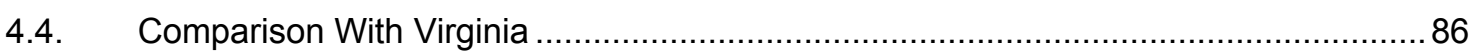

Chapter 5. Test Pilot Project (I-65 Near Merrillville, IN) ................................................... 88

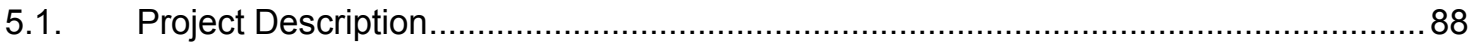

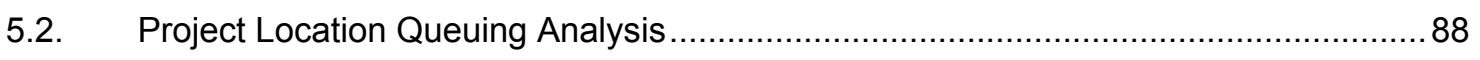

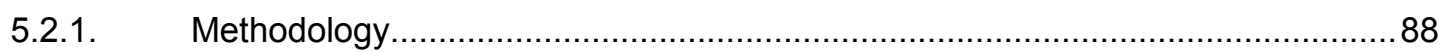

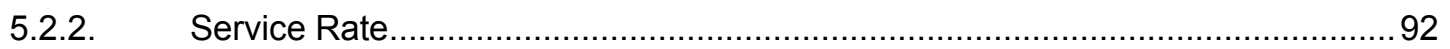

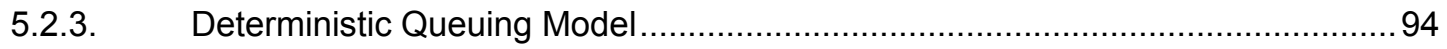

5.2.3.1. One Operational Lane Per Direction of Travel ............................................ 94

5.2.3.2. Two Operational Lanes Per Direction of Travel ........................................... 99

5.3. Analysis of Deterministic Queuing Model ................................................................ 104

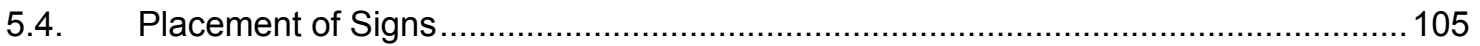

Chapter 6. Testing The Effectiveness of The Experimental Signs ................................... 111

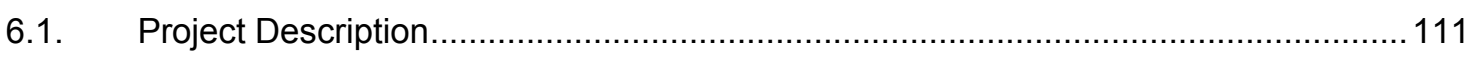

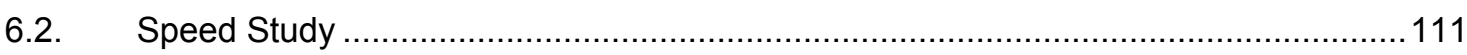




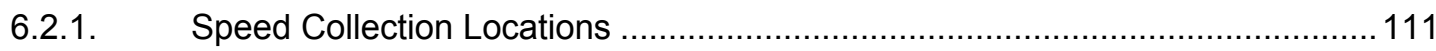

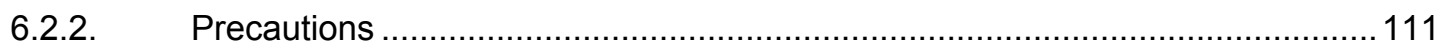

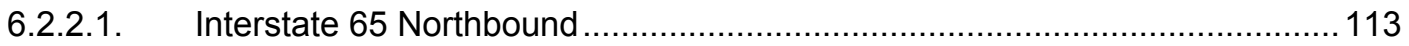

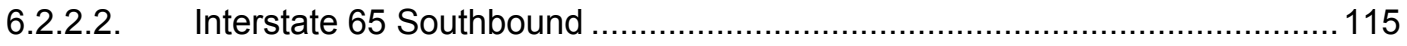

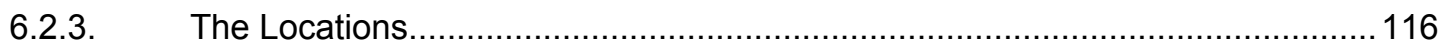

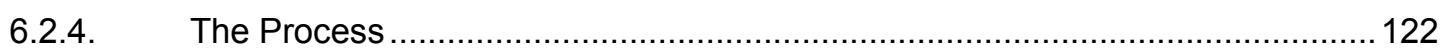

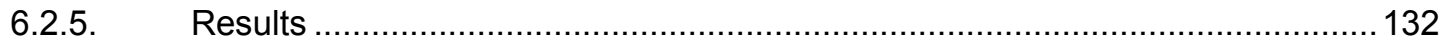

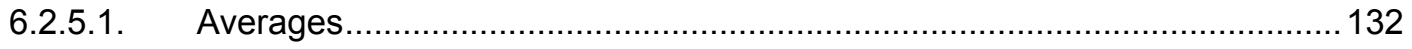

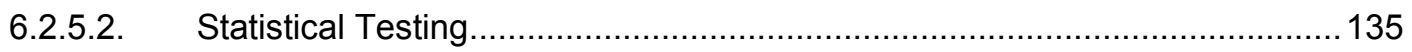

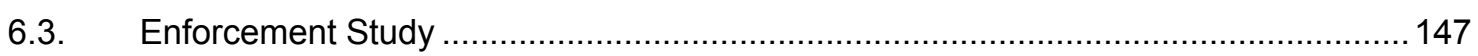

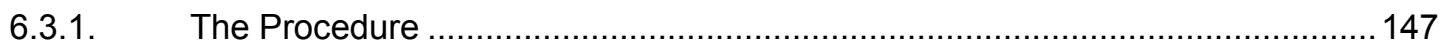

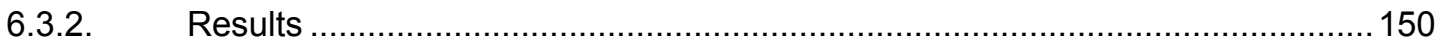

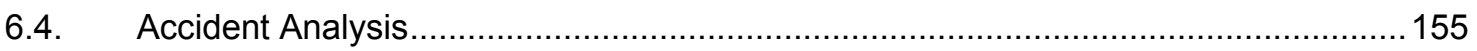

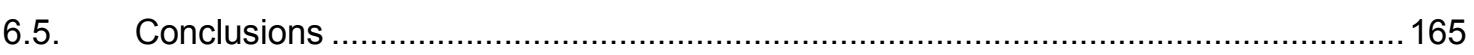

Chapter 7. Travel Time Studies Through Work Zones Using Global Positioning Systems (GPS) 166

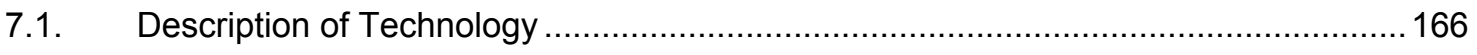

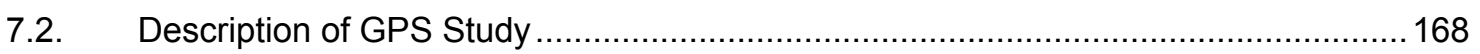

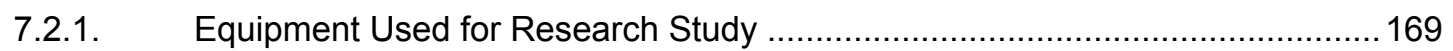

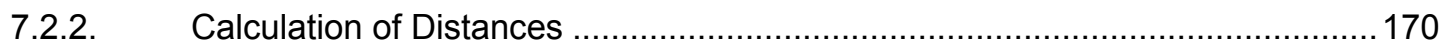

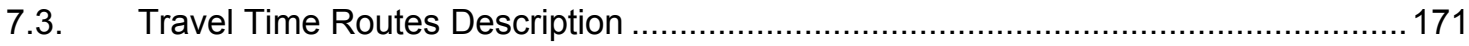

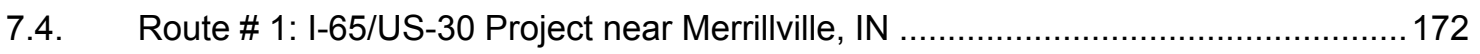

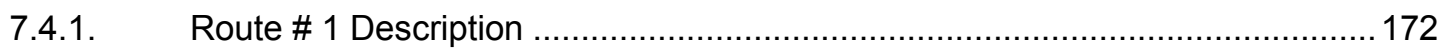

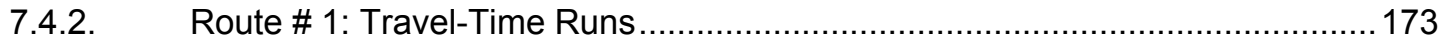

7.5. Route \# 2: I-65/US-30 Project near Merrillville, IN ............................................... 176

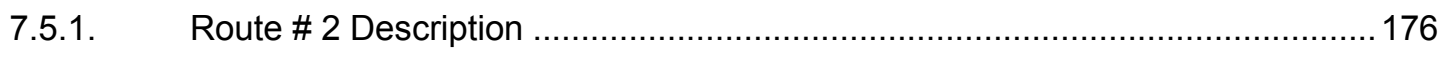

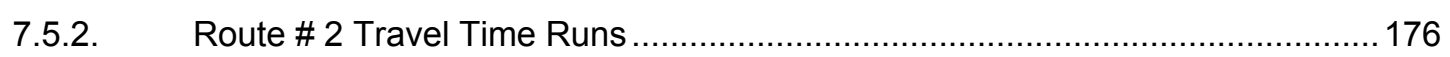

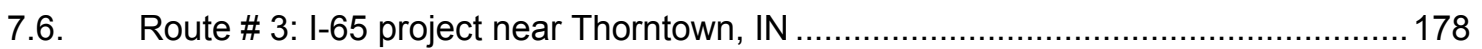

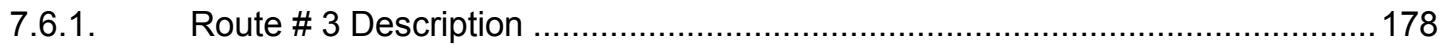

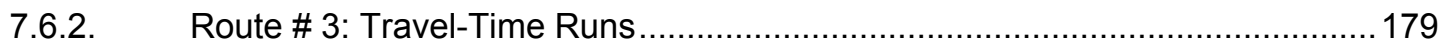

7.7. Route \# 4: I-65/US-30 project near Merrillville, IN ................................................. 181

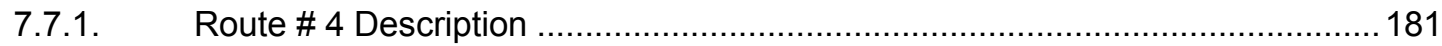

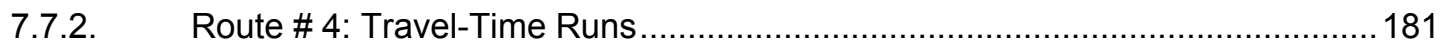

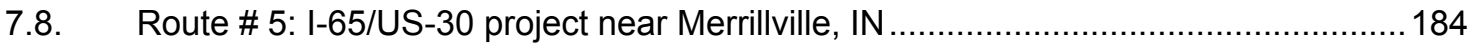

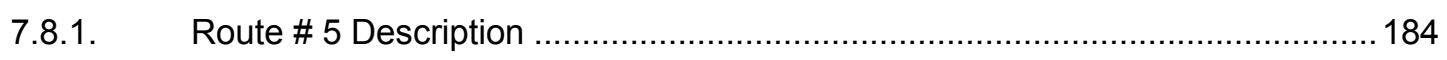

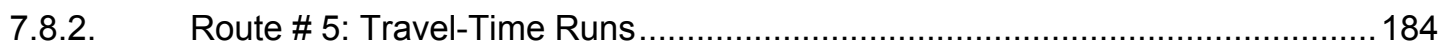




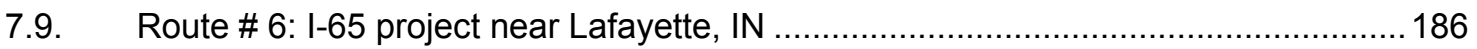

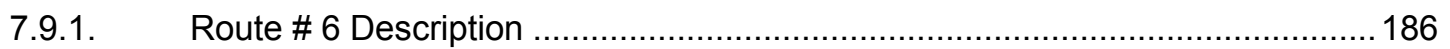

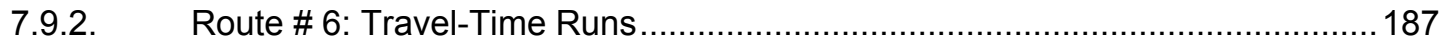

7.10. Evaluation of GPS System as a traffic collection device ....................................... 189

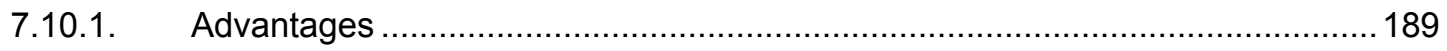

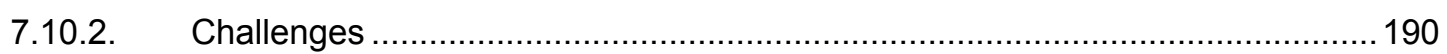

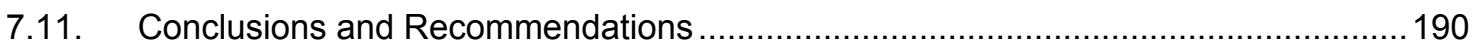

Chapter 8. Evaluation of Two Lane Open Policy ............................................................ 193

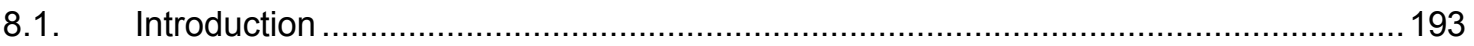

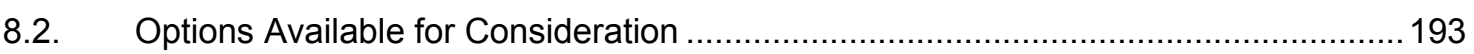

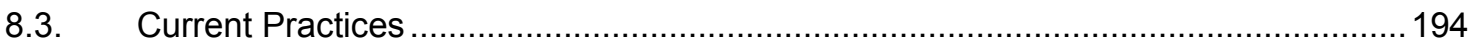

8.4. Example of Lane Closure Analysis Procedure ....................................................... 196

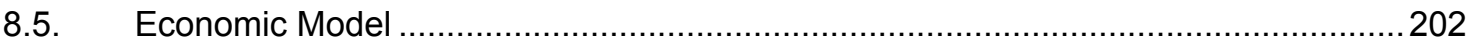

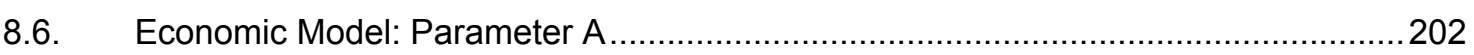

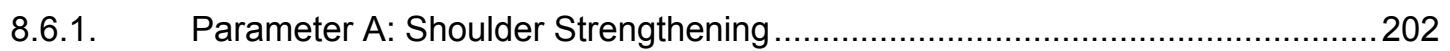

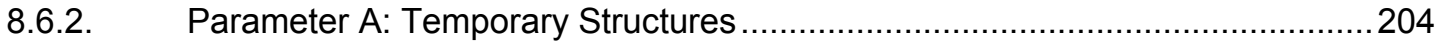

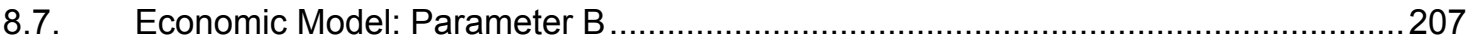

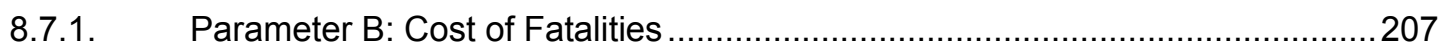

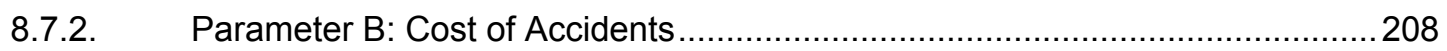

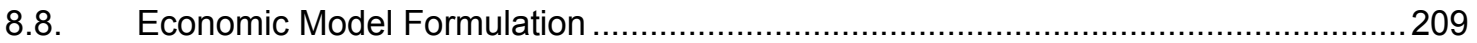

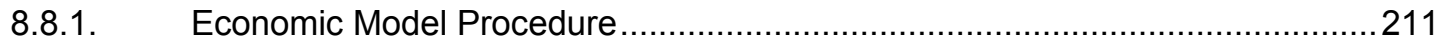

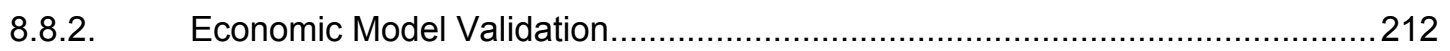

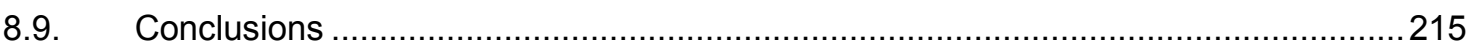

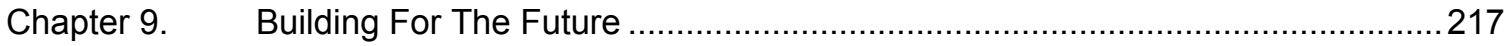

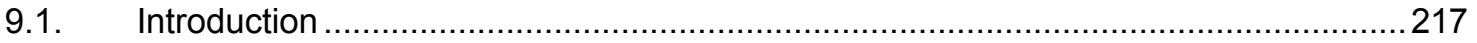

9.2. Case Study: I-35/80 Reconstruction Project near Des Moines, IA ............................218

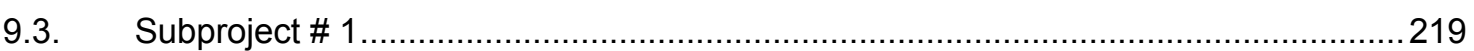

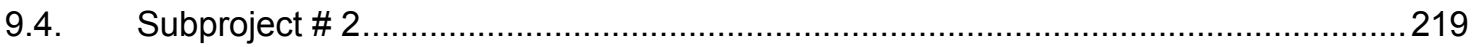

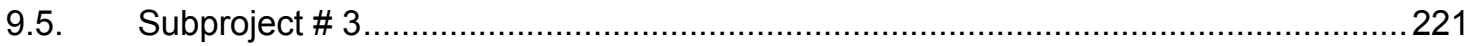

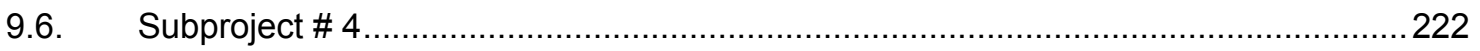

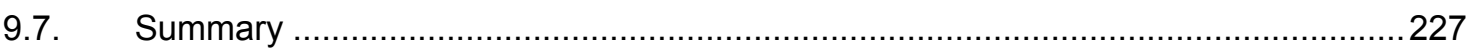

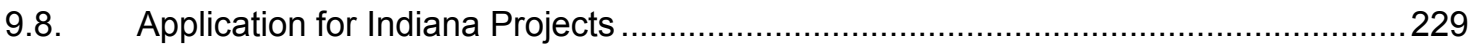

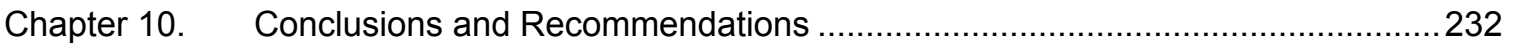

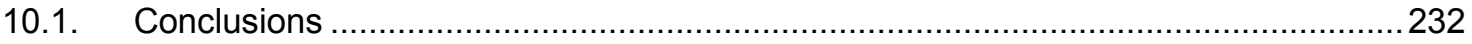

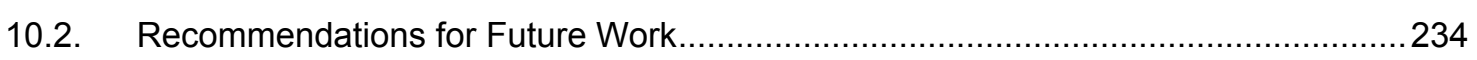

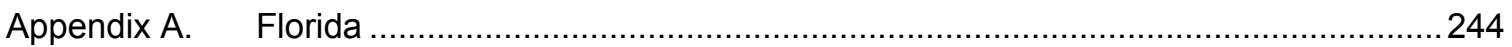




\section{LIST OF TABLES}

Table 2-1 Work Zone Practices of DOTs in Midwestern States ............................................... 17

Table 2-2 Work Zone Practices of DOTs in Midwestern States (con't) .................................... 18

Table 2-3 Work Zone Practices of DOTs in Midwestern States (con't) ....................................... 19

Table 2-4 Work Zone Practices of DOTs in Midwestern States (con't) ....................................20

Table 2-5 Work Zone Practices of DOTs in Midwestern States (con't) .......................................21

Table 2-6 Summary Matrix of European Work Zone Practices .................................................29

Table 2-7 Summary Matrix of European Work Zone Practices (con't) ......................................... 30

Table 3-1 Summary Matrix of technologies ........................................................................ 53

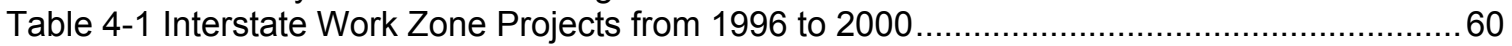

Table 4-2 Interstate Work Zone Projects from 1996 to 2000 (cont'd)..........................................61

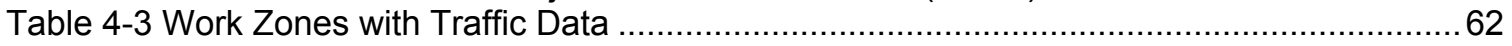

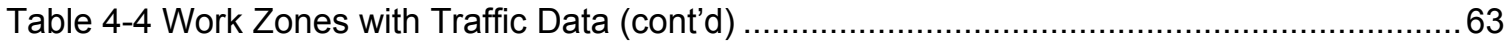

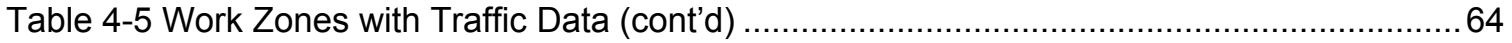

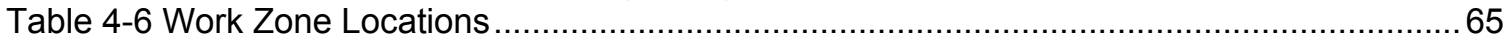

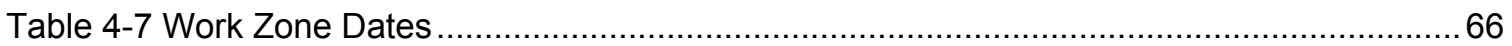

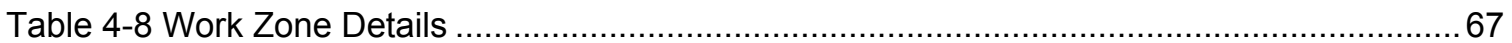

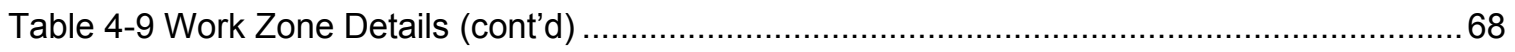

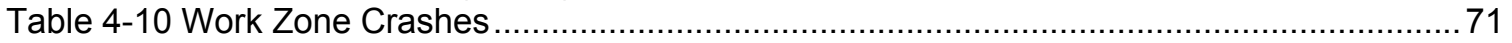

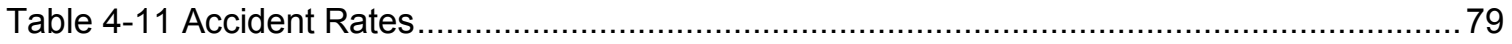

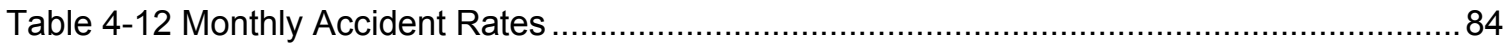

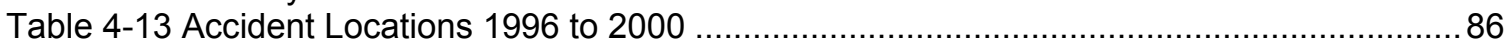

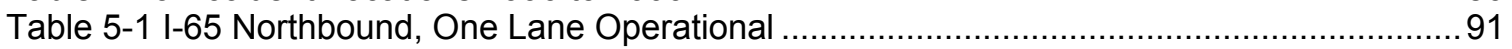

Table 5-2 I-65 Southbound, One Lane Operational.............................................................. 92

Table 5-3 Adjustment Factors for Directional Distribution on General Terrain Segments (HCM 2000).

Table 5-4 Adjustment Factors for the Combined Effect of Narrow Lanes \& Restricted Shoulder

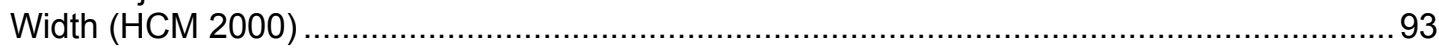

Table 5-5 Adjustment Factors for Restricted Lane Width \& Lateral Clearance (HCM 2000) .........94

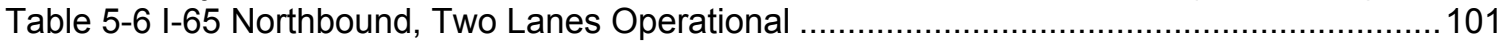

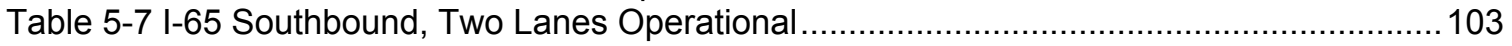

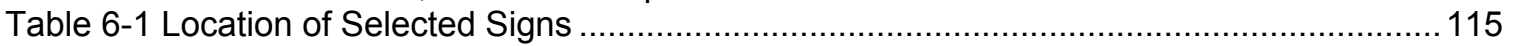

Table 6-2 General Information of Speed Collection Locations ............................................... 115

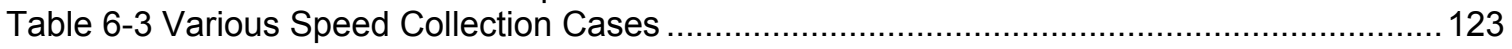

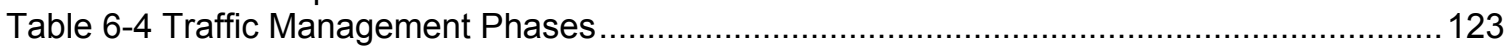

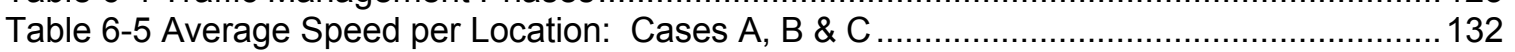

Table 6-6 Average Speed per Location: Cases D, E \& F ...................................................... 133

Table 6-7 Average Speed per Location: Cases G, H \& I ..................................................... 133

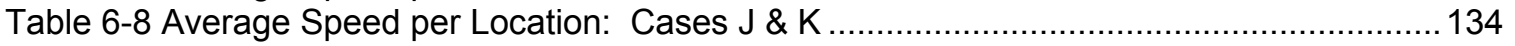

Table 6-9 Testing for Speed Change > $5 \mathrm{mph}$ : Cases A \& B ............................................... 136

Table 6-10 Testing for Speed Change > 5 mph: Cases A \& C ..........................................137

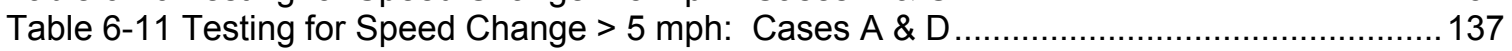

Table 6-12 Testing for Speed Change > 5 mph: Cases A \& E ............................................ 138

Table 6-13 Testing for Speed Change > $5 \mathrm{mph}$ : Cases A \& F ........................................... 138

Table 6-14 Testing for Speed Change > 5 mph: Cases A \& G............................................ 139 


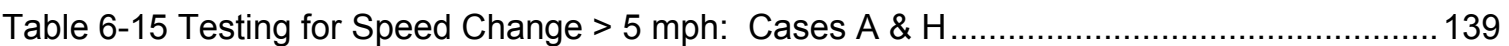

Table 6-16 Testing for Speed Change > $5 \mathrm{mph}$ : Cases A \& I ................................................ 140

Table 6-17 Testing for Speed Change > 5 mph: Cases A \& J............................................. 140

Table 6-18 Testing for Speed Change > 5 mph: Cases A \& K ............................................141

Table 6-19 Summary of Statistically Significant Speed Reductions (Fixed Panel Signs) ...........141

Table 6-20 Testing for Speed Change > $5 \mathrm{mph}$ : Cases B \& C ............................................. 143

Table 6-21 Summary of Statistically Significant Speed Reductions (Variable Message Signs).. 144

Table 6-22 Testing for Speed Change > 5 mph: Cases D \& E ............................................. 145

Table 6-23 Testing for Speed Change > $5 \mathrm{mph}$ : Cases H \& I .............................................. 145

Table 6-24 Testing for Speed Change > 5 mph: Cases J \& K.......................................... 146

Table 6-25 Summary of Statistically Significant Speed Reductions (Updating of Fine Counts).. 146

Table 6-26 Average Speed Per Location and Enforcement Status ......................................... 150

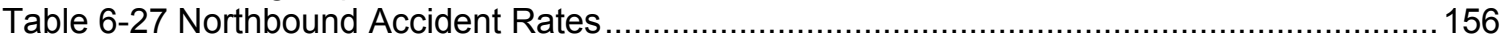

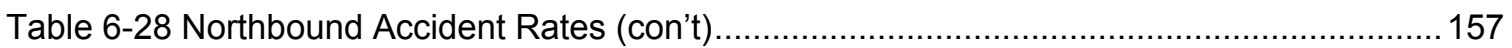

Table 6-29 Southbound Accident Rates ........................................................................ 158

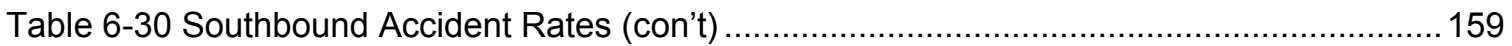

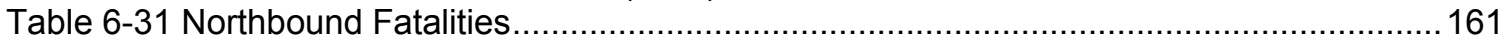

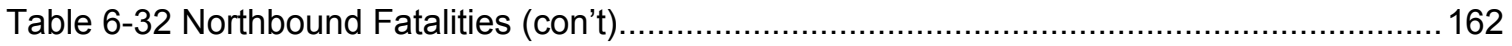

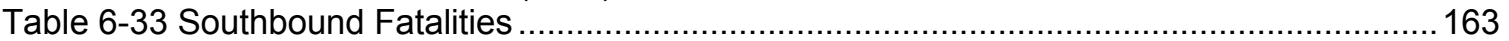

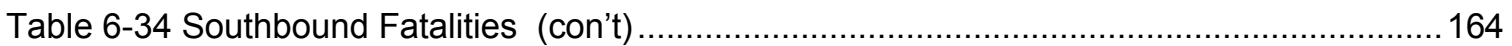

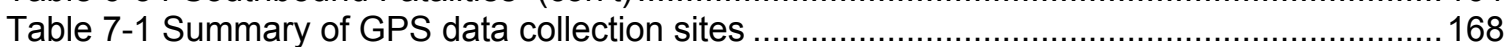

Table 7-2 Summary of $\mathrm{M}$ and $\mathrm{N}$ values (Source: van Gelder (2002)) ..................................171

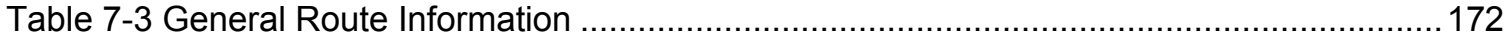

Table 7-4 I-65/US-30 Project General Coordinate Information .............................................173

Table 7-5 I-65/US-30 Project General Coordinate Information …........................................... 174

Table 7-6 Route \# 2 Travel Time Runs Completed ........................................................... 176

Table 7-7 I-65 near Thorntown Project General Coordinate Information .................................178

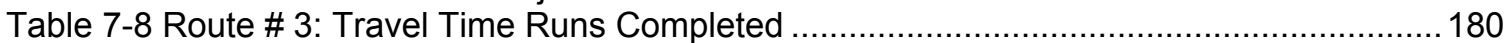

Table 7-9 Route \# 4 Travel Time Runs Completed ............................................................ 182

Table 7-10 Route \# 5 Travel Time Runs Completed .......................................................... 184

Table 7-11 I-65 near Lafayette Project General Coordinate Information................................... 186

Table 7-12 Route \# 6 Travel Time Runs Completed ......................................................... 187

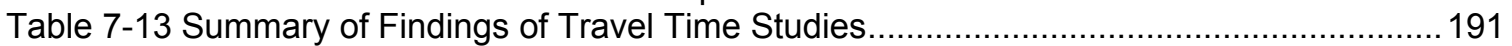

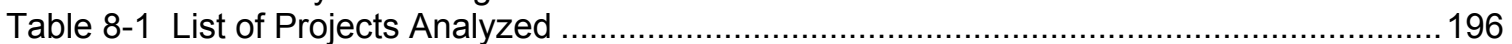

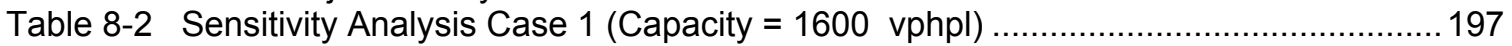

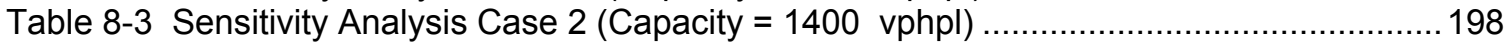

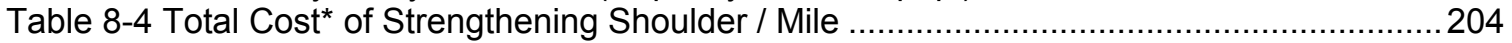

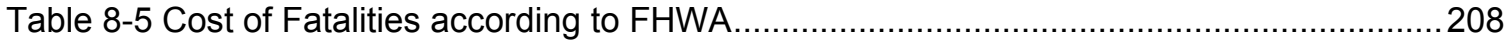

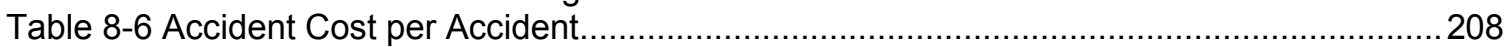

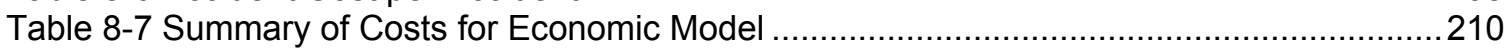

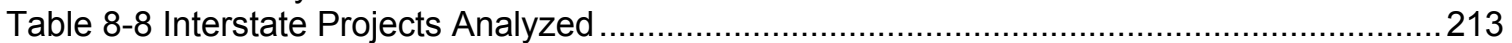

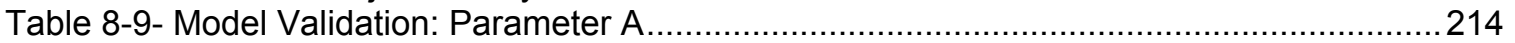

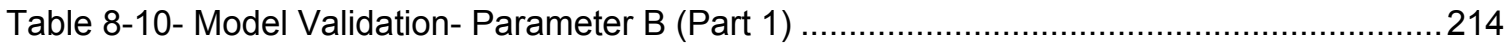

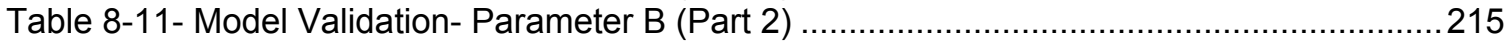

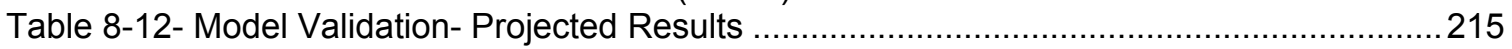

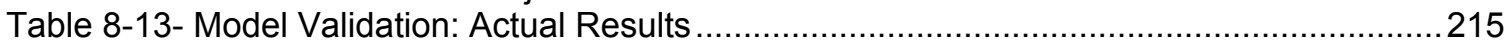

Table 9-1 Project \# 4: Summary of Pavement Grading and Replacing Operations for .................223

Table 9-2 Project \# 4: Summary of Paving and Grading Operations for Stages 1C \& 2C ..........223

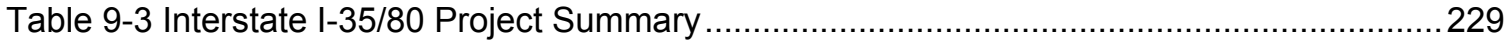




\section{LIST OF FIGURES}

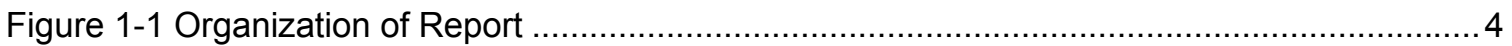

Figure 2-1 Roadway conditions of I-55 during reconstruction of Lake Springfield

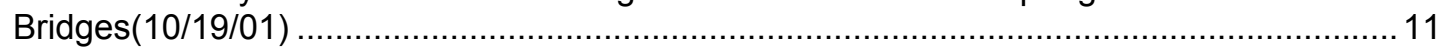

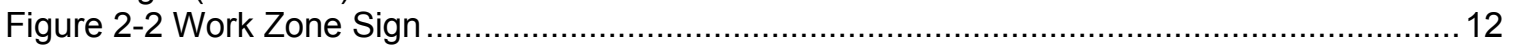

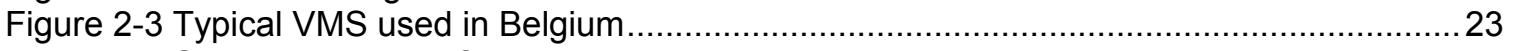

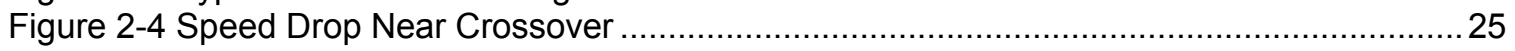

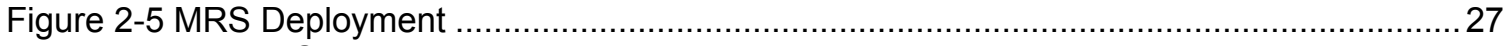

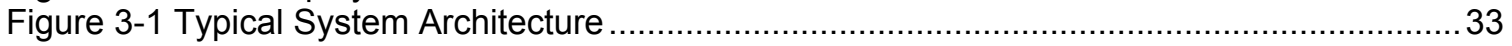

Figure 3-2 Detection zones in a side-fire traffic sensors...................................................... 34

Figure 3-3 Side-Fire Microwave deployed in Springfield, IL (AIMS TM/United Rentals) ..................34

Figure 3-4 Overview of Algorithm Response to Backup Queue (Adapted from: Register (2002)

"Real-Time Traffic Control System" ITS America, Long Beach, CA ......................................... 36

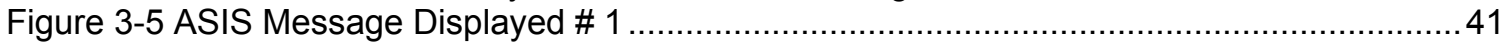

Figure 3-6 ASIS Message Displayed \# 2 …................................................................ 41

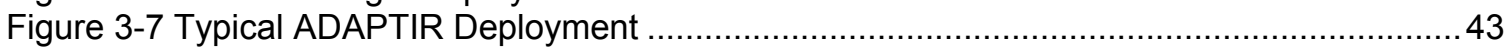

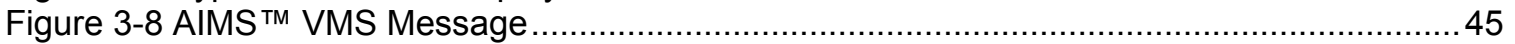

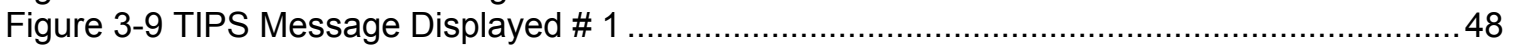

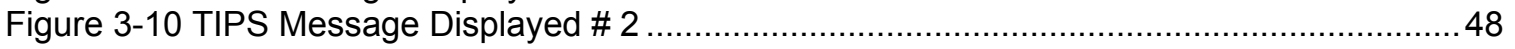

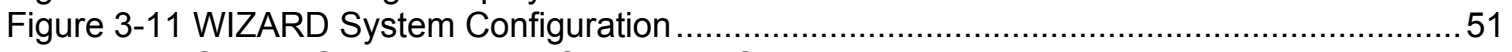

Figure 3-12 Sensor Spacing during Congested Conditions....................................................56

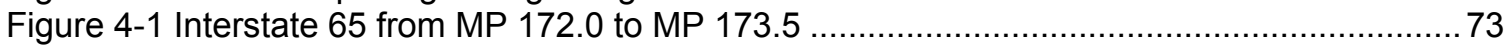

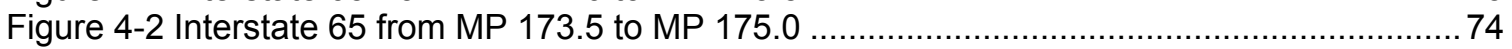

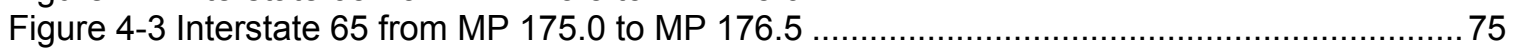

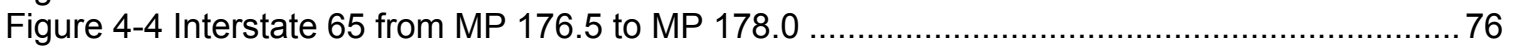

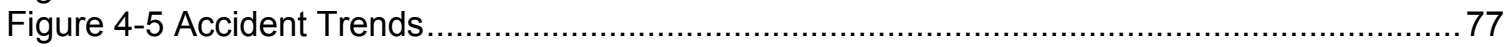

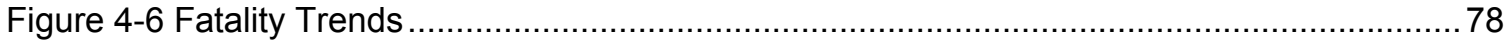

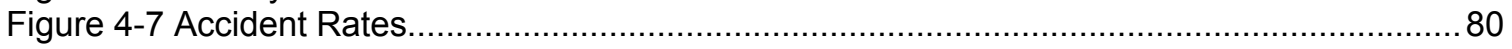

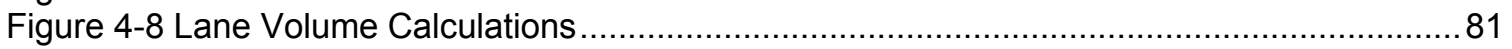

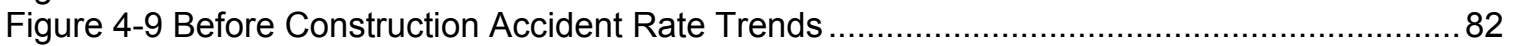

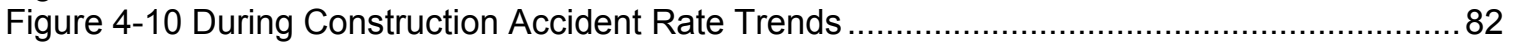

Figure 4-11 Accident Rate Trends - Before and After Construction ........................................ 83

Figure 4-12 Before Construction Monthly Accident Rate Trends ............................................... 84

Figure 4-13 During Construction Monthly Accident Rate Trends .......................................... 85

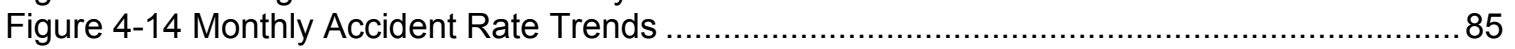

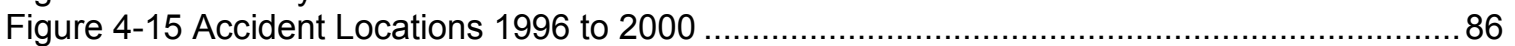

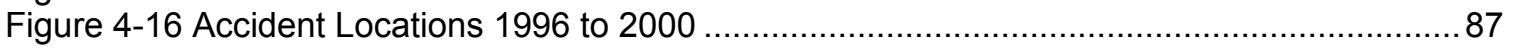

Figure 5-1 Locations of Maximum Expected Queues ........................................................... 90

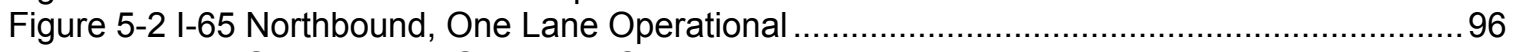

Figure 5-3 I-65 Southbound, One Lane Operational ............................................................. 99

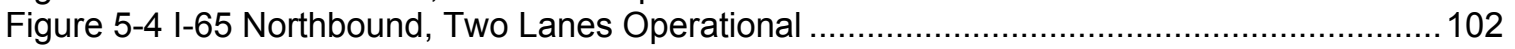

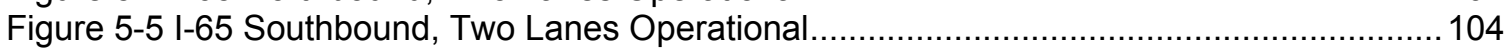

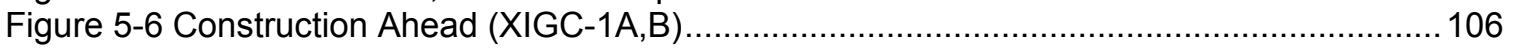

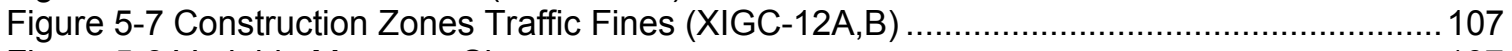

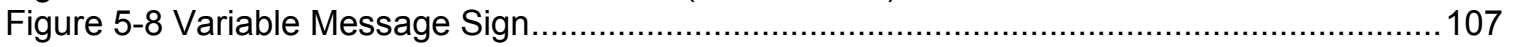




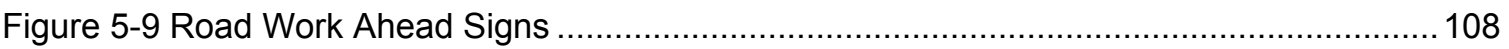

Figure 5-10 Work Zone Special Patrols (XIGC-14A-I) ...................................................... 109

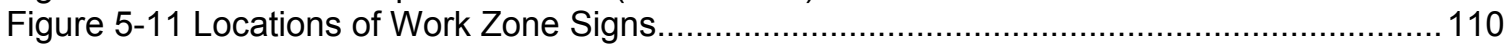

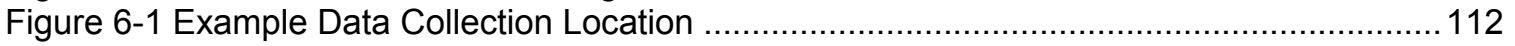

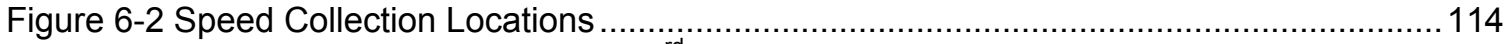

Figure 6-3 Interstate 65 Northbound at $153^{\text {rd }}$ Avenue, Posted Speed Limit $65 \mathrm{mph} . . . \ldots \ldots \ldots \ldots \ldots . . . . . .117$

Figure 6-4 Interstate 65 Northbound at $137^{\text {th }}$ Avenue, Posted Speed Limit $65 \mathrm{mph}$....................117

Figure 6-5 Interstate 65 Northbound at $113^{\text {th }}$ Avenue, Posted Speed Limit $65 \mathrm{mph}$..................118

Figure 6-6 Interstate 65 Northbound at $93^{\text {rd }}$ Avenue, Posted Speed Limit................................. 118

Figure 6-7 Interstate 65 Northbound at US 30, Posted Speed Limit .......................................119

Figure 6-8 Interstate 65 Northbound at $73^{\text {rd }}$ Avenue, Posted Speed Limit................................119

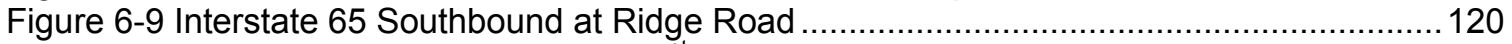

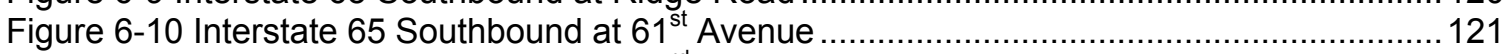

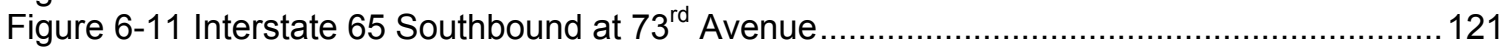

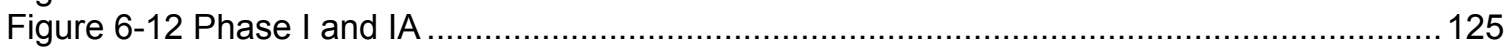

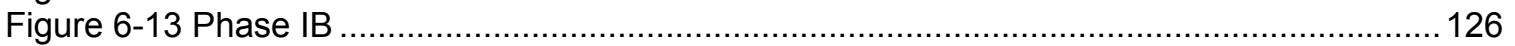

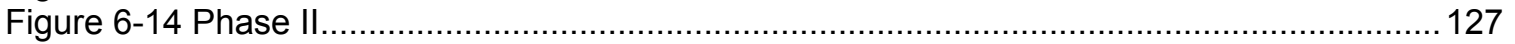

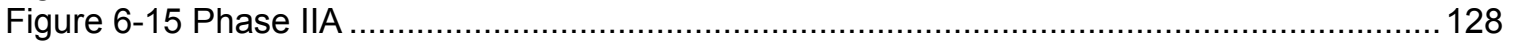

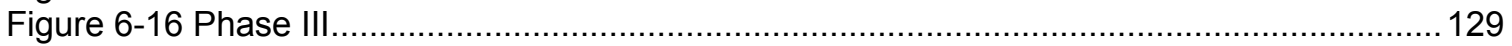

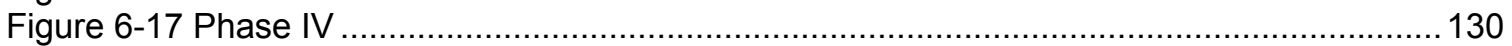

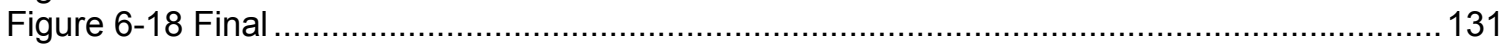

Figure 6-19 I-65 Northbound Speeds per Location and Case ................................................. 134

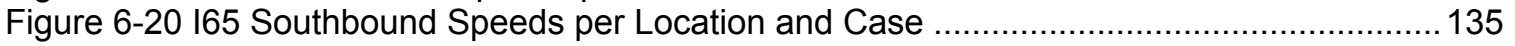

Figure 6-21 Significant Speed Reduction Location........................................................... 142

Figure 6-22 Enforcement Study Speed Collection Locations ............................................. 149

Figure 6-23 Speeds Adjacent to Trooper at $93^{\text {rd }}$ Ave, Trooper Location: MP 251.2Collection

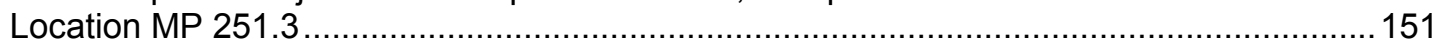

Figure 6-24 Downstream Speeds at US 30, Trooper Location: MP 251.2Collection Location MP 252.4

Figure 6-25 Downstream Speeds @ 73 ${ }^{\text {rd }}$ Ave, Trooper Location: MP 251.2Collection Location MP 253.6.

Figure 7-1 Calculation of Distances (Source: Adapted from van Gelder (2002)) .................... 170

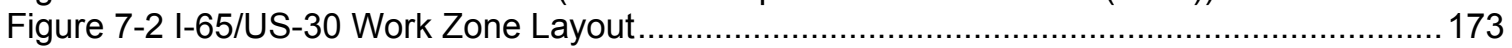

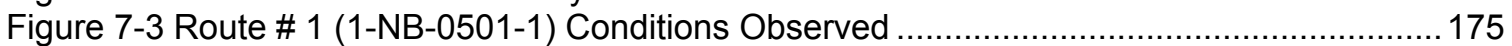

Figure 7-4 Route \# 2 (1-NB-0501-1) Conditions Observed .................................................. 177

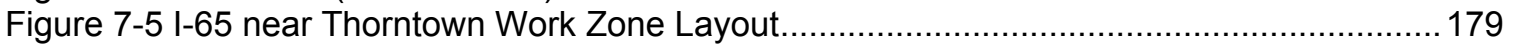

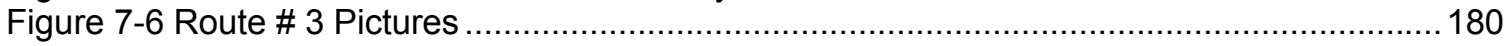

Figure 7-7 Route \# 3 (3-SB-0515-05) Conditions Observed ................................................... 181

Figure 7-8 Route \# 4 (4-SB-0612-01) Conditions Observed ................................................... 183

Figure 7-9 Route \# 4 (4-SB-0612-01) Detailed Observation ............................................... 183

Figure 7-10 Route \# 5 (5-SB-0612-01) Conditions Observed .............................................. 185

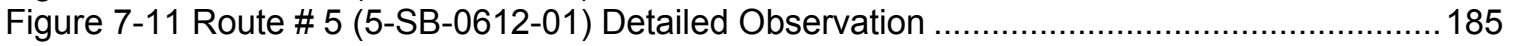

Figure 7-12 I-65 near Lafayette Work Zone Layout.......................................................... 186

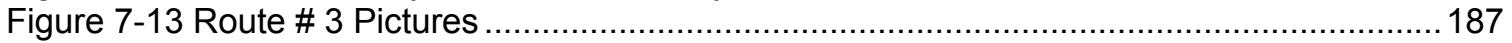

Figure 7-14 Route \# 6 (6-NB-0702-04) Conditions Observed ...............................................189

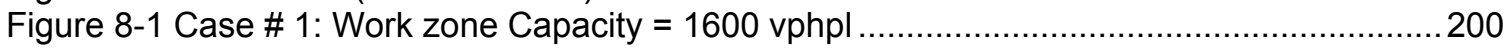

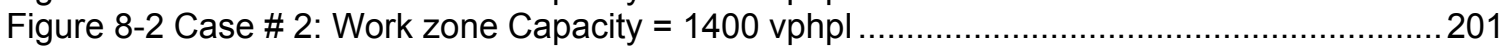

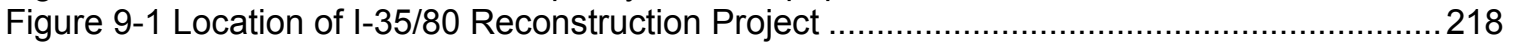

Figure 9-2 Overview of Project Work Zone Location and Staging..........................................220

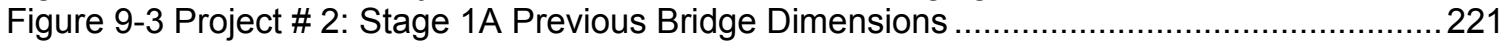

Figure 9-4 Project \# 2: Reduction of Bridge Dimensions during Stage 1A ...............................221

Figure 9-5 Project \# 2: Grading and Paving of Median Section ............................................ 222

Figure 9-6 Project \# 3: Final Placement of Traffic on Stage 1C .......................................... 222

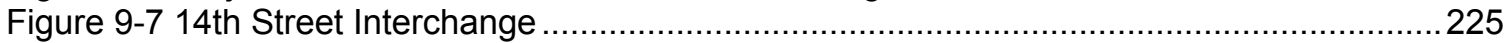




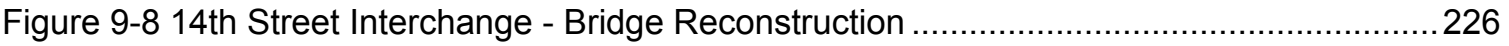

Figure 9-9 Project \# 4: Final Placement of Traffic Stage 3B............................................... 227

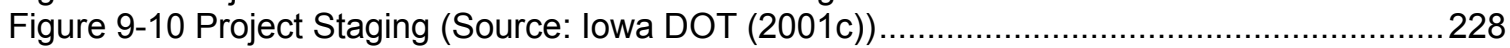




\section{IMPLEMENTATION REPORT}

Improving safety of both motorists and construction workers has led departments of transportation to implement several alternatives in an effort to minimize the occurrences of accidents and fatalities during periods of work on interstates. Changes in traveling conditions typically associated with work zones increase the likelihood of accident occurrences. It is therefore important to inform the traveling public well in advance of the work zone of the changing conditions that lie ahead.

The Indiana Department of Transportation has initiated this study in an effort to find mechanisms to improve the safety on rural interstate work zones in the state of Indiana. The most important findings of this evaluation:

- The benefits associated with deploying traffic management technologies were found to be outweighed by their costs.

- Accident rates on rural interstates can be expected to increase approximately thirty percent during periods of construction.

- Fixed panel signs result in isolated speed reduction in the work zone. This may be of some safety benefit to the construction workers in the immediate construction area.

- Neither the fixed signs nor the variable message signs advising motorists of the enforcing activity appeared to have an impact on upstream speeds. Since high speed rear end collisions are the most significant motorist safety problem, it is not clear these signs will reduce fatal accidents resulting from approaching the work zone traffic queue at prevalent speeds.

- Enforcement activity was found to significantly reduce speeds (greater than $5 \mathrm{mph}$ ) at the location adjacent to the trooper. However, the effect of the trooper diminishes as the motorists increase their distance from the trooper.

- GPS systems provide the capability of linking a type of lane restriction to its impact on traffic flow and use this knowledge in future construction seasons.

- The decision to maintain two operational lanes per direction in a particular project can be evaluated using the economic model provided in the report. 


\section{ACKNOWLEDGMENTS}

We would like to thank the following people who served on the Study Advisory Committee for this project:

Project Administrator:

- David Ward - Indiana Department of Transportation

Advisory Members:

- David Boruff - Indiana Department of Transportation

- Gary Bowser - Indiana Department of Transportation

- Mike Byers - American Concrete Pavement Association

- Bob Cales - Indiana Department of Transportation

- Rick Drumm - Federal Highway Administration

- Matt Fuller - Federal Highway Administration

- Eryn Hays - Indiana Department of Transportation

- Mike Houghland - Indiana Department of Transportation

- Sami Mohamed- Indiana Department of Transportation

- John Nagle - Indiana Department of Transportation

- Mark Newland - Indiana Department of Transportation

- Michael Wink - Indiana Department of Transportation

- Rick Yunker - Indiana Department of Transportation

We would also like to thank the people from various organizations who assisted with this project:

- Troy Boyd - Indiana Department of Transportation

- Dale Hertweck - Indiana Department of Transportation

- Greg Kicinski - Indiana Department of Transportation

- Arpad Marton - Indiana Department of Transportation

- Gary Mroczka - Indiana Department of Transportation

- Roger Tepner - Indiana Department of Transportation 
- Lt. Guy Boruff - Indiana State Police

- Lt. Doug Shelton - Indiana State Police

- Peter Manekas - Acrow Corporation of America

- Ricardo Soria - Acrow Corporation of America

- Bill Wellman - ASTI Transportation Systems

- Brian Nicholson - AADCO Corporation

- Mark Bare - Cedar Valley Corporation

- Cheryl Adams - Florida Department of Transportation

- Joe Bhuvasorakul - Florida Department of Transportation

- David Ballard - Granite Construction Company

- Jim Schoenherr - Illinois Department of Transportation

- Mark Bortle - lowa Department of Transportation

- Deanna Mayfield - lowa Department of Transportation

- Paul Berebitski - Indiana Constructors Inc (ICI)

- Dave Cochran - Joint Transportation Research Project

- Simon Cornett - Kentucky Transportation Cabinet

- Jeff Grossklaus - Michigan Department of Transportation

- Mack Braxton - Ohio Department of Transportation

- Steve Young - Ohio Department of Transportation

- Eric Pfenning - Ohio Department of Transportation

- Ricard Sesny - Pennsylvania Department of Transportation

- Prahlad Pant - PDP Associates, Inc

- George Hairston - The Scientex Corporation

- Mark McSkimming - Trafcon / Highway Technologies

- Race Miner - United Rentals 


\section{CHAPTER 1. INTRODUCTION}

\subsection{Project Description}

As our interstate system ages, the volume of reconstruction and rehabilitation work that is performed on the system continues to grow. Associated with each of these construction projects is a segment of roadway commonly known as a work zone. As drivers approach and travel through such areas, they often encounter reduced lane widths, lane shifts and varying pavement surfaces.

When these roadway conditions are coupled with the traffic conditions that result from the reduced capacity of the work zone, accidents often arise. In fact, during the 1994-1998 period approximately 39,000 people were injured as a result of motor vehicle crashes in work zones (FHWA 2001). Along with this high number of accidents, the number of work zone fatalities has been increasing over the past few years (ATSSA 2001).

Several of these accidents and fatalities have occurred in or near the state of Indiana. In 2001, Interstate 74 between St. Joseph, IL and Danville, IL was rehabilitated. During this project, the interstate was reduced to one lane because of the construction activities. This lane closure caused queues to form frequently. As a result of these queues, numerous accidents occurred, all of which were within three-mile a radius from work zone.

From April of 2000 through May 2001, Interstate 65 between Indiana 26 and Indiana 43 near Lafayette, Indiana was rehabilitated. This project involved rehabilitation of the I-65/ SR 25 interchange and reduced traffic to one lane per direction. Despite the 60 warning signs, five message boards and three arrow boards that were placed to warn motorists of the work zone, most drivers neglected to reduce their speeds. As a result of their high speed through the work zone, troopers issued well over 1,500 citations mostly for exceeding the $55 \mathrm{mph}$ speed limit. The high speeds also resulted in an average 2.1 wrecks per week during 4 months of construction as well as several fatalities. 
As a result of these work zones, the Indiana Department of Transportation (INDOT) developed three goals. These goals are:

1) To ensure the safety of personnel and property in work zones

2) To keep delays in work zones a minimum

3) To maintain traffic flow through construction zones

\subsection{Project Objectives}

In the spring of 2001 , a study was initiated at Purdue University with the following objectives:

1) Development of quantitative procedures to determine if temporary roads and bridges should be considered.

2) Evaluate improved signing or active warning devices to determine their influence on work zone safety.

Once the above objectives were met, INDOT would then have a procedure to assess the viability of maintaining two lanes during interstate highway construction. In addition to this model, INDOT would also have a rational analysis for determining if temporary road and bridges should be opened and a quantitative analysis regarding the influence of active and passive signing techniques.

\subsection{Scope of the Report}

In the process of accomplishing these objectives, several tasks were completed along the way. To begin the project, the current work zone practices of INDOT and surrounding states were reviewed. The location and duration of work zones on Indiana interstates from 1998 to 2000 were determined. The average daily traffic volumes for these segments of interstate were also determined. The locations of accidents that occurred due to these work zones were investigated in an attempt to determine how to reduce the frequency of such crashes. The impact of added speed enforcement patrols was also investigated to determine if this method could be used to reduce the frequency of crashes. After investigating these work zones, the research group then developed a procedure to assess the viability of maintaining two lanes during interstate highway construction.

In addition to these tasks, the research group also performed studies with active work zones. The first study involving active work zones involved the evaluation of several new traffic management technologies. The research group evaluated several traffic management 
technologies that were currently being used on interstate work zones across the nation. In this evaluation, the advantages and disadvantages of each technology was examined.

The second study involving active work zones was limited to the state of Indiana. In this study, travel times through several active work zones on Interstate 65 were obtained. These travel times were obtained through the use of a Global Positioning System.

The third study conducted that involved an active work zone took place at the I-65/ US 30 interchange reconstruction project near Merrillville, IN. For this study, a series of signs was installed on the approaches to the work zone. The goal of these signs was to reduce accident rates for the work zone as well as to reduce the speeds of motorists approaching and passing though the work zone. To evaluate the effectiveness of the signs, the research team compared past and present accident rates and conducted a detailed speed study.

The final task of the research group was to examine an interstate reconstruction project in which road users were provided with normal interstate conditions as they traveled through the work zone. The goal of this evaluation was to aid INDOT in obtaining insight on how to develop and implement a set of guidelines and strategies that would minimize the impact of work zones on capacity.

\section{4. $\quad$ Organization of the Report}

This study was initiated in an effort to find mechanisms to improve the safety on rural interstate work zones in the state of Indiana. The findings of this evaluation can be found in the following report as shown in Figure 1-1. The report is divided into four parts. The first part of this report (presented in Chapter 1 and Chapter 2) documents the introduction and objectives of this research project. A review of current work zone practices in neighboring states and abroad is also presented. The review consisted of analyzing the work zone practices of five Midwestern states (Indiana, Illinois, Michigan, Kentucky and Ohio) as well as an analysis of current European work zone practices.

The second part of the report (Chapter 3) discusses the evaluation conducted on several of the traffic management technologies currently available. A Summary Matrix was developed to provide a comparative analysis of the technologies. 
The third part of the report presents studies of active work zones. Chapter 4 discusses the accident data evaluation conducted in several interstate work zone projects in the state of Indiana. Chapter 4 presents the description of the test pilot project that included the deployment of a series of fixed signs in conjunction with Variable Message Signs in the I-65/US-30 reconstruction project near Merrillville, IN. The purpose of the deployment was to inform motorists prior to entering the work zone to expect changes in the road condition ahead.

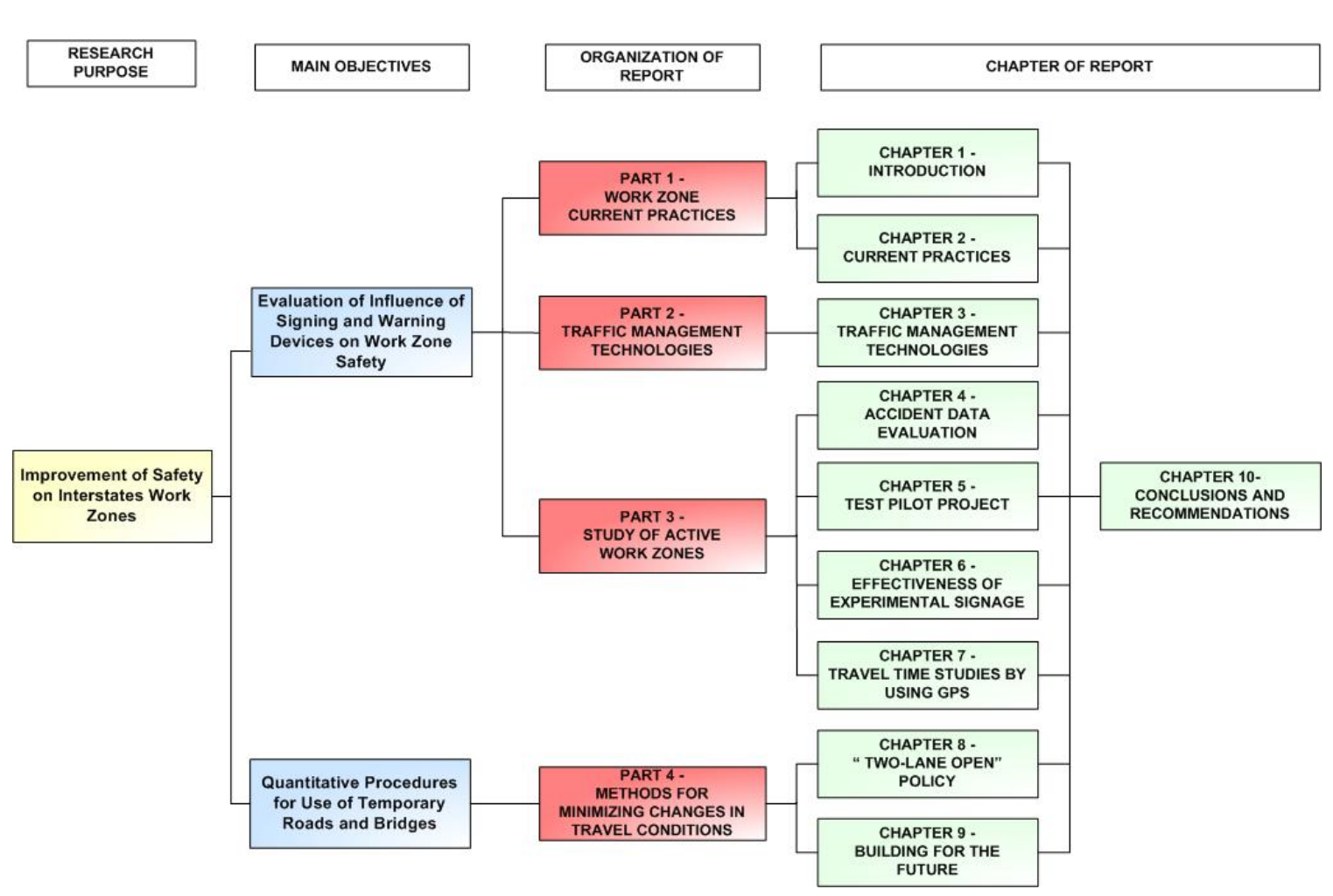

Figure 1-1 Organization of Report

Chapter 6 provides the results of the speed study conducted at this work zone. A comprehensive before and after study was conducted in an effort to quantify the impact of the added signs on the speeds of motorists traveling the work zone. In addition, an enforcement study was also conducted in this work zone. The study showed the benefits associated when a trooper was present in the work zone. Chapter 7 provides the findings of the travel time study trough work zones conducted by using Global Positioning Systems (GPS). The study showed that GPS can be satisfactorily implemented to document and reference points of interest in work zones.

The fourth part of the report covers the evaluation conducted to determine the feasibility of maintaining two lanes open at all times during work zones on interstates. Chapter 8 presents an 
economic model developed that can be implemented by INDOT for conducting preliminary decision making as to what projects need to maintain two lanes open at all times. The model was validated by using one project in the state of Indiana. In Chapter 9, a case study of what is being termed Building for the Future approach is presented. A successful project recently constructed in lowa near Des Moines is presented.

Finally, recommendations and conclusion are presented in Chapter 10. 


\title{
CHAPTER 2. WORK ZONE CURRENT PRACTICES
}

\begin{abstract}
2.1. Introduction
Although the types of work performed in a work zone remains much the same from state to state, the manner in which these tasks are performed is rarely uniform from one state to the next.

Nearly every state department of transportation in the United States has a different view on which type of traffic control devices and traffic control plans outperform the rest of the field. An extensive search was performed to learn of the various traffic control plans and devices that are preferred by each state. The results of this search are presented in the following sections.
\end{abstract}

\subsection{Indiana Department of Transportation (INDOT)}

INDOT has several practices that are commonly used to improve safety and traffic flow in and around work zones. The most recent of these practices is that of maintaining two operational lanes open in each direction of travel during construction on interstate routes, when feasible. Currently, the application of this practice is chosen from project to project.

To maintain two operational lanes during construction, shoulders are commonly being used to carry traffic. To use shoulders as traveling lanes, shoulders are constructed as full depth pavement. When shoulders must be used as traveling lanes during a reconstruction project, the existing shoulders are built up to be of the same quality of full depth shoulders. Construction of full depth shoulders is standard on all new urban projects in Indiana. Construction of full depth shoulders for new rural projects is made on a case-by-case basis.

Not all projects require that lane closures be in effect throughout the day. Projects that involve such tasks as the placement of thin overlays or temporary shoulder strengthening can be performed during the nighttime hours if necessary and return the roadway to satisfactory conditions by the start of the next day.

Although various traffic management plans can be created which allow a segment of interstate to remain in service during construction, such a case occasionally arises when it is not feasible to 
keep the segment open. Such interstate closures are rare in Indiana, but they do occur. In the mid 1990's, a segment of I-65 near Indianapolis was closed in one direction during a construction project. In the summer of 2003, the segment of I-65 that passes though downtown Indianapolis will be reconstructed. INDOT is currently considering closing this segment of interstate during the reconstruction process.

To reduce accidents, it is necessary for motorists to be aware of lane closures well in advance of reaching them. To make motorists aware of lane closures, INDOT often uses a variable message sign well in advance of any static signs warning of the lane closure. Although rumble strips have been used to alert motorist of the changing roadway conditions, they are currently not being used.

When bridge decks must be rehabilitated, several types of traffic management plans can be used. The most desirable of these plans is to maintain two operational lanes of traffic per direction. Addition of this extra lane then relieves work zone related congestion and allows traffic to flow more freely than when one lane is provided. In order to provide two operational lanes per direction, lane widths are often decreased and used in conjunction with a small shoulder to provide two lanes where one would typically exist. Such a situation arose when reconstructing the I-65 overpass of US 30 in 2002. Another option is to perform the work one lane at a time. When possible, one lane of a structure is rehabilitated while traffic is maintained in the adjacent lane. In the event that the structure cannot be repaired on a lane-by-lane basis, median crossovers are often used and traffic is maintained with one lane per direction on the other structure. .

Throughout any type of construction project, the traffic control plan should be checked to make sure that it is working correctly. A key element of this plan is the traffic control devices. If the traffic control devices are not placed as they were intended, the traffic control plan may not work correctly. To insure that the plan and the devices are working properly, INDOT requires the contractor to supply a person to check the traffic control plan daily. By doing so, any errors or damaged equipment can be found and corrected quickly.

Currently, INDOT has no guidelines for predicting when a queue will develop due to work zone lane restrictions. However, for larger scale projects INDOT uses the QUEWZ work zone analysis program. Prediction of a queue simply results from experience with the area and the typical traffic conditions. Although the Indiana Lane Merge System was once used by INDOT, no lane merge, queue detection or advanced warning systems are being used to date. 
One method of encouraging motorists to obey the posted work zone speed limits is to have the work zone patrolled frequently by police officers. Following this idea, INDOT uses money collected from work zone fines, which are double amount of a fine collected outside of a work zone, to fund increased police patrols in work zones.

Information about all major roadway projects in Indiana is publicized by INDOT. Large scale projects, such as the reconstruction of the I-65/ US30 interchange receive their own web page. On a web page such as this, the public can find information on when lane closures will begin, alternative routes, what type of work is being done and when the work will be finished. Besides web sites, INDOT also uses news releases to update the public on what the current roadway conditions are.

\subsection{Midwestern States Current Practices}

In an effort to improve the work zone policies and practices of INDOT, several states in the Midwest were queried through phone conversations and electronic mail communications to determine their policies and practices. When practical and beneficial, INDOT would then consider implementing these methods in its work zones.

The work zone policies and practices of the Illinois, Kentucky, Michigan, and Ohio Departments of Transportation were obtained by contacting engineers at each DOT that supervise work zone traffic control. The findings are discussed in the following sections. A matrix that summarizes all findings is presented in Table 2-1 through Table 2-5.

\subsubsection{Illinois Department of Transportation (IDOT)}

The Illinois Department of Transportation lacks a formal policy for handling traffic in and around work zones. Despite this lack of policy, IDOT does have several practices that are commonly used to improve safety and traffic flow in and around work zones. One such practice is that of maintaining two operational lanes open in each direction of travel during construction on interstate routes. To maintain two operational lanes during construction, shoulders are commonly being used to carry traffic. To use shoulders as traveling lanes, shoulders are being constructed as full depth pavement on all new construction and reconstruction projects on interstates that involve the construction of new shoulders. 
Despite the efforts made by IDOT to maintain traffic on an interstate during a construction project, it is sometimes not feasible to do so. Although this type of event is uncommon, a section of I-74 passing through Peoria was completely closed during the 2002 construction season. In this case, interstate traffic was rerouted though Peoria on major city streets. During this rerouting period, the city streets that were used by interstate traffic were closed to local traffic.

Similar to INDOT, IDOT has noticed a pattern of severe accidents that occur when queues form due to work zones. Due to a varying capacity of the work zone as well as varying traffic demands, queues typically are inconsistent in length. This inconsistent length can surprise motorists and result in a rear end collision. IDOT has noticed that this type of problem tends to develop most frequently on interstate patching projects.

In an attempt to predict when queues will develop, IDOT examines the average daily traffic (ADT) of a given segment of roadway. When an ADT for a roadway exceeds 20,000 , it is believed that traffic slows and that queues form during times of construction. For these segments, a greater than usual effort is required when creating traffic maintenance plans.

After making this decision on when queues form, IDOT engineers observed the ADT of each interstate in Illinois from the year 1995 to the year 2000. This data showed that only a few segments of interstate in Illinois had an ADT greater than 20,000 in 1995. It also showed that the volume of many of these segments grew to well over 20,000 for the year 2000 . For this reason, IDOT made many changes to the way in which traffic is maintained through interstate work zones. These changes are aimed at reducing accidents that result when queues form.

The changes involve many aspects of traffic control. For instance, drivers may run across rumble strips as they approach a taper. These strips are intended to alert the driver that a change in roadway conditions lays ahead. Currently, rumble strips are only used in circumstances when IDOT engineers feel that a work zone will be prone to accidents. When drivers reach the taper, they may encounter guidance in the form of arrows placed on the main panels of barrels that make up the taper. It is intended that these arrows be pointed in the direction of the operational lane of the work zone, however due to the great detail that is required to place and maintain these barrels, their use is still being tested under the SHRP program. Another effort to make the merging procedure safer for drivers is the use of the Dynamic Lane Merge System. This system would decrease the time required for vehicles to merge at a taper and thus reduce the queue lengths, however IDOT is only considering its use at this time. 
Once inside a work zone, drivers may notice vertical barricades (Type II) and 42" cones instead of barrels. These barricades are being chosen over barrels because numerous drivers become uneasy when passing through work zones that provide little room for driving error. When drivers are uneasy, they tend to drive at speeds below the posted work zone speed limit of $45 \mathrm{mph}$, which causes queues to form. Through the use of vertical barricades and 42" cones, greater lane widths are given for drivers in work zones than when barrels are used, which in turn will help to maintain speeds at the posted speed of the work zone. Such devices are also being used near ramps, instead of barrels, because they increase the amount of usable roadway.

In addition to new type of barricades and guidance, IDOT is also requiring that all interstate projects be under full-time surveillance. To achieve this, an employee of IDOT is assigned to observe the work zone. This person is then to pass through the work zone every two to four hours and to confirm that the traffic control methods used for the work zone meet all standards set forth by IDOT and the Manual on Uniform Traffic Control Devices. In the future, IDOT may require contractors to assign a member of their crew to this task.

IDOT has also changed its construction procedures. One change is that of removing a section of a lane entirely with a grinding machine and replacing all layers of the pavement removed instead of replacing the wearing surface, when patching is required. This procedure is done in an effort to increase the time between patching, and thus reduce the frequency of lane closures. When resurfacing, there often exists a difference in pavement heights between the shoulder and the right hand lane. To eliminate this height variation and thus improve the safety of motorists traveling on interstate routes that are in the process of being resurfaced, IDOT requires that shoulders be resurfaced to a level equal of that lane before resurfacing any adjacent lane.

Construction involving bridge deck rehabilitations are done in several ways. When rehabbing the McClugage Bridge over the Illinois River, all traffic was moved to the westbound lanes. A movable barrier system was then used on this three-lane roadway. Two lanes were provided for westbound traffic during the morning peak hours, while two lanes were provided for eastbound traffic during the evening peak hours. In other instances, a median crossover is used and traffic is restricted to fewer lanes, or lanes are closed and no median crossover is used. When rehabilitating the I-55 bridges over Lake Springfield, two operational lanes were maintained at all times. This was accomplished through the use of concrete barrier walls and narrowed lane widths, as seen in Figure 2-1. 


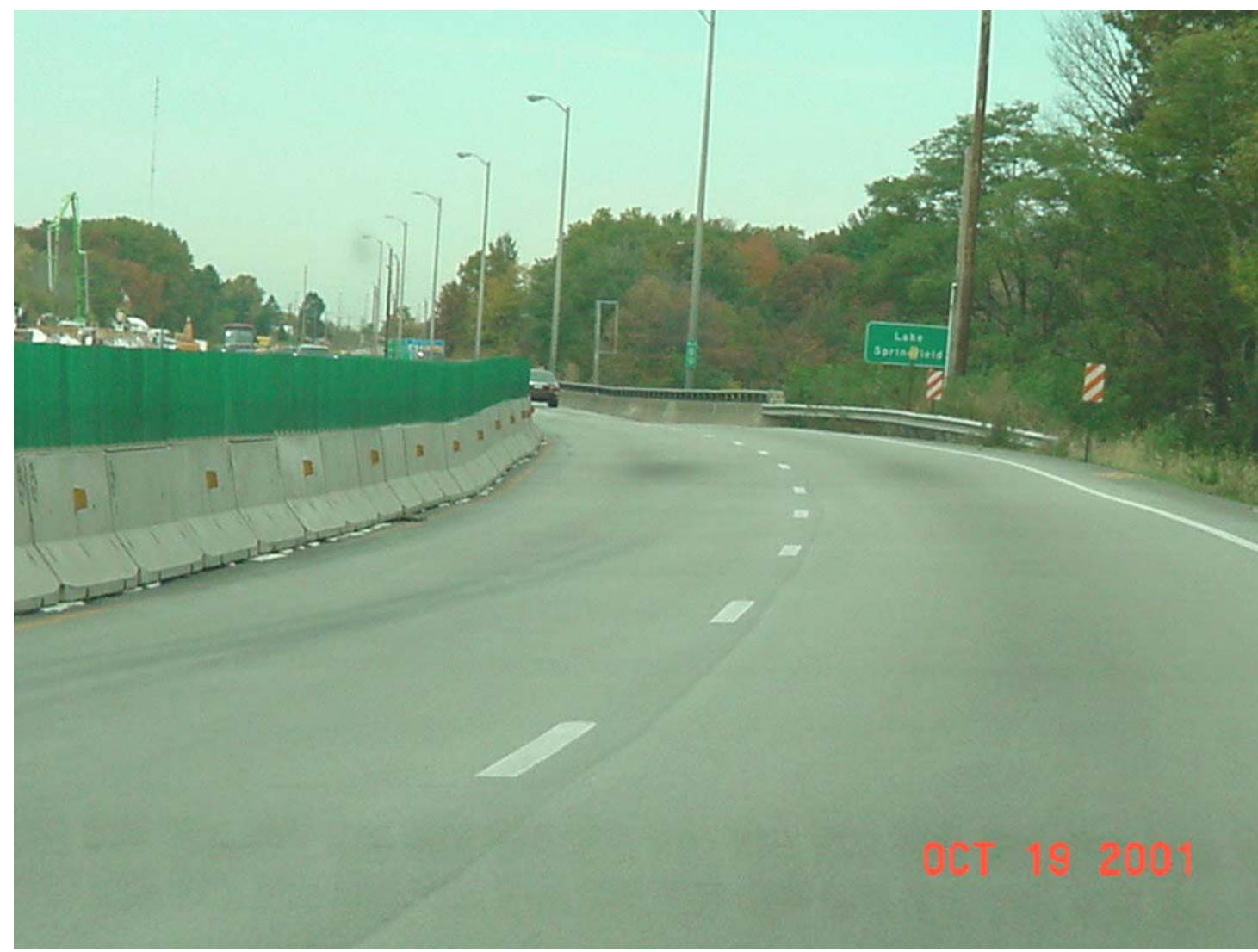

Figure 2-1 Roadway conditions of I-55 during reconstruction of Lake Springfield Bridges(10/19/01)

In 2001, I-74 between St. Joseph and Danville, Illinois was under construction. During this project, the flow of traffic was restricted to one lane in each direction. The queues that were produced from this lane restriction, coupled with driver inattentiveness and vehicles traveling at excessive speeds, caused numerous crashes and three fatalities, all of which occurred within a three-mile radius of the work zone.

In an effort to reduce the frequency and severity of these crashes, IDOT is attempting to alert motorists of a work zone well in advance of reaching the site. This is being done in several ways. Possibly the least expensive of these methods was the installation of a flashing amber beacon on static "RIGHT (LEFT) LANE CLOSED" signs that are placed on interstate routes with such signs. Also being used to alert motorists well in advance of a work zone are variable message signs. These signs were being placed three miles in advance of the "Road Construction 1 Mile" signs. Such variable message signs displayed the message "RIGHT (LEFT) LANE CLOSED - 3 MILES 
AHEAD/ BE PREPARED TO STOP". To slow motorists traveling through a work zone, signs, as shown in Figure 2-2, are being placed on the approach to the work zone.

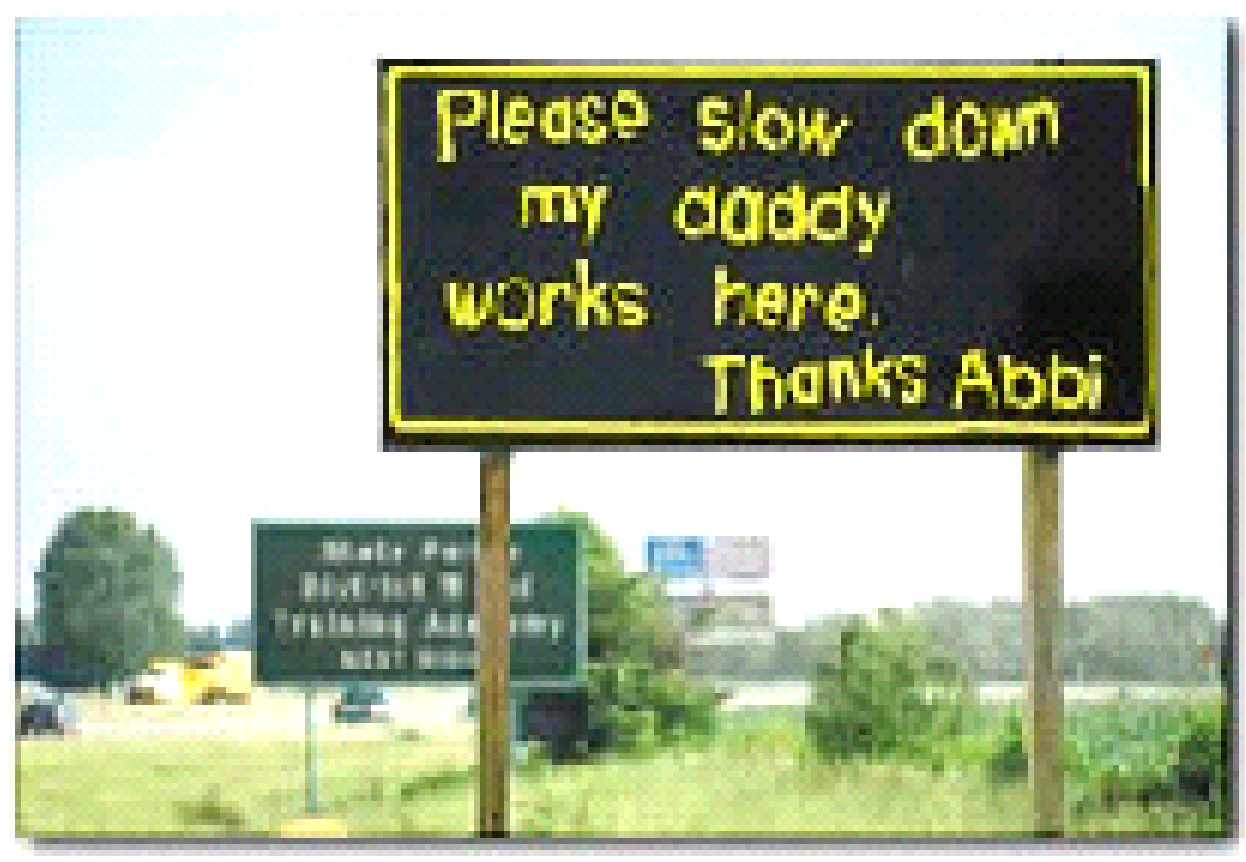

Figure 2-2 Work Zone Sign

Although these signs are effective, many motorists do not heed their warning and reduce their speeds. In an attempt to convince these drivers to reduce their speeds, variable message signs that display the number of tickets issued to date in and around the work zone are commonly being placed in advance of the work zone. Despite these signs, some drivers still remain reluctant to slow down. For these individuals, increased police patrols have been assigned to work zones. These special patrols are not funded through the work zone traffic fines collected at the site, which are double the amount of a fine outside a work zone, but are instead funded through construction funds for the project.

IDOT also has deployed some limited ITS technology to reduce the frequency and severity of crashes. This method involves the used of a mobile intelligent transportation system that is intended specifically for use in work zones. To date, the Automated Information Management 
System (AIMS) has been used at several locations through out the state of Illinois. This system, as well as others, will be discussed in Chapter 3 of this report.

\subsubsection{Kentucky Transportation Cabinet}

The Kentucky Transportation Cabinet has several methods and policies that are used regularly to increase safety in and around work zones. These methods involve the use of increased police patrols, work zone signs that incorporate the theme of the area, and restrictions on when work can be performed.

Like many states, Kentucky uses the revenue collected from the double fines issued in work zones to fund special work zone patrols in the vicinity of an interstate work zone. In an effort to reduce speeds before issuing tickets for traffic violations, the Kentucky Transportation Cabinet commonly posts numerous signs in advance of a work zone. These signs often display various messages that are aimed at slowing traffic. For instance, when the interstates that pass through Louisville, Kentucky were under construction in 2000 , creative messages were posted around the work zone in an effort to slow traffic. Using the Kentucky Derby theme that accompanies the Louisville area, the Transportation Cabinet erected signs with the messages "Whoa Baby Whoa!" and "Leave the racing to the horses". These creative signs, which were approved by the FHWA, caught the attention of drivers and were reported to have a positive effect on the reduction of speeds in the area.

To minimize the delay imposed on motorists, the Kentucky Transportation Cabinet prefers to close lanes during the nighttime hours, however this is not always possible. In some instances, interstate segments that were under construction were completely closed until the work is substantially completed. This method is most often used when an alternate interstate route is available, such as when I-65 through the Louisville area was closed. In this instance, motorists traveling on I-65 were notified as far south as the Kentucky-Tennessee State Line and as far to the north as Indianapolis that I-65 was closed. These messages also advised motorists of alternate routes around the construction. According to the Kentucky Transportation Cabinet, the general public seems to support this idea of complete closure, despite the extra travel time that may result. This alternative is often preferred because it allows the work to be finished as quickly as possible. 


\subsubsection{Michigan Department of Transportation (MDOT)}

Similar to the agencies previously discussed, MDOT has several methods and policies that are used regularly to increase safety in and around work zones. These practices and policies involve lane closures and restrictions, the use of increased police patrols, and work zone signs that are to be displayed.

MDOT takes an approach to lane closures that is similar to that of neighboring DOTs. MDOT also has a policy to maintain two lanes of travel in both directions while performing construction on interstate routes. Unlike the other agencies, this policy is only enforced on weekends. This is due to the large number of motorists who travel through the state of Michigan on the weekends. MDOT also attempts to keep lane closures to nighttime hours only. Although this procedure is commonly used; it does not apply to all work zones. For instance, complete freeway closures for an entire weekend are common in the Detroit area.

MDOT also has increased police patrols in its work zones. These patrols are not funded by the fines collected, but by MDOT itself. Work zone traffic violations can only be collected when lights flash on the posted work zone speed limit signs. These signs indicate that workers are present, and that the lower speeds are enforceable. Although this form of variable speed limits has its advantages, there are also problems involved. One such problem that MDOT has experienced with these signs is that it is common for the lights to be left on. Contractors often neglect to turn off the lights when no workers are present. When this happens, motorists often become less likely to honor the work zone speed limits when workers are present.

To inform motorists that they are approaching a work zone, MDOT has several requirements. One such requirement is the placement of variable message signs five to ten miles in advance of the lane closure. The message displayed on these signs is intended to warn motorists of the conditions ahead. To alert drivers that a lane closure is near, rumble strips are being placed in advance of the taper. To ensure a safe and efficient merging of the lanes of traffic at the taper, MDOT has often used the Indiana Lane Merge System.

Once a motorist enters a work zone, MDOT makes an effort to continue to communicate with them. This is accomplished through the use of informational signs that are located along the roadside. Each sign in the series displays a face that changes from a frown at the beginning of the work zone to a smiling face at the end of the work zone. These signs are intended to inform drivers inside work zones of the distance they have remaining before exiting the work zone. It is 
believed that informing motorists of their distance to travel through the work zone will reduce their frustration and result in fewer accidents.

MDOT has also made another effort to inform motorists and reduce their frustration while traveling through work zones. This involves the use of the Travel Time Prediction System (TIPS), which is intended to ease frustration by informing drivers of their time to travel before reaching the end of the work zone. This traffic management technology is discussed in greater detail in Chapter 3.

To ensure that the traffic maintenance plans for a given project are followed, MDOT requires contractors of interstate work zones to designate one employee to traffic control. This person, called a "Work Site Traffic Supervisor", is then responsible for maintaining the signs and barrels associated with the work zone. It is intended that this person also make suggestions on how to improve safety at that particular work zone.

MDOT informs the public of construction activities through press releases that are issued almost daily. On all major construction projects, a news conference is held to inform the public of the upcoming events and lane closures.

Since October of 2001, the state of Michigan has had a law that pertains to work zones. This law specifies prison time for any motorist who hits or kills a construction worker in a work zone. The law also has harsher penalties for drivers who commit these offenses while driving under the influence of alcohol.

\subsubsection{Ohio Department of Transportation (ODOT)}

The Ohio Department of Transportation has a very detailed policy for work zones. The policy, which is known as the "Traffic Master Plan and Work Zone Policy", defines how traffic must be handled in work zones. Included in this document are Permitted Lane Closure Maps (PLCMs) for each district. Each map "defines the allowable times that a lane(s) may be closed on the Interstate/Freeway system within that District". Currently, the PLCMs are available either at the Office of Traffic Engineering or on the ODOT website.

The Traffic Master Plan and Work Zone Policy used by ODOT covers several important topics. It first defines a position within each district of ODOT titled the District Work Zone Traffic Manager (DWZTM). This person has several responsibilities. These responsibilities include maintaining 
the PLCM, providing guidance on the use of the PLCM to all who will use the map, developing a traffic plan for all interstate and freeway lane closures that fall outside the bounds of the PLCM, as well as the coordination and monitoring all projects that may affect traffic flow on interstates and freeways in a district.

Before work is begun, a work zone is first modeled using software such as Quewz-92 or Corsim. The model is created in an effort to predict the length of the maximum queue that will result from the work zone. If the predicted queue length is less than 0.75 miles, then the impacts of the work zone on the traffic flow is acceptable, and no action is required. If the length of the queue exceeds 0.75 miles for less than two hours, the queue is also deemed acceptable. However in this situation, advanced warning signing is required to inform motorists of the queue that lies ahead. Any queue that exceeds 0.75 miles for more than a two-hour period, or exceeds 1.5 miles for any amount of time is deemed unacceptable. When it is predicted that such a queue will occur, ODOT requires that alternative traffic maintenance strategies be developed.

Once implemented, a work zone is then monitored by the DWZTM. After allowing one week for drivers to become accustomed to the work zone, the lengths of any queues that occur due to the work zone are then compared to the queues predicted through the modeling procedure. If the existing queue lengths exceed the expected queue lengths, the DWZTM must then inform the Multi-Lane Coordinator (MLC) of this variation and propose some corrective action.

ODOT traffic engineers assume that a one-lane roadway can only handle an ADT of 20,000. When the ADT for a direction of travel exceeds 20,000, a practice known as Part Width Construction is used. Part Width Construction is the practice of decreasing the lane width(s) of the open lane(s). The shoulder is then used with the narrowed lane(s) in order to maintain two lanes of traffic.

Traffic management systems have been used by ODOT on several past projects that caused a considerable delay to the roadway users. The Travel Time Prediction System (TIPS) has been used in the Dayton and Columbus areas in an effort to reduce driver frustration. This technology is discussed in greater detail in Chapter 3. 
Table 2-1 Work Zone Practices of DOTs in Midwestern States

\begin{tabular}{|c|c|c|c|c|}
\hline & $\begin{array}{c}\text { Traffic Work Zone } \\
\text { Policy For Queue } \\
\text { Management }\end{array}$ & $\begin{array}{l}\text { Permitted Lane } \\
\text { Closure Map }\end{array}$ & $\begin{array}{c}\text { Two Lanes When } \\
\text { Practical }\end{array}$ & $\begin{array}{l}\text { Method to Aid } \\
\text { Practice }\end{array}$ \\
\hline $\begin{array}{c}\text { Indiana } \\
\text { Gary Mroczka } \\
\text { (317) 232-5226 }\end{array}$ & Under Revision & Under Revision & Yes & $\begin{array}{c}\text { Design new } \\
\text { shoulders to } \\
\text { pavement standards, } \\
\text { improve existing } \\
\text { shoulders }\end{array}$ \\
\hline $\begin{array}{c}\text { Illinios } \\
\text { Jim Schoenherr } \\
\text { (217) 782-3450 }\end{array}$ & Various policies & Under Revision & At all times & $\begin{array}{l}\text { Design shoulders to } \\
\text { pavement standards } \\
\text { (depth \& width) }\end{array}$ \\
\hline $\begin{array}{l}\text { Kentucky } \\
\text { Simon Cornett } \\
\text { (502) 564-3020 }\end{array}$ & Under Revision & Under Revision & Under Revision & Under Revision \\
\hline $\begin{array}{l}\text { Michigan } \\
\text { Jeff Grossklaus } \\
\text { (517) 322-5769 }\end{array}$ & Under Revision & Under Revision & Weekends only & $\begin{array}{l}\text { Design new } \\
\text { shoulders to } \\
\text { pavement standards } \\
\left(\text { width }=10^{\prime}\right)\end{array}$ \\
\hline $\begin{array}{c}\text { Ohio } \\
\text { Mack Braxton } \\
\text { (634) } 752-8829\end{array}$ & $\begin{array}{l}\text { Traffic Master Plan \& } \\
\text { Work Zone Policy }\end{array}$ & Available on Web & Daylight hours only & $\begin{array}{c}\text { Various methods } \\
\text { outlined in traffic work } \\
\text { zone policy }\end{array}$ \\
\hline
\end{tabular}


Table 2-2 Work Zone Practices of DOTs in Midwestern States (con't)

\begin{tabular}{|c|c|c|c|c|}
\hline & $\begin{array}{c}\text { Complete Interstate } \\
\text { Closures }\end{array}$ & $\begin{array}{l}\text { Night Time Lane } \\
\text { ClosuresWhen } \\
\text { Possible }\end{array}$ & $\begin{array}{l}\text { VMS in Advance of } \\
\text { Lane Closure Signs }\end{array}$ & $\begin{array}{l}\text { Rumble Strips in } \\
\text { Advance of Lane } \\
\text { Closures }\end{array}$ \\
\hline $\begin{array}{c}\text { Indiana } \\
\text { Gary Mroczka } \\
\text { (317) 232-5226 }\end{array}$ & $\begin{array}{l}\text { Not typical. Will be } \\
\text { considered for rehab } \\
\text { of I-65 through } \\
\text { Indianapolis, IN }\end{array}$ & Yes & $\begin{array}{l}\text { Not mandatory, but } \\
\text { prefered }\end{array}$ & No \\
\hline $\begin{array}{c}\text { Illinios } \\
\text { Jim Schoenherr } \\
\text { (217) } 782-3450\end{array}$ & $\begin{array}{l}\text { Not typical. Will be } \\
\text { done on I-74 through } \\
\text { Peoria, IL in } 2002\end{array}$ & Yes & $\begin{array}{c}\text { Placed } 3 \text { miles ahead } \\
\text { on } 1-55 \text { and } 1-72\end{array}$ & $\begin{array}{l}\text { Not standard. Used } \\
\text { on accident prone } \\
\text { sites }\end{array}$ \\
\hline $\begin{array}{l}\text { Kentucky } \\
\text { Simon Cornett } \\
\text { (502) 564-3020 }\end{array}$ & $\begin{array}{c}\text { When alternate } \\
\text { interstate route exists }\end{array}$ & Yes & $\begin{array}{l}\text { Yes, but no set } \\
\text { distance ahead of } \\
\text { signage }\end{array}$ & no \\
\hline $\begin{array}{l}\text { Michigan } \\
\text { Jeff Grossklaus } \\
\text { (517) 322-5769 }\end{array}$ & $\begin{array}{c}\text { Common in Detroit } \\
\text { area }\end{array}$ & Yes & 5 to 10 miles ahead & Yes \\
\hline $\begin{array}{c}\text { Ohio } \\
\text { Mack Braxton } \\
\text { (634) } 752-8829\end{array}$ & Not typical & Yes & No & No \\
\hline
\end{tabular}


Table 2-3 Work Zone Practices of DOTs in Midwestern States (con't)

\begin{tabular}{|c|c|c|c|c|}
\hline & $\begin{array}{c}\text { Type of Barricade } \\
\text { Used }\end{array}$ & $\begin{array}{l}\text { Traffic Control for } \\
\text { Bridge Deck } \\
\text { Rehabs. }\end{array}$ & $\begin{array}{c}\text { Queue Prediction } \\
\text { Method }\end{array}$ & $\begin{array}{c}\text { Queue Detection \& } \\
\text { Advanced Warning } \\
\text { System }\end{array}$ \\
\hline $\begin{array}{c}\text { Indiana } \\
\text { Gary Mroczka } \\
\text { (317) 232-5226 }\end{array}$ & $\begin{array}{l}\text { Barrels, concrete } \\
\text { barrier walls }\end{array}$ & $\begin{array}{l}\text { Partial width lanes, } \\
\text { median crossover }\end{array}$ & QUEWZ & None \\
\hline $\begin{array}{c}\text { Illinios } \\
\text { Jim Schoenherr } \\
\text { (217) 782-3450 }\end{array}$ & $\begin{array}{l}\text { Vertical (Type II), } \\
\text { barrels, barrels with } \\
\text { arrow panels, 42" } \\
\text { cones }\end{array}$ & $\begin{array}{l}\text { Movable barrier } \\
\text { system, median } \\
\text { crossover }\end{array}$ & ADT $>20,000$ & RTTMS \\
\hline $\begin{array}{l}\text { Kentucky } \\
\text { Simon Cornett } \\
\text { (502) } 564-3020\end{array}$ & $\begin{array}{l}\text { Barrels, concrete } \\
\text { barrier walls }\end{array}$ & $\begin{array}{l}\text { Complete closure } \\
\text { (when possible), } \\
\text { median crossovers }\end{array}$ & None & None \\
\hline $\begin{array}{l}\text { Michigan } \\
\text { Jeff Grossklaus } \\
\text { (517) } 322-5769\end{array}$ & $\begin{array}{l}\text { Barrels, concrete } \\
\text { barrier walls }\end{array}$ & $\begin{array}{l}\text { Partial width lanes, } \\
\text { median crossover } \\
\text { with one lane per } \\
\text { direction }\end{array}$ & None & $\begin{array}{l}\text { Experiment with TIPS } \\
\text { in } 2002\end{array}$ \\
\hline $\begin{array}{c}\text { Ohio } \\
\text { Mack Braxton } \\
\text { (634) } 752-8829\end{array}$ & $\begin{array}{c}\text { Movalbe barrier } \\
\text { systems, concrete } \\
\text { barrier walls, barrels }\end{array}$ & $\begin{array}{l}\text { Bridge widening, } \\
\text { median crossover }\end{array}$ & $\begin{array}{c}\text { ADT > 20,000 } \\
\text { QUEWZ-92, } \\
\text { Simtraffic or Corsim }\end{array}$ & TIPS \\
\hline
\end{tabular}


Table 2-4 Work Zone Practices of DOTs in Midwestern States (con't)

\begin{tabular}{|c|c|c|c|c|}
\hline & Lane Merge System & $\begin{array}{l}\text { Work Zone } \\
\text { Surveillance } \\
\text { Employee }\end{array}$ & $\begin{array}{c}\text { Methods to } \\
\text { Publicize Work } \\
\text { Zone }\end{array}$ & $\begin{array}{c}\text { Creative } \\
\text { Informational Signs }\end{array}$ \\
\hline $\begin{array}{c}\text { Indiana } \\
\text { Gary Mroczka } \\
\text { (317) 232-5226 }\end{array}$ & $\begin{array}{c}\text { Indiana Lane Merge } \\
\text { System }\end{array}$ & $\begin{array}{l}\text { Provided by } \\
\text { contractor }\end{array}$ & $\begin{array}{l}\text { Web sites for major } \\
\text { projects, news } \\
\text { releases }\end{array}$ & Smiley Faces \\
\hline $\begin{array}{c}\text { Illinios } \\
\text { Jim Schoenherr } \\
\text { (217) 782-3450 }\end{array}$ & $\begin{array}{l}\text { Considering dynamic } \\
\text { lane merge system }\end{array}$ & Provided by IDOT & $\begin{array}{l}\text { Fliers distributed to } \\
\text { truck drivers, } \\
\text { publicized through } \\
\text { media }\end{array}$ & $\begin{array}{l}\text { VMS displaying \# of } \\
\text { tickets issued in work } \\
\text { zone, "Please Slow } \\
\text { Down, My Mommy } \\
\text { (Daddy) Works Here" }\end{array}$ \\
\hline $\begin{array}{l}\text { Kentucky } \\
\text { Simon Cornett } \\
\text { (502) 564-3020 }\end{array}$ & None & None & $\begin{array}{l}\text { Publicized through } \\
\text { media }\end{array}$ & $\begin{array}{l}\text { "Whoa Baby, Whoa!", } \\
\text { "Leave The Racing } \\
\text { To The Horses" }\end{array}$ \\
\hline $\begin{array}{l}\text { Michigan } \\
\text { Jeff Grossklaus } \\
\text { (517) } 322-5769\end{array}$ & $\begin{array}{c}\text { Indiana Lane Merge } \\
\text { System }\end{array}$ & $\begin{array}{l}\text { Provided by } \\
\text { contractor }\end{array}$ & $\begin{array}{c}\text { Frequent press } \\
\text { conferences, news } \\
\text { conferences for major } \\
\text { projects }\end{array}$ & Smiley Faces \\
\hline $\begin{array}{c}\text { Ohio } \\
\text { Mack Braxton } \\
\text { (634) } 752-8829\end{array}$ & None & $\begin{array}{c}\text { DWZTM }^{1} \text { provided by } \\
\text { ODOT }\end{array}$ & $\begin{array}{l}\text { Press releases, } \\
\text { media alerts, maps, } \\
\text { brochures, } \\
\text { newsletters }\end{array}$ & $\begin{array}{l}\text { "Please Slow Down, } \\
\text { My Mommy (Daddy) } \\
\text { Works Here" }\end{array}$ \\
\hline
\end{tabular}


Table 2-5 Work Zone Practices of DOTs in Midwestern States (con't)

\begin{tabular}{|c|c|c|c|}
\hline & $\begin{array}{c}\text { Increased Police } \\
\text { Patrol }\end{array}$ & $\begin{array}{l}\text { Fines Doubled in } \\
\text { Work Zones }\end{array}$ & $\begin{array}{c}\text { Work Zone Accident } \\
\text { Laws }\end{array}$ \\
\hline $\begin{array}{c}\text { Indiana } \\
\text { Gary Mroczka } \\
\text { (317) 232-5226 }\end{array}$ & Yes & Yes & None \\
\hline $\begin{array}{c}\text { Illinios } \\
\text { Jim Schoenherr } \\
\text { (217) 782-3450 }\end{array}$ & $\begin{array}{l}\text { Construction funds } \\
\text { used to hire off duty } \\
\text { officers }\end{array}$ & Yes & None \\
\hline $\begin{array}{l}\text { Kentucky } \\
\text { Simon Cornett } \\
\text { (502) 564-3020 }\end{array}$ & $\begin{array}{l}\text { Money collected from } \\
\text { double fines funds } \\
\text { police force }\end{array}$ & Yes & None \\
\hline $\begin{array}{l}\text { Michigan } \\
\text { Jeff Grossklaus } \\
\text { (517) } 322-5769\end{array}$ & Funded by MDOT & Yes & $\begin{array}{l}\text { Specifies prison time } \\
\text { for injuring a worker }\end{array}$ \\
\hline $\begin{array}{c}\text { Ohio } \\
\text { Mack Braxton } \\
\text { (634) } 752-8829\end{array}$ & Yes & Yes & None \\
\hline
\end{tabular}

\subsection{European Work Zone Practices}

The Federal Highway Administration (FHWA) and the National Cooperative Highway Research Program (NCHRP) sponsored a project in 1999 in an effort to provide U.S. transportation officials and industry with an overview of different approaches for addressing interstate work zone mobility and safety in other countries. This FHWA international scanning review consisted of evaluating initiatives in five European countries. The countries analyzed included: Belgium, France, Germany, Scotland and The Netherlands. The information presented in this section is a summary of the report of this evaluation titled "Methods and Procedures to Reduce Motorist Delays in 
European Work Zones ${ }^{1 "}$. Each country will be analyzed independently by following the same categories: 1) Construction and Traffic Operations 2) Motorist Information and 3) Innovations. A summary matrix is presented for comparing the different practices in the countries analyzed.

\subsubsection{Belgium}

\subsubsection{Construction and Traffic Operations}

With the exception of Scotland yellow pavement markings are used to delineate travel lanes on the interstates during construction work. In Belgium for example, white markings are not removed during construction. In order to minimize the duration of work zone projects, contractors must be certified based on past experience. Depending on the complexity of projects contractors are selected to submit bids.

Similar to practices in other countries, Belgium officials avoid lane closures and strive for maintaining normal traffic lanes opened at all times. Shoulders are strengthened and converted to traffic lanes, and if necessary lanes are narrowed. Typically work zone lanes consist of $10 \mathrm{ft}$. wide lanes open to all vehicles and $8.2 \mathrm{ft}$. lanes restricted to only automobiles.

\subsubsection{Motorist Information}

Communications with motorists is vital to informing the public of the changing road conditions during work zones. All the European countries analyzed use Intelligent Transportation Systems frequently. Belgium uses traffic management technologies to provide motorists with information on major reconstruction projects by using radio, variable message signs and the Internet.

To provide road users of real-time traffic conditions, portable queue detectors are installed. These portable systems monitor traffic speed and lane occupancy by means of detectors and cameras. When a slowdown is detected, the system automatically displays warning messages as shown in Figure 2-3.

\footnotetext{
${ }^{1}$ Taken from: Steinke, D et. al (2000) "Methods and Procedures to Reduce Motorist Delays in European Work Zones" FHWA (Publication No. FHWA-PL-01-001) Washington, D.C.
} 


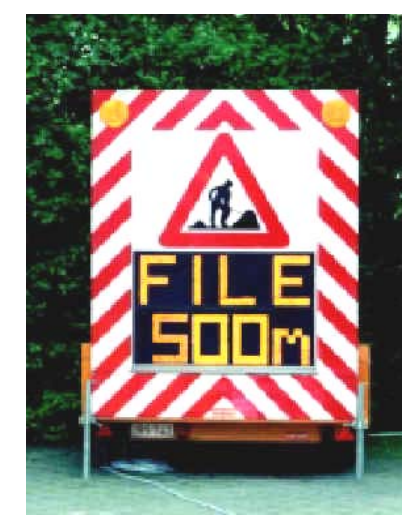

Figure 2-3 Typical VMS used in Belgium

In addition, Belgium officials provide when feasible, two alternate routes in major reconstruction projects. These routes are displayed by the numerals "1" and "2" by using additional signs and informing motorists by means of radio, VMS and the Internet. Based on the conditions and type of incident, the traffic is rerouted or informed to be rerouted accordingly

\subsubsection{Innovations}

When possible, replacement bridges are built "in-the-shop" in Belgium and Scotland. These bridges are "inserted" into place during the weekend for minimizing impacts on traffic and traveling conditions.

\subsection{2. $\quad$ France}

\subsubsection{Construction and Traffic Operations}

In France yellow pavement markings are also used to delineate travel lanes in work zone areas. The main difference with Belgium is that during construction activity permanent white markings are removed for denoting the work area. Also, a $40 \mathrm{ft}$. long movable metal barrier is commonly used for separating traffic from the work zone activity area. 
In an effort to minimize delays French officials emphasize that delays cannot exceed more than 6 percent lost of time on a 62-mile stretch. To reduce the duration of work zones, contractors are assessed penalties for every day the project is extended after the agreed completion date.

Typically penalties are 0.3 percent of project cost

\subsubsection{Motorist Information}

France in particular, uses extensive pictograms/symbols in work zone signs instead of text for communicating with motorists. France distributes eleven million calendars showing location and dates for future projects. In addition, traffic management technologies are heavily used. Trailer mounted signs with multicolored fiber optic signs are used on temporary work zones. French officials believe that variable message signs displaying information on delays rather than backup queue lengths are more effective for informing motorists.

\subsubsection{Innovations:}

A "road innovation charter" was established in 1982 for addressing problems related to current needs of the infrastructure system.

\subsection{3.}

Germany

\subsubsection{Construction and Traffic Operations}

Yellow pavement markings are used to mark travel lanes in work zones. Analogous to Belgium, permanent white markings are not removed. Metal barriers are used for separation of traffic from work zones, in a similar fashion to the Jersey barriers used in Indiana. For minimizing duration of work zones, contractors are assessed bonuses or penalties for every day the project is extended or completed upon the agreed completion date. These incentives/disincentives vary according to average daily traffic (ADTs) volumes for the roadway under construction. In addition, contractors are required to provide a warranty (typically $2-5$ years) on all completed projects.

When possible all lanes must be maintained open during work zones. If a roadway is expected to have an ADT greater than 105,000 vehicles per day, lane closures are not permitted. Shoulders 
are converted to traffic lanes, and if necessary lanes are narrowed. According to research studies completed by the German Road Authority (See Figure 2-4), as lanes are narrowed the attention of drivers is increased and traffic is slowed as vehicles approach a crossover.

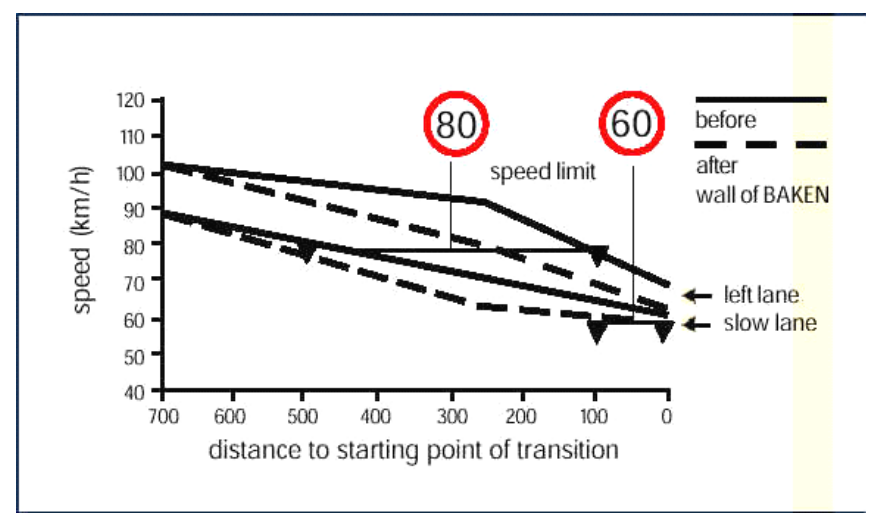

Figure 2-4 Speed Drop Near Crossover

\subsubsection{Motorist Information}

Signs are posted throughout interstates reminding motorists that the job is being completed for their benefit. Germany uses to a great extent variable message signs in addition to permanent orange trailblazers. According to the report, overhead signs are more prevalent in Germany and Europe, than in the United States. Signs posted over each lane provide information about speed limits. Whereas, overhead signs between lanes announce information about detours and work zones. Interestingly, Germany uses considerably pictorials on signs. Words are allowed when signs are aimed to inform drivers of incident management and weather conditions (such as fog).

\subsubsection{Innovations:}

German authorities have been developing a mechanism for providing more accurate information to the traveling public. Small devices similar to pagers are used to inform motorists of the changing conditions on interstates. 


\subsubsection{Scotland}

\subsubsection{Construction and Traffic Operations}

Lane rental charges are used to expedite process of project completion and minimize duration of work zones. The most common lane rental charge is a bonus/charge system which is determined by lane occupation (lane closed for performing work) during the project. Contractors are required to provide an amount for the lane rental charges of the project, and this figure is included in the bid evaluation. Contractors are charged/ rewarded accordingly.

Scottish officials typically narrow lanes during work zones on interstates. Lanes when narrowed consist of a $12 \mathrm{ft}$ wide lane open to all vehicles and a $9 \mathrm{ft}$ lane restricted to only automobiles. To avoid lane closures and reduce the amount of traffic in work zones, officials provide alternate routes, coordinate ridesharing programs, and provide temporary park-and-ride parking lots.

\subsubsection{Motorist Information}

Variable message signs informing motorists of delay during the work zone rather than backup queue lengths are more commonly used. Scotland has found an effective way to reducing speed near work zones by informing motorists of the numbers of persons ticketed in the prior week in the work zone. In addition, safety brochures are distributed throughout the country to inform motorists of changing road conditions during interstate work.

\subsubsection{Innovations}

Replacement bridges are built "in-the-shop" in Scotland similar to Belgium. In addition, work zone audits are conducted by an independent evaluator in an attempt to detect and correct unsafe conditions for road users. 


\subsubsection{The Netherlands}

\subsubsection{Construction and Traffic Operations}

Yellow pavement markings are used in the Netherlands to delineate travel lanes in work zones. Work zone delays are expected to be approximately 13 percent of the total traffic delay. The objective is to reduce the delay in work zone projects to be less than 6 percent of total traffic delay. Dutch officials have sometimes found it cost-effective to close-down completely an interstate during construction operations.

A software called Meldwerk has been developed to coordinate road construction projects between agencies. This program is aimed to minimize project durations by ensuring that information within transportation officials across agencies is disseminated. This program allows engineers to maintain up-to-date information of work zone areas, lane reductions and location and length of projects.

\subsubsection{Motorists Information}

Contractors are required to provide appropriate lighting throughout the entire project to assist drivers in road changing conditions. The Netherlands implements a device similar to the rumble strips currently used in the United States for informing the motorists that is entering a construction work zone. In addition, Mobile Lane Signaling Systems (MRS) has been deployed to display information. These portable signs mounted on metal structures are easily installed and are visible at a distance of 2500-3000 feet (Figure 2-5).

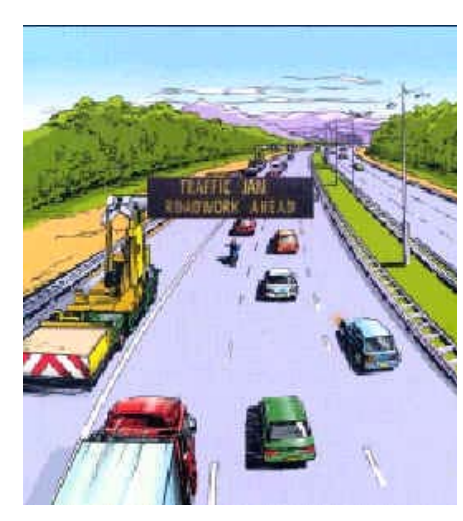

Figure 2-5 MRS Deployment 


\subsubsection{Innovations}

The Netherlands is developing a computer program similar to the FHWA Quickzone initiative, to calculate work zone delays. The system also has the capability of assessing the impact of closing down a lane, an entire segment or just conducting work with nearby traffic.

\subsection{Summary}

Based on the evaluation of current European practices, the research team recommended a set of goals for U.S. transportation officials. The most important objectives included: 1) to minimize duration of construction periods, 2) to improve communication with motorists 3) to adopt a coordinated policy among responsible agencies, 4) when feasible to reduce lane widths in work zones if necessary to maintain the normal number of lanes, 5 ) to design interstates for accessible future maintenance, 6 ) to evaluate the use of yellow pavement markings in work zones, 7) to use traffic control devices to guide motorists through work areas and 8) to encourage innovation in different transportation agencies. Table 2-6 and Table 2-7 present a summary of all the different work zone practices conducted in the European countries analyzed. 
Table 2-6 Summary Matrix of European Work Zone Practices

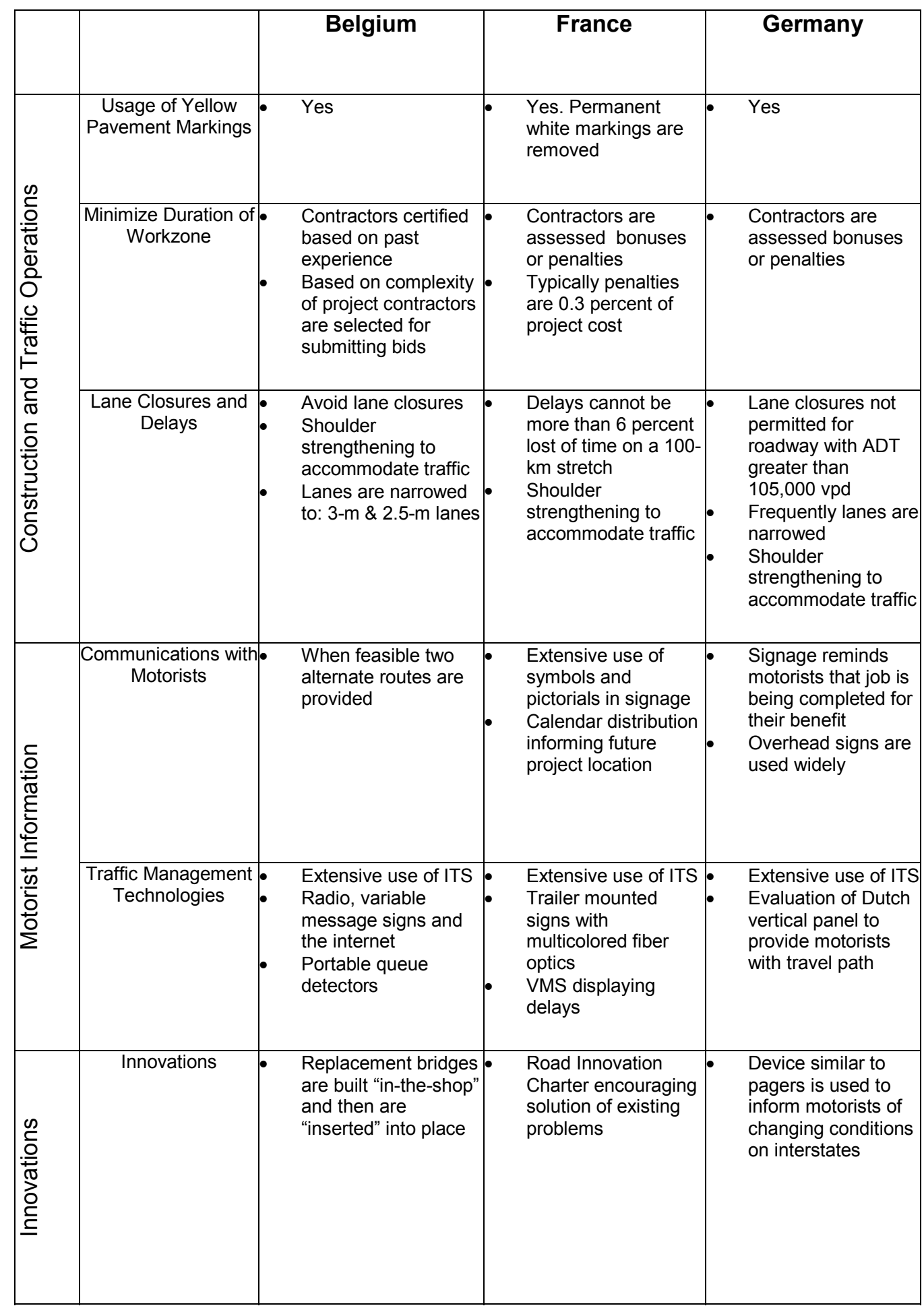


Table 2-7 Summary Matrix of European Work Zone Practices (con't)

\begin{tabular}{|c|c|c|c|}
\hline & & Scotland & The Netherlands \\
\hline \multirow{3}{*}{ 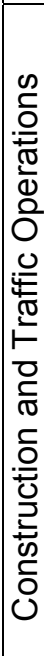 } & $\begin{array}{l}\text { Usage of Yellow } \\
\text { Pavement } \\
\text { Markings }\end{array}$ & - No & $\begin{array}{ll}\text { - } & \text { Yes. Permanent } \\
\text { white markings are } \\
\text { removed }\end{array}$ \\
\hline & $\begin{array}{l}\text { Minimize Duration } \\
\text { of Workzone }\end{array}$ & $\begin{array}{l}\text { - Implementation of } \\
\text { lane rental charges } \\
\text { Lane rental charge is } \\
\text { a bonus/charge } \\
\text { system determined } \\
\text { by calculating lane } \\
\text { occupation }\end{array}$ & $\begin{array}{l}\text { Meldwerk is a } \\
\text { national } \\
\text { computerized } \\
\text { planning program } \\
\text { to coordinate } \\
\text { construction } \\
\text { operations, lane } \\
\text { closures, etc }\end{array}$ \\
\hline & $\begin{array}{c}\text { Lane Closures and } \\
\text { Delays }\end{array}$ & $\begin{array}{l}\text { - Avoid lane closures } \\
\text { Lanes are narrowed } \\
\text { to: } 3.65-m \& 2.5-m \\
\text { lanes } \\
\text { Officials coordinate } \\
\text { ridesharing } \\
\text { programs, and } \\
\text { provide park-and- } \\
\text { ride lots }\end{array}$ & $\begin{array}{l}\text { Dutch officials have } \\
\text { found cost-effective } \\
\text { to closed down a } \\
\text { segment while } \\
\text { performing work } \\
\text { Objective is to } \\
\text { reduce delay to no } \\
\text { more than } 6 \% \text { of } \\
\text { total traffic delay }\end{array}$ \\
\hline \multirow{2}{*}{ 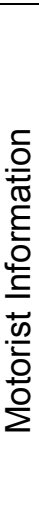 } & $\begin{array}{l}\text { Communications } \\
\text { with Motorists }\end{array}$ & $\begin{array}{l}\text { Safety brochures } \\
\text { with work zone } \\
\text { information are } \\
\text { distributed } \\
\text { extensively } \\
\text { Informing drivers of } \\
\text { the numbers of } \\
\text { persons ticketed in } \\
\text { the work zone }\end{array}$ & $\begin{array}{l}\text { - } \quad \text { Contractors are } \\
\text { required to provide } \\
\text { appropriate lighting } \\
\text { during projects } \\
\text { Implement device } \\
\text { similar to rumble } \\
\text { strips }\end{array}$ \\
\hline & $\begin{array}{c}\text { Traffic } \\
\text { Management } \\
\text { Technologies }\end{array}$ & $\begin{array}{l}\text { - } \quad \text { Extensive use of ITS } \\
\text { VMS displaying } \\
\text { delays rather than } \\
\text { queues }\end{array}$ & $\begin{array}{ll}\text { - } & \text { Extensive use of } \\
\text { ITS } \\
\text { Mobile Lane } \\
\text { Signaling Systems } \\
\text { (MRS) have been } \\
\text { deployed broadly }\end{array}$ \\
\hline 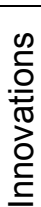 & Innovations & $\begin{array}{l}\text { Replacement } \\
\text { bridges are built "in- } \\
\text { the-shop" and then } \\
\text { are "inserted" into } \\
\text { place } \\
\text { Work zone audits }\end{array}$ & $\begin{array}{l}\text { Development of } \\
\text { software for } \\
\text { calculating user } \\
\text { delays through } \\
\text { work zone }\end{array}$ \\
\hline
\end{tabular}




\title{
CHAPTER 3. TRAFFIC MANAGEMENT TECHNOLOGIES
}

\begin{abstract}
3.1. Introduction
Maintaining traffic flow and safety of motorists and construction workers on interstate work zones are major concerns for state DOTs. The vast majority of the necessary construction work is performed with high exposure to existing traffic. Due to increased traffic demand, delays, long queues and lines of stopped vehicles tend to be a typical and growing irritant for road users traveling through work zones. It is important to find ways by which safety can be improved in construction work zones, especially since there is an increasing volume of rebuilding and maintaining of existing highway infrastructure, in addition to new highway construction in the United States.
\end{abstract}

The natural aging of the interstate infrastructure has lead to an increase on interstate construction activity. Accidents tend to increase when there is an increase in construction activity, as evidenced in recent years (ATSSA 2001). In order to reduce the frequency of crashes occurring in these work zones, traffic agencies have implemented different technologies to provide road users with more information of the dangers that lie ahead. The consensus among transportation officials is that driver awareness must be improved by providing more effective information of the upcoming roadwork.

For example, from April 2000 until May 2001, Interstate 65 (between Indiana SR-26 and Indiana SR-43) in Indiana was the site of several accidents. The project consisted of a bridge rehabilitation on an existing rural 4-lane median divided highway with a typical average daily traffic (ADT) of 40,000 vehicles per day. In total, 92 accidents and 4 fatalities occurred in this 6mile rehabilitation project. On average, the work zone experienced 3.3 wrecks per week during the 6-month duration of the project. Indiana is not the only state where such problems have occurred. Illinois experienced similar accidents on Interstate 74 between St. Joseph and Danville, IL near a construction work zone during the construction season of 2001. 


\subsubsection{Purpose of Chapter}

This chapter will give an overview of several traffic management devices that are currently implemented for enhancing the safety on interstate work zones. The identification of the different traffic management technologies and their analyses was based on a comprehensive literature review, discussions with the developers of each technology, site visits and discussions with engineers and personnel of various Departments of Transportation. The following sections provide a description of the traffic management technologies analyzed.

\subsection{Description of the Technology}

The different traffic management technologies that were analyzed function on a very similar manner. In order to understand the concepts of the traffic management technologies, it is important to provide a system overview. Figure 3-1 represents the system architecture of the functional elements involved in these technologies. The technologies are comprised of 1) traffic sensors, 2) proprietary algorithm, 3) communications, and 4) devices used for transmitting information to motorists (Variable Message Signs (VMS), Highway Advisory Radio (HAR), Internet, etc).

\subsubsection{Traffic Sensors}

Several traffic sensors are available for monitoring traffic patterns on freeways. Typical technologies include pneumatic tubes, inductive loops and microwave detectors among others. In addition, radar, cellular and video processing technologies can also be used as tools for collecting data and monitoring traffic. Cameras are extensively used for visually monitoring work zones. Interestingly, the vast majority of technologies analyzed utilize microwave as their preferred detection devices. This is due to the fact that surveillance cameras are frequently moved, which makes it difficult to maintain data acquisition during all time periods. Advantages of using microwave detectors is that these detectors require no pavement cuts and can be installed with minimal or no traffic disruptions. Microwave detectors are used extensively instead of image processing detectors primarily due to low cost and quick installation.

The main purpose of microwave detectors is to obtain real-time traffic conditions and acquire speed data constantly. According to Hauser and Massey (2001), microwave detectors can be categorized as true-presence detectors. They can provide presence indication as well as many other important traffic characteristics. The most significant characteristics that can be obtained by 
using these detectors include volume, occupancy, speed, and classification information for up to eight discreet detection zones (See Figure 3-2)

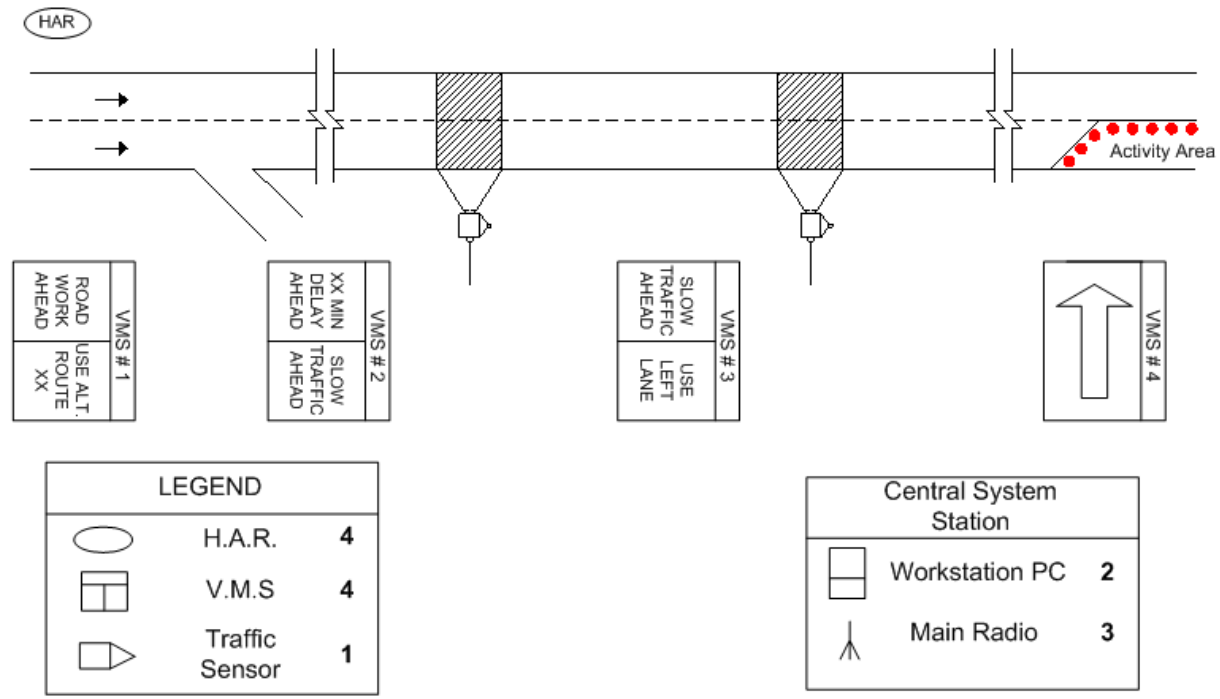

Figure 3-1 Typical System Architecture

(Adapted from: The Scientex Corporation Company Literature \& I-95 Smartzone Application in Fayetteville, NC (NCDOT))

Microwave detectors can be defined as above-ground detection units typically mounted on a pole or in a two-wheel trailer. These detectors can be either solar-powered or powered by a 12-volt source. They are normally called "side-fire" microwave due to their configuration when deployed (Figure 3-3). The main function of microwave detectors is to capture traffic conditions and acquire continuously speed and traffic data. Current sensors have the capability of counting vehicles, reporting speeds and detecting stopped vehicles. 


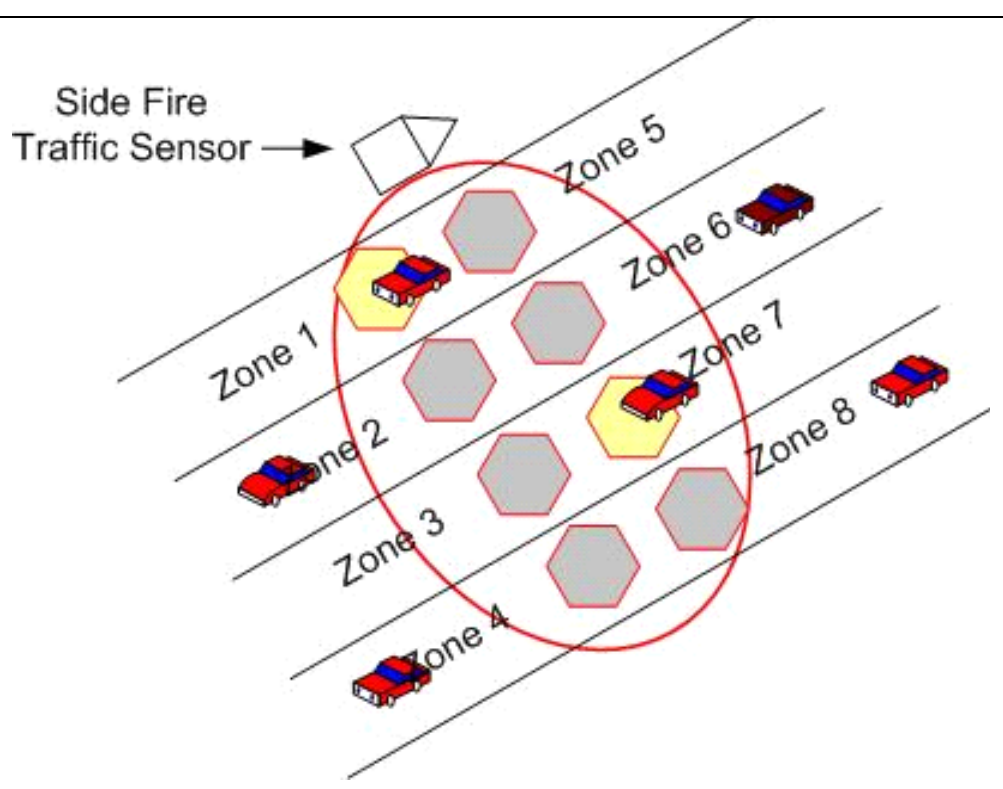

Figure 3-2 Detection zones in a side-fire traffic sensors

When deploying, special attention must be given to insure that the installation provides a clear view of detection area after determining if multiple or a single lane might be covered. The biggest challenge is determining the adequate spacing between sensors on the Interstate. There is no standard or procedure to follow. Detectors are installed based on topographical conditions, experience of technology developers, and based on funds available.

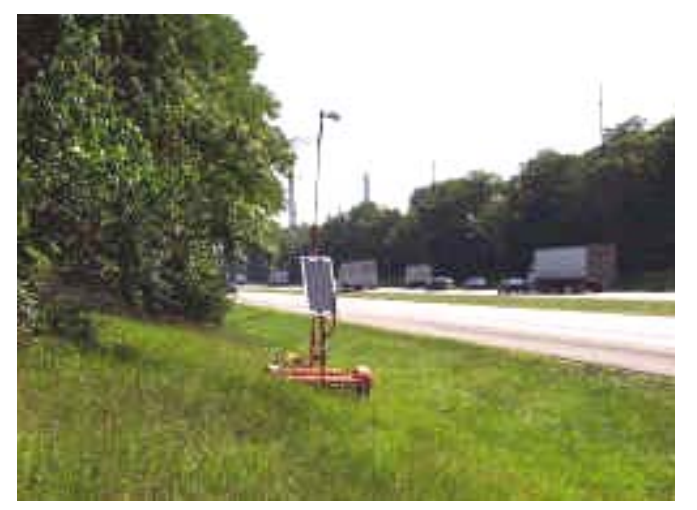

Figure 3-3 Side-Fire Microwave deployed in Springfield, IL (AIMS TM/United Rentals)

The most common microwave detector used is the RTMS (Remote Traffic Microwave Sensor) radar manufactured by Electronic Integrated Systems. Several evaluations have been conducted to evaluate the performance of the RTMS on Interstates. In the Minnesota Guidestar Report 
(1996), researchers found that RTMS undercounted vehicles by 2 percent or less in the overhead position and 5 percent in the side fire position.

Another evaluation of these sensors was conducted in Texas by Middleton and Parker (2000). The purpose of this study was to conduct an evaluation of three non-intrusive detectors for freeways. The traffic data obtained was compared with the data of the RTMS detector. Based on their findings, 53 percent of the RTMS speeds evaluated were within 0 or $1 \mathrm{mph}$ of the laser speeds. In this same evaluation, the data obtained was combined into bins of 10 samples. The means between RTMS and a laser speed detector were compared. Results showed that differences between readings of the data collection were only less than 1 percent and never more than 2 percent. As it can be seen, RTMS has proven to be a very efficient and effective sensor for collecting traffic data.

Once collected by the sensors, the traffic parameters are sent to the base station controller by means of communication devices (most typically wireless radio). Alternative vendors use this information differently in their proprietary algorithm. Different technologies manipulate the information received by the contact closures differently. As it will be shown later, some of the technologies for instance, display the information obtained (average speed for example), whereas others used the binary output to modify and display a calculated travel time though the work zone.

\subsubsection{Proprietary Algorithm}

The developers of the different traffic management technologies provide special attention and do not disclose the specifics of their algorithms. These algorithms are what differentiate one technology with respect to the other. Some of these technologies hold patents and others have patents pending for their system. It was therefore not possible to gain a better understanding of the actual algorithm employed by any of these technologies.

The main purpose of the intelligent-algorithm is to manipulate the information received from the sensors and relay the output to other communication devices. The most common devices include:

- Variable Message Signs (VMS)

- Highway Advisory Radio (HAR)

- Pagers

- Internet/E-mail 
According to Dumke and Doyle (2001) the key factor in the deployment of the traffic management technologies is the flexibility of communicating with any number of devices not limited to devices that support the NTCIP protocol ("National Transportation Communications for ITS Protocol NTCIP 1101:1996"). This is achieved by creating individual "drivers" between each of the devices (i.e. VMSs) and the algorithm. The algorithm becomes then, the server or core layer of the system, and sends back commands to the devices by means of the "drivers".

Generally, transportation officials are given the possibility of determining the threshold levels for displaying specific messages. Officials can determine in most of the technologies, the desired intervals for 1)"Polling" the detectors to check their operational status and storing the most actual recent information in holding bins, and 2) The interval for updating the message based on realtime traffic information received. Figure 3-4 represents a simplified overview of the procedure followed when a backup queue is detected. The microwave detectors would trigger the radio and send traffic data to the server when queue is detected. When the information is received at the base station, the algorithm checks if the queue observed is above the normal threshold specified. If for example Level 2 queue is observed, then the algorithm will send a signal to the VMSs and Highway Advisory Radio (HAR) to display messages accordingly.

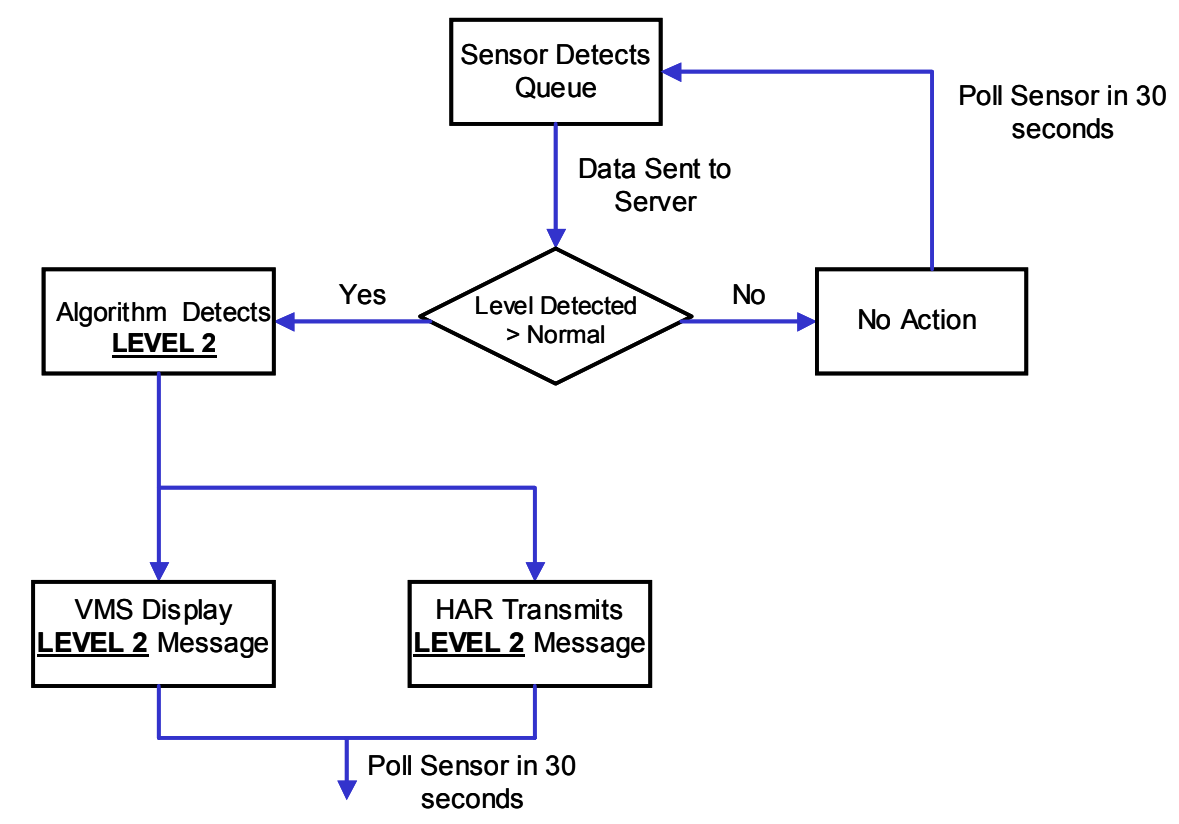

Figure 3-4 Overview of Algorithm Response to Backup Queue (Adapted from: Register (2002) "Real-Time Traffic Control System" ITS America, Long Beach, CA 
The output of the protocol is provided by means of a user interface tool. Most of the intelligent algorithms were developed in a high level programming language and all of them are Microsoft Windows compatible. The software is menu-driven, and allows for real-time monitoring of the status of the entire system. Different devices deployed can be tracked and monitored as well as the traffic conditions of the interstate.

\subsubsection{Communications}

Communication issues are one of the most difficult challenges faced by the traffic management vendors. The option chosen is critical, because the placement of signage is dependent on the zone where the information can be transmitted. In most cases, variable message signs cannot be placed well in advance of the work zone to inform drivers of the upcoming change conditions because the communications devices do not support the desired range. The three most common types of communications options available for the technologies are: 1) wireless radio, 2) wired or landline connections and 3) Cellular Digital Packet Data (CDPD) wireless Internet.

The vast majority of technologies utilize a $2.4 \mathrm{GHz}$ radio for transmitting information from the sensors to the central station and from the central station to the VMSs or other devices. This wireless radio option utilizes a dedicated frequency licensed by the FHWA and operated in an FHWA band that does not require an FCC license. The communication range effectiveness is dependent on the topographical conditions of the work zone and on the existing line of sight (LOS). The repeater pod is often mounted on a pole in the central system station and when possible is placed on existing high-points such as bridges, towers, etc. The biggest drawback of this communication option is that the radio is typically centered about the heart of the work zone, and does not provide information at long distances upstream.

The second option available is the utilization of wired or landline connections. In this alternative, the entire system can be connected through a phone line, or a landline such as analog line, Digital Subscriber Line (DSL), Integrated Services Digital Network (ISDN) or a T-1 connection. Several technologies evaluated can also function as a combination of the different options. Greater flexibility is achieved when communicating the devices as a combination of wireless radio and landlines.

In addition to the above mention options, CDPD can also be used as a communication alternative. The latter technology has been especially developed to transmit data on cellular phone frequencies. CDPD is an effective option due to its flexibility. However, one disadvantage 
of utilizing CDPD wireless Internet connection is that this technology is not widely available, especially in rural areas. In addition, during periods of severe congestion, which are typically associated with heavy cellular usage, the system may not perform at an optimal level.

\subsubsection{Central System Station}

A central system station is composed mainly of a PC for running the algorithm. The key benefit of these condition-responsive technologies is that they will run autonomously with little or no human intervention. Therefore, a PC is required and must be located on a central station. This station can be located in the field office trailer or it can be located remotely. One of the technologies analyzed for example, has its station located in Pennsylvania. All the acquired data is directed and routed to this office where it is received, transformed and automatically sent back to the devices to be displayed accordingly. In addition of having the PC, the central system station must also be equipped with the master communication equipment chosen, as explained in the previous section.

The central system station is also used as the library for archiving data obtained. The system is therefore capable of displaying and storing traffic data and camera images as needed.

\subsubsection{Devices to Transmit Information}

The algorithm is capable of providing motorists with delay, lane closures, speed reductions and travel time through the work zones. This algorithm supports installation of several types of devices. Basically, all the technologies can support equipments from a variety of vendors. In fact, devices already owned by Departments of Transportation can also be utilized without any major impediment. Variable Message Signs (VMS) are the most common and familiar devices used for conveying real-time traffic information for road users. These devices are intended to affect road users' behavior by improving the traffic flow throughout the work zone. The messages displayed and the message change criterion is entirely programmed by the user in the intelligent algorithm. The messages displayed are generally composed of letters, symbols, or both. The main function of the VMS is to disseminate the desired information to motorists after it has been processed in the central system station. According to the Manual on Uniform Traffic Control Devices (MUTCD, 2001), the VMSs are temporary traffic control devices displaying a variety of messages. A message shall consist of either one or two phases, with a phase typically consisting of up to three lines of text. 
The location of the VMSs, similarly to the traffic sensors, must be determined carefully to maximize effectiveness and efficiency in alerting traffic. The spacing of these signs is critical, and is determined according to geometric conditions, alternate routes, and previous experience. The format and selection of message must also be carefully determined. By providing a poor format and wrong wording it may confuse the traveling public. In addition, it may not give motorists sufficient time to read, understand and perform an action based on the information provided (ITS Decision (2002)).

Other communication devices used include Highway Advisory Radio (HAR). HAR is utilized to inform drivers of upcoming road work activity. Fixed signage with a warning light is used to inform drivers to tune to a specific radio station. In general, the HAR system broadcasts on AM band. In an effort to disseminate the information to vehicles approaching the work zone in both directions, a HAR unit is located at the beginning of the work area and another at the end.

The use of the Internet has also gained wide acceptance among transportation officials that have deployed these technologies. The Internet now enables fast, cost-effective and efficient intelligent transportation systems in the work zone (Dumke and Doyle, 2001). Internet can be used to monitor traffic condition in the work zone, as well as for displaying images and maps with current status of the VMS.

Finally, several other devices such as alert beacons can also be installed to provide more information to motorists. In addition, $\mathrm{CB}$ alert radio is an effective tool for providing information to commercial vehicles. Unfortunately, it has not been deployed extensively in combination with traffic management technologies.

\subsection{Description of Characteristics}

In order to analyze and compare different technologies the system characteristics must be taken into consideration. The factors considered in the analysis include: Need, Methods to Transmit Information, Information to be transmitted, and Deployments.

The Need describes the purpose of development for each traffic management technology. The factor Methods to Transmit Information includes the type of detection devices currently used by each technology and the types of remote administration capabilities of the different technologies. The factor Deployments addresses previous, current and past projects that have adopted each technology. 


\section{4. $\quad$ Advance Speed Information System (ASIS)}

\subsubsection{Need}

Vehicular speeds before and through work zones vary significantly. Drivers may sometimes not have sufficient time to react to the varying speeds, when they are involved in a rear-end collision. ASIS (Advance Speed Information System), developed by PDP Associates, Cincinnati, $\mathrm{OH}$, is a condition-responsive technology designed to provide real time information to road users about the vehicular speeds throughout several points upstream of a work zone. The purpose of this technology is to reduce the number of rear end crashes and minimize surprises to drivers approaching stopped or slowed traffic.

\subsubsection{Methods to Transmit Information}

ASIS deployment consists of equipment, which is mounted on variable message signs. ASIS has two separate models available to the public. Both models can consist of as few as two message boards or as many message boards as is desired by a DOT. The Basic System runs autonomously without any central control. No indication is given to the owner if a component fails. The advanced system has the feature of central control (Base Station). The owner is notified in the event of a failure of one of the components. More messages are available for this system than the Basic system. The Advanced System, unlike the Basic System, has the ability to store traffic data if required.

ASIS can be described as an extension of the Travel Time Prediction System (TIPS) technology, developed earlier by the company. In a typical configuration, ASIS utilizes side-fire microwave detectors, similar to TIPS. The information is transmitted to motorists mainly by using Variable Message Signs (VMS) located throughout each approach of the work zone. Mounted or incorporated on each VMS, a traffic sensor, a micro controller and an antenna are integrated.

\subsubsection{Information to be Transmitted}

ASIS displays actual vehicular speeds at upstream points on a highway. The vehicle speeds are calculated as vehicles pass a sensor and are stored in holding bins with a unit of time specified by the user. Separate holding time is used to delay the changing of the message. The speed is updated on an upstream message board when this holding time is over. This sequence is repeated and the information received by the sensor is displayed (Figure 3-5 \& Figure 3-6) to the motorists on the upstream locations of the work zone. The information can be displayed by 
following different formats specified by the DOTs. In addition to displaying the information on VMS, the information can also be transmitted by using the Internet.

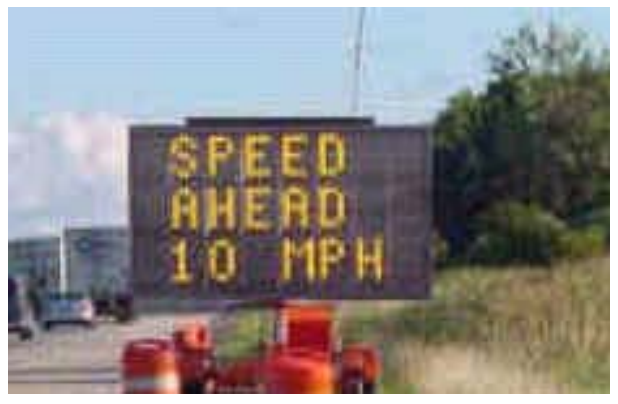

Figure 3-5 ASIS Message Displayed \# 1 (Source: PDP Associates, Inc)

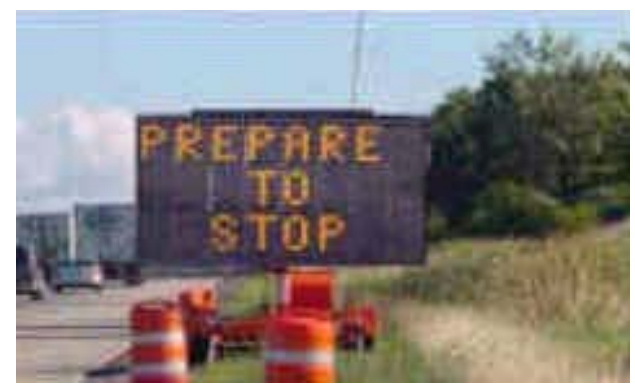

Figure 3-6 ASIS Message Displayed \# 2 (Source: PDP Associates, Inc)

$$
\text { 3.4.4. Deployments }
$$

Since ASIS is a new technology, this system has had no previous deployments. This technology is planned for deployment in the upcoming construction seasons. 


\subsection{Automated Data Acquisition and Processing of Traffic Information in Real-time}

$\underline{\left(\text { ADAPTIR }{ }^{\mathrm{TM}}\right)}$

\subsubsection{Need}

ADAPTIR ${ }^{\mathrm{TM}}$ is believed by many to be one of the pioneer systems of automated, real-time technologies developed to increase driver awareness on interstates in the United States. ADAPTIR $^{\text {TM }}$ (Automated Data Acquisition and Processing of Traffic Information in Real-time) is a patented system developed by The Scientex Corporation, Arlington, Virginia. It is a conditionresponsive technology designed to integrate several units (VMSs, HARs, internet, etc) into the system's algorithm to provide motorists with accurate, reliable and credible advisories of the road conditions ahead.

\subsubsection{Methods to Transmit Information}

ADAPTIR $^{\text {TM }}$ retrieves traffic data by utilizing Doppler radar and microwave sensors. After the information is retrieved from the sensors, it is transmitted to the central base station. At the central base station, the algorithm manipulates the information obtained and transmits the information to the different units selected for transmitting the information. Most of the deployments of ADAPTIR ${ }^{\mathrm{TM}}$ have employed an enhanced Variable Message Sign. This enhanced VMS, includes in addition of the regular VMS displaying panel, a Roadside Remote Station (RRS), and a traffic sensor.

The RRS has been developed to validate and filter the traffic data collected by the sensor. The RRS checks the data obtained, and by filtering and rejecting the erroneous data, the only data sent to the central base station is "valid" according to the parameters specified by the user. In addition, the RRS is responsible for determining the battery voltage and power source for the signs. The information is also displayed by means of Variable Message Signs, flashing beacons, Internet, Highway Advisory Radio (HAR) and lane control signals. Similar to most of these technologies, ADAPTIR ${ }^{\text {TM's }}$ algorithm is not fixed to any VMS manufacturer and can be adjusted to utilize existing signs from the Department of Transportation's own inventory.

\subsubsection{Information to be Transmitted}

Due to its extensive deployments, ADAPTIR ${ }^{\mathrm{TM}}$ provides a wide range of possible options for transmitting information to motorists. The most common uses of this system include displaying 
information to the traveling public about speed reductions ahead, delays, dynamic merging and diversion messages. In addition, variable speed limits can also be transmitted to motorists in advance or during a work zone. As shown on Figure 3-7, ADAPTIR ${ }^{\text {TM }}$ has been used extensively for informing motorists of speed reductions.

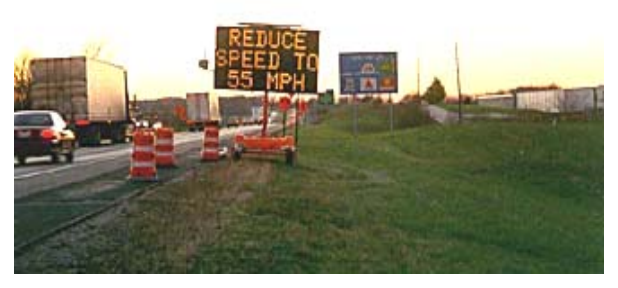

Figure 3-7 Typical ADAPTIR Deployment

(Source: http://www.tfhrc.gov/focus/archives/fcs199/workzone.htm

\begin{abstract}
3.5.4. Deployments
According to information provided by the Scientex Corporation, ADAPTIR ${ }^{\mathrm{TM}}$ has been deployed numerous times. The most relevant and recent deployments of ADAPTIR ${ }^{\mathrm{TM}}$ have taken place in Ohio, Arkansas, California, Illinois and Nebraska. ADAPTIR ${ }^{\mathrm{TM}}$ was deployed on I-75 just north of downtown Toledo, $\mathrm{OH}$ during an interstate reconstruction project during a five-month project (From April to September 2001). In this deployment, motorists were provided with real-time information of traffic conditions as well as advisory diversion messages in both northbound and southbound directions. ADAPTIR ${ }^{\mathrm{TM}}$ was also deployed in the state of California during a bridge rehabilitation project on Interstate 5. In this project for example, ten VMSs, ten RRS and ten traffic sensors were deployed to provide motorists with accurate information. In addition, this system has also been deployed on I-40 near Carlisle, Arkansas and on I-74 near Peoria, IL.
\end{abstract}

The most important deployment of this technology was conducted in 1999 in the state of Nebraska as part of the Midwest States Smart Work Zone Deployment Initiative. For this project, Professor Patrick McCoy of the University of Nebraska-Lincoln conducted an evaluation of this technology. During this evaluation, ADAPTIR was deployed on I-80 near Greenwood. ADAPTIR ${ }^{\text {TM }}$ was deployed on this rural highway reconstruction project in advance of a lane closure. The results showed that ADAPTIR ${ }^{\mathrm{TM}}$ had no effect on speed and lane distribution within 
2,000 feet of the lane closure taper. Speed advisory messages were not effective during periods of uncongested flow. However, when traffic flow approached congestion levels the system was proven effective. When there was more than 30 minutes of delay, the system was effective in encouraging drivers to take an alternate route (MwSWZDI, 2000).

ADAPTIR $^{\text {TM }}$ is currently deployed in the state of California, on Interstate 5 near Sacramento. In addition, this system has been deployed in North Carolina. This project consists of an interchange reconstruction on I-95 north of Fayetteville.

\section{6. $\quad$ Automated Information Management System (A.I.M.S.)}

3.6.1. Need

To reduce driver frustration, it is important to inform drivers of what lies ahead, expected travel times, and also of alternative routes. AIMS ${ }^{\mathrm{TM}}$ developed by United Rental Traffic Division, Mechanicsburg, Pennsylvania provides drivers with continuously updated information about travel times, vehicle speeds through a work zone, and even alternative routes that can be used to avoid delay.

\subsubsection{Methods to Transmit Information}

AIMS $^{\mathrm{TM}}$ is an algorithm designed to provide continuous monitoring of interstate traffic for improving safety. The software collects traffic data from current traveling conditions typically through the use of microwave sensors as detection devices. However, other types of detection devices such as radar detectors can also be used for data collection. Traffic data collected by the sensors is transmitted to a central base station were the AIMS ${ }^{\mathrm{TM}}$ algorithm processes the data and relays informational messages to motorists by means of Variable Message Signs (Figure 3-8) Highway Advisory Radio (HAR) and also through the use of Alert Beacons. AIMS ${ }^{\mathrm{TM}}$ can also relay information about the roadway conditions to Department of Transportation officials by means of video, website, or though the use of pagers. The public can also gain information about the roadway by accessing a website designated for the construction project and viewing the messages displayed to motorists. 
3.6.3. Information to be Transmitted

AIMS $^{\mathrm{TM}}$ can inform motorists approaching the work zone of vital information such as a speed reduction that lies ahead and the location of an accident that has occurred. Besides these crucial messages, AIMS ${ }^{\mathrm{TM}}$ can also display to motorists the level of congestion of the roadway, the degree of enforcement activity that has occurred in the work zone and other warning messages that are necessary.

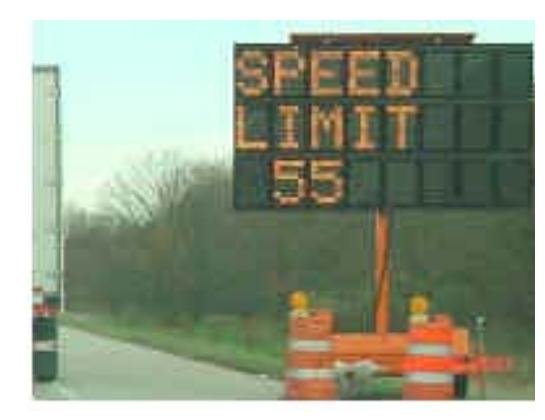

Figure 3-8 AIMS ${ }^{\text {TM }}$ VMS Message

\subsubsection{Deployments}

The Automated Information Management System has been deployed in several states. The state of Pennsylvania deployed AIMS ${ }^{\mathrm{TM}}$ on the Pennsylvania Turnpike near exits 13 through 15. During the Winter of 2001, AIMS ${ }^{\mathrm{TM}}$ was deployed on a construction project on I-55 near Springfield, IL, and it will remain active until the fall of 2002.

During the construction season of 2002, AIMS ${ }^{\mathrm{TM}}$ was in operation in four different projects. Two of these projects took place in the state of Illinois. One of the projects is located on I-70 near Paris and another on I-74 near Moline. In addition of these deployments, Arkansas (east of Memphis) and Florida (Peace River Bridge project) included deployments of AIMS ${ }^{\text {TM }}$. 


\section{7. $\quad$ Computerized Highway Information Processing System (CHIPS TM)}

\subsubsection{Need}

The need of a technology that incorporates infrared queue length detectors to determine when traffic has slowed below a threshold or has completely stopped, led to the development of CHIPS $^{\mathrm{TM}}$ (Computerized Highway Information Processing System) by ASTI Transportation Systems, Inc, New Castle, Delaware. CHIPS ${ }^{\mathrm{TM}}$ is a real-time system to improve highway safety and reduce work zone accidents by providing motorists information about the expected conditions on the Interstate.

\subsubsection{Methods to Transmit Information}

CHIPS $^{\text {TM }}$ is an algorithm designed to provide continuous monitoring of interstate traffic for improving safety. This technology stores different traffic data of current traveling conditions by utilizing microwave sensors as detection devices. The information is transmitted to motorists by means of Variable Message Signs, blank-out fiber optic signs, Highway Advisory Radio (HAR) and ramp metering. In addition, a Wizard CB radio was used in a project in Arkansas on I-55/I-40 to inform drivers of halted vehicles and road conditions further downstream.

\subsubsection{Information to be Transmitted}

CHIPS ${ }^{\text {TM }}$ benefits motorists through improved safety by providing accurate advisories of current traffic conditions. This technology was developed to provide road users of warning and advisory messages. In addition, the DOT can specify if alternate routing and dynamic speed alerts are desired. CHIPS ${ }^{\text {TM }}$ was developed to run autonomously and can be easily modifiable to adjust the condition required during a long-term construction project.

\subsubsection{Deployments}

This technology was deployed in the state of Pennsylvania. Current deployments of CHIPS TM include the Arkansas project (I-55/I-40) several projects in Delaware and a project near Rochester in New York. 


\section{8. $\quad$ Travel Time Prediction System (TIPS)}

\subsubsection{Need}

Messages displayed in Variable Message Signs (VMS) can sometimes be ambiguous and somehow confusing for motorists. Most available traffic management technologies display delay in the upcoming segment of road construction. The developers of TIPS (Travel Time Prediction System) believe that delays must not be displayed. Delay requires a reference point which is not common to all users of the roadway. Travel time, on the other hand, is assumed to be easily understood by the traveling public. TIPS is an automated technology developed by PDP Associates that calculates and displays on VMS the travel time in advance and through work zones.

\subsubsection{Methods to Transmit Information}

TIPS typical deployment consists of one PC, located on a central station (mainly in the field office trailer), which analyzes the data. After investigation of different available detection devices, the developers of TIPS determined to operate the system by using side-fire microwave detectors.

Most of the traffic management technologies analyzed have been developed by utilizing software with an intelligent algorithm using an open-end architecture. By doing so, these traffic management technologies are designed to easily accept the incorporation of different "technologies" to provide additional information to motorists. TIPS for example, can use the Internet to display 24-hour road information by using a dynamic web site posted on the responsible DOT domain or on an individual project web site. In addition, highway advisory radio (HAR) can also be integrated in the system configuration to transmit information.

The developers of TIPS have also envisioned providing the real time information near project work zones and in other facilities to establish a proactive approach to transmitting information. Monitors can be located in rest areas, commercial and tourist attractions to facilitate the planning and if possible give drivers the opportunity of finding an alternate route to avoid the congestion through the work zone. 
3.8.3. Information to be Transmitted

TIPS displays calculated travel time in advance of and through work zones. By providing motorists with accurate information, decreases the probability of accidents near a construction work zone (Figure 3-9). TIPS does not use actual vehicle speeds to determine travel time. Travel times are calculated as vehicles pass the sensors. Once they are detected by the sensors, the travel times are collected in holding "bins" with a storing time specified by the user. Travel times are not instantly displayed because they can change from one vehicle to the next. A separate holding time is used to delay the changing of the travel time message. Travel time is updated on the message boards when this holding time is completed (Figure 3-10).

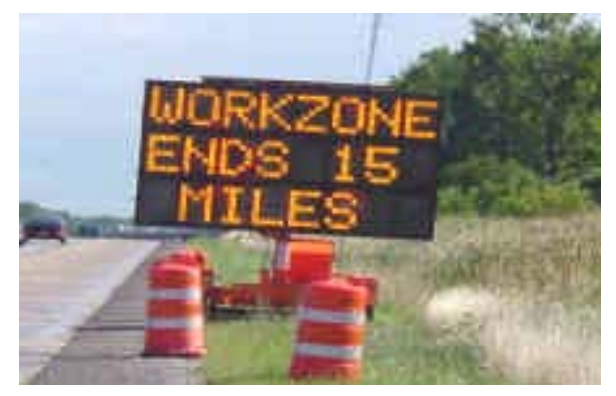

Figure 3-9 TIPS Message Displayed \# 1

(Source: PDP Associates, Inc)

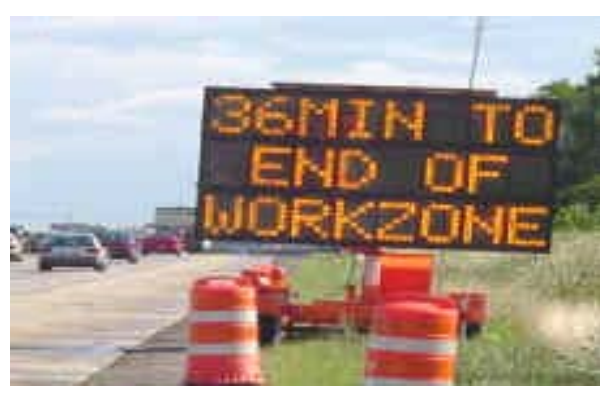

Figure 3-10 TIPS Message Displayed \# 2

(Source: PDP Associates, Inc) 


$$
\text { 3.8.4. Deployments }
$$

The Travel Time Prediction System has had three deployments. TIPS was deployed during the summer and fall of 2000 on a 13-mile segment northbound of Interstate 75 in Dayton, Ohio. In 2001 TIPS was deployed again on Interstate 75 in Dayton, Ohio and Interstate 94 near Milwaukee, Wisconsin. During the construction season of 2002 TIPS was not deployed.

An independent evaluation of TIPS was completed by Helmut Zwahlen (Zwahlen 2001) of the Ohio University for the 2000 Dayton, Ohio project. The most important findings of the evaluation concluded that about $88 \%$ of the actual times recorded for each sign, and for all the signs combined, were within a range of \pm 4 minutes of the predicted time. In addition, based on anecdotal data obtained by sending a questionnaire to approximately 3000 motorists recorded to be traveling the work zone when TIPS was deployed, $97 \%$ of road users surveyed (with an approximate $20 \%$ response margin) found the system to be helpful and effective in providing travel times.

\subsection{Work Zone Alert and Information Radio (WIZARD)}

\subsubsection{Need}

A high percentage of accidents occurring near work zones involve rear-end collisions. Commercial Vehicle Operators are involved in most of these types of collisions. Approximately 25 percent of the 719 of the work-zone fatalities in 1996 involved large trucks (Turner 1999). The Wizard Work Zone Alert and Information Radio patented by Highway Technologies, Inc. is designed to give drivers of commercial vehicles enough advance warning of upcoming delays or incidents on the interstate, to enable them to stop safely before encountering lines of stopped vehicles (Kamyab A. Et. Al (2000). The Wizard CB Alert System was developed and patented by Highway Technologies, and built and marketed by TRAFCON industries.

It was originally developed at the request of the Pennsylvania Department of Transportation as a response to problems on a major construction project during the 1993 construction season. A high number of accidents and fatalities occurred in this 12-mile length project. Most of the accidents involved trucks (18-wheelers) crashing into slow moving vehicles (Sesny 2001). Although the Wizard is not exactly a traffic management technology, it has been analyzed 
because a combination of this technology incorporated with any other of the condition-responsive technologies can offer valuable information to truckers and drivers in general.

\subsubsection{Methods to Transmit Information}

Many of the traffic management technologies analyzed have remote administration capabilities, i.e., they run autonomously on a $24 / 7$ basis. The Wizard is remote in the sense that it can be activated on/off by a pager. Operators dial a call number and the system "remotely" is switched on/off when desired with capability of storing three messages. The goal for future prototypes of the WIZARD is to obtain a total microprocessor control technology product that can be fully activated by detectors.

The Wizard CB alert system automatically broadcasts an alert message over a CB channel (Channel 19) to warn drivers of traffic or road conditions ahead. The system can record up to three different messages and transmit over two different CB channels. Messages can be either static (three selectable messages) or dynamic (changed by an operator). The system components include a standard CB-antenna with a guaranteed broadcast range of one-to-two miles. It can be either solar-powered or one can use a 12-volt power source. The transmitting interval can be selected by the responsible DOT to three different interval alternatives: 30,60 , and 90 seconds.

\subsubsection{Information to be Transmitted}

The Wizard is a portable, lightweight device (Figure 3-11). This radio system can be used as part of a static long-term work zone project mounted on a two-wheel trailer. It can also be used as a powerful portable tool used for service/maintenance operations (such as painting crews) on Interstates for improving safety and minimizing collisions to the trailing maintenance vehicle. Because the CB radio can be modified by an operator (interestingly, female voices have been reported to be more effective), the information to be transmitted is very wide in scope. DOTs have implemented the Wizard for several purposes during construction on interstate work zones. The most significant are: incident location, warning messages, advisory messages and speed reduction ahead. 


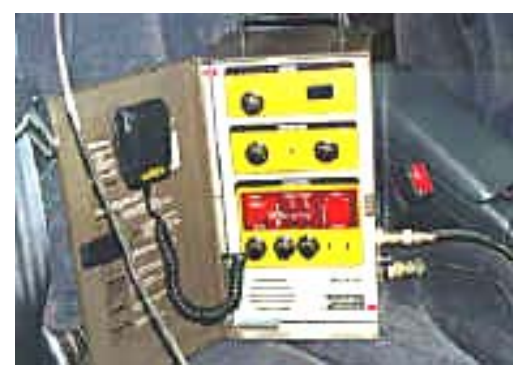

Figure 3-11 WIZARD System Configuration

(Source: MwSWZDI 2000)

\subsubsection{Deployments}

The most relevant of the previous deployments of the CB Alert system were in lowa, Kansas and Missouri as part of the Midwest States Smart Work Zone Deployment Initiative (MwSWZDI). The system was effective on its deployments in lowa and Missouri. In lowa, the CB system was effective at warning drivers of upcoming road conditions. The system reached a large portion of the targeted audience and passed on information that was important to listeners. In Missouri, the CB messaging system was associated with improved lane distribution, especially for nonpassenger vehicles. It was also associated with higher speeds upstream from the lane closure but lower speeds near the lane closure, and improved higher standard deviations of speed upstream from the lane closure but lower standard deviations of speed near the lane closure (MwSWZDI 2000).

Because this technology has had several deployments, DOTs (for example, Pennsylvania) have policies encouraging the use of the CB system. Other deployments of this technology include Interstate 65 near Louisville, Kentucky, Missouri, and Indiana.

\subsection{Summary Matrix of Technologies}

The selection of the most appropriate traffic management alternative to be deployed during an interstate reconstruction/rehabilitation project is very specific and needs to be considered on a project-by-project basis. All the technologies available have advantages and disadvantages, and some alternatives are best suitable for specific projects. A summary Matrix is presented in Table 3-1 in an effort to provide a comparative analysis of the aforementioned technologies. 
This matrix is the result of the investigation presented in this chapter. It is important to point out that many technologies are introduced and have been developed recently. This summary represents a snapshot of the different traffic management technologies developed as of August 2002. One of the most demanding tasks for the authors was to narrow the technologies down in order to perform a successful comparison. The matrix presented, outlines the main characteristics of each system, summarizes the information provided in this chapter, and gives additional information about each technology deployments and costs. 
Table 3-1 - Summary Matrix of Traffic Management Technologies ${ }^{1}$

\begin{tabular}{|c|c|c|c|c|c|c|c|}
\hline & $\begin{array}{l}\text { Advance Speed Information } \\
\text { System (ASIS) }\end{array}$ & $\begin{array}{l}\text { Automated Data Acquisition } \\
\text { and Processing of Traffic } \\
\text { Information in Real-time } \\
\left(\text { ADAPTIR }^{\mathrm{TM}}\right)\end{array}$ & $\begin{array}{l}\text { Automated Information } \\
\text { Management System } \\
\text { (A.I.M.S. }^{\mathrm{TM}}{ }^{\text {) }}\end{array}$ & $\begin{array}{l}\text { Computerized Highway } \\
\text { Information Processing } \\
\text { System }\left(\mathrm{CHIPS}^{\mathrm{TM}}\right)\end{array}$ & Smart Work Zone $\left(\mathrm{SWZ}^{\mathrm{IM}}\right)$ & $\begin{array}{l}\text { Travel Time Prediction } \\
\text { System (TIPS) }\end{array}$ & $\begin{array}{l}\text { Work Zone Alert and } \\
\text { Information Radio } \\
\text { (WIZARD) }\end{array}$ \\
\hline Provider/Developer & PDP Associates Inc. & The Scientex Corporation & United Rentals & ASTI Transportation Systems & AADCO & PDP Associates Inc. & $\begin{array}{l}\text { Trafcon/Highway } \\
\text { Technologies }\end{array}$ \\
\hline Detection Devices & $\begin{array}{l}\text { - Side-fire microwave } \\
\text { detectors }\end{array}$ & $\begin{array}{l}\text { - Radar } \\
\text { - Microwave Sensors }\end{array}$ & $\begin{array}{l}\text { - Radar } \\
\text { - Video } \\
\text { - Pneumatic Tubes }\end{array}$ & $\begin{array}{l}\text { - Microwave sensors } \\
\text { - Radar }\end{array}$ & $\begin{array}{l}\text { - Radar } \\
\text { - Video Image Processing } \\
\text { - Microwave Sensors }\end{array}$ & $\begin{array}{l}\text { - Side-fire microwave } \\
\text { Detectors }\end{array}$ & - None \\
\hline Remote Administration & Yes & Yes & Yes & Yes & No & Yes & No \\
\hline $\begin{array}{l}\text { Methods to transmit } \\
\text { information }\end{array}$ & $\begin{array}{l}\text { - Variable Message Signs } \\
\text { - Internet }\end{array}$ & $\begin{array}{l}\text { - Variable Message Signs } \\
\text { - Lane Control } \\
\text { Signals } \\
\text { - Highway Advisory Radio } \\
\text { - Internet } \\
\text { - Flashing Beacons }\end{array}$ & $\begin{array}{l}\text { - Video } \\
\text { - Variable Message Signs } \\
\text { - Internet } \\
\text { - Highway Advisory Radio } \\
\text { - Alert Beacons }\end{array}$ & $\begin{array}{ll}\text { - } & \text { Variable Message Signs } \\
\text { - } & \text { Blank-out Fiber Optic } \\
\text { - } & \text { Signs } \\
\text { - } & \text { Higernet } \\
\text { - } & \text { Ramp Metering } \\
\text { - } & \text { CB Using Wizard } \\
\end{array}$ & $\begin{array}{l}\text { - Variable Message Signs } \\
\text { - Internet } \\
\text { - Highway Advisory } \\
\text { Radio } \\
\text { - Video }\end{array}$ & $\begin{array}{l}-\quad \text { Variable Message Signs } \\
\text { - Internet } \\
\text { Monitors in Rest Area, } \\
\text { Commercial and Tourist } \\
\text { attractions }\end{array}$ & $\begin{array}{l}\text { - Transmits over CB } \\
\text { channel } \\
\text { - Messages can be static } \\
\text { (3-selectable } \\
\text { messages) or dynamic } \\
\text { - Transmitting intervals: } \\
\text { 30,60,90 sec } \\
\end{array}$ \\
\hline \begin{tabular}{lll|}
$\begin{array}{l}\text { Information } \\
\text { transmitted }\end{array}$ & to & be \\
\end{tabular} & $\begin{array}{l}\text { Displays actual vehicular } \\
\text { speeds at upstream points on } \\
\text { a highway }\end{array}$ & $\begin{array}{l}\text { - Speed Reductions Ahead } \\
\text { - Delays } \\
\text { - Diversion Messages } \\
\text { - Variable Speed Limit } \\
\text { - Dynamic Merging } \\
\end{array}$ & $\begin{array}{l}\text { - Speeds Reductions Ahead } \\
\text { - Warning Messages } \\
\text { - Incident Locations } \\
\text { - Traffic Congestion Levels } \\
\text { - Enforcement Activity } \\
\end{array}$ & $\begin{array}{ll}\text { - } & \text { Traffic Stopped } \\
\text { - Warning Messages } \\
\text { - Advisory Messages } \\
\text { - } \text { Alternate Routing } \\
\end{array}$ & $\begin{array}{l}\text { - Incident Locations } \\
\text { - Speeds } \\
\text { - Warning Messages } \\
\text { Advisory Messages }\end{array}$ & $\begin{array}{l}- \text { Displays calculated } \\
\text { travel time in advance } \\
\text { of and through work } \\
\text { zones }\end{array}$ & $\begin{array}{l}\text { - Incident Locations } \\
\text { - Warning Messages } \\
\text { - Advisory Messages } \\
\text { - Speeds }\end{array}$ \\
\hline \multicolumn{8}{|c|}{$\begin{array}{l}\text { DEPLOYMENT } \\
\end{array}$} \\
\hline Previous Projects & - None- New Technology & $\begin{array}{l}\text { - Nebraska:I-80 near } \\
\text { Greenwood (1999) } \\
\text { Ohio: I-75 north of } \\
\text { Toledo (2001) } \\
\text { - Arkansas: I-40 in Carlisle } \\
\text { (2001) }\end{array}$ & $\begin{array}{l}\text { - Illinois: I-80 near Chicago } \\
\text { Pa. Turnpike: Exits 13-15 } \\
\text { - Illinois: I-55 near Springfield }\end{array}$ & $\begin{array}{l}\text { - Pennsylvania } \\
\text { - Several other states }\end{array}$ & $\begin{array}{l}\text { - New Mexico: The Big I } \\
\text { Project (2000) } \\
\text { - Other Projects Include: } \\
\text { MN, WA, MA, FL, KS }\end{array}$ & $\begin{array}{l}\text { - Ohio: I-75 in Dayton (2000 } \\
\text { \& 2001) } \\
\text { - Wisconsin: I-94 near } \\
\text { Milwaukee (2001) }\end{array}$ & $\begin{array}{l}- \text { Iowa: I-35 (1999) } \\
\text { - } \text { Missouri: I-70 near } \\
\text { Columbia (1999) } \\
\text { - Kansas: I-135 in } \\
\text { Harvey County }\end{array}$ \\
\hline $\begin{array}{l}\text { Current Projects } \\
\end{array}$ & - None-New Technology & $\begin{array}{l}\text { - California:I-5 near } \\
\text { Sacramento } \\
\text { - North Carolina: I-95 north } \\
\text { of Fayetteville }\end{array}$ & $\begin{array}{l}\text { - Florida: Peace River Bridge } \\
\text { - Illinois: I-70 near Paris } \\
\text { - Illinois: I-74 near Moline } \\
\text { - Arkansas: I-40 east of } \\
\text { Memphis } \\
\end{array}$ & $\begin{array}{l}\text { - Arkansas: I-75/I-40 } \\
\text { - New York: Near Rochester }\end{array}$ & $\begin{array}{l}\text { - Currently deployments in } \\
\text { many states }\end{array}$ & - None & $\begin{array}{l}\text { - Kentucky: I-65 near } \\
\text { Louisville } \\
\text { - Missouri: Mobile Unit }\end{array}$ \\
\hline Expected Projects & - Unknown & $\begin{array}{l}\text { - Virginia: } 2 \text { projects } \\
\text { - Kansas: I-35 near Wichita }\end{array}$ & $\begin{array}{l}\text { - Illinois: I-74 near Moline } \\
\text { (cont.) Spring } 2003 \\
\text { - Louisiana: I-10 near New } \\
\text { Orleans } \\
\end{array}$ & $\begin{array}{l}\text { - Delaware: Several VSL } \\
\text { deployments } \\
\text { - Maryland: Pending } \\
\text { deployment } \\
\end{array}$ & $\begin{array}{l}\text { - Florida: I-95 near Palm } \\
\text { Beach }\end{array}$ & - Deployments Pending & $\begin{array}{l}\text { - Pennsylvania: I-76 } \\
\text { (2002) }\end{array}$ \\
\hline \multicolumn{8}{|c|}{ COST } \\
\hline Cost & $\begin{array}{l}\text { Three different packages. } \\
\text { For "Full Package" option: } \\
\text { Includes } 2 \text { VMS, } 2 \text { detectors, } \\
\text { software, and hardware. } \\
\text { Intitial: } \$ 89,000 \\
\text { Monthly: } \$ \$ 17,000\end{array}$ & $\begin{array}{l}\text { Typical installation } 10 \text { VMS } \\
\& 10 \text { sensors } \\
\$ 400,000\end{array}$ & $\begin{array}{l}\text { Lake Springfield Project: } \\
\text { System (6 detectors, cameras, } \\
\text { AIMS): } \\
\text { Initial: } \$ 517,000 \\
\text { Monthly (17 VMS): } \$ 336,870 \\
\quad \text { TOTAL: } \$ 853,870\end{array}$ & $\begin{array}{l}\text { Project Cost based on site. } \\
\text { Options: "Sale", "Rental" or } \\
\text { "Rental - with option to buy". }\end{array}$ & $\begin{array}{l}\text { Price ranges from } \$ 50,000 \\
\text { to } \$ 90,000 \text { depending on } \\
\text { optimal equipment supplied }\end{array}$ & $\begin{array}{l}\text { Three different packages. } \\
\text { For "Full Package" option: } \\
\text { Includes 4 VMS, } 5 \text { detectors, } \\
\text { software, and hardware. } \\
\text { Intitial: } \$ 145,000 \\
\text { Monthly: } \$ 16,000\end{array}$ & $\begin{array}{l}\text { WIZARD only w/power } \\
\text { cord } \\
\$ 3,890 \\
\text { WIZARD and two wheel } \\
\text { trailer, stand alone with } \\
\text { solar/battery power } \\
\$ 7,094\end{array}$ \\
\hline \multicolumn{8}{|c|}{$\begin{array}{l}\text { CONTACT INFORMATION } \\
\end{array}$} \\
\hline $\begin{array}{l}\text { Contact Person / Office } \\
\text { Location }\end{array}$ & $\begin{array}{l}\text { Dr. Prahlad Pant } \\
\text { (513) 226-6009 } \\
\text { Cincinnati, OH } \\
\end{array}$ & $\begin{array}{l}\text { George Hairston } \\
\text { (703)-276-3377 } \\
\text { Arlington, VA }\end{array}$ & $\begin{array}{l}\text { Race Miner } \\
\text { (717) 766-8961 } \\
\text { Mechanicsburg, PA } \\
\end{array}$ & $\begin{array}{l}\text { Bill Wellman } \\
\text { (302) 328-3220 } \\
\text { New Castle, DE } \\
\end{array}$ & $\begin{array}{l}\text { Brian Nicholson } \\
\text { (651) 558-3588 } \\
\text { St. Paul, MN } \\
\end{array}$ & $\begin{array}{l}\text { Dr. Prahlad Pant } \\
\text { (513) 226-6009 } \\
\text { Cincinnati, OH } \\
\end{array}$ & $\begin{array}{l}\text { Mark McSkimming } \\
\text { (717) 691-8007 } \\
\text { Mechanicsburg, PA }\end{array}$ \\
\hline Web Site & http://www.pptips.com/ & $\begin{array}{l}\text { hhtp://www.scientexcorp.com/ad } \\
\text { aptir.htm. }\end{array}$ & http://www.unitedrentals.com/ & http://www.asti-trans.com/ & $\begin{array}{l}\text { http://www.addcoinc.com/t sm } \\
\text { art.htm }\end{array}$ & http://www.pptips.com/ & $\begin{array}{l}\text { http://www.trafcon.com/wiza } \\
\text { rd.html }\end{array}$ \\
\hline INDOT Meeting Date & Thursday, December 62001 & Tuesday, January 152002 & Friday, November 302001 & Wednesday, December 192001 & None & Thursday, December 62001 & None \\
\hline
\end{tabular}

${ }^{1}$ Adapted from: Ullman, G et. al (2001) “A Review of Traffic Management and Enforcement Problems and Improvement Options at High Volume, High Speed Work Zones in Texas". Texas Transportation Institute. 


\subsection{Evaluation and Findings}

\subsubsection{Advantages}

Most of the technologies analyzed with the exception of the Wizard CB Alert Radio, have been strictly designed to function autonomously. The possibility of having an entire set of message signs displaying information to motorists without any human intervention is greatly beneficial for state officials. The vendors of these technologies provide a wide variety of contract options which allow clients to either lease or purchase the equipment required for a given system. In either case, full-service agreements are often available which require all necessary work on the system to be performed by the vendor and not by the client. Such agreements often have a large initial fee and smaller monthly fees that are required for services performed by the vendor.

The capability of controlling, monitoring and modifying the information remotely constitutes a great advantage. In particular, during construction activities on interstates where traffic conditions are dynamic and change rapidly at the most unexpected times.

These technologies provide motorists with a good amount of information for planning and coordinating their traveling routes accordingly. The possibility of utilizing the Internet, or email alerts informing motorists about accidents or conditions in their planned routes is advantageous. By deploying these traffic management technologies more extensively, a "driver culture" will be generated where drivers will be available to monitor the actual conditions of the interstate and obtain information such as the travel time through a construction work zone. This "culture" also involves having monitors displaying the upcoming information in rest areas and main tourists attractions, so travelers can be better informed of the conditions they will be expecting on the interstate of interest. One of the most important benefits of these technologies is the option of displaying alternate routes during activity work areas. If real-time traffic data is collected and displayed accordingly, drivers will be able to take a better decision regarding the path of travel to follow.

Zwahlen (2001) reports that these systems do a reasonable job in predicting on average the travel time through the work zones. Besides, these technologies may help reducing the aggressive driving behavior in work zones. Aggressive driver behavior includes tailgating, abrupt 
lane changes, and speeding alone or in combination (Foundation AAA (2002)). With appropriate information displayed in the VMSs drivers will be persuaded to reduce their speed and will be aware of the changing interstate conditions during the work zone.

\subsubsection{Disadvantages}

One of the most important disadvantages of these systems is the high cost associated with each deployment. Although each deployment depends on the requirements desired by the Department of Transportation, a system with enough capability of displaying accurate information can cost in the range of $\$ 200,000$ to $\$ 900,000$. The prices for the different technologies analyzed are provided in the summary matrix presented before (See Table 3-1). As it can be easily understood, the larger the number of sensors and VMSs required for the project, the higher the cost of the system.

The high price of these technologies is somewhat surprising. Sometimes, the cost recovery of these systems it is outweighed by the benefits. The vendors provide the algorithm, and some times the sensors and the VMSs. This algorithm patented in many cases, constitutes the backbone of the system and provides vendors with their marketing advantage. However, the cost of these technologies is still very high.

These systems are designed to inform people and towards more public relations rather than improving the actual safety on the interstates. It has been impossible to find before and after accident data, which indicated whether accidents near a work zone, were decreased by deploying any of the above or any other traffic management technologies currently available. However, it has been very easy to find anecdotic data showing that motorists were very satisfied with the use of these technologies as an information dissemination tool (MwSWZDI 2000).

There is also a dichotomy between cost and accuracy. Most of the deployments placed the sensors at such a distance apart that is very difficult to actually determine the traffic conditions. If greater accuracy is warranted, then more sensors and consequently more funds must be allocated. Interestingly, the vast majority of the deployments analyzed had several Variable Message Signs displaying the information collected by a few sensors, rather than having the opposite configuration. It is more beneficial to have more sensors and less VMS. It is believed to be more important to collect sufficient data by placing several sensors and only provide motorists with better information well in advance of the work zone. 
Furthermore, there is a big challenge for the traffic management technologies developers. The traffic sensors are placed beside the road on a side-fire configuration and they "look at traffic" immediately in front of them and predict travel time on a greater spacing. The sensors have a narrow detection area and just by sampling this space, the algorithm is predicting what is happening throughout several miles of interstate (Figure 3-12). If the sensors were deployed spaced by a hundred feet or so, they may have a greater chance of accomplishing this task. It is believed to be very difficult to predict traffic conditions by deploying just a couple of sensors spaced miles apart.

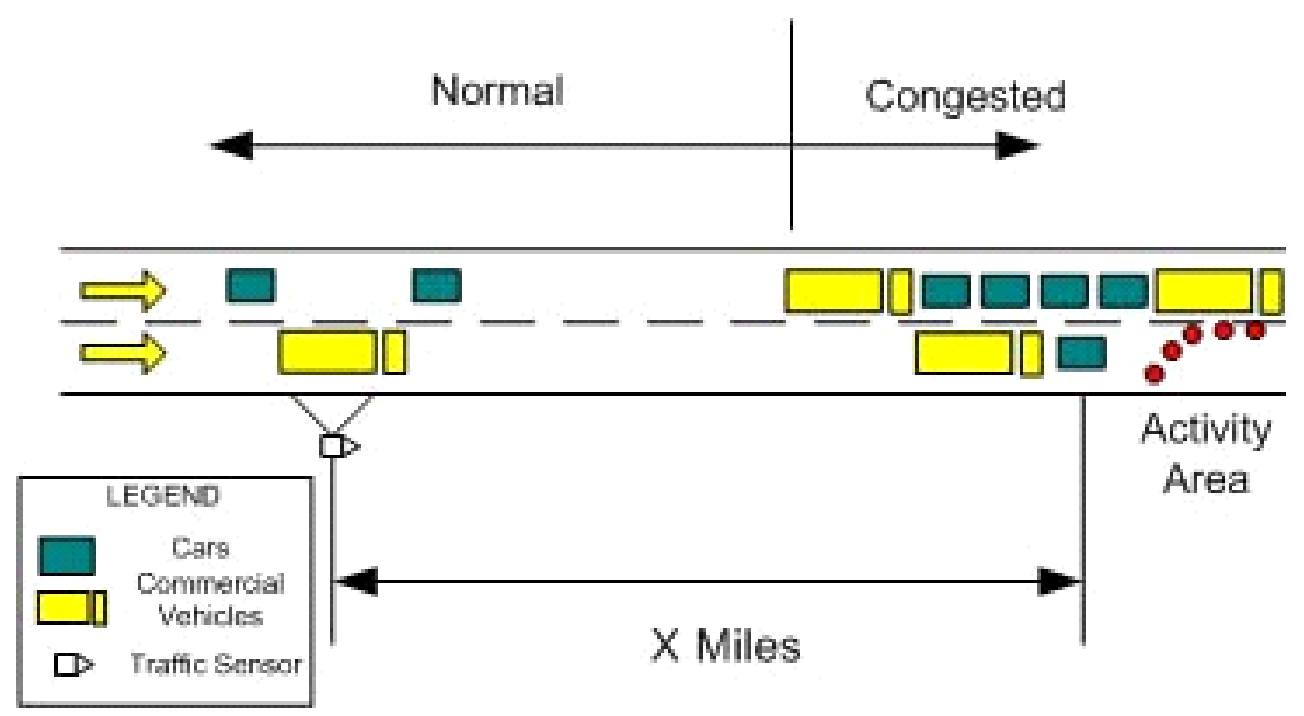

Figure 3-12 Sensor Spacing during Congested Conditions

Saturating motorists with to much information may also be unsafe. It is better to provide a few signs well placed informing reliable information rather than overcrowding the work zone. For example, one work zone examined in Illinois deployed several variable message signs, and few detectors. The congestion observed during the entire construction period was not as expected and never triggered the system. The cost of the system represented a good amount of the total project cost, and in some extent, the system was never operational to its full capacity.

Another disadvantage of these technologies are the communications. Most of the times the placement of the signs and actual deployment of the technologies is determined by the range on the communications. As mentioned previously, signs tend to be placed in the heart of the work zone rather than well in advance mainly due to limitations on their communications. Therefore, these technologies are placed near the activity area where queues have already formed thus 
minimizing the possibility of avoiding rear-end collisions, the most typical accidents encountered in work zones.

\subsection{2. $\quad \underline{\text { Recommendations }}$}

Based on the information presented above, the deployments of these technologies must be treated carefully. The costs of these systems are quite high and the benefits not clearly documented. In addition, the importance of just providing motorists with sufficient and enough information in order to make an educated decision is essential. The driver must not be saturated with information.

It is imperative to initiate a formal process coordinated by the Federal Highway Administration (FHWA) to ensure that the deployments of traffic management technologies are designed by qualified professionals using standard well documented procedures.

In addition, deployments must be standardized, by providing a set of guidelines or codes. To this date, the only sources of information when conducting a deployment are the MUTCD and the experience of parties involved. As it was discussed in the previous section, the key point of these deployments is the sensor spacing. It can be understood, that every project is different. However, by specifying some threshold values then the deployments will be completed more satisfactory and drivers will be provided with information that is more accurate. Furthermore, sensors are not the only factor that needs guidelines. A checklist or some kind of control document to track the deployment of units such as VMSs, HARs, etc must be developed. The checklist must be easily modifiable and adaptable to different projects. Rural interstates constitute the scope of this project. However, this document must also be designed for projects on highly traveled urban interstates. Some kind of ITS guidelines for completing these deployments is imperative.

\subsection{Conclusions}

Maintaining traffic flow and safety of motorists and construction workers on interstate work zones are major concerns for DOTs. Delays, long queues and lines of halted vehicles are growing irritants for motorists. Accidents tend to increase when there is an increase in construction activity. In order to reduce the frequency of crashes occurring in these work zones, traffic agencies have implemented different technologies to provide road users with more information of the dangers that lie ahead. 
The systems ADAPTIR ${ }^{\text {TM }}$, AIMS ${ }^{\text {TM }}$, ASIS, CHIPS ${ }^{\text {TM }}$, TIPS and WIZARD, attempt to influence drivers behavior in an effort to decrease the number of accidents and fatalities near a work zone Although, the benefits of these technologies are obvious, they can be sometimes outweighed by the cost of the traffic management system itself if not deployed appropriately. Special attention must be given to provide motorists with enough information to perform an action, but not to over saturate them with information by using several Variable Message Signs.

Standardization of ITS during work zones must be a priority. The development of a checklist is necessary as well. By developing this standardization, better deployments will be performed, costs will be reduced and a proactive approach will be undertaken.

This evaluation represents a snapshot in time and it is intended to evaluate several traffic management technologies that have been developed as of today. Several technologies have been introduced recently. It has been difficult to limit the number of systems to be analyzed. This study is intended to evaluate the technologies mentioned above by providing the same format. The advantages and disadvantages of the technology as a whole and not of any particular system have been presented. 


\title{
CHAPTER 4. ACCIDENT DATA EVALUATION
}

\begin{abstract}
4.1. Description of Projects
Numerous interstate rehabilitation projects have been completed in Indiana since the creation of the state's interstate system. When conducting a study of accidents that have occurred as a result of these projects, the obvious approach is to include all such accidents that have occurred since the process of recording accidents was first begun. This method would apply only if traffic control methods have remained constant during all construction projects.
\end{abstract}

In 1996, INDOT's traffic management policies for interstate work zones were modified. Since 1996, concrete barrier walls, which are used to separate opposing traffic that travels in adjacent lanes of an interstate, are required on all major interstate construction projects. This change in policy improved the safety of interstate work zones. For this reason comparing accidents before 1996 to those after 1996 is not appropriate. In this study, only interstate projects that occurred during the 1996 construction season and after have been considered.

Between the years of 1996 and 2000, the interstates of Indiana experienced twenty-seven rehabilitation projects in which a lane or lanes of traffic inside the work zone was closed for a significant period of time. This list can be seen in Table 4-1 and Table 4-2. Included in the table is information about the contract number, location as well as start and end dates of each project. 
Table 4-1 Interstate Work Zone Projects from 1996 to 2000

\begin{tabular}{|c|c|c|c|c|c|c|c|c|}
\hline $\begin{array}{l}\text { Project } \\
\text { Number }\end{array}$ & $\begin{array}{c}\text { Contract No. I Des. } \\
\text { No. }\end{array}$ & $\begin{array}{l}\text { Interstate } \\
\text { Route }\end{array}$ & Start Construction & $\begin{array}{c}\text { Start } \\
\text { Milepost }\end{array}$ & Start Date & End Construction & End Milepost & End Date \\
\hline 1 & R-24847 / 9614740 & $1-65$ & $\begin{array}{l}3.7 \text { mile S. of } \\
\text { Memphis Rd. }\end{array}$ & 12.3 & $07 / 13 / 00$ & $\begin{array}{l}0.7 \text { mile N. of SR } \\
160 \text { in Clark Co. }\end{array}$ & 18.3 & $10 / 27 / 00$ \\
\hline 2 & R-24551 / 9614673 & $\mathrm{I}-65$ & $\begin{array}{c}1.57 \text { miles S. of SR } \\
11\end{array}$ & 53.4 & $03 / 28 / 00$ & $\begin{array}{c}0.64 \text { miles } N \text { of } S R \\
11 \text { in Jackson Co. }\end{array}$ & 55.6 & 08/03/01 \\
\hline 3 & R-22854 / 9520190 & $\mathrm{I}-65$ & $\begin{array}{l}0.26 \text { mile N. of US } \\
31\end{array}$ & 76.3 & $02 / 16 / 97$ & $\begin{array}{c}0.5 \text { mile N. of SR } \\
252 \text { in } \\
\text { Bartholomew \& } \\
\text { Shelby } \\
\end{array}$ & 80.5 & $08 / 12 / 97$ \\
\hline 4 & B-24138 / 9702110 & $\mathrm{I}-65$ & $\begin{array}{c}\text { Bridge over SR } 25 \text { in } \\
\text { Tippecanoe Co. }\end{array}$ & 175.0 & $04 / 21 / 00$ & & & $05 / 25 / 01$ \\
\hline 5 & R-23500 / 9614570 & I-65 & $\begin{array}{c}1.71 \text { mile N. of SR } \\
43\end{array}$ & 179.7 & $02 / 23 / 98$ & $\begin{array}{c}1 \text { mile N. of Rest } \\
\text { Area in } \\
\text { Tippecanoe \& } \\
\text { White }\end{array}$ & 189.0 & $08 / 31 / 99$ \\
\hline 6 & R-22348 / 9244205 & $1-65$ & $\begin{array}{c}2.3 \text { mile N. of US } \\
231\end{array}$ & 203.3 & $04 / 10 / 96$ & $\begin{array}{l}2.4 \text { mile N. of SR } \\
114 \text { in Jasper Co. }\end{array}$ & 217.4 & $12 / 19 / 97$ \\
\hline 7 & $\begin{array}{c}\text { B-24466 / } 9903200 \\
\& 8919157\end{array}$ & $1-65$ & $\begin{array}{c}2 \text { bridge rehabs over } \\
\text { Wirtz \& Singleton } \\
\text { Ditches in Lake Co. }\end{array}$ & & $04 / 17 / 00$ & & 241.0 & $11 / 14 / 00$ \\
\hline 8 & B-23288 / 9407080 & $\mathrm{I}-65$ & $\begin{array}{l}\text { Bridge over US } \\
\text { 231/Aban. RR. In } \\
\text { Lake Co. }\end{array}$ & 247.0 & $02 / 09 / 98$ & & & $11 / 09 / 98$ \\
\hline 9 & B-23520 / 8917050 & $\mathrm{I}-65$ & $\begin{array}{l}\text { Bridge removal } 0.5 \\
\text { mile N. of US } 30 \text { in } \\
\text { Lake Co. }\end{array}$ & 253.5 & $04 / 13 / 98$ & & & 08/02/99 \\
\hline 10 & R-24941 / 9614690 & $\mathrm{I}-65$ & 2.1 mile S. of SR 2 & 237.9 & $05 / 17 / 01$ & $\begin{array}{l}0.6 \text { mile S. of US } \\
231 \text { in Lake Co. }\end{array}$ & 246.4 & $09 / 24 / 01$ \\
\hline 11 & R-22751 / 9520320 & $\mathrm{I}-65$ & $\begin{array}{l}3.44 \text { mile S. of SR } \\
38\end{array}$ & 164.6 & $03 / 24 / 97$ & $\begin{array}{c}0.6 \text { mile N. of SR } \\
26 \text { in Tippecanoe } \\
\text { Co. }\end{array}$ & 172.6 & $07 / 07 / 97$ \\
\hline 12 & $\begin{array}{c}\text { B-23513 / } 9520160 \\
\& 9520161\end{array}$ & $\mathrm{I}-69$ & $\begin{array}{l}2 \text { bridge rehabs over } \\
\text { Sand \& Mud Creeks } \\
\text { in Hamilton Co. }\end{array}$ & 7.0 & $03 / 27 / 98$ & & 12.7 & $07 / 16 / 98$ \\
\hline 13 & $\begin{array}{c}\text { B-23884 / } 9831970 \\
\& 9831980\end{array}$ & $\mathrm{I}-69$ & \begin{tabular}{|c|}
2 bridge rehabs over \\
Kilbuck \& Prairie \\
Creeks in Delaware \\
Co.
\end{tabular} & 42.0 & $09 / 01 / 98$ & & 76.5 & $11 / 18 / 98$ \\
\hline 14 & $\begin{array}{c}B-25168 / 9803610 \\
\& 9803590\end{array}$ & $1-69$ & $\begin{array}{l}2 \text { bridge rehabs over } \\
\text { Tippey \& Baker } \\
\text { Ditches in Grant Co. }\end{array}$ & 65.1 & $07 / 15 / 01$ & & 68.0 & $11 / 16 / 01$ \\
\hline 15 & R-22912 / 9520210 & $1-69$ & 2 mile N. of SR 5 & 80.0 & $03 / 17 / 97$ & $\begin{array}{c}0.38 \text { mile S. of US } \\
224 \text { in Huntington } \\
\text { Co. }\end{array}$ & 85.6 & $11 / 04 / 97$ \\
\hline 16 & R-23889 / 9133836 & $1-69$ & $\begin{array}{c}\text { Interchange } \\
\text { modification @ US } \\
24 \text { in Allen Co. } \\
\end{array}$ & 102.0 & $10 / 09 / 99$ & & & $09 / 11 / 01$ \\
\hline 17 & R-23799 / 9520170 & $\mathrm{I}-69$ & $\begin{array}{c}0.1 \text { mile S. of Cedar } \\
\text { Creek }\end{array}$ & 134.3 & 09/10/99 & $\begin{array}{c}0.4 \text { mile N. of SR } 8 \\
\text { in Dekalb Co. }\end{array}$ & 129.4 & $09 / 20 / 01$ \\
\hline 18 & B-22710 / 9406820 & $\mathrm{I}-69$ & $\begin{array}{c}\text { Bridge rehab over } \\
\text { Pigeon Creek in } \\
\text { Steuben Co. } \\
\end{array}$ & 145.7 & $11 / 01 / 96$ & & & $11 / 05 / 97$ \\
\hline 19 & R-23389 / 9520130 & $1-69$ & 1 mile S. of SR 4 & 139.0 & 03/06/98 & $\begin{array}{c}1 \text { mile N. of US } 20 \\
\text { in Steuben Co. }\end{array}$ & 149.0 & $11 / 24 / 98$ \\
\hline
\end{tabular}


Table 4-2 Interstate Work Zone Projects from 1996 to 2000 (cont'd)

\begin{tabular}{|c|c|c|c|c|c|c|c|c|}
\hline $\begin{array}{l}\text { Project } \\
\text { Number }\end{array}$ & $\begin{array}{c}\text { Contract No. / Des. } \\
\text { No. }\end{array}$ & $\begin{array}{l}\text { Interstate } \\
\text { Route }\end{array}$ & Start Construction & $\begin{array}{c}\text { Start } \\
\text { Milepost }\end{array}$ & Start Date & End Construction & End Milepost & End Date \\
\hline 20 & R-23890 / 9520280 & $\mathrm{I}-69$ & 1 mile $\mathrm{N}$. of US 20 & 149.0 & 02/22/99 & $\begin{array}{l}\text { IN/MI State Line in } \\
\text { Steuben Co. }\end{array}$ & 156.9 & 09/10/99 \\
\hline 21 & \begin{tabular}{|} 
B-23206 / 9406600 \\
9406610,9612770 \\
9406620,9406640 \\
9406580
\end{tabular} & $1-70$ & $\begin{array}{c}6 \text { bridge rehabs in } \\
\text { Vigo Co. }\end{array}$ & & $08 / 18 / 97$ & & & $11 / 19 / 97$ \\
\hline 22 & $\begin{array}{c}\text { B-24411 / } 9614602 \\
9614603,9614604 \\
9702300\end{array}$ & $1-70$ & $\begin{array}{l}4 \text { bridge rehabs with } \\
\text { District resurfacing } \\
\text { project in Wayne Co. }\end{array}$ & 137.8 & 04/01/01 & & 141.2 & $11 / 01 / 01$ \\
\hline 23 & R-23641 / 9520300 & $\mathrm{I}-70$ & $\begin{array}{l}0.31 \text { mile W. of } \\
\text { Centerville Rd. }\end{array}$ & 144.7 & $02 / 15 / 99$ & $\begin{array}{c}0.86 \text { mile W. of US } \\
27 \text { in Wayne Co. }\end{array}$ & 150.1 & 08/14/01 \\
\hline 24 & R-23988 / 9709040 & $\mathrm{I}-70$ & IL/IN State Line & 0.0 & 03/24/99 & $\begin{array}{c}\text { Wabash River } \\
\text { bridge in Vigo Co. }\end{array}$ & 8.5 & 07/19/99 \\
\hline 25 & R-24410 / 9614630 & $1-70$ & $\begin{array}{c}0.45 \text { mile E. of SR } \\
109\end{array}$ & 115.5 & $03 / 22 / 00$ & $\begin{array}{c}0.35 \text { mile W. of SR } \\
3 \text { in Henry Co. }\end{array}$ & 122.7 & $10 / 27 / 00$ \\
\hline 26 & R-24411 / 9614600 & $1-70$ & 0.5 mile W. of SR 1 & 136.5 & $04 / 11 / 01$ & $\begin{array}{l}0.3 \text { mile } \mathrm{W} \text {. of } \\
\text { Centerville } \mathrm{Rd} \text {. }\end{array}$ & 144.7 & $11 / 01 / 01$ \\
\hline 27 & R-22861 / 9520230 & $\mathrm{I}-70$ & $\begin{array}{c}0.86 \text { mile } \mathrm{W} \text {. of US } \\
27\end{array}$ & 150.1 & $05 / 13 / 97$ & $\begin{array}{c}\text { IN/OH State Line in } \\
\text { Wayne Co. }\end{array}$ & 154.3 & $04 / 28 / 98$ \\
\hline
\end{tabular}

To investigate the relationship between crashes and traffic volume, daily traffic volumes were obtained for each work zone. To acquire the most accurate vehicle counts, counts from Weigh in Motion (WIM)stations located near the work zones were used when possible. The counts recorded at these stations were used as the average daily traffic volumes for their respective work zone. For several projects, no Weigh in Motion station was located close enough to the location of the work zone to provide an accurate count of vehicles traveling through the work zone. For such work zones, AADT values were obtained from the Indiana Department of Transportation (INDOT) website (INDOT 2002). The ADT values corresponding to each site can be found in Table 4-3, Table 4-4 and Table 4-5. 
Table 4-3 Work Zones with Traffic Data

\begin{tabular}{|c|c|c|c|c|c|}
\hline $\begin{array}{l}\text { Project } \\
\text { Number }\end{array}$ & $\begin{array}{l}\text { Contract No. I } \\
\text { Des. No. }\end{array}$ & Interstate Route & $\begin{array}{l}\text { Station } \\
\text { Number }\end{array}$ & $\begin{array}{l}\text { Dates of } \\
\text { Data }\end{array}$ & $\begin{array}{l}\text { Average Daily } \\
\text { Traffic }\end{array}$ \\
\hline 1 & R-24847 / 9614740 & $1-65$ & 6420 & $\begin{array}{l}06 / 21 / 00 \text { to } \\
06 / 24 / 00\end{array}$ & 41,710 \\
\hline 2 & R-24551 / 9614673 & $1-65$ & 507 & $\begin{array}{l}06 / 18 / 00 \text { to } \\
06 / 24 / 00\end{array}$ & 30,749 \\
\hline 3 & R-22854 / 9520190 & $1-65$ & 5120 & $\begin{array}{l}06 / 18 / 00 \text { to } \\
06 / 24 / 00\end{array}$ & 42,490 \\
\hline 4 & B-24138 / 9702110 & $1-65$ & 5450 & $\begin{array}{l}06 / 18 / 00 \text { to } \\
06 / 24 / 0\end{array}$ & 45,840 \\
\hline 5 & R-23500 / 9614570 & $1-65$ & 4140 & $\begin{array}{l}06 / 23 / 00 \text { to } \\
06 / 24 / 00\end{array}$ & 32,987 \\
\hline 6 & R-22348 / 9244205 & $1-65$ & 4110 & $\begin{array}{l}06 / 18 / 00 \text { to } \\
06 / 24 / 00\end{array}$ & 26,050 \\
\hline 7 & $\begin{array}{l}\text { B-24466 / } 9903200 \\
\& 8919157\end{array}$ & I-65 & $4410 / 4420$ & & 33,780 \\
\hline 8 & B-23288 / 9407080 & $1-65$ & $4410 / 4420$ & & 38,550 \\
\hline 9 & B-23520 / 8917050 & $1-65$ & $4410 / 4420$ & & 72,940 \\
\hline 10 & R-24941 / 9614690 & $1-65$ & $4410 / 4420$ & & 33,780 \\
\hline 11 & R-22751 / 9520320 & $1-65$ & 5450 & $\begin{array}{l}06 / 18 / 00 \text { to } \\
06 / 24 / 0\end{array}$ & 45,840 \\
\hline 12 & $\begin{array}{l}\text { B-23513 / } 9520160 \\
\& 9520161\end{array}$ & $1-69$ & & & 40,120 \\
\hline 13 & $\begin{array}{l}\text { B-23884 / } 9831970 \\
\& 9831980\end{array}$ & $1-69$ & 4140 & $\begin{array}{l}06 / 18 / 00 \text { to } \\
06 / 24 / 00\end{array}$ & 30,570 \\
\hline
\end{tabular}


Table 4-4 Work Zones with Traffic Data (cont'd)

\begin{tabular}{|c|c|c|c|c|c|}
\hline $\begin{array}{l}\text { Project } \\
\text { Number }\end{array}$ & $\begin{array}{l}\text { Contract No. / Des. } \\
\text { No. }\end{array}$ & Interstate Route & $\begin{array}{l}\text { Station } \\
\text { Number }\end{array}$ & Dates of Data & $\begin{array}{l}\text { Average Daily } \\
\text { Traffic }\end{array}$ \\
\hline 14 & $\begin{array}{l}\text { B-25168 / } 9803610 \\
\& 9803590\end{array}$ & I-69 & 4140 & $\begin{array}{l}06 / 18 / 00 \text { to } \\
06 / 24 / 00\end{array}$ & 26,720 \\
\hline 15 & R-22912 / 9520210 & I-69 & 206 & $\begin{array}{l}06 / 18 / 00 \text { to } \\
06 / 24 / 00\end{array}$ & 26,559 \\
\hline 16 & R-23889 / 9133836 & I-69 & 204 & $\begin{array}{l}06 / 18 / 00 \text { to } \\
06 / 24 / 00\end{array}$ & 58,421 \\
\hline 17 & R-23799 / 9520170 & I-69 & 4150 & $\begin{array}{l}06 / 18 / 00 \text { to } \\
06 / 24 / 00\end{array}$ & 27,090 \\
\hline 18 & B-22710 / 9406820 & I-69 & 4150 & $\begin{array}{l}06 / 18 / 00 \text { to } \\
06 / 24 / 00\end{array}$ & 22,230 \\
\hline 19 & R-23389 / 9520130 & I-69 & 4150 & $\begin{array}{l}06 / 18 / 00 \text { to } \\
06 / 24 / 00\end{array}$ & 22,236 \\
\hline 20 & R-23890 / 9520280 & $1-69$ & 4150 & $\begin{array}{l}06 / 18 / 00 \text { to } \\
06 / 24 / 00\end{array}$ & 19,890 \\
\hline 21 & $\begin{array}{l}\text { B-23206 / } \\
9406600, \\
9406610, \\
9612770, \\
9406620, \\
9406640 \\
9406580\end{array}$ & $\mid-70$ & & & 24,830 \\
\hline
\end{tabular}


Table 4-5 Work Zones with Traffic Data (cont'd)

\begin{tabular}{|c|c|c|c|c|c|}
\hline $\begin{array}{l}\text { Project } \\
\text { Number }\end{array}$ & $\begin{array}{l}\text { Contract No. / Des. } \\
\text { No. }\end{array}$ & Interstate Route & $\begin{array}{l}\text { Station } \\
\text { Number }\end{array}$ & Dates of Data & $\begin{array}{l}\text { Average Daily } \\
\text { Traffic }\end{array}$ \\
\hline 22 & $\begin{array}{l}\text { B-24411/ } \\
9614602, \\
9614603, \\
9614604, \\
9702300\end{array}$ & $1-70$ & & & 33,570 \\
\hline 23 & R-23641 / 9520300 & $1-70$ & 4150 & $\begin{array}{l}06 / 18 / 00 \text { to } \\
06 / 24 / 00\end{array}$ & 36,530 \\
\hline 24 & R-23988 / 9709040 & $1-70$ & 5440 & $\begin{array}{l}06 / 18 / 00 \text { to } \\
06 / 24 / 00\end{array}$ & 24,830 \\
\hline 25 & R-24410 / 9614630 & $1-70$ & 5140 & $\begin{array}{l}06 / 18 / 00 \text { to } \\
06 / 24 / 00\end{array}$ & 36,700 \\
\hline 26 & R-24411 / 9614600 & $1-70$ & 5140 & $\begin{array}{l}06 / 18 / 00 \text { to } \\
06 / 24 / 00\end{array}$ & 33,390 \\
\hline 27 & R-22861 / 9520230 & $1-70$ & 5140 & $\begin{array}{l}06 / 18 / 00 \text { to } \\
06 / 24 / 00\end{array}$ & 36,320 \\
\hline
\end{tabular}

No Data Available

To acquire crash records for these work zones, the INDOT crash database was used. This database contains information about crashes that occurred approximately sixteen months prior to the date of inquiry. Due to this time lag, crash information for projects extending into the 2001 calendar year could not be easily obtained. For this reason, the list was narrowed to fifteen work zones. One additional project was added to this list. That project was the rehabilitation of the Interstate-65 interchange and State Route 25, which took place in 2000. This project was included because of the large numerous accidents associated with it, and also because the accident reports could be obtained with relative ease. The final list of sixteen interstate work zones and their locations can be seen in Table 4-6. Table 4-7, Table 4-8 and Table 4-9 each give information on the duration, type of work performed, and the number of operational lanes per direction during the construction for each of these projects. 
Table 4-6 Work Zone Locations

\begin{tabular}{|c|c|c|c|c|c|c|c|}
\hline \multirow[b]{2}{*}{ Zone } & \multirow[b]{2}{*}{ Site } & \multicolumn{3}{|c|}{ Work Zone Limits } & \multicolumn{3}{|c|}{ Study Area } \\
\hline & & $\begin{array}{l}\text { From } \\
\text { Milepost }\end{array}$ & To Milepost & \# of Miles & $\begin{array}{l}\text { From } \\
\text { Milepost }\end{array}$ & To Milepost & \# of Miles \\
\hline 1 & $1-65$ & 174.9 & 175.6-+ & 0.7 & 169.9 & 180.6 & 10.7 \\
\hline 2 & $1-65$ & 76.2 & 80.6 & 4.4 & 71.2 & 85.6 & 14.4 \\
\hline 3 & | I-65 & 179.6 & 197.8 & 18.2 & 174.6 & 202.8 & 28.2 \\
\hline 4 & I-65 & 203.2 & 217.5 & 14.3 & 198.2 & 222.5 & 24.3 \\
\hline 5 & I-65 & 246.9 & 253.6 & 6.7 & 241.9 & 258.6 & 16.7 \\
\hline 6 & $1-65$ & 252.9 & 253.6 & $\theta .7$ & 247.9 & 258.6 & 10.7 \\
\hline $6^{*}$ & I-65 & 246.9 & 253.6 & 6.7 & 241.9 & 258.6 & 16.7 \\
\hline 7 & $\mid-65$ & 164.5 & 172.7 & 8.2 & 159.5 & 177.7 & 18.2 \\
\hline 8 & I-69 & 6.9 & 12.8 & 5.9 & 1.9 & 17.8 & 15.9 \\
\hline $9^{* *}$ & 169 & 41.9 & 76.6 & 34.7 & 36.9 & 81.6 & 44.7 \\
\hline 10 & I-69 & 79.9 & 85.7 & 5.8 & 74.9 & 90.7 & 15.8 \\
\hline 11 & |I-69 & 145.6 & 157.1 & 11.5 & 140.6 & 162.1 & 21.5 \\
\hline 12 & I-69 & 138.9 & 149.1 & 10.2 & 133.9 & 154.1 & 20.2 \\
\hline 13 & $I-69$ & 148.9 & 157.0 & 8.1 & 143.9 & 162.0 & 18.1 \\
\hline 14 & |I-70 & 3.9 & 7.1 & 3.2 & 0.0 & 12.1 & 12.1 \\
\hline 15 & $\mid-70$ & 0.0 & 8.6 & 8.6 & 0.0 & 13.6 & 13.6 \\
\hline 16 & $\mid-70$ & 150.0 & 154.4 & 4.4 & 145.0 & 159.4 & 14.4 \\
\hline
\end{tabular}

${ }^{*}$ Combined Zones 5 \& 6 due to overlapping dates and limits

** Not included in graphs due to distance between bridge rehabilitations 
Table 4-7 Work Zone Dates

\begin{tabular}{|c|c|c|c|c|}
\hline Zone & Start Date & $\begin{array}{l}\text { Completion } \\
\text { Date }\end{array}$ & $\begin{array}{l}\# \text { of } \\
\text { Days }\end{array}$ & Estimated \# of Months \\
\hline 1 & 21-Apr-00 & 25-May-01 & 399 & 13.3 \\
\hline 2 & 16-Mar-97 & 12-Aug-97 & 149 & 5.0 \\
\hline 3 & 23-Feb-98 & 31-Aug-99 & 554 & 18.5 \\
\hline 4 & 10-Apr-96 & 19-Dec-97 & 630 & 21.0 \\
\hline 5 & $\theta 9$-98 & $\theta 9$ Noマ-98 & 273 & 9.1 \\
\hline$\theta$ & 13-Apr 98 & $\theta 2$ Aug 99 & 476 & 15.9 \\
\hline $6^{*}$ & $09-F e b-98$ & 02-Aug-99 & 817 & 27.2 \\
\hline 7 & 24-Mar-97 & 07-Jul-97 & 105 & 3.5 \\
\hline 8 & 27-Mar-98 & 16-Jul-98 & 111 & 3.7 \\
\hline $9^{* *}$ & $01 \operatorname{sep}-98$ & 18-Nov98 & 78 & 2.6 \\
\hline 10 & 17-Mar-97 & 04-Nov-97 & 232 & 7.7 \\
\hline 11 & 01-Nov-96 & 05-Nov-97 & 369 & 12.3 \\
\hline 12 & 06-Mar-98 & 24-Nov-98 & 263 & 8.8 \\
\hline 13 & 22-Feb-99 & 10-Sep-99 & 200 & 6.7 \\
\hline 14 & 18-Aug-97 & 19-Nov-97 & 93 & 3.1 \\
\hline 15 & 24-Mar-99 & 19-Jul-99 & 117 & 3.9 \\
\hline 16 & 13-May-97 & 28-Apr-98 & 350 & 11.7 \\
\hline
\end{tabular}

${ }^{*}$ Combined Zones $5 \& 6$ due to overlapping dates and limits

** Not included in graphs due to distance between bridge rehabilitations 
Table 4-8 Work Zone Details

\begin{tabular}{|c|c|c|c|c|c|}
\hline Zone & Site & $\begin{array}{l}\text { Contract No. I } \\
\text { Des. No. }\end{array}$ & Direction & Type of Construction & Lanes Open \\
\hline 1 & $1-65$ & $\begin{array}{l}\text { B-24138 / } \\
9702110\end{array}$ & NB / SB & Bridge Rehabilitation & 1 each direction \\
\hline 2 & $1-65$ & $\begin{array}{l}\text { R-22854 / } \\
9520190\end{array}$ & NB / SB & Resurfacing & 1 each direction \\
\hline 3 & $1-65$ & $\begin{array}{l}\text { R-23500 / } \\
9614570\end{array}$ & NB / SB & Resurfacing & 1 each direction \\
\hline 4 & $1-65$ & $\begin{array}{l}\text { R-22348 / } \\
9244205\end{array}$ & NB / SB & Resurfacing & 1 each direction \\
\hline 5 & 165 & $\begin{array}{l}\text { B-232884 } \\
9407080\end{array}$ & AB $/ S B$ & Bridgo Rehabilitation & 1-ach direction \\
\hline 6 & $1-65$ & $\begin{array}{l}\text { B-235201 } \\
8917050\end{array}$ & $\mathrm{AB} / \mathrm{SB}$ & Bridge Rehabilitation & 1 each direction \\
\hline $6^{*}$ & $1-65$ & $\mathrm{~N} / \mathrm{A}$ & NB / SB & Bridge Rehabilitation & 1 each direction \\
\hline 7 & $1-65$ & $\begin{array}{l}\text { R-22751 / } \\
9520320\end{array}$ & NB / SB & Resurfacing & 1 each direction \\
\hline 8 & $1-69$ & $\begin{array}{l}\text { B-23513 / } \\
9520160 \text { \& } \\
9520161\end{array}$ & NB / SB & Bridge Rehabilitation & 1 each direction \\
\hline $9 *$ & 169 & $\begin{array}{l}B-235131 \\
9520160 \& \\
9520161\end{array}$ & AB/SB & Bridgo-Rehabilitation & 1-ach direction \\
\hline 10 & $1-69$ & $\begin{array}{l}\text { R-22912 I } \\
9520210\end{array}$ & NB / SB & Resurfacing & 1 each direction \\
\hline
\end{tabular}


Table 4-9 Work Zone Details (cont'd)

\begin{tabular}{|l|l|l|l|l|l|}
\hline Zone & Site & $\begin{array}{l}\text { Contract No. I } \\
\text { Des. No. }\end{array}$ & Direction & Type of Construction & Lanes Open \\
\hline \hline 11 & I-69 & $\begin{array}{l}\text { B-22710 / } \\
9406820\end{array}$ & NB / SB & Bridge Rehabilitation & 1 each direction \\
\hline 12 & I-69 & $\begin{array}{l}\text { R-23389 / } \\
9520130\end{array}$ & NB / SB & Resurfacing & 1 each direction \\
\hline 13 & I-69 & $\begin{array}{l}\text { R-23890 / } \\
9520280\end{array}$ & NB / SB & Resurfacing & 1 each direction \\
\hline 14 & I-70 & $\begin{array}{l}\text { B-23206 / } \\
9406600, \\
9406610, \\
9612770, \\
9406620, \\
9406640, \\
9406580\end{array}$ & EB / WB & Bridge Rehabilitation & 1 each direction \\
\hline 15 & I-70 & $\begin{array}{l}\text { R-23988 / } \\
9709040\end{array}$ & EB / WB & Resurfacing & 1 each direction \\
\hline 16 & I-70 & $\begin{array}{l}\text { R-22861 / } \\
9520230\end{array}$ & EB / WB & Resurfacing & 1 each direction \\
\hline
\end{tabular}

When the sixteen projects listed in Table 4-6 were examined in detail, it became apparent that there were several issues that had to be addressed. The first dilemma was that of overlapping dates and work zone limits, which occurred for Zones Five and Six. As seen in Table 4-6, each of these work zones was located on I-65 between milepost 246.0 and milepost 253.6. Examination of Table 4-7 showed that the dates of the work zones overlapped. The overlapping of the two projects resulted in accidents and fatalities being double counted, and thus made each work zone appear to be more hazardous than it actually was. To address this issue, Zones Five and Six were combined into one work zone, named Zone $6^{*}$, with a duration and location that encompassed the location and duration of both Zones Five and Six.

A similar problem occurred with Zone Nine. Two bridges that are located approximately thirteen miles apart on Interstate 69 were rehabilitated during this project. Due to the large distance between the two bridges, separate work zones were used for each bridge. However, no written 
records could be located that indicated the beginning and the ending locations of each of the two work zones. The only obtainable information was the locations of the bridges. To assume that all accidents that occurred on this segment of roadway were associated with the work zone would not be a valid assumption. For instance, a vehicle may have crashed between the two work zones and the crash may not have resulted from the work zone traffic conditions. Including such a crash into the analysis would falsely inflate the number of work zone crashes and thus would make the work zone appear more dangerous than it actually was. To avoid such an error, Zone Nine was excluded from the study.

\subsection{Data Collection Process}

Although it may seem that the work zone itself is the most dangerous segment of roadway that a driver will face, this is not always the case. In fact, the approach to a work zone can be a more dangerous location. This is mostly due to the large variation in speeds that can exist between vehicles approaching a work zone and vehicles stopped in a queue. For this reason, it was deemed necessary to study those accidents that have occurred prior to the work zone as well as those accidents that have occurred inside the work zone. To include those accidents that have occurred prior to the work zone, a study area was created that expands five miles in both directions from the work zone. Such areas, as shown in Table 4-6, will allow accidents that result from queuing type of accident to be accounted for.

To determine the number of accidents that have occurred within the study areas listed in Table 4-6, crash reports recorded by the Indiana State Police (ISP) were used. For those work zones in place between the years of 1996 and 2000 , crash records were collected from the crash database that is maintained by INDOT. The accidents recorded in this database are a digital summary of the reports created by the ISP. This database was chosen because it provided easy access to all crashes that occurred in this time period. For Zone 1, which was too recent to have crash information in the database, the hand written ISP crash reports were examined. The number of accidents, for each work zone, that occurred while construction was underway can be found in Table 4-10 under the heading "During Construction".

To determine the number of accidents that occurred at each of the sixteen locations as a result of the work zones, a second time period was chosen for each location. This period of time was chosen to have the same start and end dates as that of the work zone, but was to be in the year prior to the construction. Once these dates were determined, not all the desired data was 
available. Crash records for those work zones that occurred in or after 1995 were obtained from the INDOT crash database. Although concrete barrier walls were not mandatory for work zones in 1995, no problem results in using this information because 1995 crash records are only used for the time period in which no construction occurred. Crash records for the years prior to 1995 could not be obtained, and thus an exact number of accidents that occurred before the construction took place could not be determined for such zones. Crashes that occurred during these comparison periods can be found in Table 4-10 under the category "Before Construction".

The crash records of the ISP indicate all crucial details of the crash. Included in these reports are details of the date and location of that accident, which is recorded to the nearest mile. Also included in the reports are the direction of travel, type of accident, number of injuries and fatalities, number of vehicles involved and estimates of the distance in feet from the nearest mile marker to the accident. Using this information, each crash was then placed with its respective work zone and a summary of each work zone's accidents and fatalities were then created. This summary of crashes occurring during the existence of a work zone and during each comparison period can be seen in Table 4-10. 
Table 4-10 Work Zone Crashes

\begin{tabular}{|c|c|c|c|c|c|c|c|}
\hline & & & & Before CoI & truction & During Col & truction \\
\hline Zone & Site & AADT & $\begin{array}{l}\text { Estimated \# of } \\
\text { Months }\end{array}$ & Accidents & Fatalities & Accidents & Fatalities \\
\hline 1 & I-65 & 45,840 & 13.3 & 34 & 0 & 42 & 4 \\
\hline 2 & $1-65$ & 42,940 & 5.0 & 20 & 0 & 48 & 1 \\
\hline 3 & I-65 & 32,987 & 18.5 & 188 & 1 & 242 & 4 \\
\hline 4 & $1-65$ & 26,050 & 21.0 & 155 & 0 & 218 & 0 \\
\hline $6^{*}$ & I-65 & 72,940 & 27.2 & 443 & 3 & 567 & 3 \\
\hline 7 & $1-65$ & 45,840 & 3.5 & 34 & 0 & 32 & 0 \\
\hline 8 & I-69 & 40,120 & 3.7 & 38 & 1 & 53 & 2 \\
\hline $9 *$ & $1-69$ & 30,570 & 2.6 & 17 & $\theta$ & 13 & $\theta$ \\
\hline 10 & I-69 & 26,559 & 7.7 & 26 & 1 & 28 & 1 \\
\hline 11 & I-69 & 22,230 & 12.3 & 70 & 0 & 102 & 0 \\
\hline 12 & I-69 & 22,236 & 8.8 & 28 & 0 & 45 & 0 \\
\hline 13 & I-69 & 19,890 & 6.7 & 38 & 1 & 54 & 0 \\
\hline 14 & I-70 & 24,830 & 3.1 & 15 & 0 & 34 & 0 \\
\hline 15 & $\mid-70$ & 24,830 & 3.9 & 26 & 2 & 26 & 2 \\
\hline 16 & $1-70$ & 36,320 & 11.7 & 88 & 1 & 110 & 0 \\
\hline Totals & & & & 1815 & 18 & 2208 & 20 \\
\hline
\end{tabular}

4.2.1. Zone 1: I-65/SR 25 Interchange Reconstruction Project To begin the analysis of the work zones, Zone 1 was first looked at in detail. This work zone was chosen for several reasons. First, this work zone occurred in 2000, making it the most recent of the sixteen work zones studied in detail. Second, associated with the work zone were numerous accidents and four fatalities. Third, crash records with collision diagrams could be easily obtained from the state police post. The final reason for choosing this work zone was the terrain. The terrain in this area is filled with rolling hills, which is similar to the terrain found throughout a majority of the state of Indiana. For this reason, it was believed that the analysis of this work zone could then apply to other work zones throughout the state of Indiana. 
The locations of each crash that occurred as a result of this work zone were determined and plotted on photographs of the interstate and surrounding land. This was done in an effort to determine if the geometry of the roadway played a role in the numerous crashes. These photos, which can be found in Figure 4-1, Figure 4-2, Figure 4-3 and Figure 4-4 show the location of each crash to the nearest tenth of a mile. The figures also separate the crashes by time period (Construction or Pre-Construction) and by severity (fatality or accident).

As seen in Figure 4-1 and Figure 4-2, thirteen accidents and two fatalities occurred as motorists traveled north toward the work zone, which was centered about the I-65/SR 25 interchange (Figure 4-2). Figure 4-3 and Figure 4-4 indicate that twenty accidents and two fatalities occurred as motorists traveled south toward the work zone. Nearly all of these crashes resulted from motorists unexpectedly reaching the back of a queue of stopped or slowly moving vehicles, which was dynamic in nature, and thus becoming involved in a rear-end collision with the vehicle at the back of the queue. 


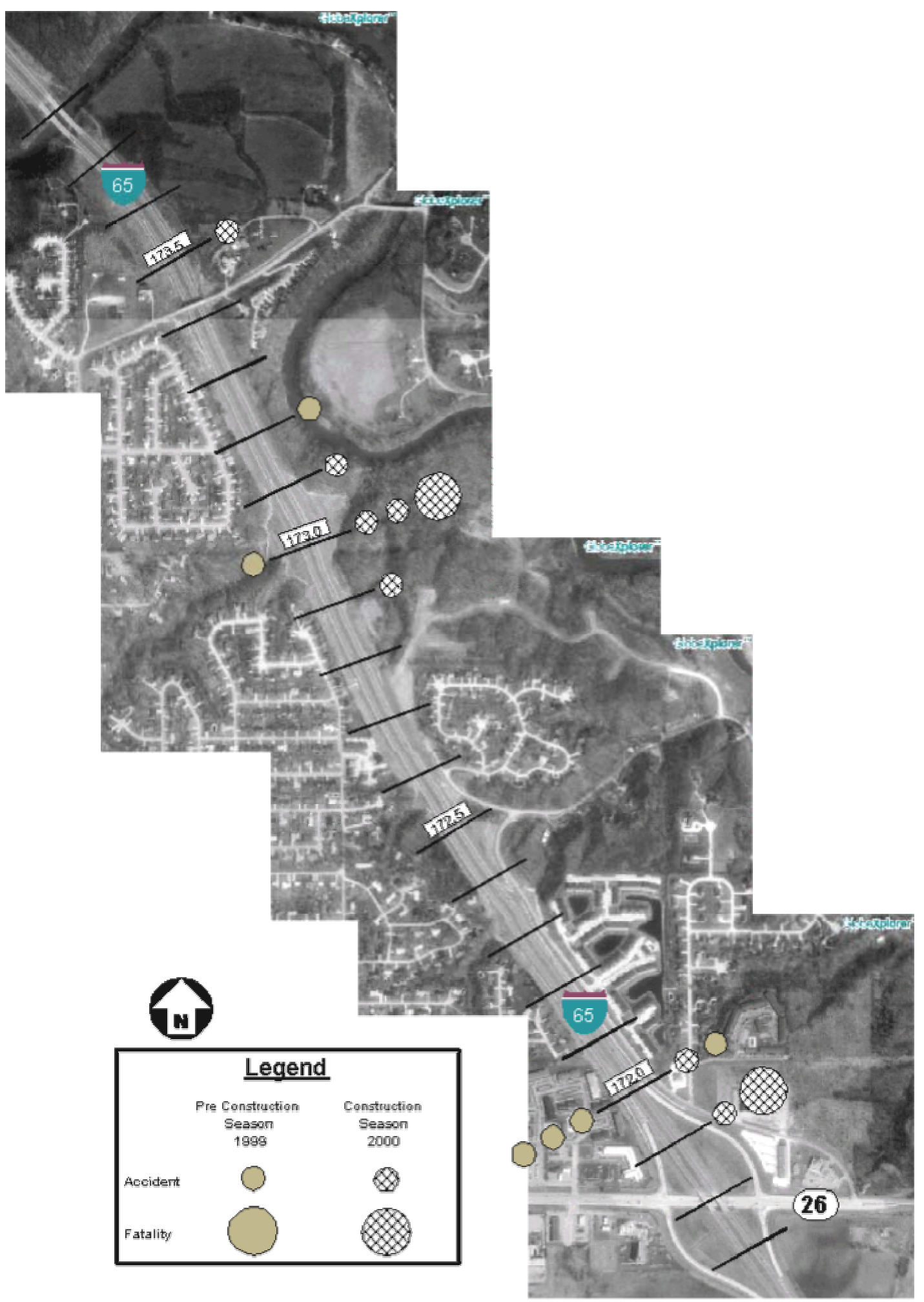

Figure 4-1 Interstate 65 from MP 172.0 to MP 173.5 


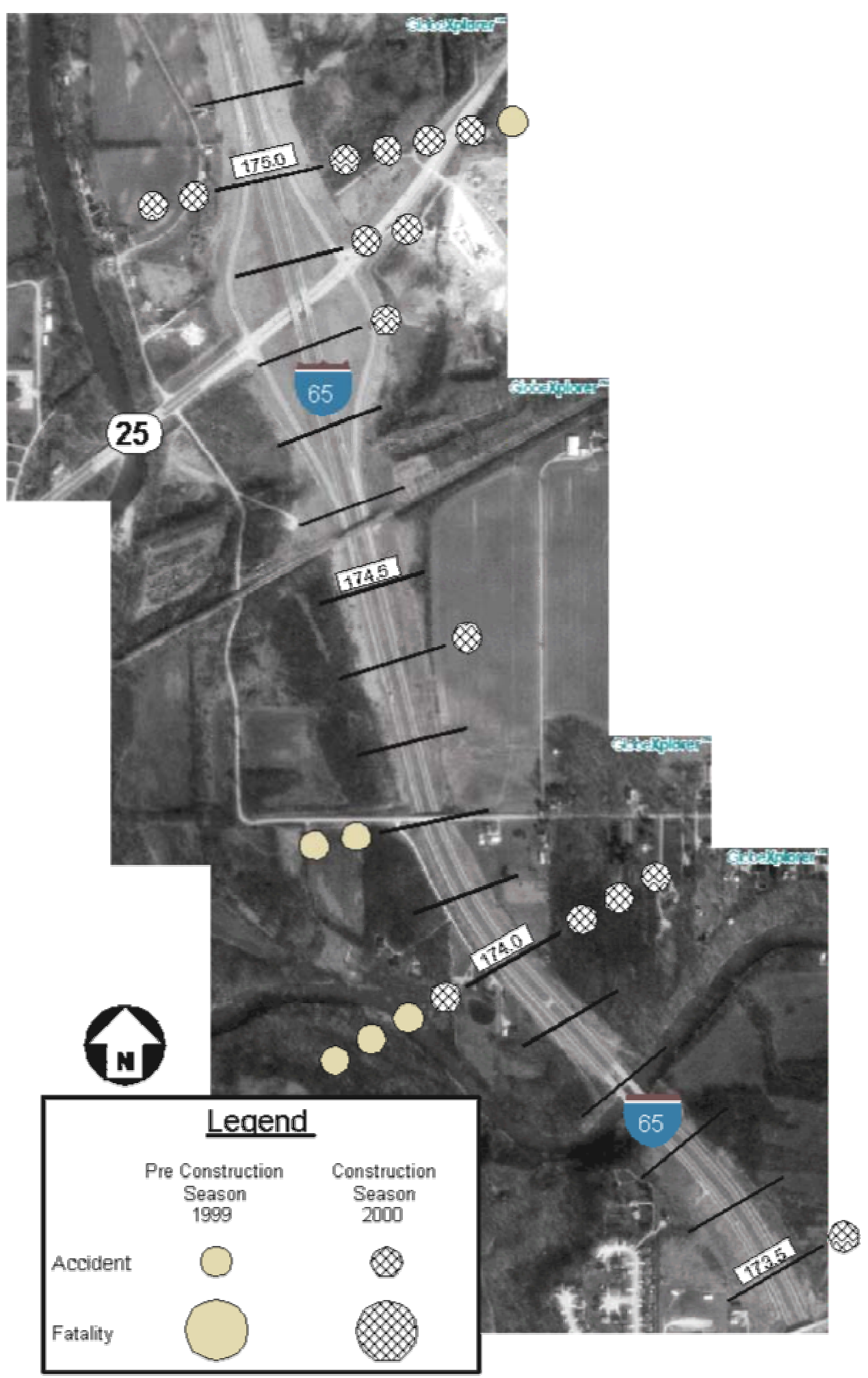

Figure 4-2 Interstate 65 from MP 173.5 to MP 175.0 


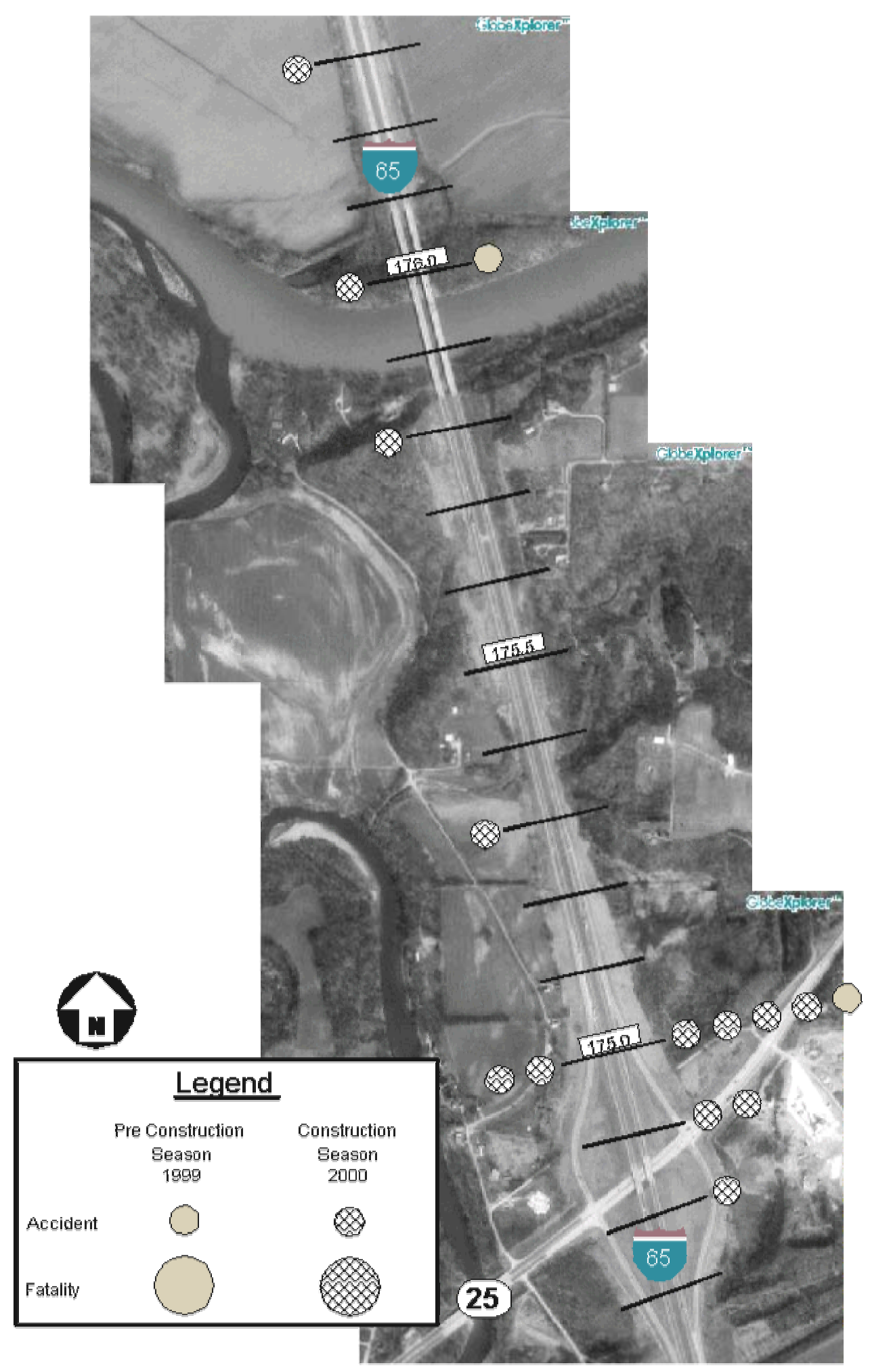

Figure 4-3 Interstate 65 from MP 175.0 to MP 176.5 


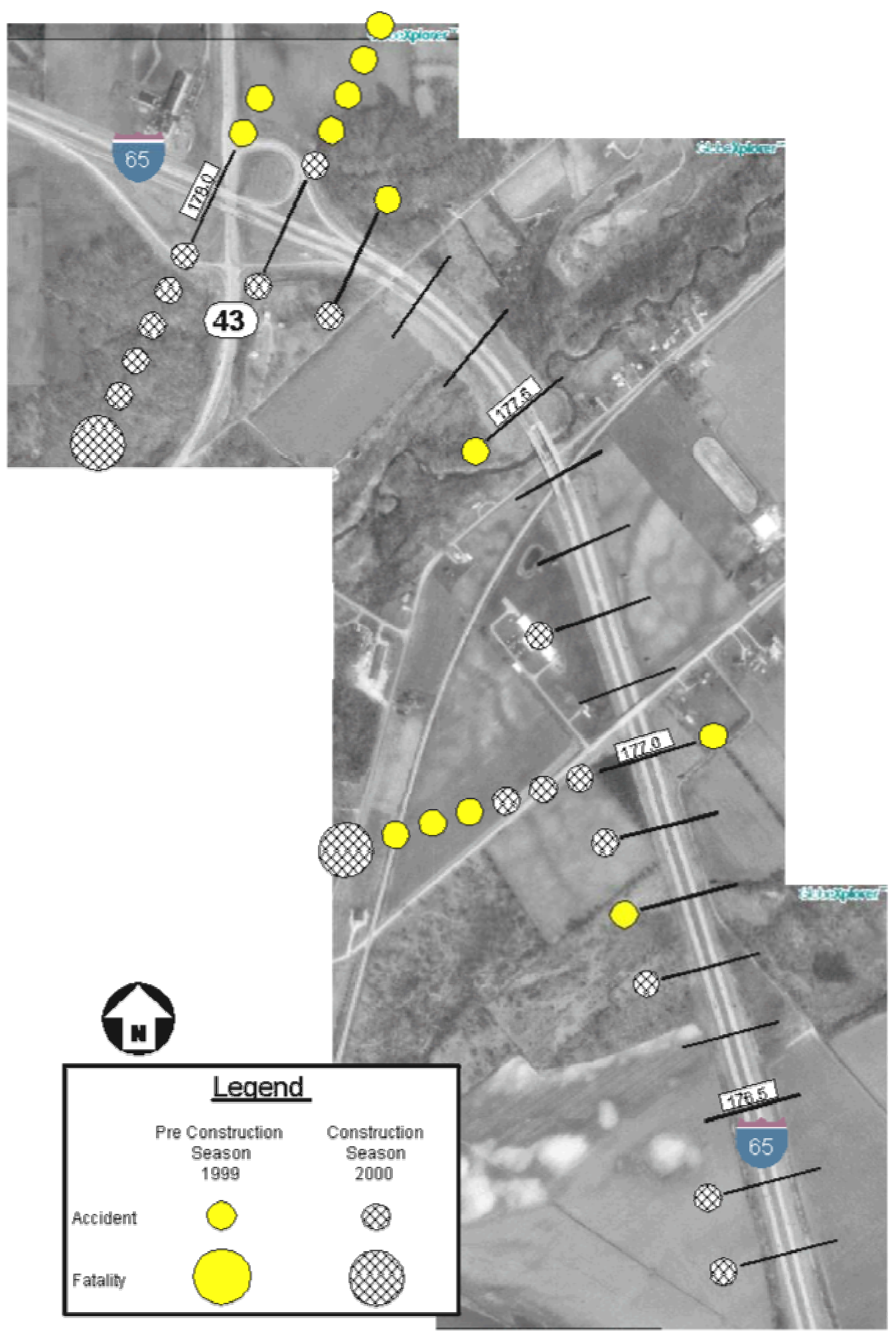

Figure 4-4 Interstate 65 from MP 176.5 to MP 178.0 


\section{3. $\quad \underline{\text { Results }}$}

To determine what affect a work zone has on a segment of interstate in Indiana, the number of crashes that occurred before and during a work zone, as found in Table 4-10, were compared. If a work zone had no effect on the crash rate of a given segment of interstate, a one-to-one relationship would exist between the number of accidents occurring before the construction and the number of accidents occurring during the construction. This is illustrated by the line $Y=1.0 X$ in Figure 4-5. Examination of the accident rates resulted in the discovery of an interesting trend, which can be seen in Figure 4-5. The dotted line in the figure is a regression line that represents the actual relationship between the accident rates of the "Before Construction" and the "During Construction" time periods. This line, represented by the equation $Y=1.275 X$, indicates that accident rates increase nearly thirty percent during the construction period. The $R^{2}$ value of 0.99 of this regression line indicates that the trend is uniform across all work zones in this study.

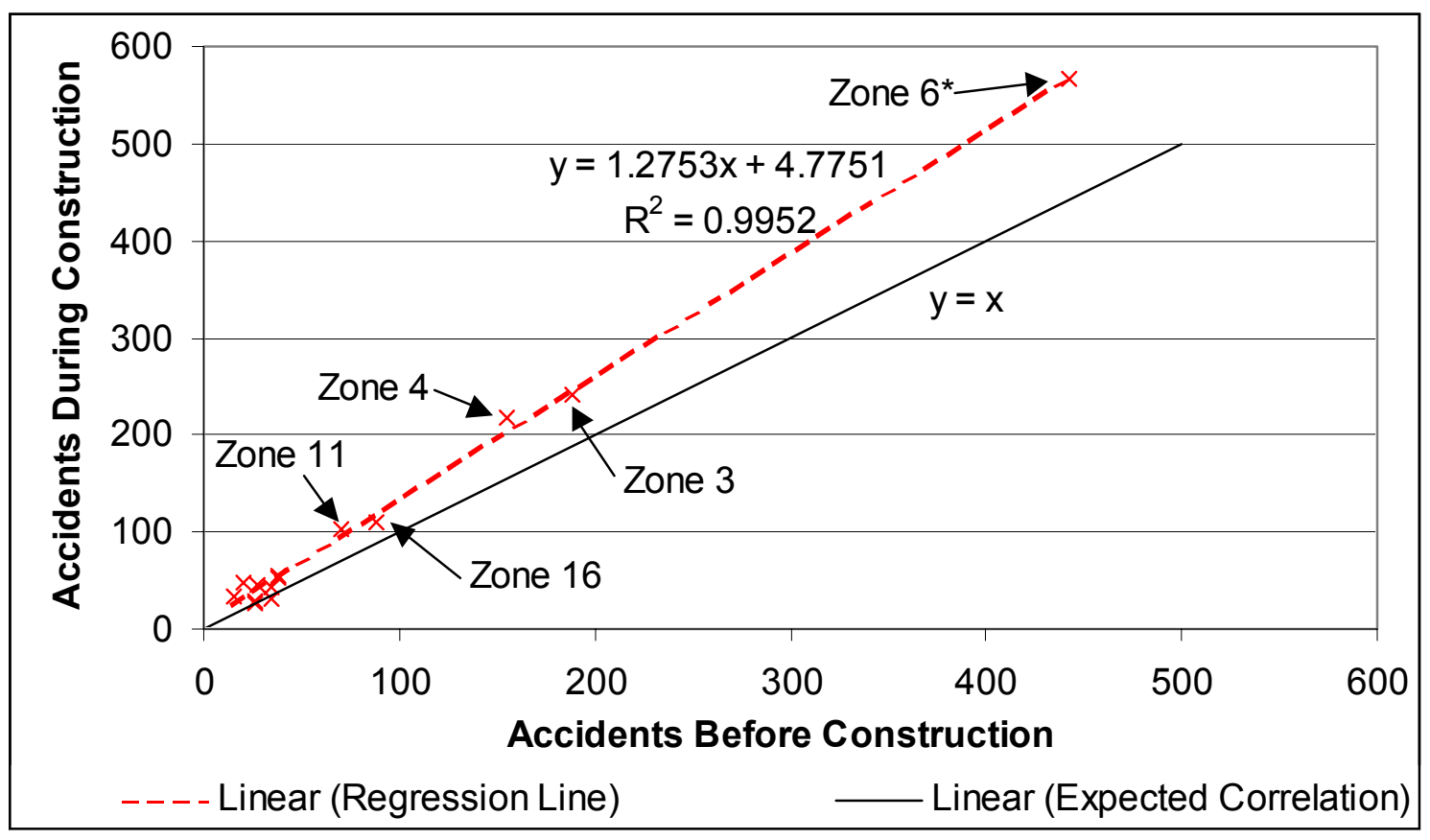

Figure 4-5 Accident Trends

The results of a similar study conducted at the University of New Mexico support this finding. The study examined nine interstate work zones from 1981 to 1984 and the increase in accidents that resulted from these work zones. To do so, the number of accidents occurring on a specific roadway sections during their construction were compared to the number of accidents occurring 
in the same sections for the same time period of the year prior to the construction. The study found that the number of accidents increased thirty three percent on rural interstates when construction was taking place (Hall and Lorenz 89).

A regression analysis was also performed for fatalities; however the results were not as profound. As seen in Figure 4-6, a regression line through the data showed the relationship between the fatality rates of the "Before Construction" and the "During Construction" time periods to be nearly one-to-one. This can be said with less certainty than that of the relationship between the accident rates because the regression coefficient of this regression line is considerably less $\left(R^{2}=0.59\right)$.

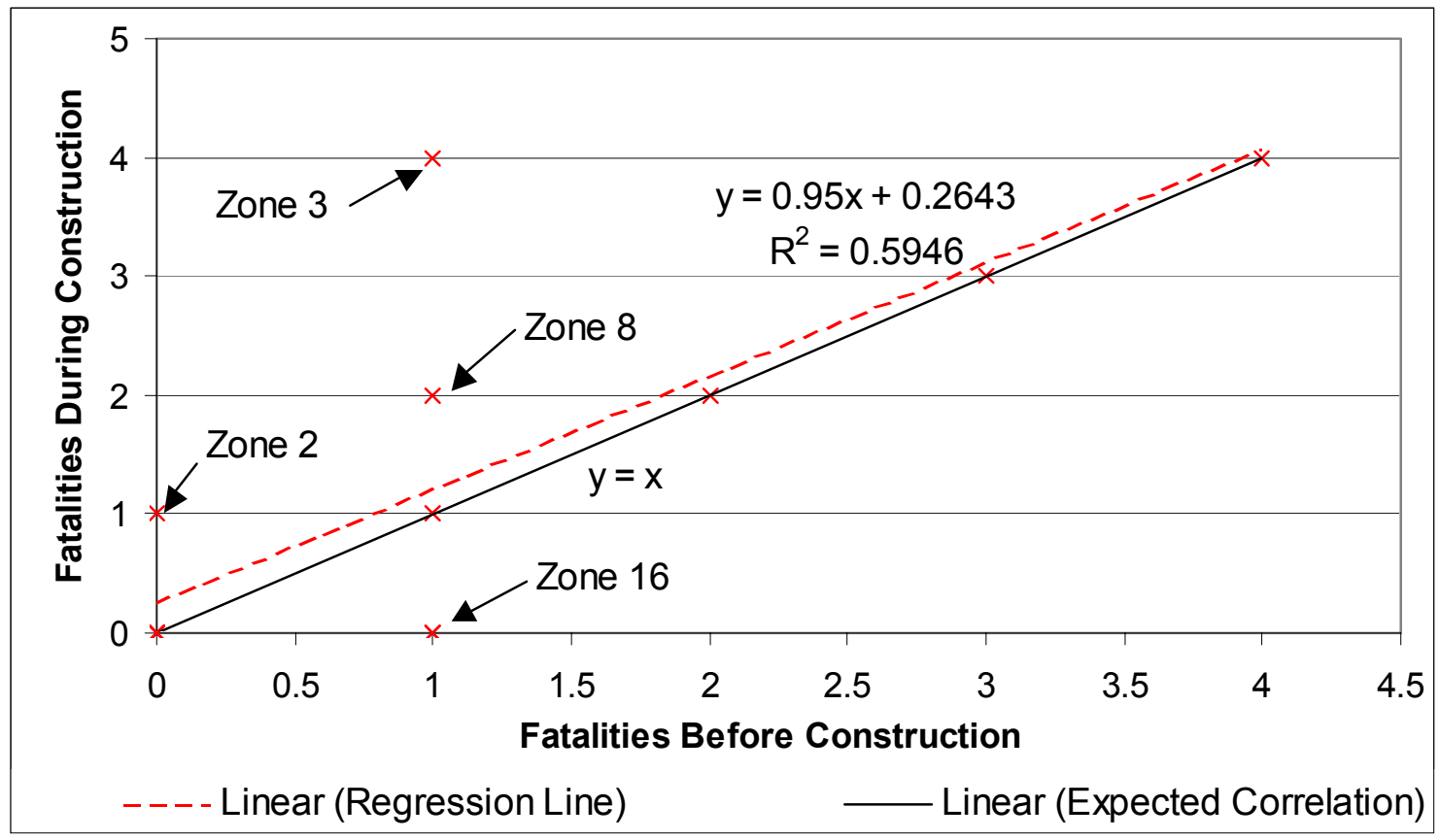

Figure 4-6 Fatality Trends

After the tabulation of these accident trends, the each individual project was examined in detail. Since none of the work zones included in this study were of equal length, a factor was needed so that the zones could be compared on an equal basis. It was decided that this factor should be the number of accidents per mile of study area. This variable, which can be found in Table 4-11, allowed all the zones to be compared on an equal basis. An important assumption made to perform this analysis was that the ADT of the section analyzed remained constant both before and during construction. These values were then plotted for both the "During Construction" and "Before Construction" periods. This plot can be found in Figure 4-7. The plot indicates that 
number of accidents per mile of study area remained nearly the same or increased when the work zone was present. The figure also shows a large difference in accident rates between Zone $6^{*}$ and the other zones for both time periods of the study.

Table 4-11 Accident Rates

\begin{tabular}{|l|l|l|l|l|l|l|}
\cline { 4 - 6 } \multicolumn{2}{c}{} & \multicolumn{2}{l}{ Ave. Daily Lane Volume } & \multicolumn{2}{l|}{ Accidents/ Mile of Study Area } \\
\hline Zone & Site & AADT & $\begin{array}{l}\text { Before } \\
\text { Construction }\end{array}$ & $\begin{array}{l}\text { During } \\
\text { Construction }\end{array}$ & $\begin{array}{l}\text { Before } \\
\text { Construction }\end{array}$ & $\begin{array}{l}\text { During } \\
\text { Construction }\end{array}$ \\
\hline 1 & I-65 & 45,840 & 11460 & 22920 & 3.2 & 3.9 \\
\hline 2 & I-65 & 42,940 & 10735 & 21470 & 1.4 & 3.3 \\
\hline 3 & I-65 & 32,987 & 8247 & 16494 & 6.7 & 8.6 \\
\hline 4 & I-65 & 26,050 & 6513 & 13025 & 6.4 & 9.0 \\
\hline $6^{*}$ & I-65 & 72,940 & 18235 & 36470 & 26.5 & 34.0 \\
\hline 7 & I-65 & 45,840 & 11460 & 22920 & 1.9 & 1.8 \\
\hline 8 & I-69 & 40,120 & 10030 & 20060 & 2.4 & 3.3 \\
\hline $9^{\star *}$ & $1-69$ & 30,570 & 7643 & 15285 & 0.4 & 0.3 \\
\hline 10 & I-69 & 26,559 & 6640 & 13280 & 1.6 & 1.8 \\
\hline 11 & I-69 & 22,230 & 5558 & 11115 & 3.3 & 4.7 \\
\hline 12 & I-69 & 22,236 & 5559 & 11118 & 1.4 & 2.2 \\
\hline 13 & I-69 & 19,890 & 4973 & 9945 & 2.1 & 3.0 \\
\hline 14 & I-70 & 24,830 & 6208 & 12415 & 1.2 & 2.8 \\
\hline 15 & I-70 & 24,830 & 6208 & 12415 & 1.9 & 1.9 \\
\hline 16 & I-70 & 36,320 & 9080 & 18160 & 6.1 & 7.6 \\
\hline
\end{tabular}

* Combined Zones $5 \& 6$ due to overlapping dates and limits

${ }^{* *}$ Not included in graphs due to distance between bridge rehabilitations 


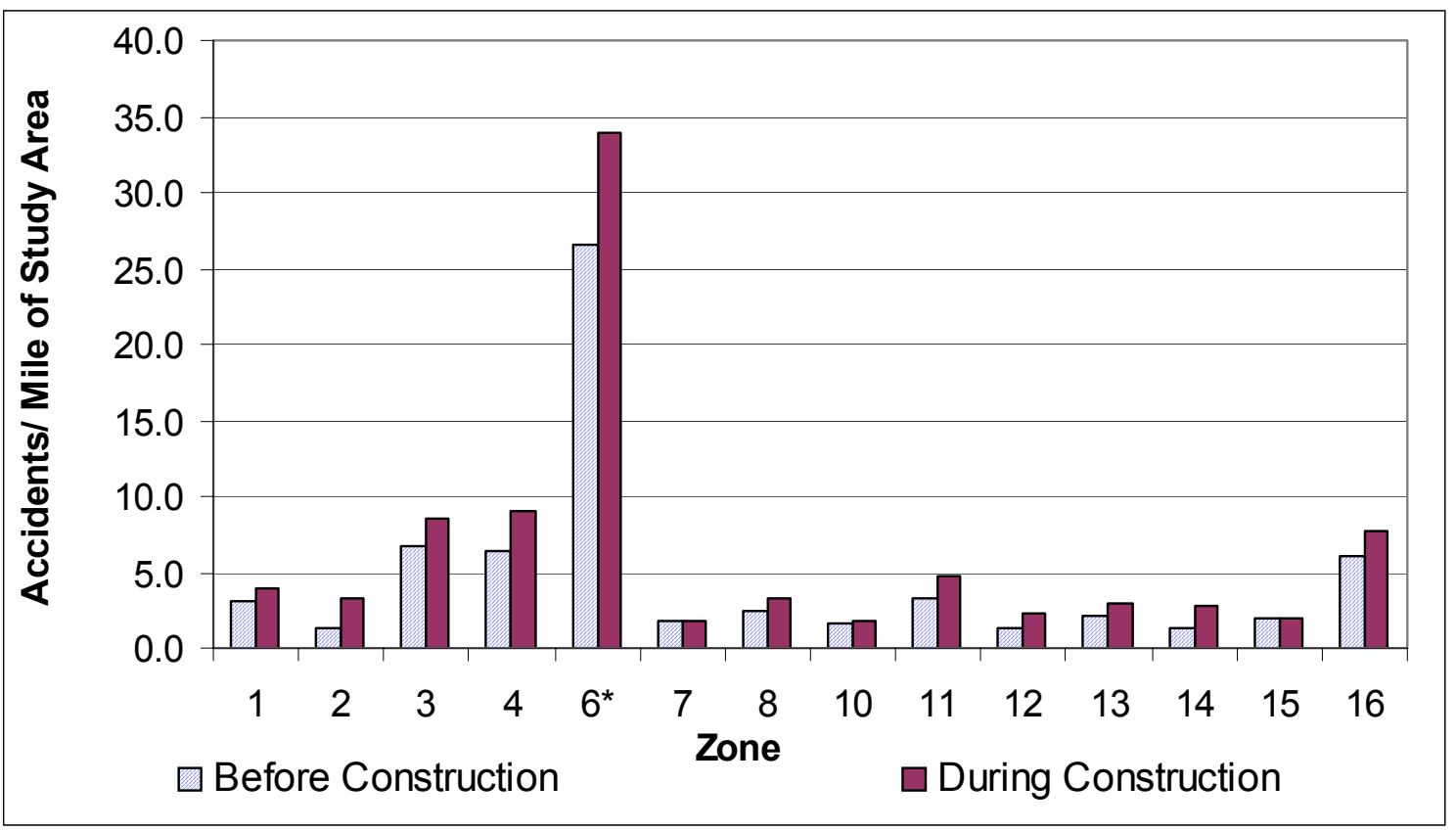

Figure 4-7 Accident Rates

It was believed that the high volume of traffic that passes through the Zone $6^{*}$ location might be linked to the greater than normal accident rates for this site. To test this hypothesis, lane volumes were calculated for each work zone. To calculate these lane volumes, the AADTs previously obtained from the Weigh in Motion stations and the INDOT website were used. Along with these AADTs came the assumption that the volume of traffic is equally distributed in each direction of travel. Based on this assumption, the number of vehicles traveling through a lane of a four lane interstate is one quarter of the AADT of the roadway. When a work zone is in place that limits the number of traveled lanes to one in each direction, the number of vehicles traveling through the work zone in a given lane is one-half of the AADT of the roadway. This procedure is illustrated in Figure 4-8. 

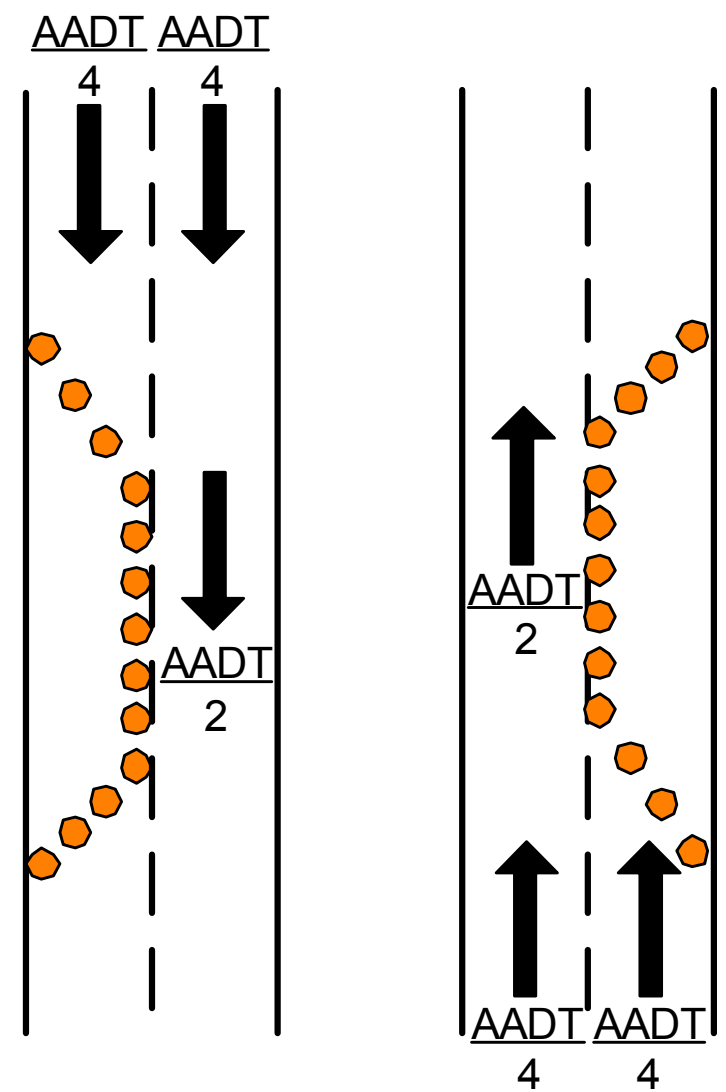

Figure 4-8 Lane Volume Calculations

The average daily lane volumes calculated in this manner can be found in Figure 4-8. These values were then plotted against the number of accidents per mile of study area for each zone, and can be found in Figure 4-9, Figure 4-10, and Figure 4-11. From these figures, it can be seen that the number of accidents per mile of study area increases as the lane volume increases. The figures also show that Zone $6^{*}$ is still appeared to be an outlier.

It is likely that Zone $6^{*}$ is not an outlier. The relationship between the number of accidents per mile and the lane volume may not be linear in nature, but instead may be parabolic or exponential. Such types of regression lines may lie near the data point that represents Zone $6^{*}$, indicating that this point is not actually an outlier. Due to the lack of data points in the analysis, no such trend line can be found that would support this hypothesis. 


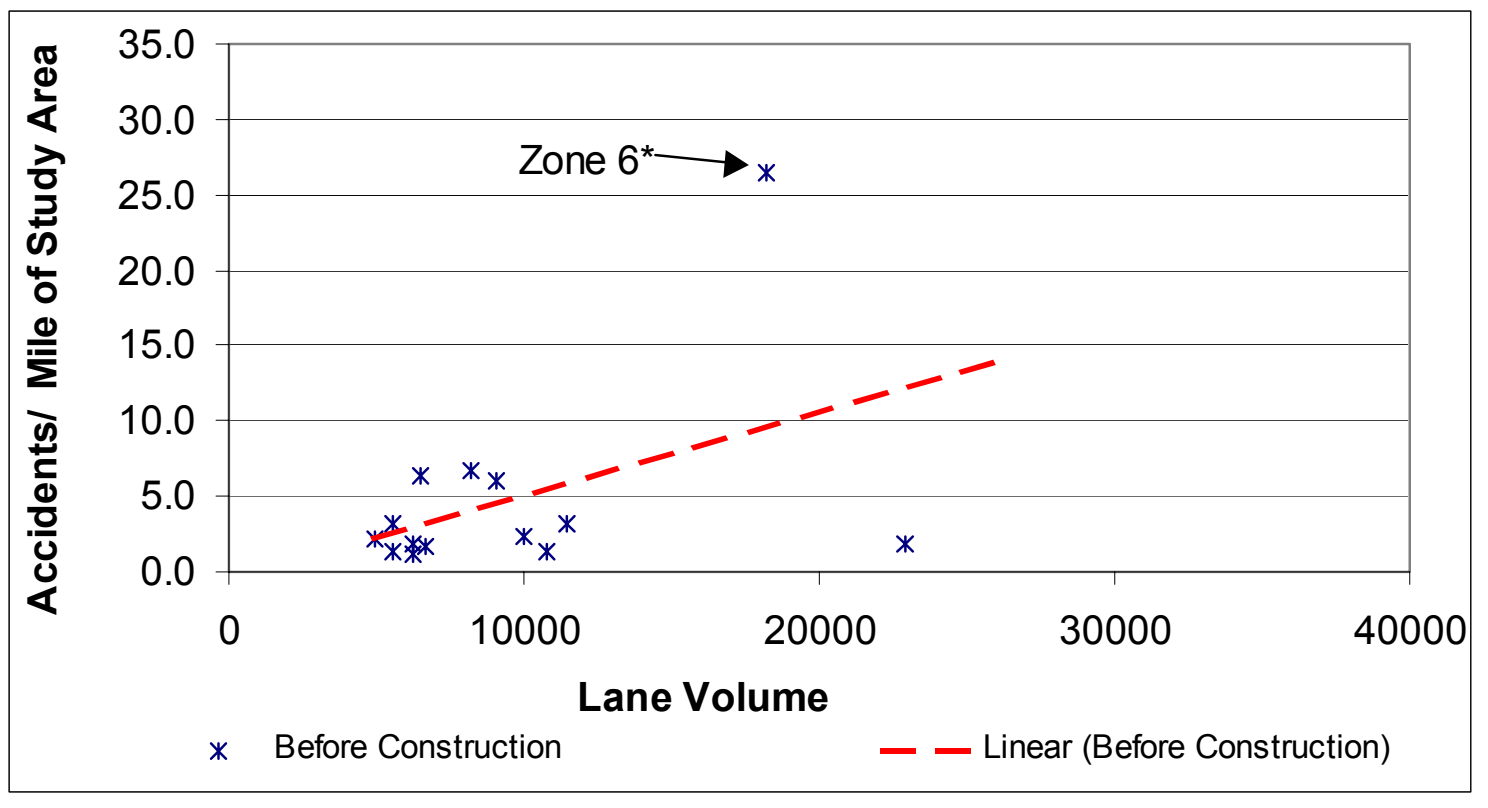

Figure 4-9 Before Construction Accident Rate Trends

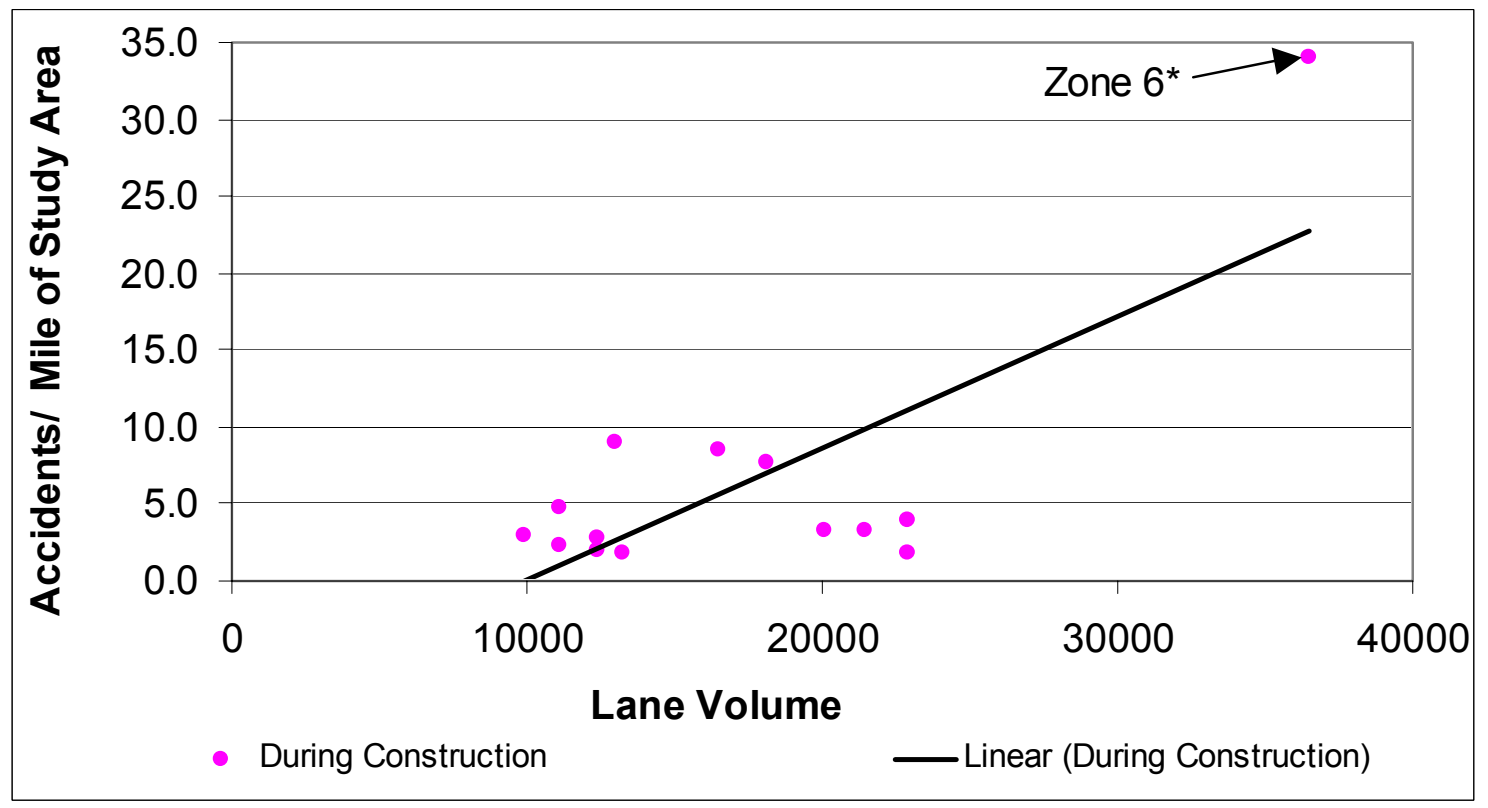

Figure 4-10 During Construction Accident Rate Trends 


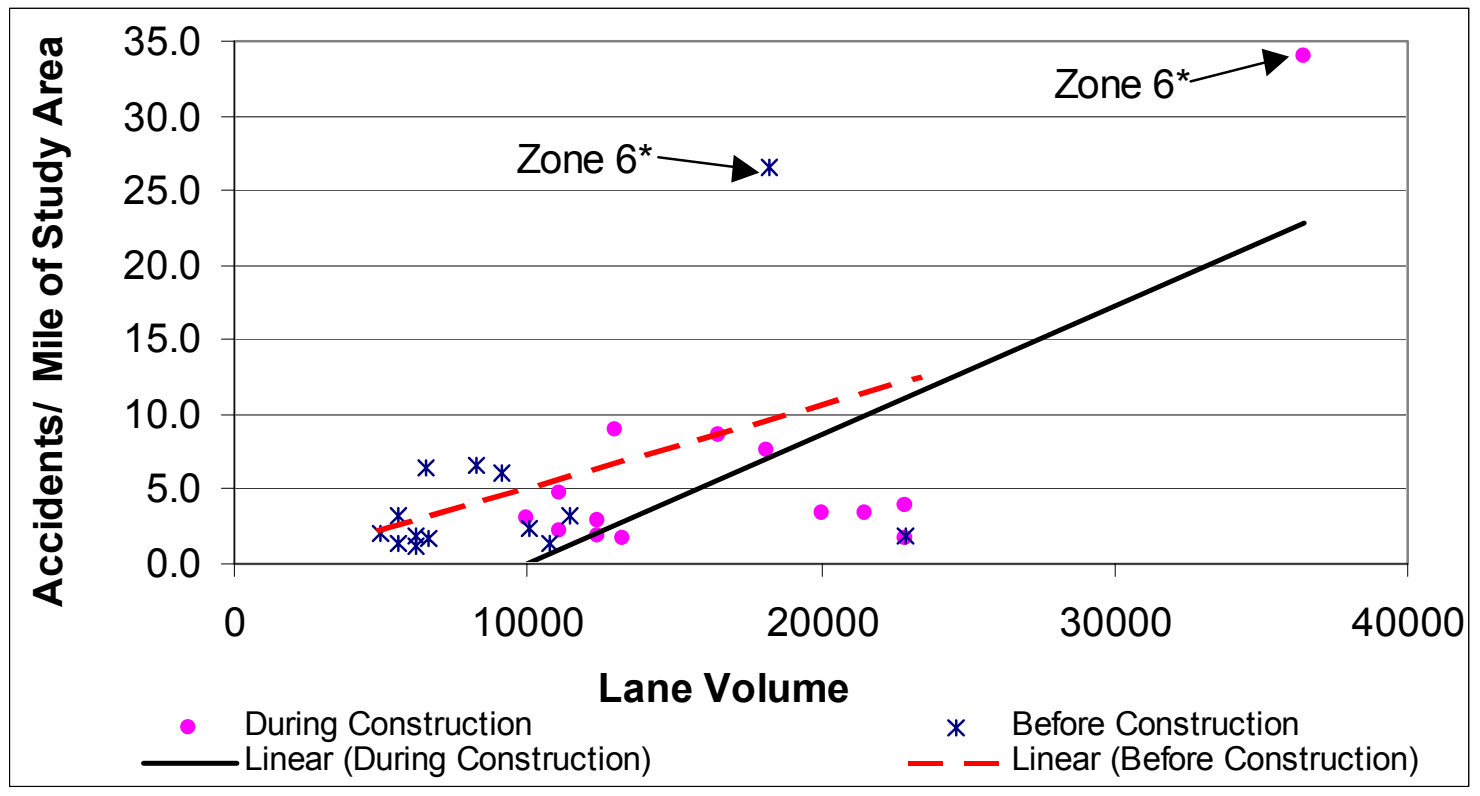

Figure 4-11 Accident Rate Trends - Before and After Construction

In an effort to adjust the data such that Zone $6^{*}$ was no longer an outlier, the number of accidents per month per mile of study area was computed for each zone. These values, which can be found in Table 4-12, were then plotted against the lane volume of their respective work zone location. These plots, found in Figure 4-12, Figure 4-13 and Figure 4-14, indicate use of the monthly accident rate results in Zone $6^{*}$ being less of an outlier. 
Table 4-12 Monthly Accident Rates

\begin{tabular}{|c|c|c|c|}
\cline { 3 - 4 } \multicolumn{2}{c|}{} & \multicolumn{2}{c|}{ Accidents/ Mile/ Month } \\
\hline Zone & Site & $\begin{array}{c}\text { Before } \\
\text { Construction }\end{array}$ & $\begin{array}{c}\text { During } \\
\text { Construction }\end{array}$ \\
\hline \hline 1 & $\mathrm{I}-65$ & 0.24 & 0.30 \\
\hline 2 & $\mathrm{I}-65$ & 0.28 & 0.67 \\
\hline 3 & $\mathrm{I}-65$ & 0.36 & 0.46 \\
\hline 4 & $\mathrm{I}-65$ & 0.30 & 0.43 \\
\hline $6^{*}$ & $\mathrm{I}-65$ & 0.97 & 1.25 \\
\hline 7 & $\mathrm{I}-65$ & 0.53 & 0.50 \\
\hline 8 & $\mathrm{I}-69$ & 0.65 & 0.90 \\
\hline $9^{* *}$ & $\mathrm{I}-69$ & 0.15 & 0.11 \\
\hline 10 & $\mathrm{I}-69$ & 0.21 & 0.23 \\
\hline 11 & $\mathrm{I}-69$ & 0.26 & 0.39 \\
\hline 12 & $\mathrm{I}-69$ & 0.16 & 0.25 \\
\hline 13 & $\mathrm{I}-69$ & 0.31 & 0.45 \\
\hline 14 & $\mathrm{I}-70$ & 0.40 & 0.91 \\
\hline 15 & $\mathrm{I}-70$ & 0.49 & 0.49 \\
\hline 16 & $\mathrm{I}-70$ & 0.52 & 0.65 \\
\hline
\end{tabular}

* Combined Zones 5 \& 6 due to overlapping dates and limits

** Not included in graphs due to distance between bridge rehabilitations

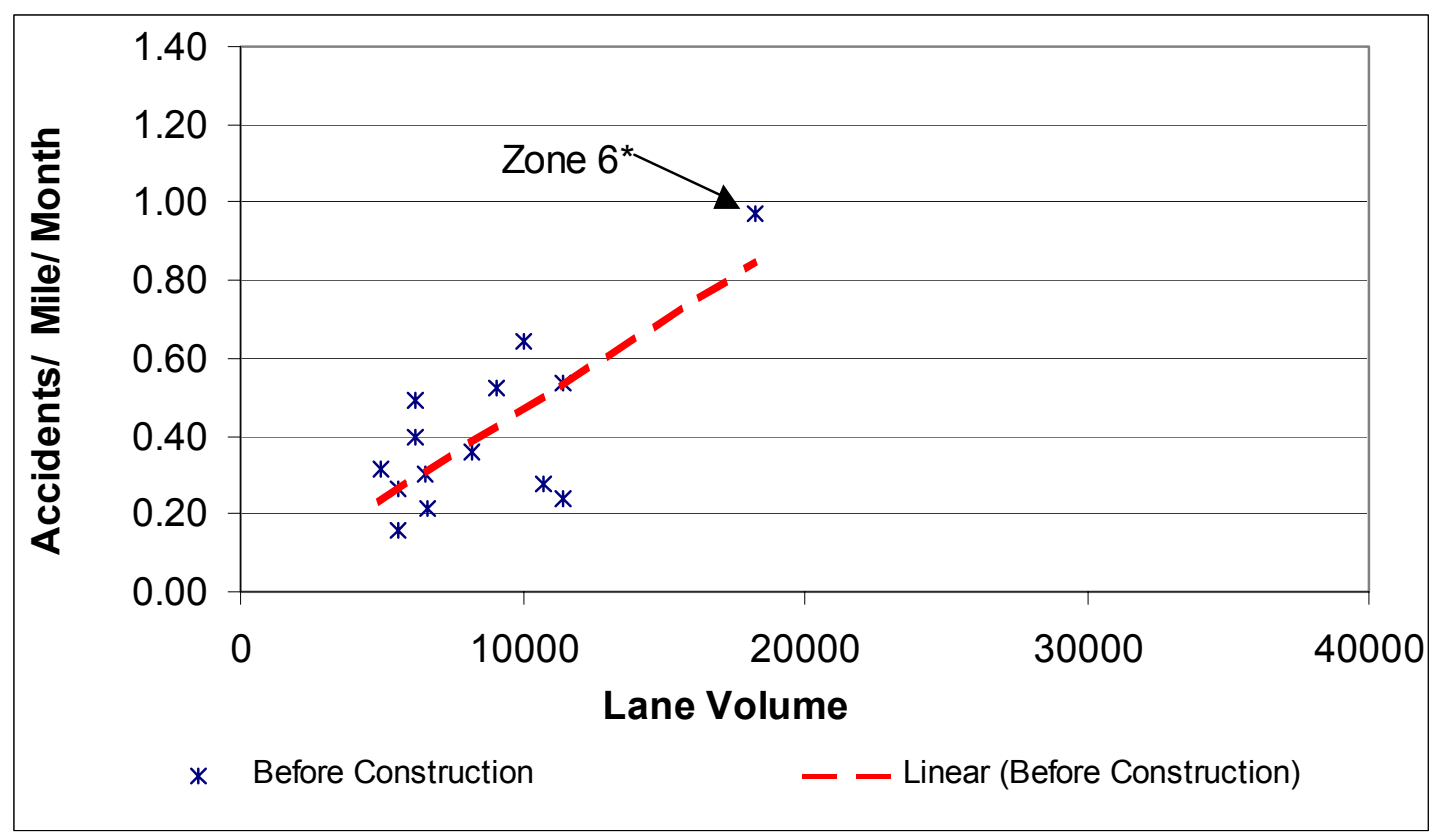

Figure 4-12 Before Construction Monthly Accident Rate Trends 


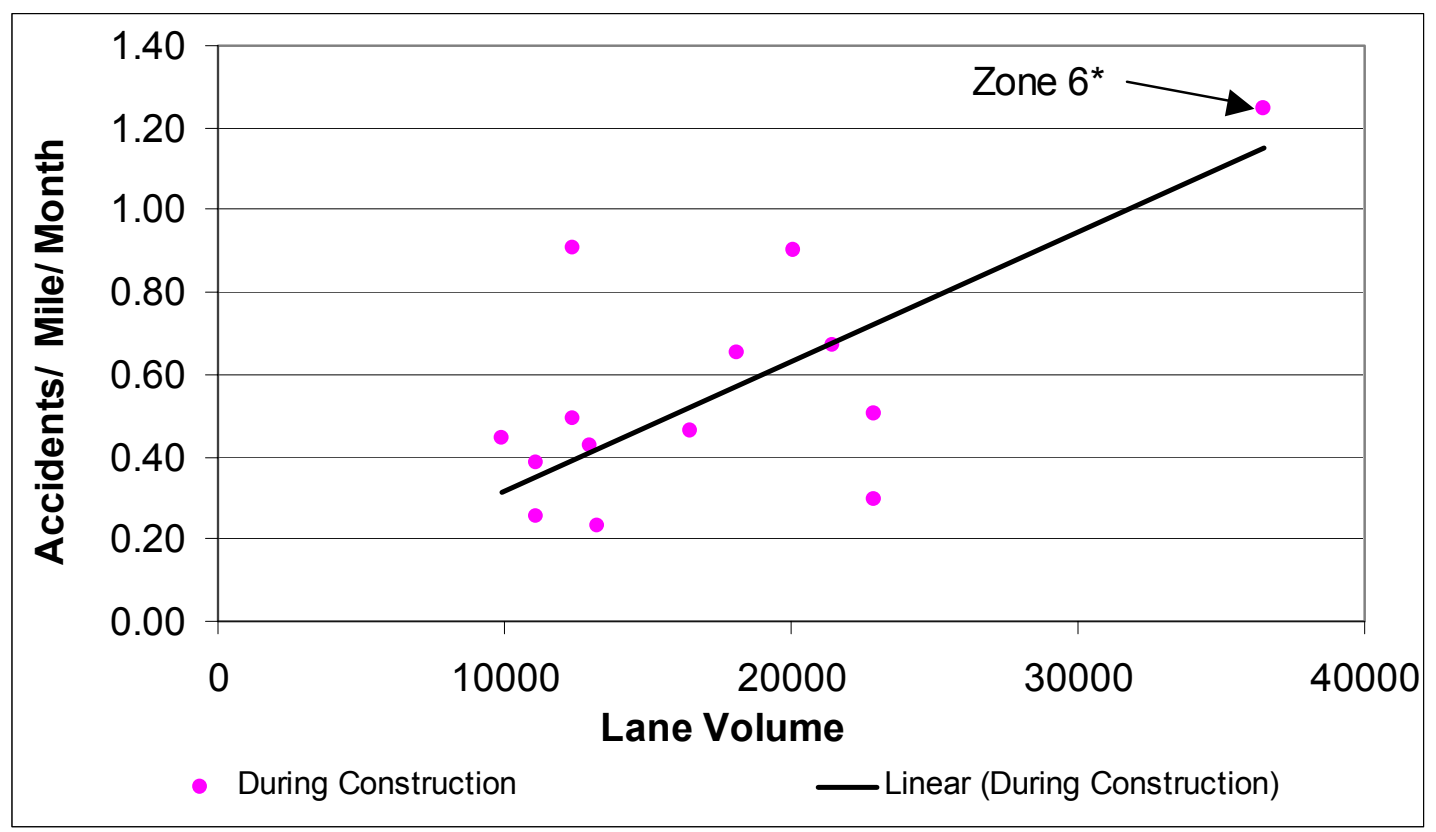

Figure 4-13 During Construction Monthly Accident Rate Trends

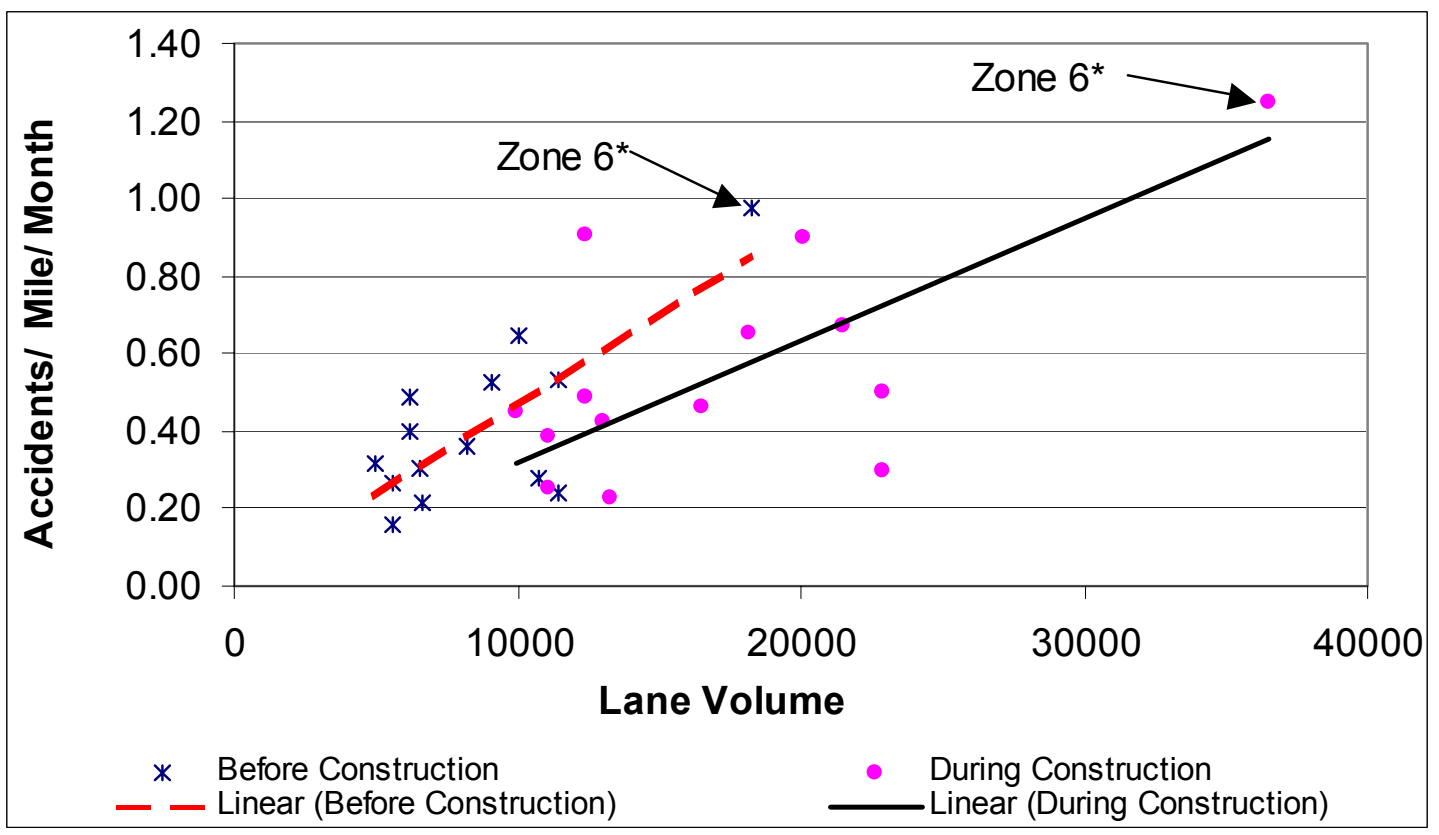

Figure 4-14 Monthly Accident Rate Trends 


\section{4. $\quad$ Comparison With Virginia}

As previously discussed, states other than Indiana have had accident-prone work zones. Virginia is one state that has also experienced these types of problems. For instance, between the years of 1996 and 2000, the state of Virginia had numerous accidents in their interstate work zones. As a result of these accidents, a study was conducted at the University of Virginia to determine a way to reduce the frequency and severity of these accidents (Garber 2001). The study found that an overwhelming majority of the accidents occurred within the work zone. When the accidents that were related to Indiana work zones were examined, it was found that a majority of the accidents occurred in the areas approaching the work zone. The number of accidents that occurred in each state can be found in Table 4-13. A comparison of accidents between the two states can be found in Figure 4-15 and Figure 4-16.

Table 4-13 Accident Locations 1996 to 2000

\begin{tabular}{|l|c|c|c|c|}
\cline { 2 - 5 } \multicolumn{1}{c|}{} & \multicolumn{2}{c|}{ Indiana } & \multicolumn{2}{c|}{ Virginia } \\
\hline WZ Location & $\begin{array}{c}\text { \# of } \\
\text { Fatalities }\end{array}$ & $\begin{array}{c}\text { \# of } \\
\text { Accidents }\end{array}$ & $\begin{array}{c}\text { \# of } \\
\text { Fatalities }\end{array}$ & $\begin{array}{c}\text { \# of } \\
\text { Accidents }\end{array}$ \\
\hline \hline Advanced Warning Area & 5 & 945 & 0 & 66 \\
\hline Inside Work Zone & 8 & 731 & 10 & 627 \\
\hline
\end{tabular}

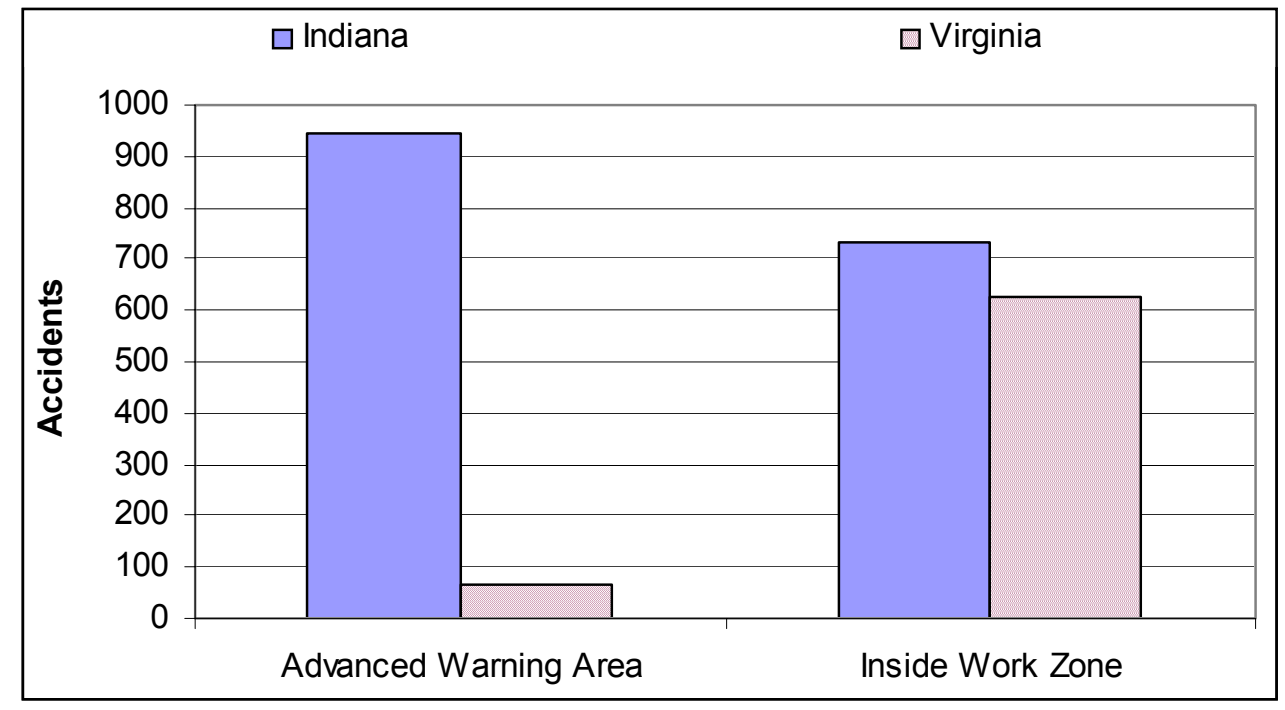

Figure 4-15 Accident Locations 1996 to 2000 


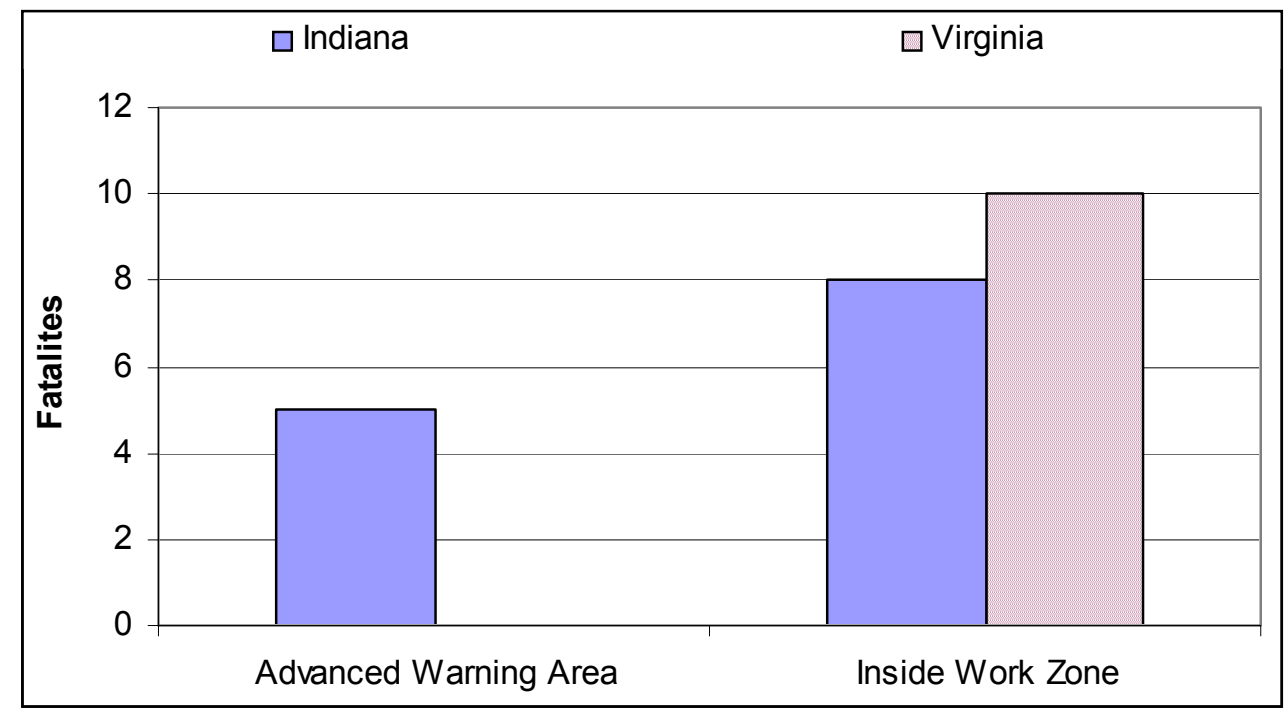

Figure 4-16 Accident Locations 1996 to 2000

From the results of the study performed at the University of Virginia it may appear that Virginia has much safer work zones than Indiana. However, this is not necessarily the case. Crash records for each study were collected in different manners. One difference is that both the number and type of work zones was known in this study, while this information was not available for the study conducted at the University of Virginia.

Another difference is the way in which the crash records were dealt with. The study of Virginia work zones simply relied on crash reports to indicate when an accident occurred inside or on the approach to a work zone. This method of determining if a work zone is present is subjective because the officer may not be aware of the work zone ahead. Also, the investigating officer may feel that the work zone did not play a role in the crash and will not indicate that a work zone is present. For these reasons, the locations of accidents were compared to the locations of work zones in this study. This method disregards the subjectivity of the police reports and allows the investigators to determine if the crash occurred in the advanced warning area, the work zone or outside of the study area. 


\section{CHAPTER 5. TEST PILOT PROJECT (I-65 NEAR MERRILLVILLE, IN)}

\section{1. $\quad$ Project Description}

To test the effectiveness of the series of signs developed by the research team, a construction project for the 2002 construction was needed. The project studied required significant lane closures and a high volume of traffic that would travel through the area. It was believed that these two characteristics would result in lengthy queues and have the potential for a high number of work zone related accidents. After a detailed study of all Indiana interstate projects with significant lane closures for the 2002 construction season, it was determined that the reconstruction of the I-65/ US 30 interchange at milepost 253 would be an acceptable location for the implementation of a series of signs aimed at reducing the number of rear end collisions.

During the reconstruction of this interchange, two lanes of traffic would remain operational while additional lanes were added in the median and the original roadway was reconstructed. To maintain two operational lanes in both directions, it was necessary to perform several shifts of traffic. Accompanied with these shifts would be a lane reduction on the southbound lanes of I-65

\section{2. $\quad$ Project Location Queuing Analysis}

\subsubsection{Methodology}

In order to effectively manage traffic flowing through a work zone, it is important to estimate the maximum length of queue that can be expected. The queue length is vital to the proposed traffic management plan because it aids in the placement of signs that warn drivers that a work zone is approaching and to expect slowed or stopped traffic. Queues that reach beyond warning signs result in motorist unexpectedly approaching the back of a queue. Such an occurrence is undesirable and is likely to increase the frequency of rear-end collisions. For this reason, the first step in developing a system of signs to alert drivers of the conditions ahead was to develop a model that would predict the maximum length of a queue. This queue length can be obtained 
from hourly counts taken on the roadway. Such counts can be obtained relatively easily though the use of an Automated Traffic Recording Station (ATR) or temporary tubes. With this data, a deterministic queuing model can be run (May 90).

The counts for I-65 near Merrillville, Indiana were obtained from a nearby Weigh-In-Motion station. The station is located to the north of the US 30 interchange, at milepost 253.6 on I-65, as illustrated in Figure 5-1. No other interchanges lie between the WIM station and the US 30 interchange, and therefore the counts do not need to be adjusted for vehicles entering or exiting the interstate in this area. The data provided directional hourly volumes, daily directional volumes and directional percentages of all FHWA vehicle classes. Once the directional hourly counts were obtained, the counts were used to establish hourly arrival rates for both the northbound and southbound approaches to the work zone as shown in column two of Table 5-1 and Table 5-2 respectively. 


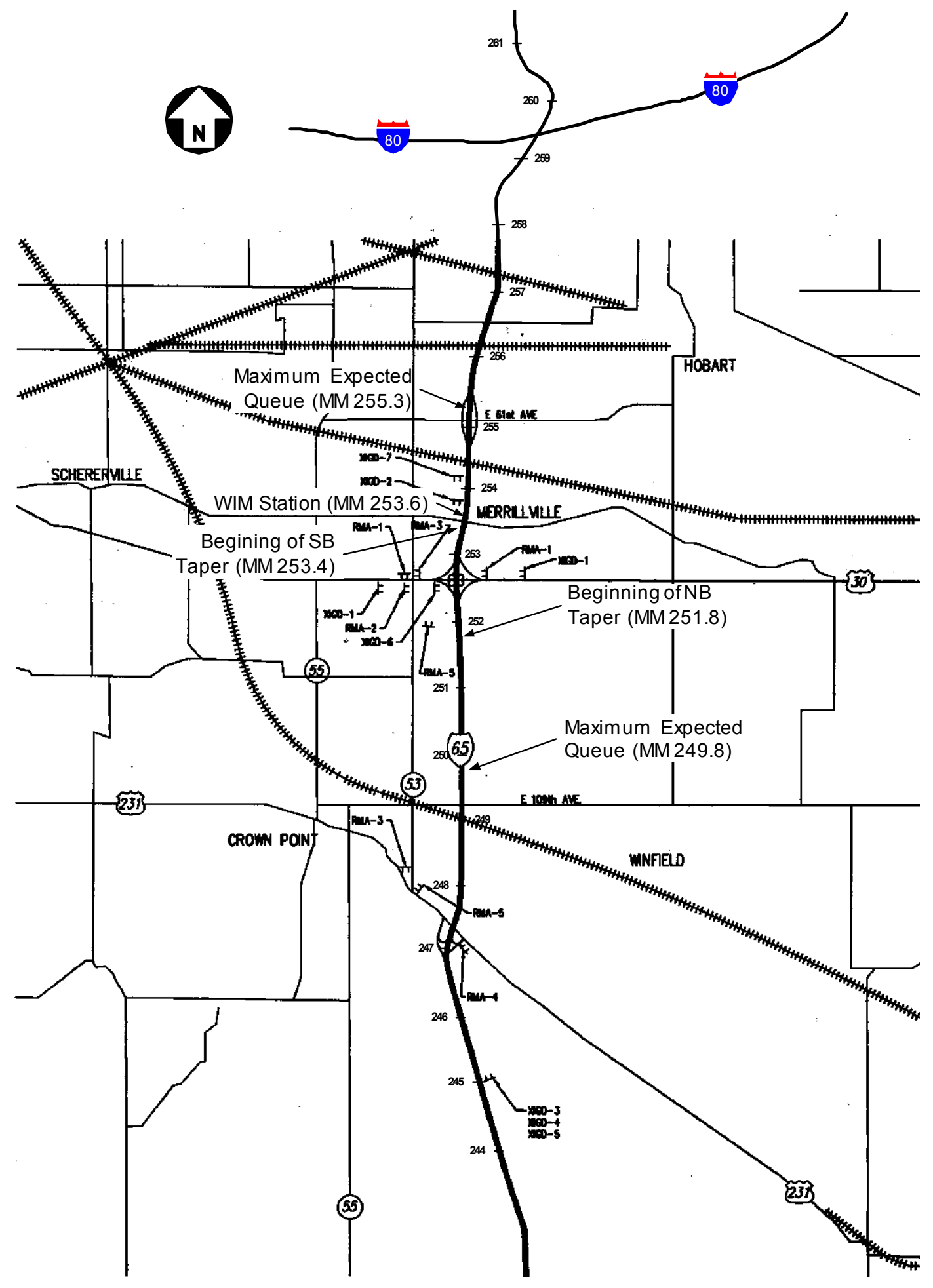

Figure 5-1 Locations of Maximum Expected Queues 
Table 5-1 I-65 Northbound, One Lane Operational

\begin{tabular}{|c|c|c|c|c|c|c|c|}
\hline \multirow{2}{*}{ Hour } & \multirow{2}{*}{$\begin{array}{l}\text { Arrival } \\
\text { Rate }\end{array}$} & \begin{tabular}{|c|} 
Dep. Rate $=$ \\
$1300 \mathrm{vpl}$ \\
\end{tabular} & \begin{tabular}{|c|} 
Dep. Rate $=$ \\
$1400 \mathrm{vpl}$ \\
\end{tabular} & \begin{tabular}{|c|} 
Dep. Rate $=$ \\
$1600 \mathrm{vpl}$ \\
\end{tabular} & \begin{tabular}{|c|} 
Dep. Rate $=$ \\
$1800 \mathrm{vpl}$ \\
\end{tabular} & \begin{tabular}{|c|} 
Dep. Rate $=$ \\
$2000 \mathrm{vpl}$ \\
\end{tabular} & \begin{tabular}{|c} 
Dep. Rate $=$ \\
$2200 \mathrm{vpl}$ \\
\end{tabular} \\
\hline & & $\begin{array}{c}\text { Queue } \\
\text { Length (mi) }\end{array}$ & $\begin{array}{c}\text { Queue } \\
\text { Length (mi) }\end{array}$ & $\begin{array}{c}\text { Queue } \\
\text { Length (mi) }\end{array}$ & $\begin{array}{c}\text { Queue } \\
\text { Length (mi) }\end{array}$ & $\begin{array}{c}\text { Queue } \\
\text { Length (mi) }\end{array}$ & $\begin{array}{c}\text { Queue } \\
\text { Length (mi) }\end{array}$ \\
\hline$\overline{\overline{1}}$ & $\overline{5554}$ & 0.0 & 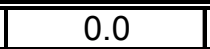 & 0.0 & 0.0 & 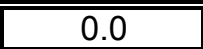 & 0.0 \\
\hline 2 & 391 & 0.0 & 0.0 & 0.0 & 0.0 & 0.0 & 0.0 \\
\hline 3 & 434 & 0.0 & 0.0 & 0.0 & 0.0 & 0.0 & 0.0 \\
\hline 4 & 544 & 0.0 & 0.0 & 0.0 & 0.0 & 0.0 & 0.0 \\
\hline 5 & 895 & 0.0 & 0.0 & 0.0 & 0.0 & 0.0 & 0.0 \\
\hline 6 & 2005 & 2.5 & 2.2 & 1.4 & 0.7 & 0.0 & 0.0 \\
\hline 7 & 3024 & 8.7 & 8.0 & 6.5 & 5.1 & 3.7 & 2.9 \\
\hline 8 & 2734 & 13.8 & 12.7 & 10.6 & 8.4 & 6.3 & 4.9 \\
\hline 9 & 1963 & 16.2 & 14.7 & 11.9 & 9.0 & 6.2 & 4.0 \\
\hline 10 & 1812 & 18.0 & 16.2 & 12.6 & 9.1 & 5.5 & 2.6 \\
\hline 11 & 1763 & 19.6 & 17.5 & 13.2 & 8.9 & 4.6 & 1.1 \\
\hline 12 & 1743 & 21.2 & 18.7 & 13.7 & 8.7 & 3.7 & 0.0 \\
\hline 13 & 607 & 18.8 & 15.9 & 10.2 & 4.5 & 0.0 & 0.0 \\
\hline 14 & 1269 & 18.6 & 15.4 & 9.0 & 2.6 & 0.0 & 0.0 \\
\hline 15 & 2072 & 21.4 & 17.8 & 10.7 & 3.5 & 0.3 & 0.0 \\
\hline 16 & 2293 & 24.9 & 21.0 & 13.2 & 5.3 & 1.3 & 0.3 \\
\hline 17 & 2334 & 28.6 & 24.4 & 15.8 & 7.2 & 2.5 & 0.8 \\
\hline 18 & 2514 & 33.0 & 28.3 & 19.0 & 9.8 & 4.3 & 1.9 \\
\hline 19 & 2688 & 37.9 & 32.9 & 22.9 & 12.9 & 6.8 & 3.7 \\
\hline 20 & 2148 & 41.0 & 35.6 & 24.9 & 14.2 & 7.3 & 3.5 \\
\hline 21 & 1725 & 42.5 & 36.8 & 25.3 & 13.9 & 6.3 & 1.8 \\
\hline 22 & 1564 & 43.4 & 37.4 & 25.2 & 13.1 & 4.8 & 0.0 \\
\hline 23 & 1686 & 44.8 & 38.4 & 25.5 & 12.7 & 3.7 & 0.0 \\
\hline 24 & 1128 & 44.2 & 37.4 & 23.8 & 10.3 & 0.5 & 0.0 \\
\hline 25 & 554 & 41.5 & 34.4 & 20.1 & 5.8 & 0.0 & 0.0 \\
\hline 26 & 391 & 38.3 & 30.8 & 15.8 & 0.8 & 0.0 & 0.0 \\
\hline 27 & 434 & 35.2 & 27.3 & 11.6 & 0.0 & 0.0 & 0.0 \\
\hline 28 & 544 & 32.5 & 24.3 & 7.8 & 0.0 & 0.0 & 0.0 \\
\hline 29 & 895 & 31.0 * & $22.5^{*}$ & $5.3^{*}$ & 0.0 & 0.0 & 0.0 \\
\hline
\end{tabular}


Table 5-2 I-65 Southbound, One Lane Operational

\begin{tabular}{|c|c|c|c|c|c|c|c|}
\hline \multirow{2}{*}{ Hour } & \multirow{2}{*}{$\begin{array}{l}\text { Arrival } \\
\text { Rate }\end{array}$} & $\begin{array}{c}\text { Dep. Rate = } \\
1300 \mathrm{vpl}\end{array}$ & \begin{tabular}{|c} 
Dep. Rate $=$ \\
$1400 \mathrm{vpl}$
\end{tabular} & \begin{tabular}{|c|} 
Dep. Rate $=$ \\
$1600 \mathrm{vpl}$ \\
\end{tabular} & \begin{tabular}{|c|}
$\begin{array}{c}\text { Dep. } \text { Rate } \\
1800 \mathrm{vpl}\end{array}$ \\
\end{tabular} & \begin{tabular}{|c|} 
Dep. Rate $=$ \\
$2000 \mathrm{vpl}$ \\
\end{tabular} & \begin{tabular}{|c} 
Dep. Rate $=$ \\
$2200 \mathrm{vpl}$ \\
\end{tabular} \\
\hline & & $\begin{array}{c}\text { Queue } \\
\text { Length (mi) }\end{array}$ & $\begin{array}{c}\text { Queue } \\
\text { Length (mi) }\end{array}$ & \begin{tabular}{|c|} 
Queue \\
Length (mi)
\end{tabular} & $\begin{array}{c}\text { Queue } \\
\text { Length }(\mathrm{mi})\end{array}$ & $\begin{array}{c}\text { Queue } \\
\text { Length (mi) }\end{array}$ & $\begin{array}{c}\text { Queue } \\
\text { Length (mi) }\end{array}$ \\
\hline 1 & 645 & $\overline{0.0}$ & $\overline{0.0}$ & 0.0 & 0.0 & $\overline{0.0}$ & $\overline{0.0}$ \\
\hline 2 & 455 & 0.0 & 0.0 & 0.0 & 0.0 & 0.0 & 0.0 \\
\hline 3 & 383 & 0.0 & 0.0 & 0.0 & 0.0 & 0.0 & 0.0 \\
\hline 4 & 397 & 0.0 & 0.0 & 0.0 & 0.0 & 0.0 & 0.0 \\
\hline 5 & 446 & 0.0 & 0.0 & 0.0 & 0.0 & 0.0 & 0.0 \\
\hline 6 & 765 & 0.0 & 0.0 & 0.0 & 0.0 & 0.0 & 0.0 \\
\hline 7 & 1480 & 0.4 & 0.2 & 0.0 & 0.0 & 0.0 & 0.0 \\
\hline 8 & 2047 & 2.2 & 1.7 & 1.1 & 0.6 & 0.1 & 0.0 \\
\hline 9 & 2278 & 4.5 & 3.8 & 2.7 & 1.7 & 0.8 & 0.2 \\
\hline 10 & 1745 & 5.6 & 4.6 & 3.0 & 1.6 & 0.2 & 0.0 \\
\hline 11 & 1863 & 6.9 & 5.7 & 3.7 & 1.7 & 0.0 & 0.0 \\
\hline 12 & 1955 & 8.5 & 7.1 & 4.5 & 2.1 & 0.0 & 0.0 \\
\hline 13 & 2002 & 10.2 & 8.5 & 5.5 & 2.6 & 0.0 & 0.0 \\
\hline 14 & 1954 & 11.7 & 9.8 & 6.3 & 3.0 & 0.0 & 0.0 \\
\hline 15 & 2320 & 14.2 & 12.0 & 8.0 & 4.2 & 0.8 & 0.3 \\
\hline 16 & 3012 & 18.2 & 15.8 & 11.4 & 7.1 & 3.2 & 2.2 \\
\hline 17 & 2907 & 22.1 & 19.4 & 14.5 & 9.7 & 5.3 & 3.9 \\
\hline 18 & 2659 & 25.3 & 22.4 & 17.0 & 11.8 & 6.9 & 5.0 \\
\hline 19 & 2113 & 27.2 & 24.1 & 18.2 & 12.5 & 7.2 & 4.8 \\
\hline 20 & 1820 & 28.5 & 25.1 & 18.8 & 12.6 & 6.7 & 3.9 \\
\hline 21 & 1474 & 28.9 & 25.3 & 18.5 & 11.8 & 5.5 & 2.2 \\
\hline 22 & 1247 & 28.8 & 24.9 & 17.6 & 10.5 & 3.7 & 0.0 \\
\hline 23 & 1118 & 28.3 & 24.3 & 16.5 & $\begin{array}{l}8.8 \\
\end{array}$ & 1.6 & 0.0 \\
\hline 24 & 900 & 27.4 & 23.1 & 14.8 & 6.7 & 0.0 & 0.0 \\
\hline 25 & 645 & 25.8 & 21.3 & 12.5 & 4.0 & 0.0 & 0.0 \\
\hline 26 & 455 & 23.8 & 19.0 & 9.8 & 0.7 & 0.0 & 0.0 \\
\hline 27 & 383 & 21.6 & 16.6 & 6.9 & 0.0 & 0.0 & 0.0 \\
\hline 28 & 397 & 19.5 & 14.2 & 4.0 & 0.0 & 0.0 & 0.0 \\
\hline 29 & 446 & $17.4^{*}$ & $12.0^{*}$ & $1.3^{*}$ & 0.0 & 0.0 & 0.0 \\
\hline
\end{tabular}

${ }^{*}$ Note: Queue length does not recover before arrival rate exceeds departure rate

\subsubsection{Service Rate}

Several steps were used to determine the hourly directional departure rate from the work zone. The initial step in this process was to determine the maximum departure rate. The maximum departure rate will vary depending on a number of factors. These factors include the number of operational lanes through the work zone, the width of these lanes and also with the width of inside and outside shoulders of this segment of roadway and the percent of traffic that is composed of heavy vehicles. For example, tables showing adjustment factors for directional 
distribution, lane and shoulder width, and lateral clearance can be found in Table 5-3, Table 5-4 and Table 5-5 respectively. The various other adjustment factors that are needed to determine the flow rate of a segment of interstate can also be found in the Highway Capacity Manual in a similar format (HCM 2000). Due to the number of variables that determine this rate, the maximum departure rate for one lane of an interstate can vary from 1300 vehicles per hour to 2200 vehicles per hour, as shown in Table 5-1 and in Table 5-2 (Dudek 82).

Table 5-3 Adjustment Factors for Directional Distribution on General Terrain Segments (HCM 2000)

\begin{tabular}{c|cccccc}
\hline Directional Distribution & $100 / 0$ & $90 / 10$ & $80 / 20$ & $70 / 30$ & $60 / 40$ & $50 / 50$ \\
\hline Adjustment Factor, $f_{d}$ & 0.71 & 0.75 & 0.83 & 0.89 & 0.94 & 1.00 \\
\hline
\end{tabular}

Table 5-4 Adjustment Factors for the Combined Effect of Narrow Lanes \& Restricted Shoulder Width (HCM 2000)

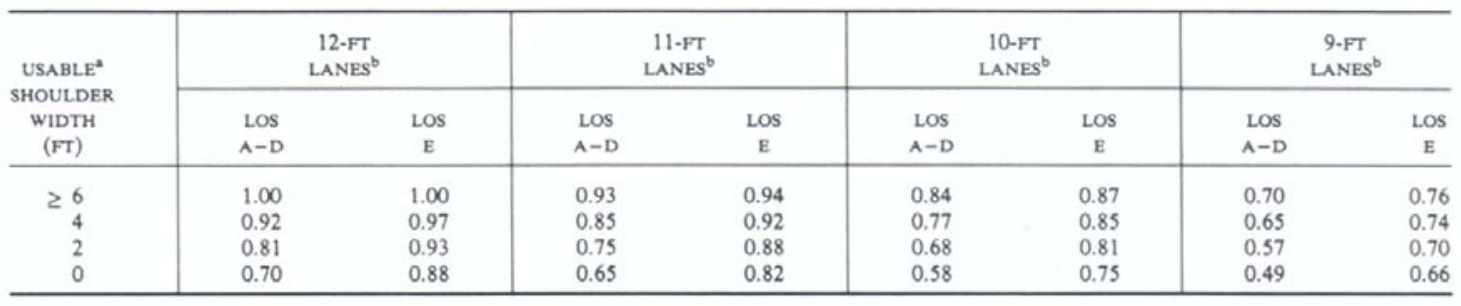

- Where shoulder width is different on each side of the roadway, use the average shoulder width.

${ }^{b}$ For analysis of specific grades, use LOS E factors for all speeds less than $45 \mathrm{mph}$. 
Table 5-5 Adjustment Factors for Restricted Lane Width \& Lateral Clearance (HCM 2000)

\begin{tabular}{|c|c|c|c|c|c|c|c|c|}
\hline \multirow{4}{*}{$\begin{array}{l}\text { DISTANCE FROM } \\
\text { TRAVELED } \\
\text { PAVEMENT } \\
\text { (FT) }\end{array}$} & \multicolumn{8}{|c|}{ ADJUSTMENT FACTOR, $f_{*}$} \\
\hline & \multicolumn{4}{|c|}{$\begin{array}{l}\text { OBSTRUCTIONS ON ONE } \\
\text { SIDE OF THE ROADWAY }\end{array}$} & \multicolumn{4}{|c|}{$\begin{array}{l}\text { OBSTRUCTIONS ON BOTH } \\
\text { SIDES OF THE ROADWAY }\end{array}$} \\
\hline & \multicolumn{8}{|c|}{ LANE WIDTH (FT) } \\
\hline & 12 & 11 & 10 & 9 & 12 & 11 & 10 & 9 \\
\hline & \multicolumn{8}{|c|}{$\begin{array}{c}\text { 4-LANE FREEWAY } \\
\text { (2 LANES EACH DIRECTION) }\end{array}$} \\
\hline $\begin{array}{r}\geq 6 \\
5 \\
4 \\
3 \\
2 \\
1 \\
1 \\
0\end{array}$ & $\begin{array}{l}1.00 \\
0.99 \\
0.99 \\
0.98 \\
0.97 \\
0.93 \\
0.90\end{array}$ & $\begin{array}{l}0.97 \\
0.96 \\
0.96 \\
0.95 \\
0.94 \\
0.90 \\
0.87\end{array}$ & $\begin{array}{l}0.91 \\
0.90 \\
0.90 \\
0.89 \\
0.88 \\
0.85 \\
0.82\end{array}$ & $\begin{array}{l}0.81 \\
0.80 \\
0.80 \\
0.79 \\
0.79 \\
0.76 \\
0.73\end{array}$ & $\begin{array}{l}1.00 \\
0.99 \\
0.98 \\
0.96 \\
0.94 \\
0.87 \\
0.81\end{array}$ & $\begin{array}{l}0.97 \\
0.96 \\
0.95 \\
0.93 \\
0.91 \\
0.85 \\
0.79\end{array}$ & $\begin{array}{l}0.91 \\
0.90 \\
0.89 \\
0.87 \\
0.86 \\
0.80 \\
0.74\end{array}$ & $\begin{array}{l}0.81 \\
0.80 \\
0.79 \\
0.77 \\
0.76 \\
0.71 \\
0.66\end{array}$ \\
\hline & \multicolumn{8}{|c|}{$\begin{array}{c}\text { 6- or 8- LANE FREEWAY } \\
\text { ( } 3 \text { or } 4 \text { LANES EACH DIRECTION) }\end{array}$} \\
\hline $\begin{array}{r}26 \\
5 \\
4 \\
3 \\
2 \\
1 \\
0\end{array}$ & $\begin{array}{l}1.00 \\
0.99 \\
0.99 \\
0.98 \\
0.97 \\
0.95 \\
0.94\end{array}$ & $\begin{array}{l}0.96 \\
0.95 \\
0.95 \\
0.94 \\
0.93 \\
0.92 \\
0.91\end{array}$ & $\begin{array}{l}0.89 \\
0.88 \\
0.88 \\
0.87 \\
0.87 \\
0.86 \\
0.85\end{array}$ & $\begin{array}{l}0.78 \\
0.77 \\
0.77 \\
0.76 \\
0.76 \\
0.75 \\
0.74\end{array}$ & $\begin{array}{l}1.00 \\
0.99 \\
0.98 \\
0.97 \\
0.96 \\
0.93 \\
0.91\end{array}$ & $\begin{array}{l}0.96 \\
0.95 \\
0.94 \\
0.93 \\
0.92 \\
0.89 \\
0.87\end{array}$ & $\begin{array}{l}0.89 \\
0.88 \\
0.87 \\
0.86 \\
0.85 \\
0.83 \\
0.81\end{array}$ & $\begin{array}{l}0.78 \\
0.77 \\
0.77 \\
0.76 \\
0.75 \\
0.72 \\
0.70\end{array}$ \\
\hline
\end{tabular}

" Certain types of obstructions, high-type median barriers in particular, do not cause any deleterious effect on traffic flow. Judgment should be exereised in applying these factors.

\subsubsection{Deterministic Queuing Model}

After deciding on a maximum departure rate, the hourly departure rate for the work zone should be calculated. This rate depends on several factors: arrival rate, maximum departure rate per lane, number of operational lanes and the existing queue. All four of these factors contribute to determine how traffic will flow through the work zone.

In effort to determine how traffic would flow through the work zone that encompassed the I-65/ US 30 interchange, a queuing model was created for this work zone. This queuing model was developed for two separate scenarios: one operational lane per direction and two operational lanes per direction. Both scenarios use actual traffic volumes collected from the nearby WIM station, along with multiple maximum departure rates to determine the theoretical maximum length of queue that would result for each hour of the day. Also, both models assume that no reduction in demand results from the work zone.

\subsubsection{One Operational Lane Per Direction of Travel}

Although the decision was made by INDOT to maintain two operational lanes of traffic per direction during the duration of this project, it was necessary to develop a queuing model for the 
case in which only one operational lane per direction was provided. This queuing model could then be compared to the queuing model developed for two operational lanes per direction in an effort to justify maintaining the extra operational lane.

To begin creation of the queuing model for one operational lane per direction, it must first be noted that the hourly departure rate for the work zone cannot exceed the maximum departure rate per lane. Based on this premise, the model can then be created using hourly volumes as the arrival rates. In the early hours of the day, the arrival rate is less than the maximum departure rate, no queue exists and traffic moves at the posted speed limit. During this time, the departure rate is equal to the arrival rate. Such periods can be found in both Table 5-1 and Figure 5-2 during hours 0100 to 0500 .

As traffic volumes increase, the arrival rate can exceed the maximum departure rate. Such a condition often occurs in the morning and afternoon peak periods, and can be seen in Table 5-1 and Figure 5-2 during the hours 0500 to 1200 . At this time, traffic must slow due to the queue that is forming. 


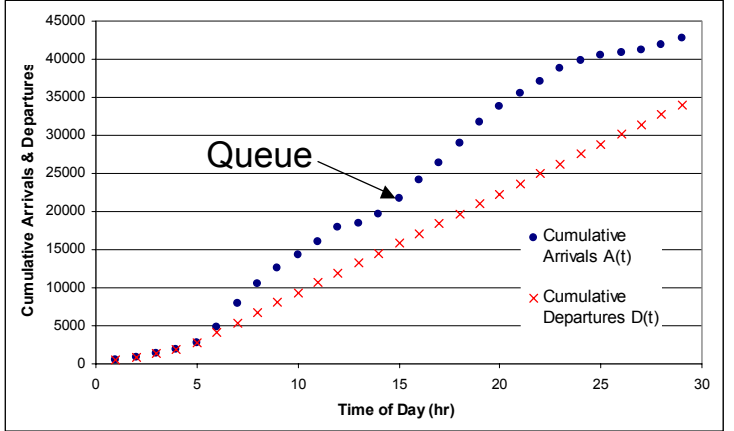

a) Departure Rate $=1300$

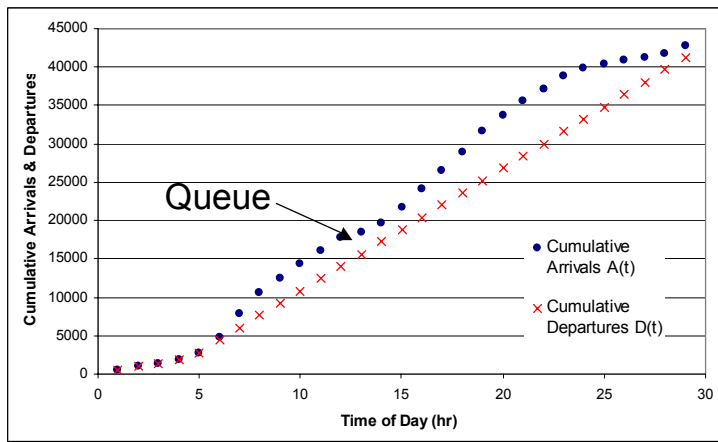

c) Departure Rate $=1600$

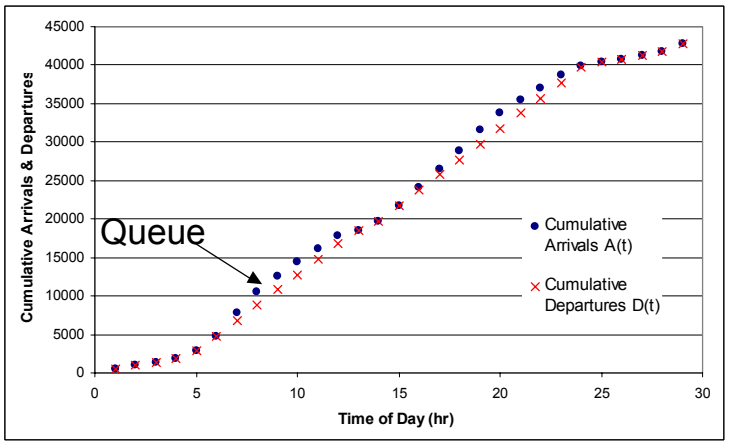

e) Departure Rate $=2000$

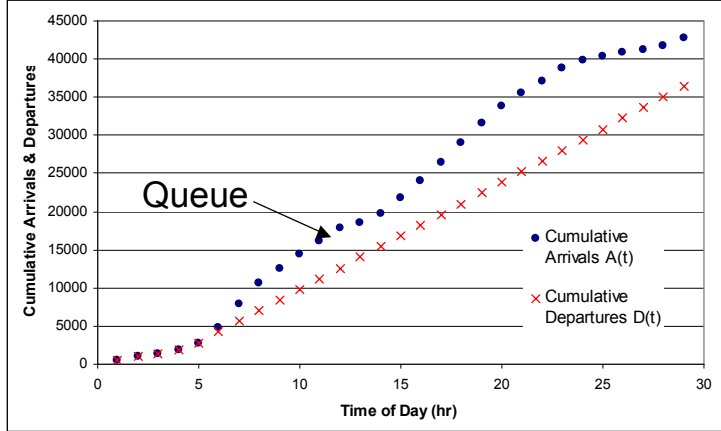

b) Departure Rate $=1400$

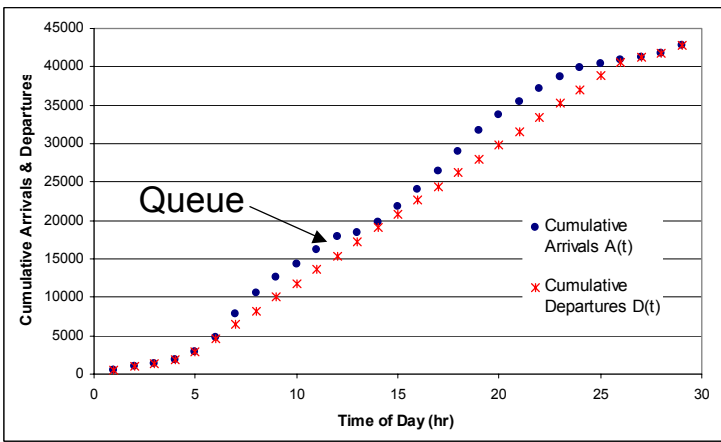

d) Departure Rate $=1800$

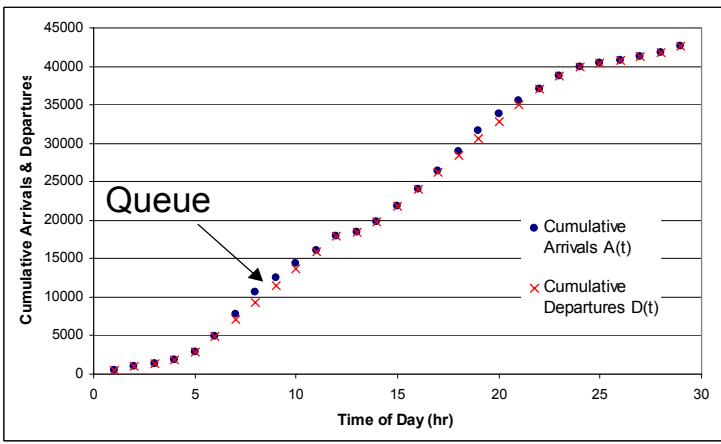

f) Departure Rate $=2200$

Figure 5-2 I-65 Northbound, One Lane Operational

The length of this queue in number of vehicles, represented as the area between the curves in Figure 5-2a, can be determined by calculating the difference between the arrival rate and the departure rate. Since traffic in the queue is closely packed, the length of the queue in miles can be obtained by assuming a maximum number of vehicles that can occupy one lane mile. Such a value is often referred to as jam density. This value can reach a maximum of 250 vehicles per mile per lane, assuming that the entire queue is composed of tightly spaced passenger cars (May 
90). This packing assumes that the vehicles are nearly touching. Although this type of spacing is possible, it is highly unlikely because motorists generally allow a space to exist between their vehicle and the vehicle in front of them. This space between vehicles, which may be up to one car length at times, greatly reduces the maximum density of the roadway from the 250 vehicles per mile suggested by May and thus must be accounted for.

The second difference between the hypothetical and the actual traffic conditions is the type of traffic that is being carried by the roadway. Since nearly all roadways carry more types of vehicles than passenger cars, the jam density of each roadway should be adapted to reflect the percentage of traffic that is comprised of trucks. For instance, traffic traveling on 1-65 near Merrillville, Indiana consists of nearly seventeen percent trucks. Since this percent of the total traffic is not negligible, the jam density of the roadway was adjusted to reflect the truck traffic. This can be accomplished by obtaining the length of a WB 40 (AASHTO, 94), and using this distance along with a reasonable length of space that a passenger car will occupy to calculate the maximum number of vehicles that can occupy one mile of roadway accomplished through the adjustment of jam density. (AASHTO, 94) The resulting jam density was estimated to be 140 vehicles per mile per lane, for this location on I-65.

As the arrival rate continues to exceed the maximum departure rate, the departure rate remains at its maximum and the queue continues to expand. This event often occurs during the peak hours, as seen in Table 5-1 and Figure 5-2e for a departure rate of 2000 vehicles per lane during the hours 1400 to 1900 . To estimate the number of vehicles in the queue when such a condition occurs, the difference between the arrival rate and the maximum departure rate must be added to the number of vehicles in the existing queue.

This queue will continue to increase in length until the arrival rate again falls below the maximum departure rate, which often occurs near the end of the peak period. At this time, there are more vehicles departing the work zone than are approaching it and thus queue decreases in size. This can be seen in Table 5-1 for a maximum departure rate of 2000 vehicles per hour and in Figure $5-2 e$ during the hours of 1900 to 2200 . As the queue dissipates, the departure rate will continue to remain at its maximum until such time when the combined total of the arrival rate and the number of vehicles in the queue is less than that of the maximum departure rate. When this event occurs, the departure rate will then equal the sum of the arrival rate and the number of vehicles in the existing queue. If the arrival rate continues to remain less than the maximum departure rate the queue will dissipate, as seen in Table 5-1 for a departure rate of 2000 vehicles 
per hour and Figure 5-2e during the hours 2200 through 2400, departure rate will again equal the arrival rate and the speed of traffic will increase to the posted speed limit.

With only one operational lane per direction and the assumption of low departure rates (1300 1500 vehicles per lane) large queues are likely to form. In theory, these queues may reach up to 30 miles in length, as seen Table 5-1 in and Figure 5-2. This incredible length was determined under the assumption that a reduction in demand would not occur during the construction process. In reality, the demand would decrease as the queues grew to great distances. This would result from motorists finding alternative routes around the work zone.

As long as there is no reduction in the demand for the roadway during the construction period, queues will carry over from one day to the next. Although the queue length will grow smaller in length as the end of the day nears, this queue will not recover before the end of one day and as a result the queue lengths for the following day will be greater. This can be seen in Table 5-1 and Table 5-2 as well as in Figure 5-2a, Figure 5-2b, Figure 5-2c, Figure 5-3a, Figure 5-3b, Figure $5-3 c$. 


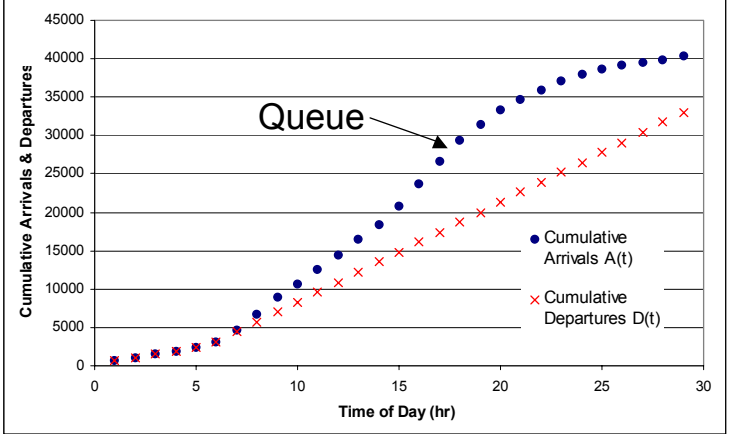

a) Departure Rate $=1300$

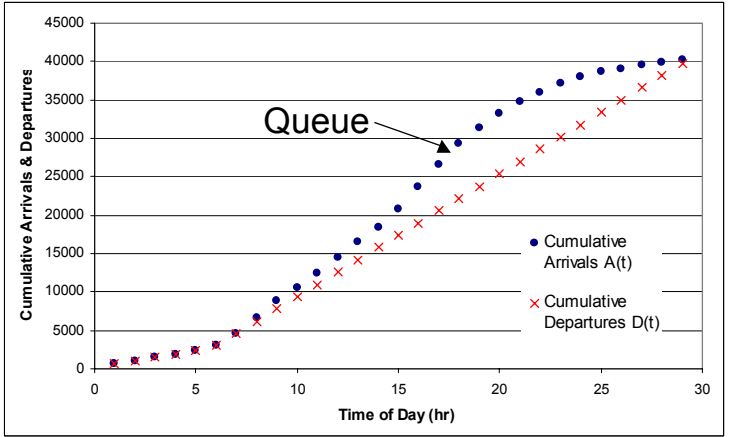

c) Departure Rate $=1600$

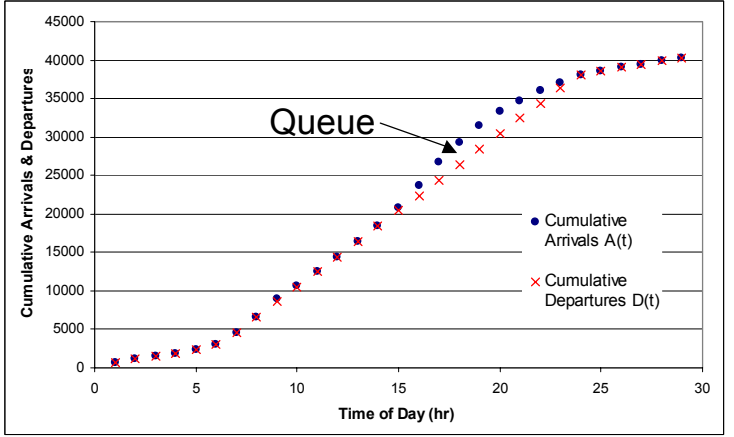

e) Departure Rate $=2000$

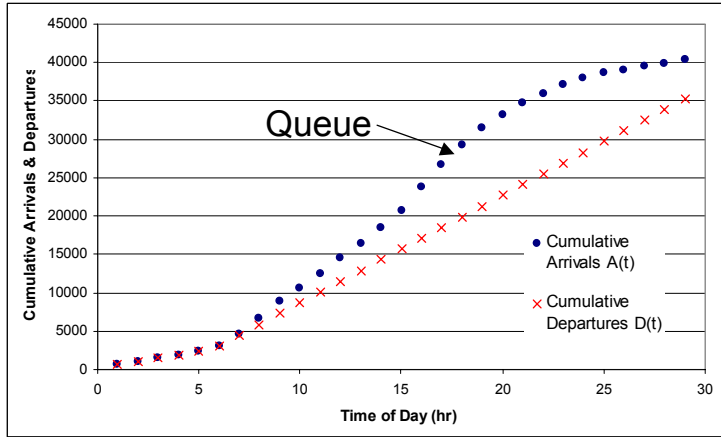

b) Departure Rate $=1400$

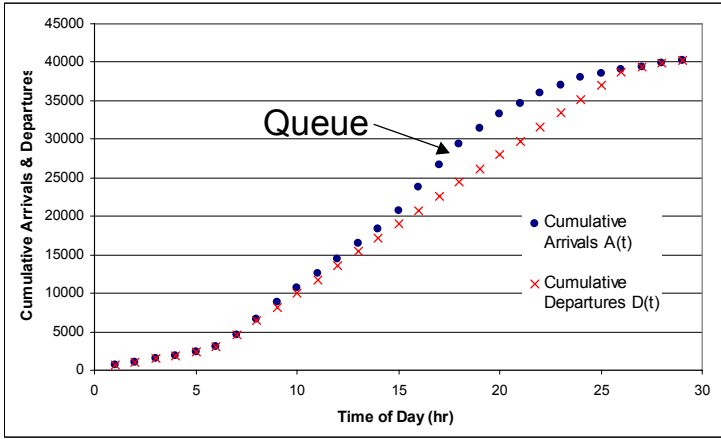

d) Departure Rate $=1800$

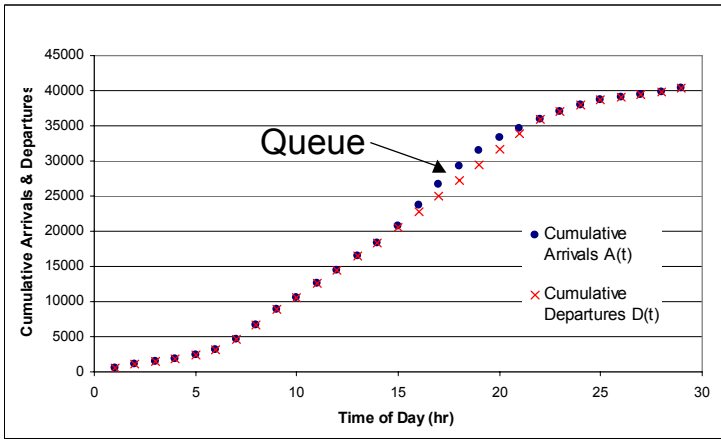

f) Departure Rate $=2200$

Figure 5-3 I-65 Southbound, One Lane Operational

\subsubsection{Two Operational Lanes Per Direction of Travel}

A second queuing model was then created. This model was based on the assumption that two lanes per direction would remain operational through out the duration of the project. Like the other queuing model, this model was also created using the same concepts and arrival rates. In 
this model, the hourly departure rate for the work zone could not exceed twice the maximum departure rate for one lane.

Since the hourly departure rate for this model is double that of the previous model, the lengthy queues that resulted from having one operational lane are nearly eliminated. The model predicts that the queues will not exceed 2.0 miles in length. As seen in Table 5-6 and in Figure 5-4, a queue is only expected to form on the northbound lanes of I-65 during the morning peak period.

Table 5-7 and Figure 5-5 indicate that queues are only expected to form on the southbound lanes of I-65 during the evening peak period. The locations of the expected northbound and southbound queues relative to the intersection of I-65 and US 30, when two lanes are provided in each direction, are indicated in Figure 5-1. 
Table 5-6 I-65 Northbound, Two Lanes Operational

\begin{tabular}{|c|c|c|c|c|c|}
\hline \multirow{2}{*}{ Hour } & \multirow{2}{*}{$\begin{array}{l}\text { Arrival } \\
\text { Rate }\end{array}$} & $\begin{array}{c}\text { Dep. Rate }= \\
1300 \mathrm{vpl}\end{array}$ & $\begin{array}{c}\text { Dep. Rate = } \\
1400 \mathrm{vpl}\end{array}$ & \begin{tabular}{|c|} 
Dep. Rate $=$ \\
$1500 \mathrm{vpl}$ \\
\end{tabular} & $\begin{array}{c}\text { Dep. Rate = } \\
1600 \mathrm{vpl} \\
\end{array}$ \\
\hline & & $\begin{array}{c}\text { Queue } \\
\text { Length (mi) }\end{array}$ & $\begin{array}{c}\text { Queue } \\
\text { Length (mi) }\end{array}$ & $\begin{array}{c}\text { Queue } \\
\text { Length (mi) }\end{array}$ & $\begin{array}{c}\text { Queue } \\
\text { Length (mi) }\end{array}$ \\
\hline 1 & 554 & 0.0 & 0.0 & 0.0 & 0.0 \\
\hline 2 & 391 & 0.0 & 0.0 & 0.0 & 0.0 \\
\hline 3 & 434 & 0.0 & 0.0 & 0.0 & 0.0 \\
\hline 4 & 544 & 0.0 & 0.0 & 0.0 & 0.0 \\
\hline 5 & 895 & 0.0 & 0.0 & 0.0 & 0.0 \\
\hline 6 & 2005 & 0.0 & 0.0 & 0.0 & 0.0 \\
\hline 7 & 3024 & 1.5 & 0.8 & 0.1 & 0.0 \\
\hline 8 & 2734 & 2.0 & 0.6 & 0.0 & 0.0 \\
\hline 9 & 1963 & 0.0 & 0.0 & 0.0 & 0.0 \\
\hline 10 & 1812 & 0.0 & 0.0 & 0.0 & 0.0 \\
\hline 11 & 1763 & 0.0 & 0.0 & 0.0 & 0.0 \\
\hline 12 & 1743 & 0.0 & 0.0 & 0.0 & 0.0 \\
\hline 13 & 607 & 0.0 & 0.0 & 0.0 & 0.0 \\
\hline 14 & 1269 & 0.0 & 0.0 & 0.0 & 0.0 \\
\hline 15 & 2072 & 0.0 & 0.0 & 0.0 & 0.0 \\
\hline 16 & 2293 & 0.0 & 0.0 & 0.0 & 0.0 \\
\hline 17 & 2334 & 0.0 & 0.0 & 0.0 & 0.0 \\
\hline 18 & 2514 & 0.0 & 0.0 & 0.0 & 0.0 \\
\hline 19 & 2688 & 0.3 & 0.0 & 0.0 & 0.0 \\
\hline 20 & 2148 & 0.0 & 0.0 & 0.0 & 0.0 \\
\hline 21 & 1725 & 0.0 & 0.0 & 0.0 & 0.0 \\
\hline 22 & 1564 & 0.0 & 0.0 & 0.0 & 0.0 \\
\hline 23 & 1686 & 0.0 & 0.0 & 0.0 & 0.0 \\
\hline 24 & 1128 & 0.0 & 0.0 & 0.0 & 0.0 \\
\hline 25 & 554 & 0.0 & 0.0 & 0.0 & 0.0 \\
\hline 26 & 391 & 0.0 & 0.0 & 0.0 & 0.0 \\
\hline 27 & 434 & 0.0 & 0.0 & 0.0 & 0.0 \\
\hline 28 & 544 & 0.0 & 0.0 & 0.0 & 0.0 \\
\hline 29 & 895 & 0.0 & 0.0 & 0.0 & 0.0 \\
\hline
\end{tabular}




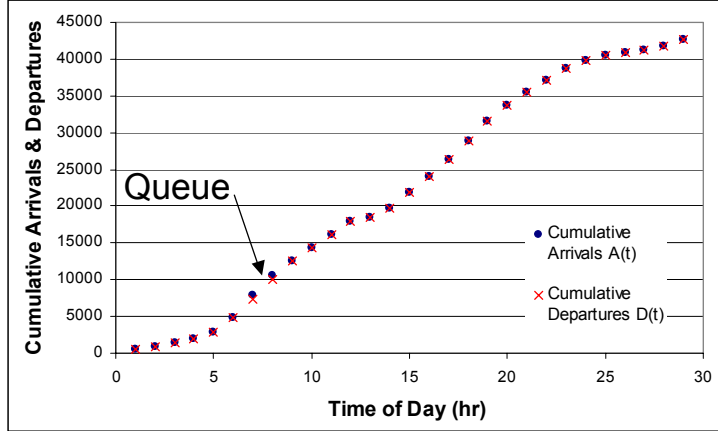

a) Departure Rate $=1300$

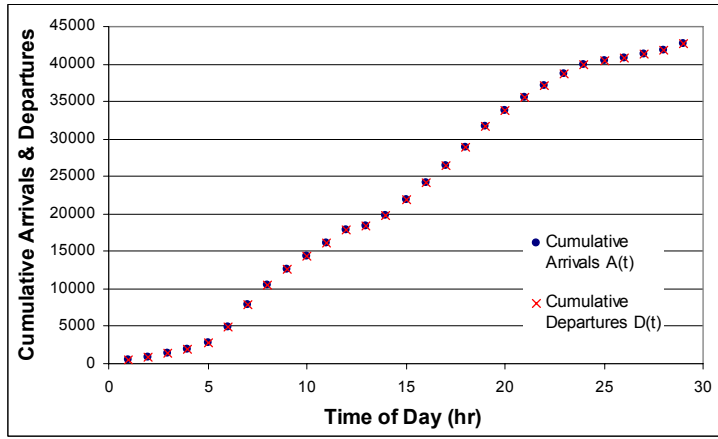

c) Departure Rate $=1500$

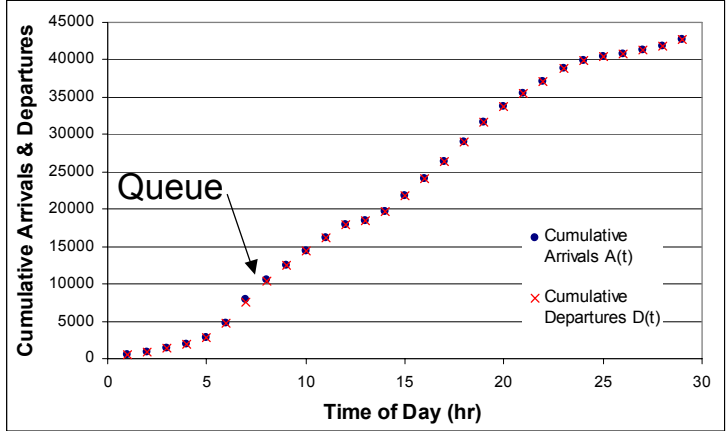

b) Departure Rate $=1400$

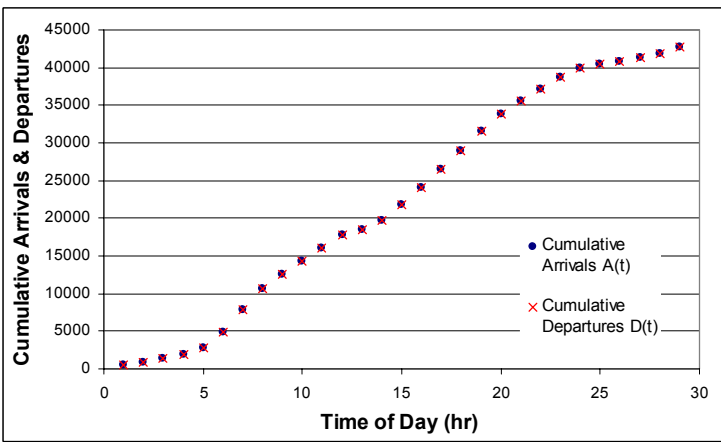

d) Departure Rate $=1600$

Figure 5-4 I-65 Northbound, Two Lanes Operational 
Table 5-7 I-65 Southbound, Two Lanes Operational

\begin{tabular}{|c|c|c|c|c|c|}
\hline \multirow{2}{*}{ Hour } & \multirow{2}{*}{$\begin{array}{l}\text { Arrival } \\
\text { Rate }\end{array}$} & $\begin{array}{c}\text { Dep. Rate = } \\
1300 \mathrm{vpl} \\
\end{array}$ & $\begin{array}{c}\text { Dep. Rate = } \\
1400 \mathrm{vpl}\end{array}$ & \begin{tabular}{|c|} 
Dep. Rate $=$ \\
$1500 \mathrm{vpl}$ \\
\end{tabular} & $\begin{array}{c}\text { Dep. Rate = } \\
1600 \mathrm{vpl} \\
\end{array}$ \\
\hline & & $\begin{array}{c}\text { Queue } \\
\text { Length (mi) }\end{array}$ & $\begin{array}{c}\text { Queue } \\
\text { Length (mi) }\end{array}$ & $\begin{array}{c}\text { Queue } \\
\text { Length (mi) }\end{array}$ & $\begin{array}{c}\text { Queue } \\
\text { Length (mi) }\end{array}$ \\
\hline 1 & 645 & 0.0 & 0.0 & 0.0 & 0.0 \\
\hline 2 & 455 & 0.0 & 0.0 & 0.0 & 0.0 \\
\hline 3 & 383 & 0.0 & 0.0 & 0.0 & 0.0 \\
\hline 4 & 397 & 0.0 & 0.0 & 0.0 & 0.0 \\
\hline 5 & 446 & 0.0 & 0.0 & 0.0 & 0.0 \\
\hline 6 & 765 & 0.0 & 0.0 & 0.0 & 0.0 \\
\hline 7 & 1480 & 0.0 & 0.0 & 0.0 & 0.0 \\
\hline 8 & 2047 & 0.0 & 0.0 & 0.0 & 0.0 \\
\hline 9 & 2278 & 0.0 & 0.0 & 0.0 & 0.0 \\
\hline 10 & 1745 & 0.0 & 0.0 & 0.0 & 0.0 \\
\hline 11 & 1863 & 0.0 & 0.0 & 0.0 & 0.0 \\
\hline 12 & 1955 & 0.0 & 0.0 & 0.0 & 0.0 \\
\hline 13 & 2002 & 0.0 & 0.0 & 0.0 & 0.0 \\
\hline 14 & 1954 & 0.0 & 0.0 & 0.0 & 0.0 \\
\hline 15 & 2320 & 0.0 & 0.0 & 0.0 & 0.0 \\
\hline 16 & 3012 & 1.0 & 0.5 & 0.0 & 0.0 \\
\hline 17 & 2907 & 1.7 & 0.8 & 0.0 & 0.0 \\
\hline 18 & 2659 & 1.9 & 0.4 & 0.0 & 0.0 \\
\hline 19 & 2113 & 0.7 & 0.0 & 0.0 & 0.0 \\
\hline 20 & 1820 & 0.0 & 0.0 & 0.0 & 0.0 \\
\hline 21 & 1474 & 0.0 & 0.0 & 0.0 & 0.0 \\
\hline 22 & 1247 & 0.0 & 0.0 & 0.0 & 0.0 \\
\hline 23 & 1118 & 0.0 & 0.0 & 0.0 & 0.0 \\
\hline 24 & 900 & 0.0 & 0.0 & 0.0 & 0.0 \\
\hline 25 & 645 & 0.0 & 0.0 & 0.0 & 0.0 \\
\hline 26 & 455 & 0.0 & 0.0 & 0.0 & 0.0 \\
\hline 27 & 383 & 0.0 & 0.0 & 0.0 & 0.0 \\
\hline 28 & 397 & 0.0 & 0.0 & 0.0 & 0.0 \\
\hline 29 & 446 & 0.0 & 0.0 & 0.0 & 0.0 \\
\hline
\end{tabular}




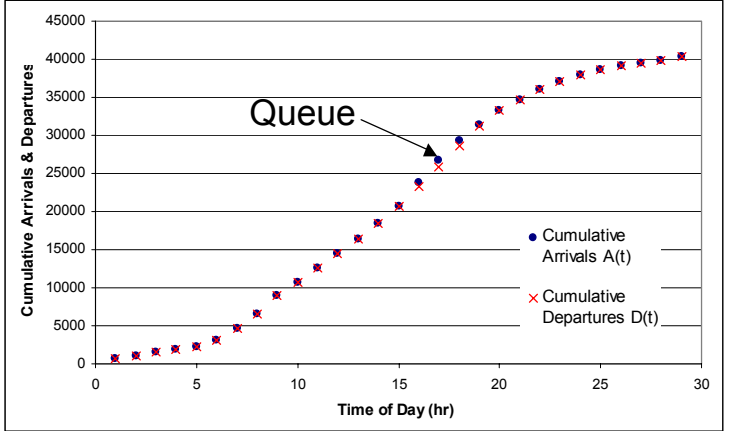

a) Departure Rate $=1300$

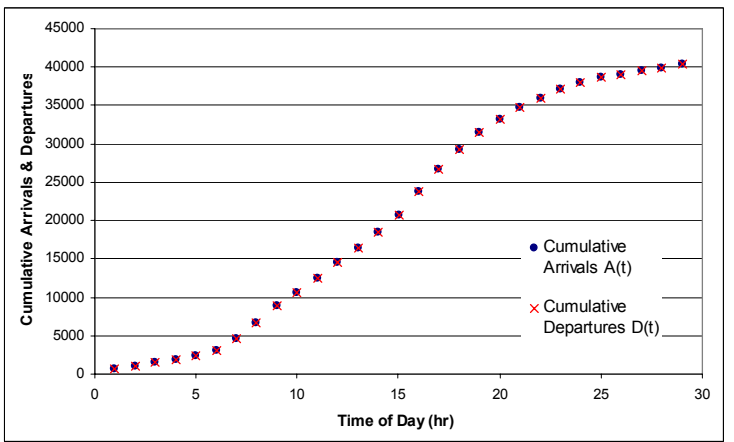

c) Departure Rate $=1500$

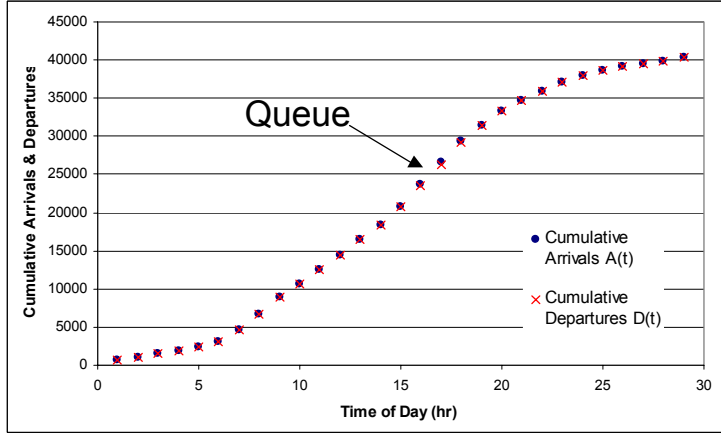

b) Departure Rate $=1400$

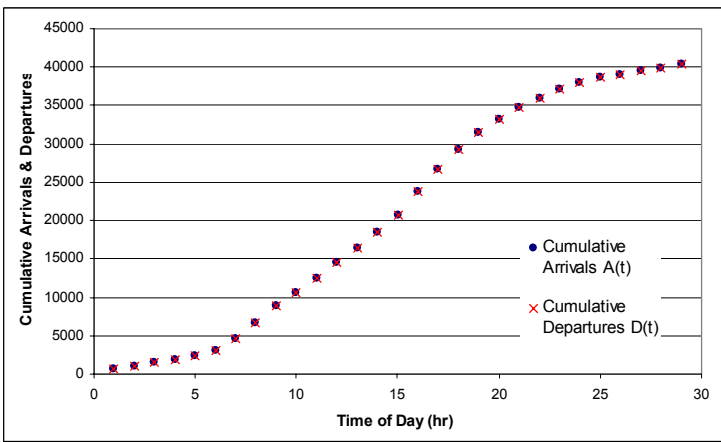

d) Departure Rate $=1600$

Figure 5-5 I-65 Southbound, Two Lanes Operational

\section{3. $\quad$ Analysis of Deterministic Queuing Model}

Due to the large AADT $(78,000+)$ that is handled by the segment of I-65 near US 30 , it appears necessary to provide two operational lanes of traffic per direction for motorists passing through a work zone found on this segment. This can be justified when a queuing analysis is performed for the work zone that will encompass reconstruction of the US 30 interchange.

As the rate of departure increases, due to increased lane widths or increasing the number of lanes, the length of the queue will decrease. This decrease in queue length can be seen when comparing various departure rates in each of the figures and when comparing similar departure rates of Table 5-1and Table 5-6. As the length of the queue decreases, motorists will see a reduction in the delays imposed on them, which will decrease their frustration and reduce the frequency of rear end collisions occurring. 
The large variation in queue lengths between providing one operational lane per direction and providing two operational lanes per direction indicates that a two-lane facility must be provided through the work zone in order to minimize user delay and the lengths of queues that are expected to form.

\section{4. $\quad$ Placement of Signs}

As discussed in Chapter 4, many of the accidents associated with Indiana work zones occurred before motorists reached the work zone. Many of these accidents were a result of motorists rearending a vehicle that was located at the back of the queue of vehicles waiting to pass through the work zone. Due to the large speed differential between vehicles traveling in free flow conditions and vehicles traveling slowly in a queue, this type of rear end accident is often very severe. To reduce the frequency of this type of accident, motorists must become aware that a work zone is ahead. They must also decrease their speed and increase their alertness because they are likely to be rapidly approaching the rear of a slowly moving queue. To inform motorists of the work zone and to convince them to reduce their speeds, a system of signs should be placed miles in advance of the work zone. This series of signs must be placed such that motorists become aware of the potential for stopped traffic before they encounter such conditions. Such a system was developed and studied under the scope of this project.

As discussed in Chapter 5.2, there is a high volume of traffic that travels the corridor of I-65 near the US 30 interchange. Also discussed in Chapter 5.2 was the queuing that would result when this large volume of traffic was coupled with the lane reduction that is associated with the reconstruction of the interchange. These queues, which are expected to reach two miles in length, would likely produce a high probability of rear end collisions.

In order to reduce the number and frequency of rear end collisions, a series of signs was developed and implemented that would inform motorists of the work zone. These signs were based on concepts that were used in work zones throughout Indiana and Illinois. In this sign plan, the first warning of the construction ahead given to motorists traveling in the northbound direction on I-65 was a sign was placed six miles to the south of the US 30 interchange. This sign, which can be seen in Figure 5-6a, was located before motorists reached Exit 247. This exit provided a route that detoured willing motorists around the construction. As drivers continued north, they would soon see a warning sign, found in Figure 5-7, displaying the fines associated with traffic violations in Indiana work zones. 
Following the traffic fines sign, motorists would then see a variable message sign. This sign would display the number of work zone associated tickets issued to date. The number of tickets issued to date would be displayed in a two-phase message and updated weekly. The sign and its two-phase message can be viewed in Figure 5-8. The procedure of displaying the number of traffic fines issued in the work zone was selected because of the anecdotal reports in Illinois of speed reductions when signs similar to Figure 5-7 were deployed upstream of the work zone

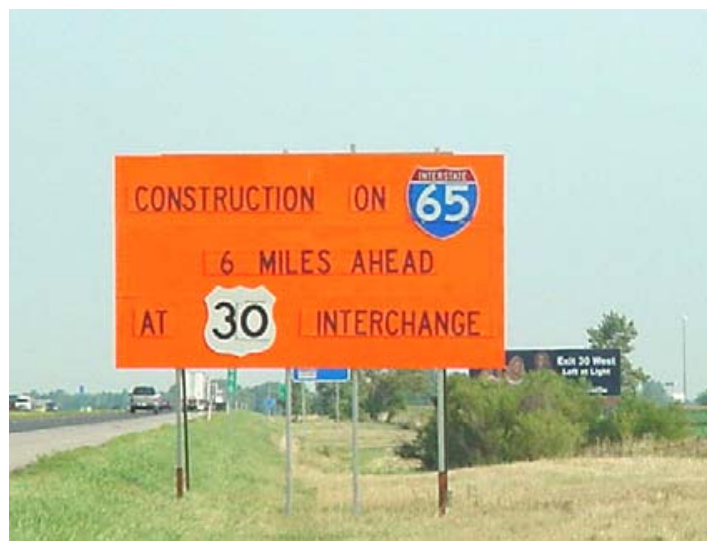

a) Northbound Sign

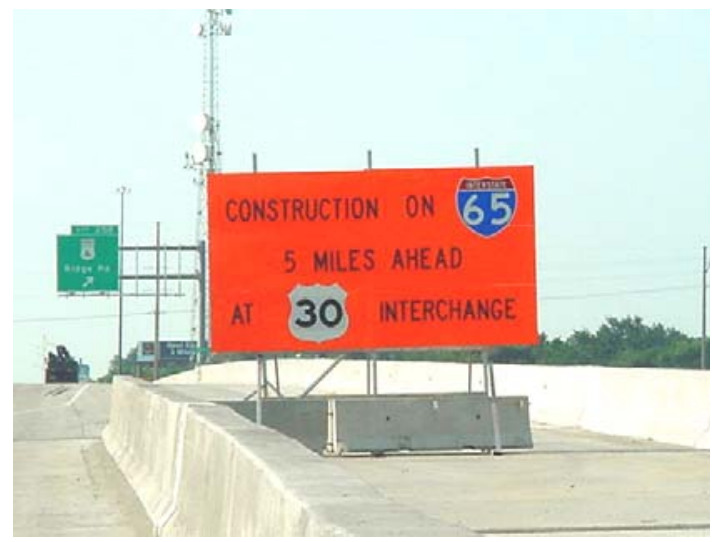

b) Southbound Sign

Figure 5-6 Construction Ahead (XIGC-1A,B) 


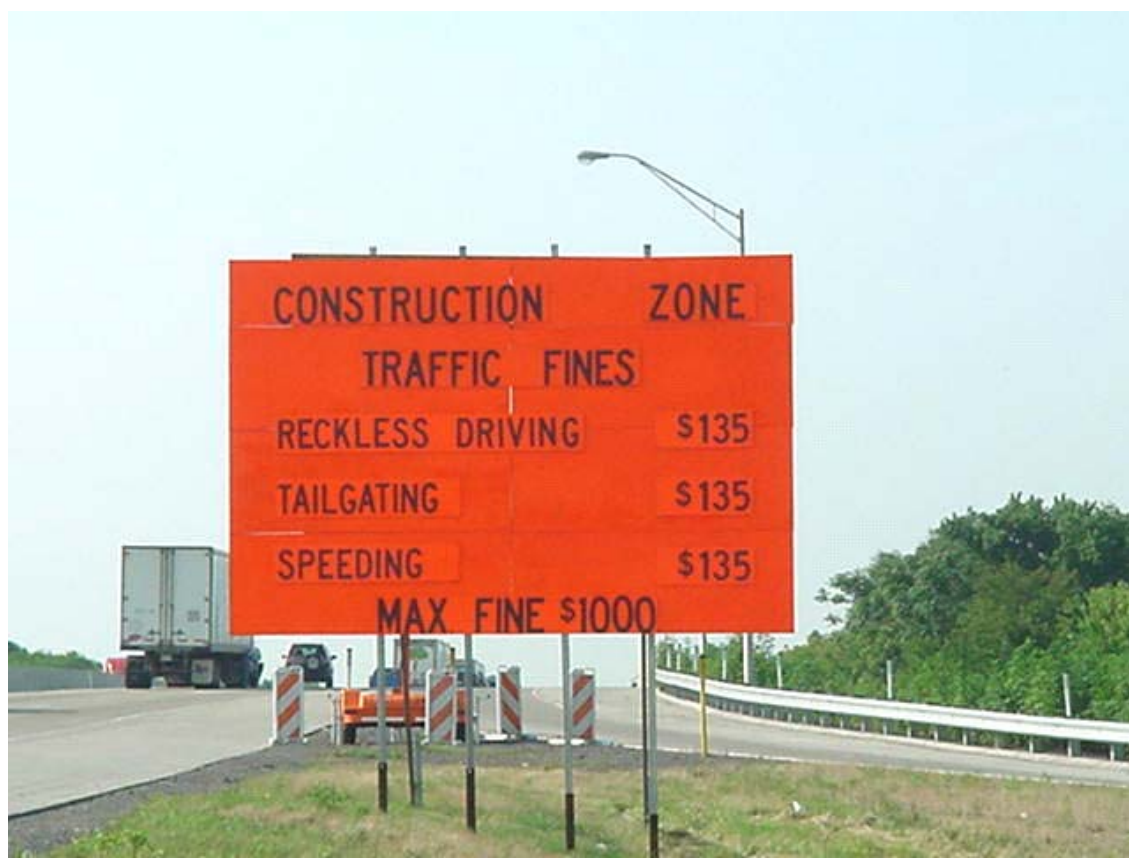

Figure 5-7 Construction Zones Traffic Fines (XIGC-12A,B)

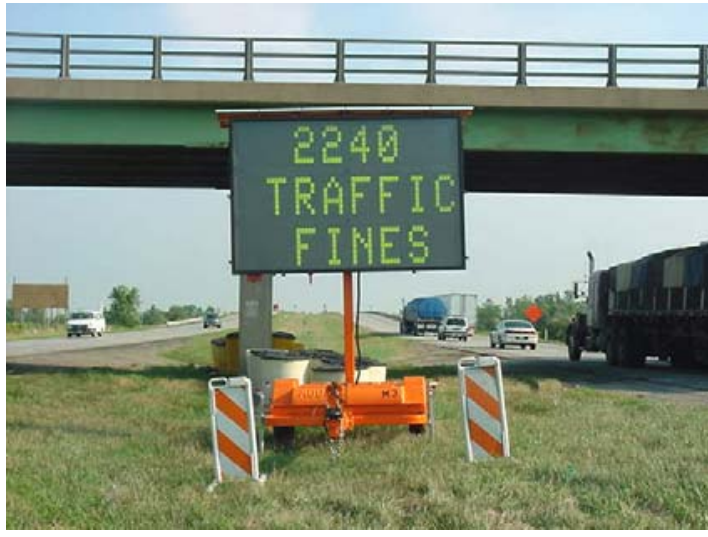

a) Message 1

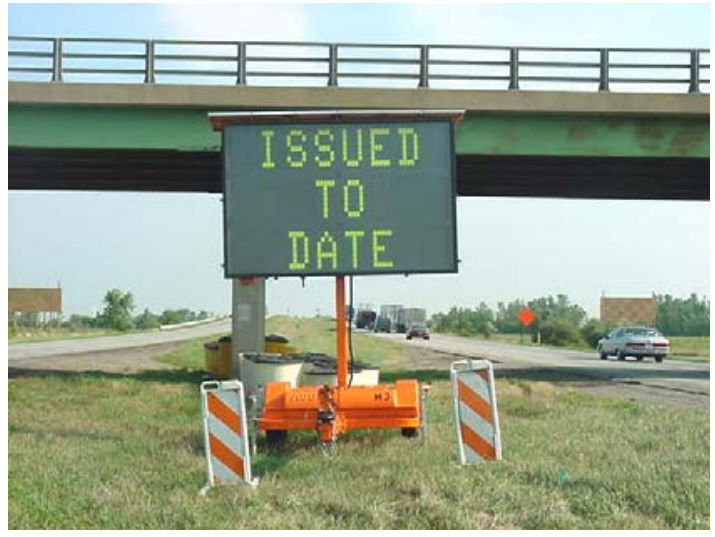

b) Message 2

Figure 5-8 Variable Message Sign

To display the number of tickets issued to date for the project site, a joint effort was needed between the Indiana State Police and INDOT. On a weekly basis, the Indiana State Police tallied 
the number of tickets issued at the project site. This information was then passed on to the graduate research assistants, who updated the variable message signs on a weekly basis.

After the variable message sign, motorists would then pass a series of signs alerting them of the road construction ahead and their distance, displayed in one-mile increments, from the beginning of the work zone. These signs can be found in Figure 5-9. Also included in the series were signs indicating that the Indiana State Police was conducting special speed patrols through the work zone and its surrounding areas. These signs, seen in Figure 5-10, were placed at one-half mile increments following each Road Construction Ahead sign and were ended once the beginning of the work zone was reached.

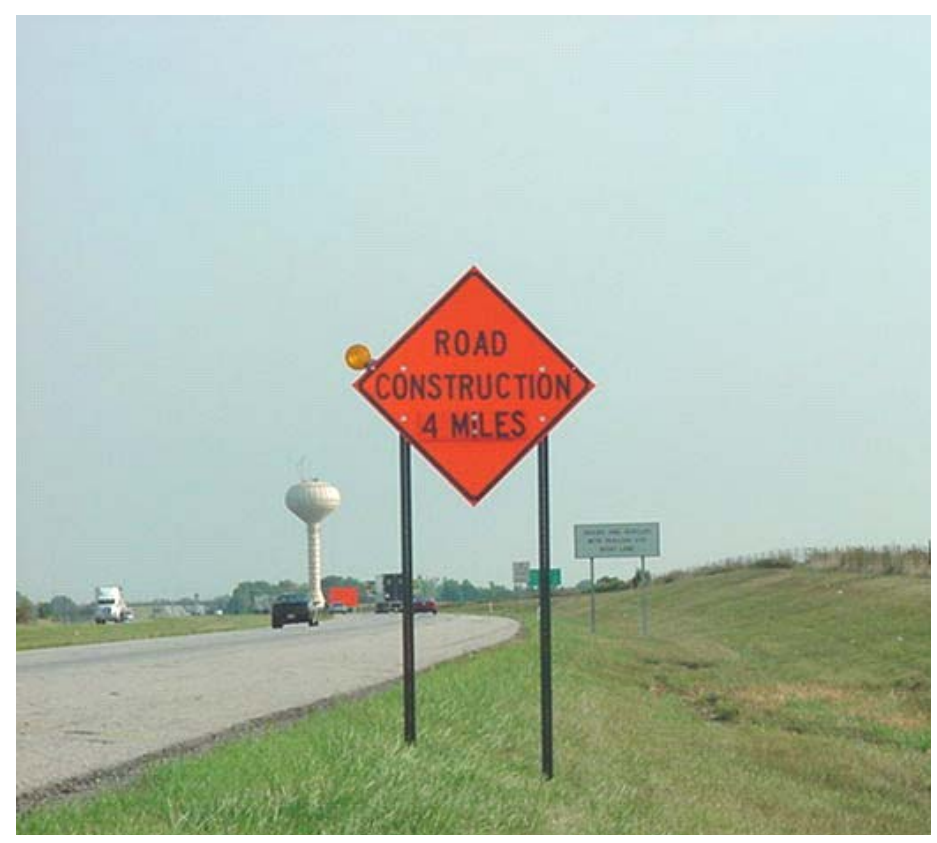

Figure 5-9 Road Work Ahead Signs 


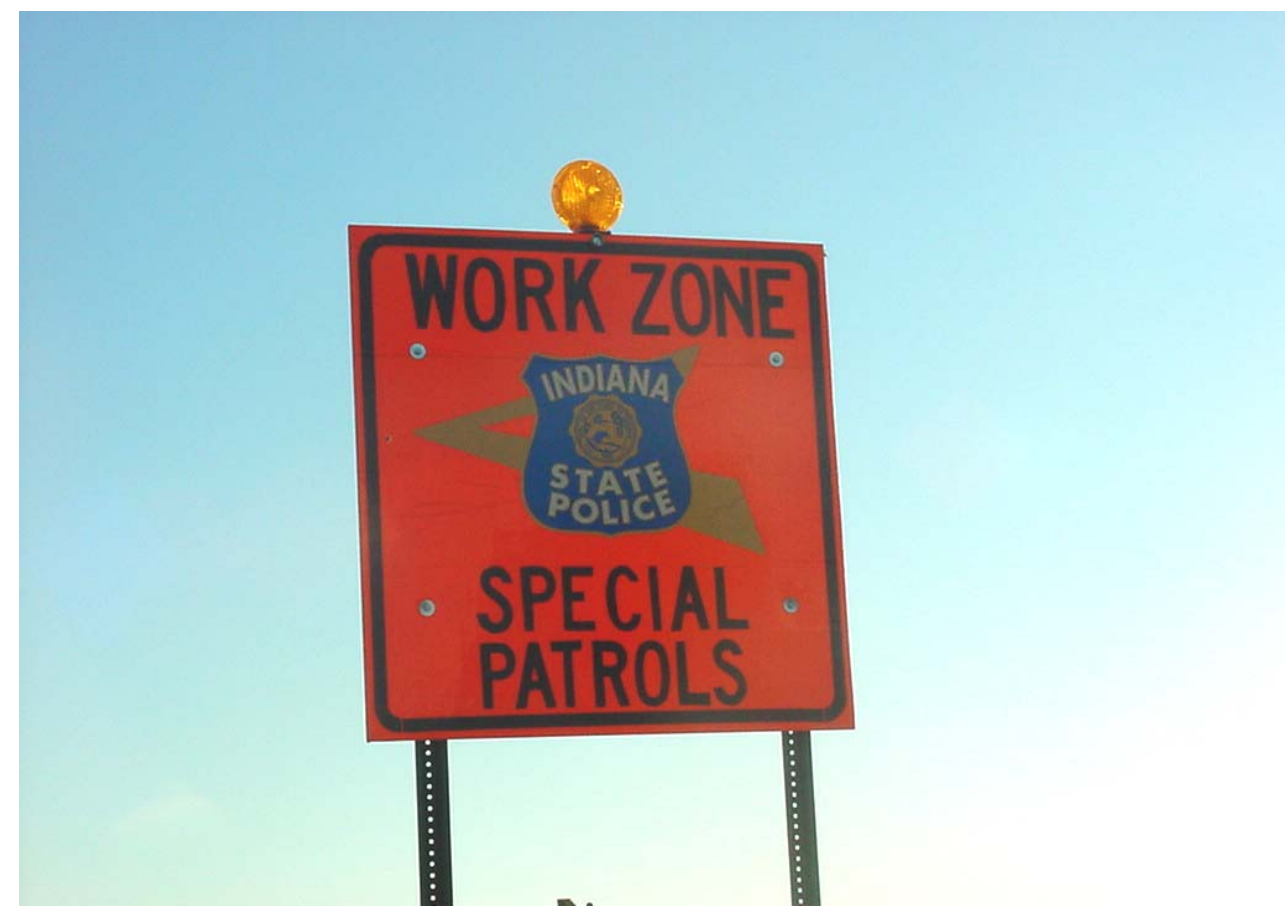

Figure 5-10 Work Zone Special Patrols (XIGC-14A-I)

A series of signs similar to that found on the northbound lanes of I-65 was also placed on the southbound approach to the interchange. This series of signs was modified slightly from those on the northbound approach because the I-80/94 interchange lays very near the US 30 interchange. Since a great deal of the traffic traveling southbound though the US 30 interchange comes from I$80 / 94$, the signs were begun slightly south of the I-80/94 interchange so that all motorists would be informed of the construction ahead. Placements of both northbound and southbound signs can be found in Figure 5-11. 


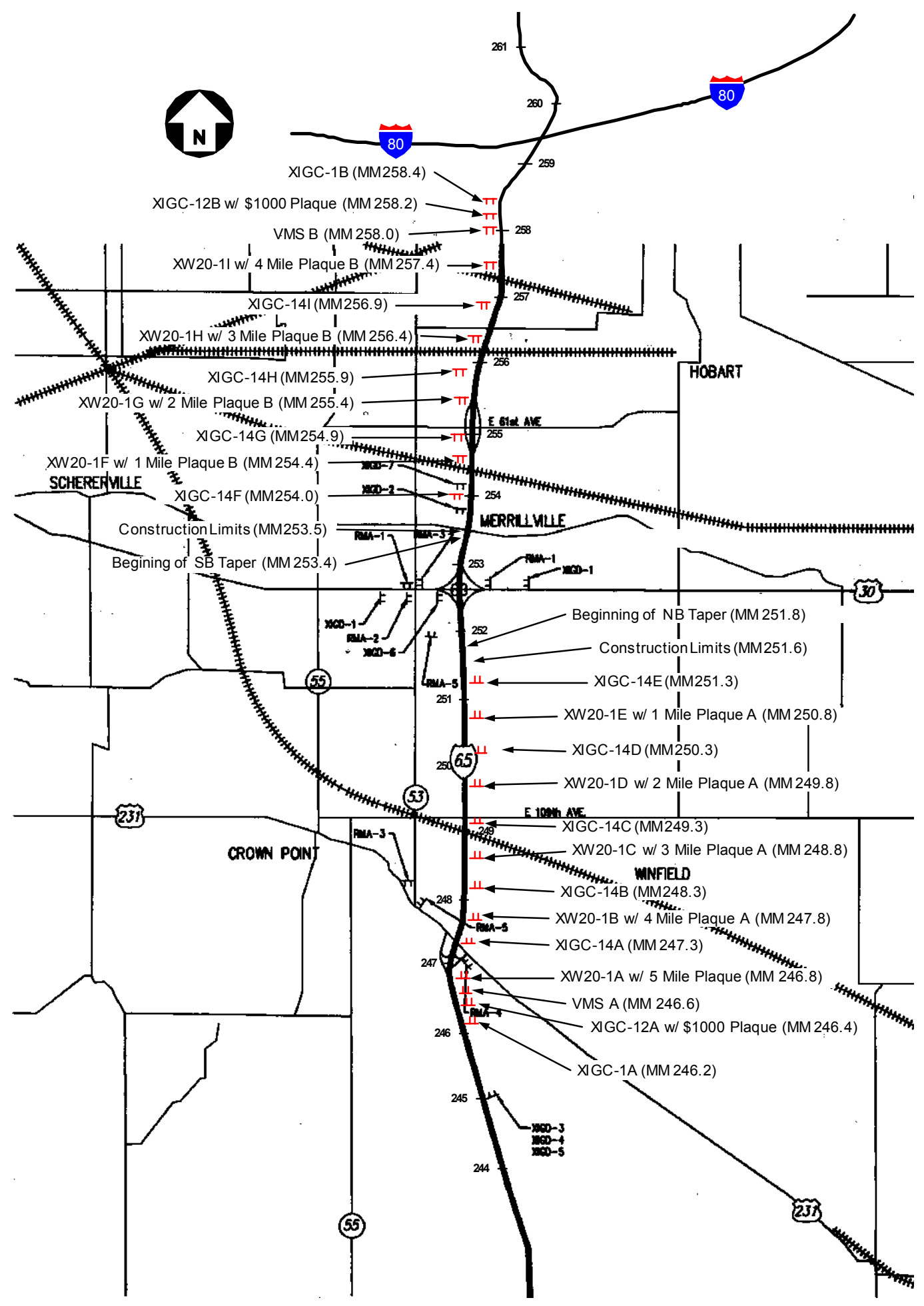

Figure 5-11 Locations of Work Zone Signs 


\section{CHAPTER 6. TESTING THE EFFECTIVENESS OF THE EXPERIMENTAL SIGNS}

\subsection{Project Description}

To determine the effectiveness of the added work zone signs, discussed in detail in Section 5.4, a testing procedure was developed. This procedure would focus on vehicle speeds and accident rates to determine if the signs improved the safety of the work zone.

\section{2. $\quad$ Speed Study}

The testing procedure called for the collection of the speeds of vehicles approaching and passing through the work zone to be collected on a regular basis at various sites. These speeds would then be used to determine if the added work zone signs had an impact on motorists, as expressed through a reduction in speeds.

\subsubsection{Speed Collection Locations}

To effectively measure the impact of the signs discussed in Section 5.4, the speeds of motorists approaching and passing through the work zone had to be collected and examined. To do so, the decision was made to choose numerous speed collection locations. Ideally, these locations would allow the research team to collect speeds of motorists before and after specific signs and at various locations on the approach to and throughout the work zone.

\subsubsection{Precautions}

The research team was concerned that their presence in the work zone during periods of data collection would influence the speeds of motorists. For this reason, several precautions were taken to reduce the research team's impact on the speeds of motorists. The first of these precautions was to remain as out of sight of approaching motorists as possible. To do so, the decision was made to collect speeds from locations that were hidden from motorists, such as from an overpass. From this vantage point, an example of which can be seen in Figure 6-1, the 
research team had a clear view of traffic as it passed under the overpass and was hidden from oncoming traffic by the overpass itself.

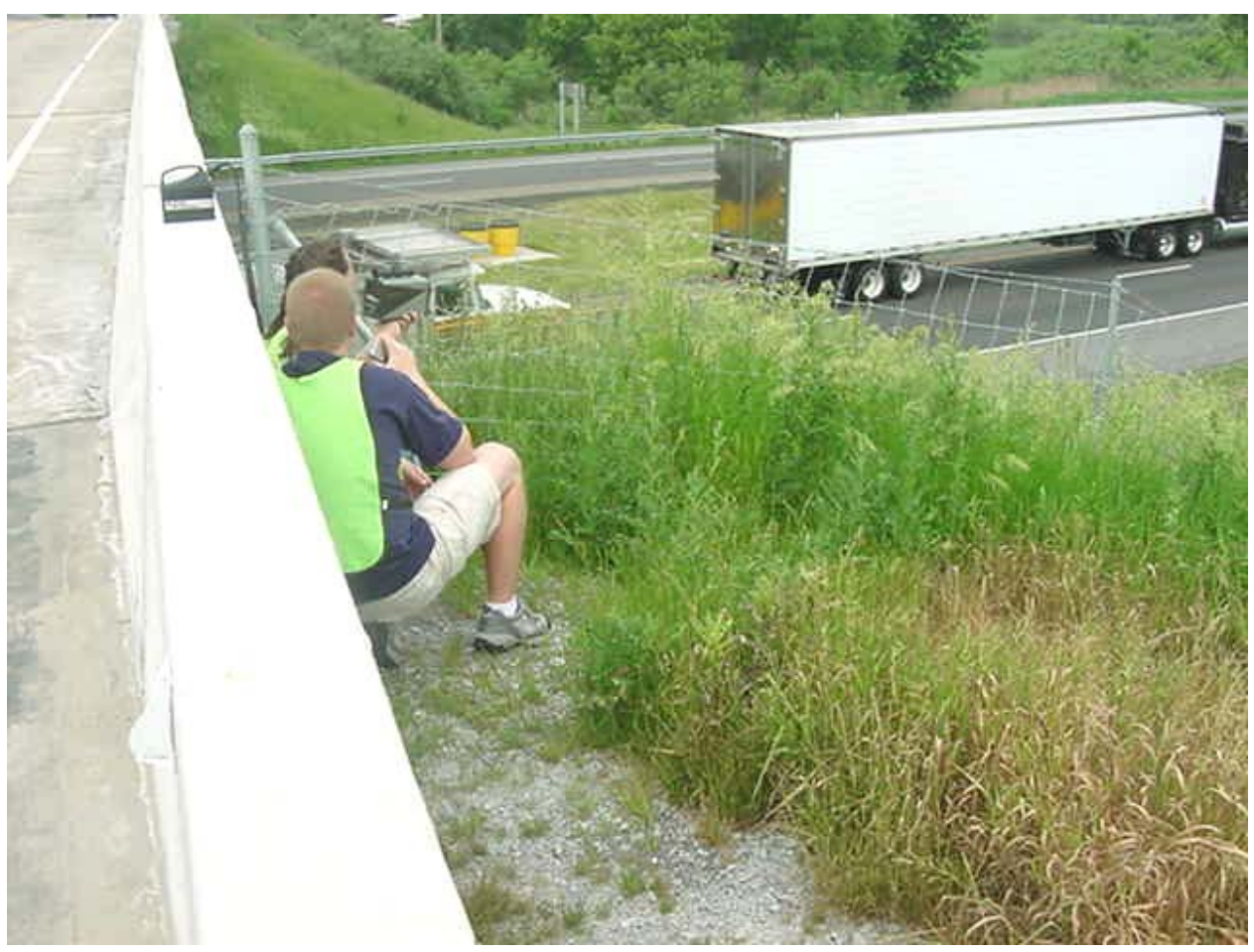

Figure 6-1 Example Data Collection Location

The second precaution taken by the research team was its choice of speed detection system. The team feared that those motorists who use radar detectors would detect the use of a radar speed detection system and thus reduce their speed. This reduction in speed by one motorist could then result in a speed reduction by several nearby motorists fearing that their speeds are being monitored by a police officer. Such an occurrence would then result in numerous skewed data points and would make the results of the study biased. To remedy this problem, the decision was made to use a laser speed detection system. A laser speed-measuring device was chosen because these devices have been found to have less of an impact on the speeds of motorists (Teed and Lund 93).

The research team also decided to attempt to verify that their presence in the work zone was not noticed. This was to be done in two ways. Members of the team would observe the behavior of vehicles as they passed the speed collection locations. Brake lights of passing vehicles would be examined as the research team searched for an indication that they had been detected by a 
motorist using a laser detection device. Also, CB radio would also be used to determine if the data collection process was unnoticed. As the research team collected speeds, they would also listen to conversations between truck drivers via a hand held CB radio. In the conversations, the team would listen for any indication that they had been noticed by passing truck drivers and for any signals to other drivers to reduce their speeds at certain locations.

\subsubsection{Interstate 65 Northbound}

The northbound approach to the work zone centered on US 30 provided ample chances to collect the speeds of motorists. This was due to two factors, which are the surrounding rural area and the abundance of overpasses. The surrounding rural area aided in the collection process because it allowed plenty of space for the research team to remain clear of the roadway as well as allowing the team and their vehicle to remain unnoticed by motorists on Interstate 65 . The abundance of overpasses aided in the collection process by providing numerous locations from which speeds of motorists could safely be collected while the research team remained hidden.

Due to these two factors, six northbound speed collection locations were chosen. Of these locations, several were chosen to determine the impact of specific signs, which is listed inTable 6-1. For instance, to determine the effect of the "Construction Ahead at US 30" sign on northbound traffic, speeds were collected from the $153^{\text {rd }}$ Avenue overpass, which is prior to motorists reaching the sign, and then from the $137^{\text {th }}$ Avenue overpass, which is immediately following the sign. To determine the impact of the Construction Fines sign and the variable message sign on northbound traffic, which would display the number of tickets issued to date in the work zone, speeds were collected at the $113^{\text {th }}$ Avenue overpass and compared to those speeds collected at the $137^{\text {th }}$ Avenue overpass. To determine the impact of all the work zone signs on the speeds of northbound motorists, speeds were collected at three other sites, which

were the $93^{\text {rd }}$ Avenue overpass, US 30 and the $73^{\text {rd }}$ Avenue overpass. It was decided that these locations, which can be seen in Figure 6-2 and also in Table 6-2, would provide a measurement of how motorists responded to the work zone signs. 


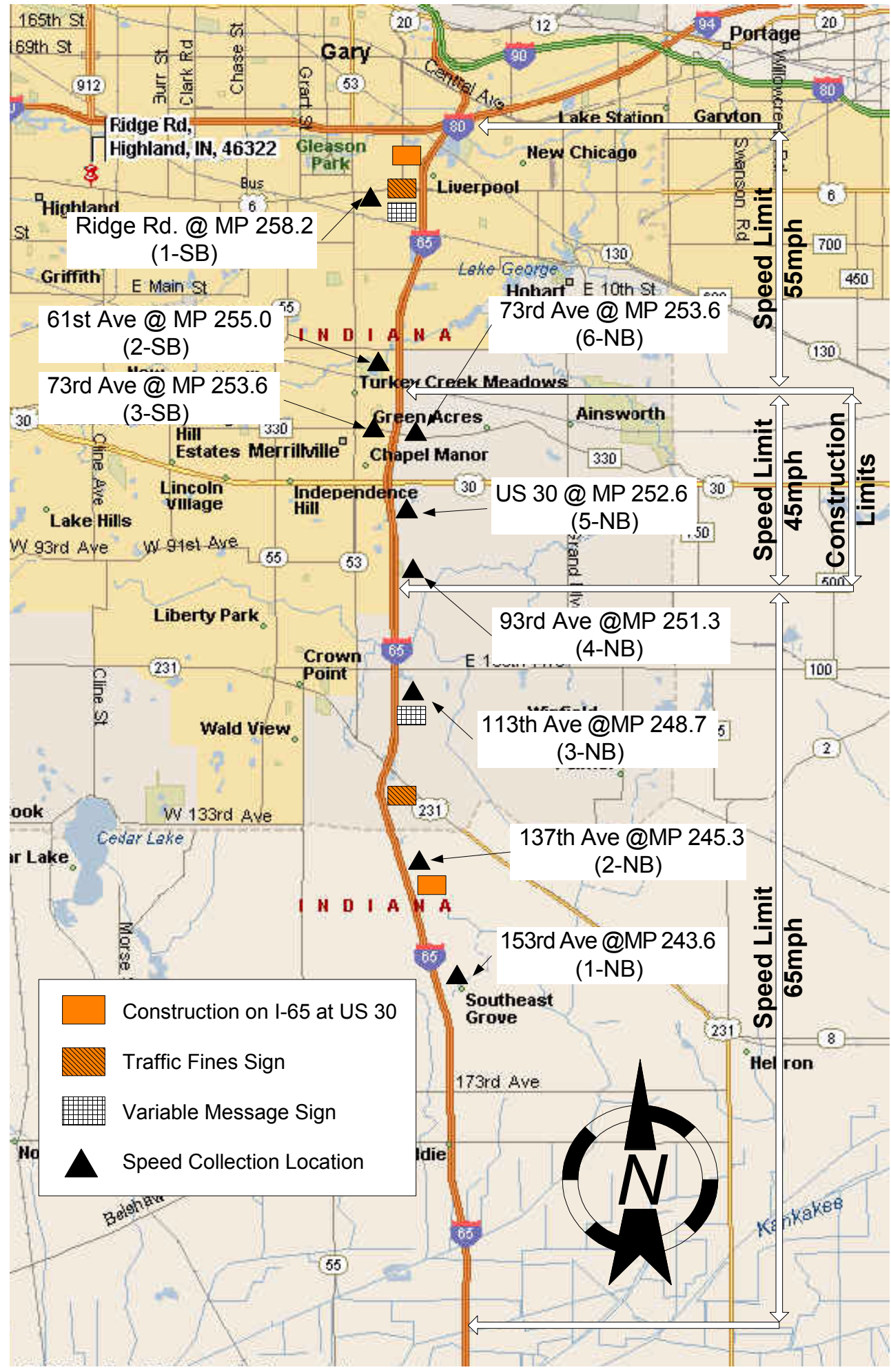

Figure 6-2 Speed Collection Locations 
Table 6-1 Location of Selected Signs

\begin{tabular}{|c|c|c|}
\cline { 2 - 3 } \multicolumn{1}{c|}{} & \multicolumn{2}{c|}{ Mile Marker } \\
\cline { 2 - 3 } \multicolumn{1}{c|}{} & NB & SB \\
\hline Construction on US-30 Sign & 245.9 & 258.7 \\
\hline Traffic Fines Schedule Sign & 248.2 & 258.2 \\
\hline Variable Message Sign & 248.7 & 258.2 \\
\hline
\end{tabular}

Table 6-2 General Information of Speed Collection Locations

\begin{tabular}{|c|c|c|c|c|c|}
\hline Number & Location & $\begin{array}{c}\text { Intersecting } \\
\text { Road }\end{array}$ & $\begin{array}{c}\text { Approx. } \\
\text { MilePost }\end{array}$ & $\begin{array}{c}\text { Description of } \\
\text { Location }\end{array}$ & Dir. \\
\hline \hline 1 & $1-\mathrm{NB}$ & $153^{\text {rd }}$ Avenue & 243.6 & Prior to VMS & NB \\
\hline 2 & $2-\mathrm{NB}$ & $137^{\text {th }}$ Avenue & 245.3 & Prior to VMS & NB \\
\hline 3 & $3-\mathrm{NB}$ & $113^{\text {th }}$ Avenue & 248.7 & After VMS & NB \\
\hline 4 & $4-\mathrm{NB}$ & $93^{\text {rd }}$ Avenue & 251.3 & $\begin{array}{c}\text { Beginning of Work } \\
\text { Zone }\end{array}$ & NB \\
\hline 5 & $5-\mathrm{NB}$ & US 30 & 252.6 & $\begin{array}{c}\text { Inside Work Zone } \\
\text { NB }\end{array}$ & NB \\
\hline 6 & $6-\mathrm{NB}$ & $73^{\text {rd }}$ Avenue & 253.6 & End of Work Zone & SB \\
\hline 7 & $1-\mathrm{SB}$ & Ridge Road & 258.1 & After VMS & SB \\
\hline 9 & $2-\mathrm{SB}$ & $61^{\text {st }}$ Avenue & 255 & After VMS & SB \\
\hline 9 & $3-\mathrm{SB}$ & $73^{\text {rd }}$ Avenue & 253.6 & $\begin{array}{c}\text { Beginning } \\
\text { Zon Work }\end{array}$ & \\
\hline
\end{tabular}

\subsubsection{Interstate 65 Southbound}

Although the northbound approach to the work zone provided numerous locations for speed collection, the southbound approach provided only limited opportunity. The area that is bounded by US 30 and Interstate 80/94 is densely populated with very few places to safely and unobtrusively park a vehicle. Interstate 65 from US 30 to Interstate $80 / 94$ has an ADT that is 
nearly twice as large as the segment of I-65 to the south of US 30. Due to the construction at US 30 , this area is often congested with frequent queues waiting to exit Interstate 65 onto US 30 . These conditions coupled with the few overpasses provided a less than ideal location for speed collection. Due to these factors, the research team was only able to collect speeds at only three locations instead of the six locations that were used for the northbound approach. As seen in Figure 6-2, it was not feasible to collect speeds of motorists before they reached the construction signs. It was possible to collect speeds of motorists after they had passed by the "Construction Fines" sign and the variable message sign displaying the number of tickets issued in the work zone to date. These speeds as well as those taken at the $61^{\text {st }}$ and $73^{\text {rd }}$ Avenue overpasses could then be used to determine the impact of the signs on the speeds of the motorists.

\subsubsection{The Locations}

As discussed in Section 6.2.2.1, the northbound approach to the work zone was very rural in nature. As can be seen in Figure 6-3, Figure 6-4, Figure 6-5 and Figure 6-6, the southernmost speed collection locations all had very similar characteristics. At each of the locations motorists were provided with wide travel lanes and shoulders and very few road side distractions due to the rural conditions. The major difference between these locations was the posted speed limit. At $153^{\text {rd }}, 137^{\text {th }}$ and $113^{\text {th }}$ Avenue, motorists could legally travel at 65 miles per hour. Once reaching $93^{\text {rd }}$ Avenue, the work zone speed limit of 45 miles per hour overruled the typical 65 miles per hour posted speed limit.

As motorists continued northward, they then passed the speed collection locations at US 30 and $73^{\text {rd }}$ Avenue, which can be seen in Figure 6-7 and Figure 6-8 respectively. As motorists approach these locations, they are faced with an increase in traffic volume, an added lane in each direction and numerous roadside distractions. Each location is within the posted work zone speed limit of 45 miles per hour; however motorists at $73^{\text {rd }}$ Avenue are typically traveling above the posted speed limit as they approach the 55 miles per hour zone which lies approximately 0.2 miles north of the overpass. 


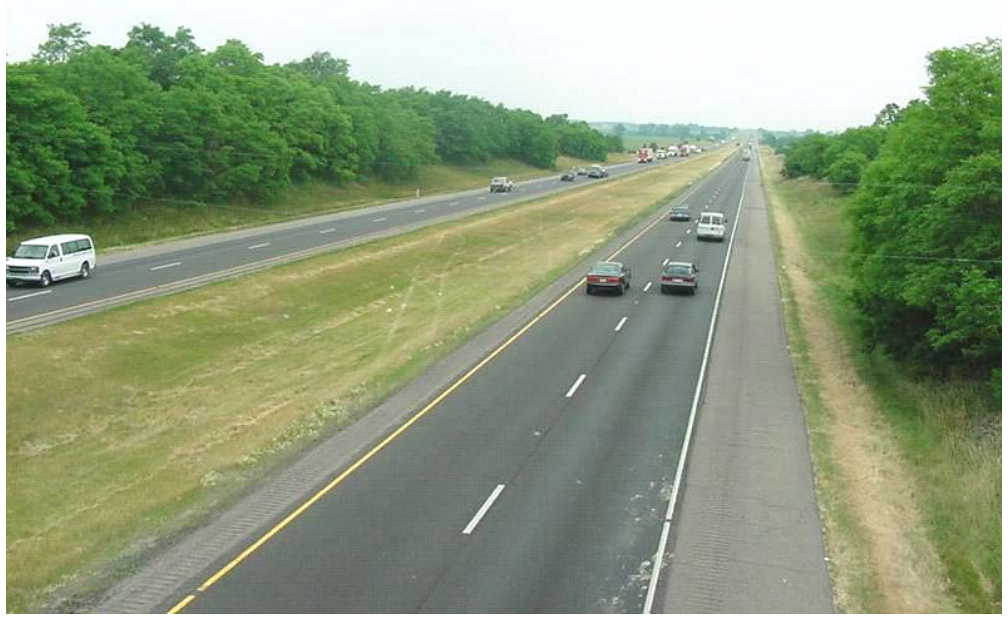

Figure 6-3 Interstate 65 Northbound at $153^{\text {rd }}$ Avenue, Posted Speed Limit 65 mph

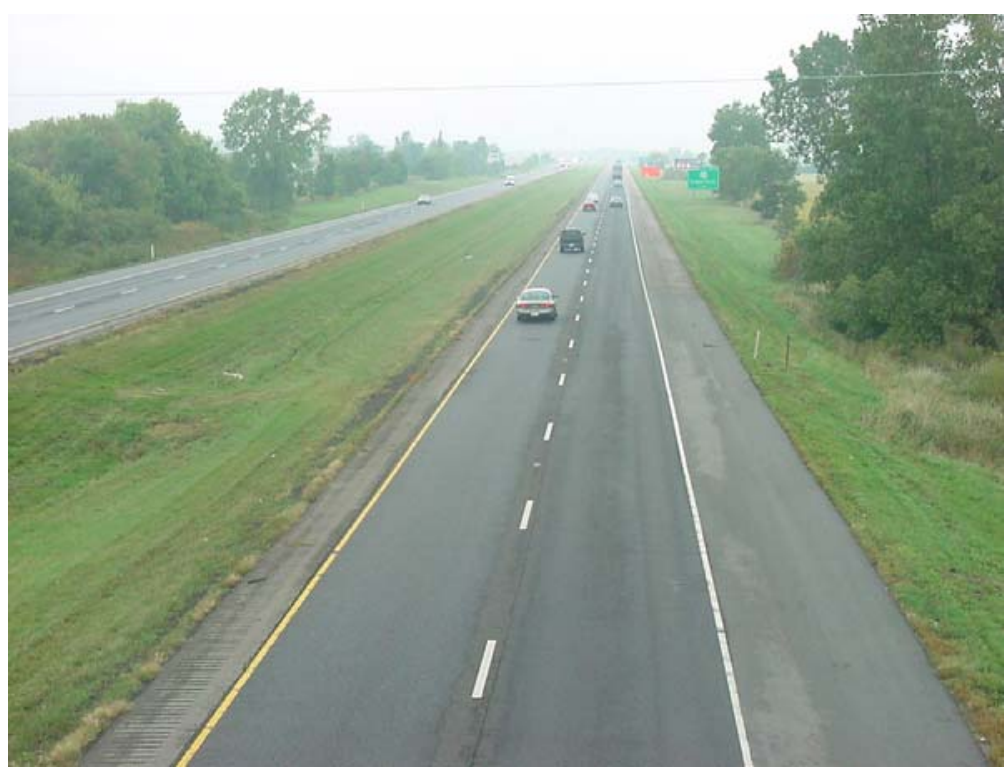

Figure 6-4 Interstate 65 Northbound at $137^{\text {th }}$ Avenue, Posted Speed Limit 65 mph 


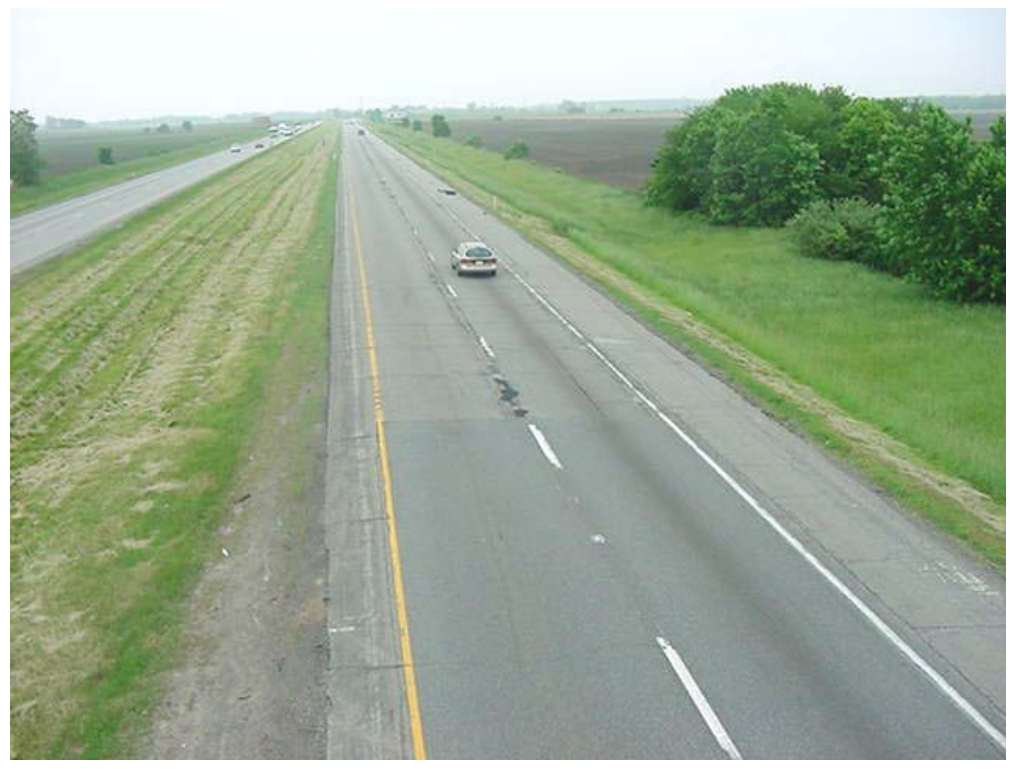

Figure 6-5 Interstate 65 Northbound at $113^{\text {th }}$ Avenue, Posted Speed Limit $65 \mathrm{mph}$

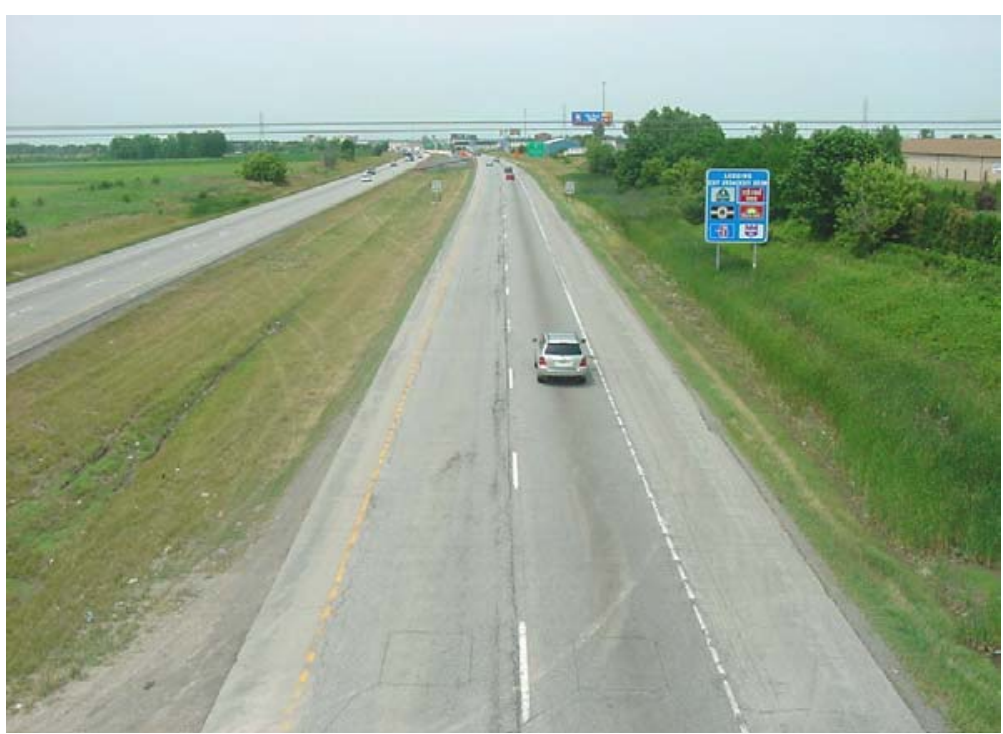

Figure 6-6 Interstate 65 Northbound at $93^{\text {rd }}$ Avenue, Posted Speed Limit 


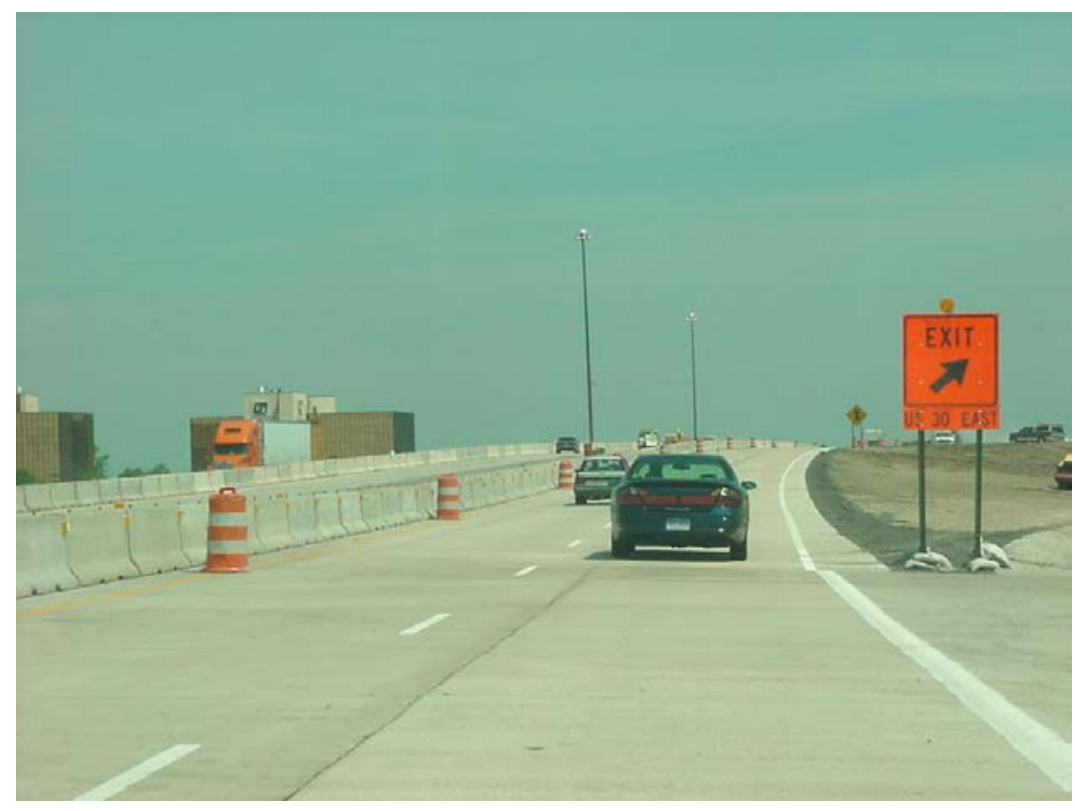

Figure 6-7 Interstate 65 Northbound at US 30, Posted Speed Limit

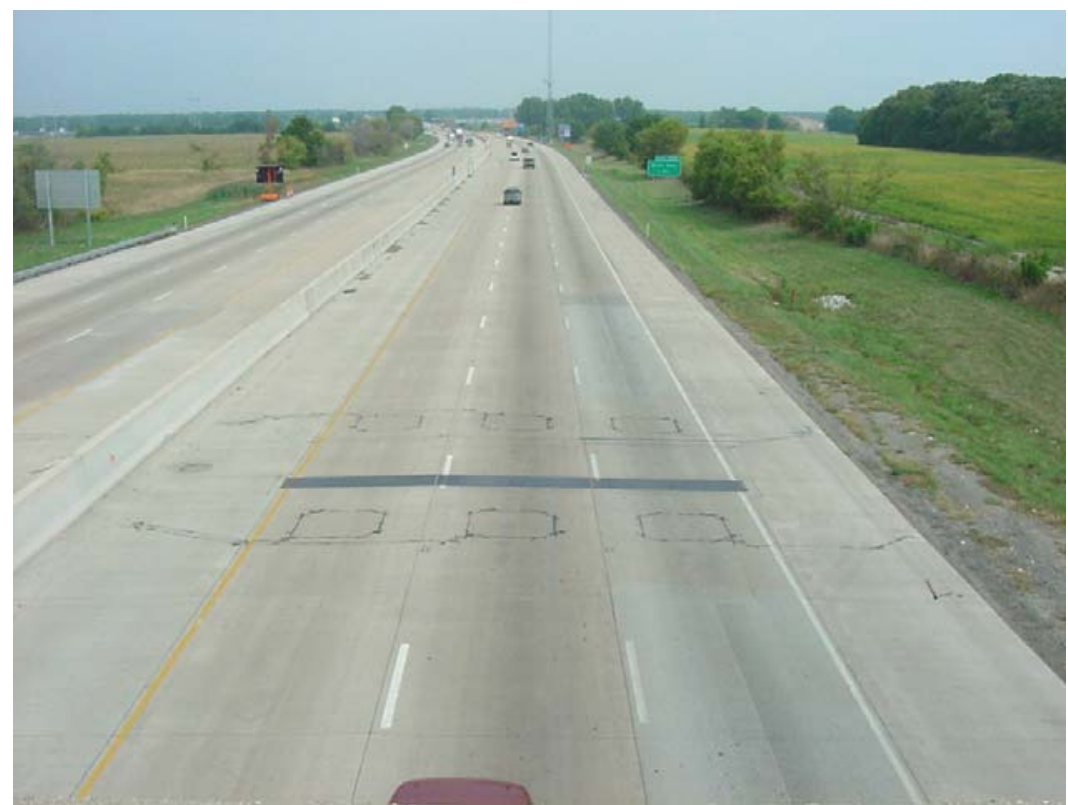

Figure 6-8 Interstate 65 Northbound at $73^{\text {rd }}$ Avenue, Posted Speed Limit

As motorists approached the work zone from the north, they encountered a much different situation than when approaching from the south. The southbound approach to the work zone 
leads motorists through a very urbanized area. This area, which can be seen in Figure 6-9, Figure 6-10 and Figure 6-11, changes very little from one speed collection location to the next. Each of the locations provides motorists with three travel lanes, narrow shoulders and high volumes of traffic. Unlike the northbound approach to the work zone, the southbound approach has three interchanges, located at Interstate 80/94, Ridge Road and $61^{\text {st }}$ Avenue, that all result in frequently merging traffic. The posted speed limit at Ridge Road and $61^{\text {st }}$ Avenue is 55 miles per hour and reduces to 45 mile per hour at $73^{\text {rd }}$ Avenue as motorists enter the work zone.

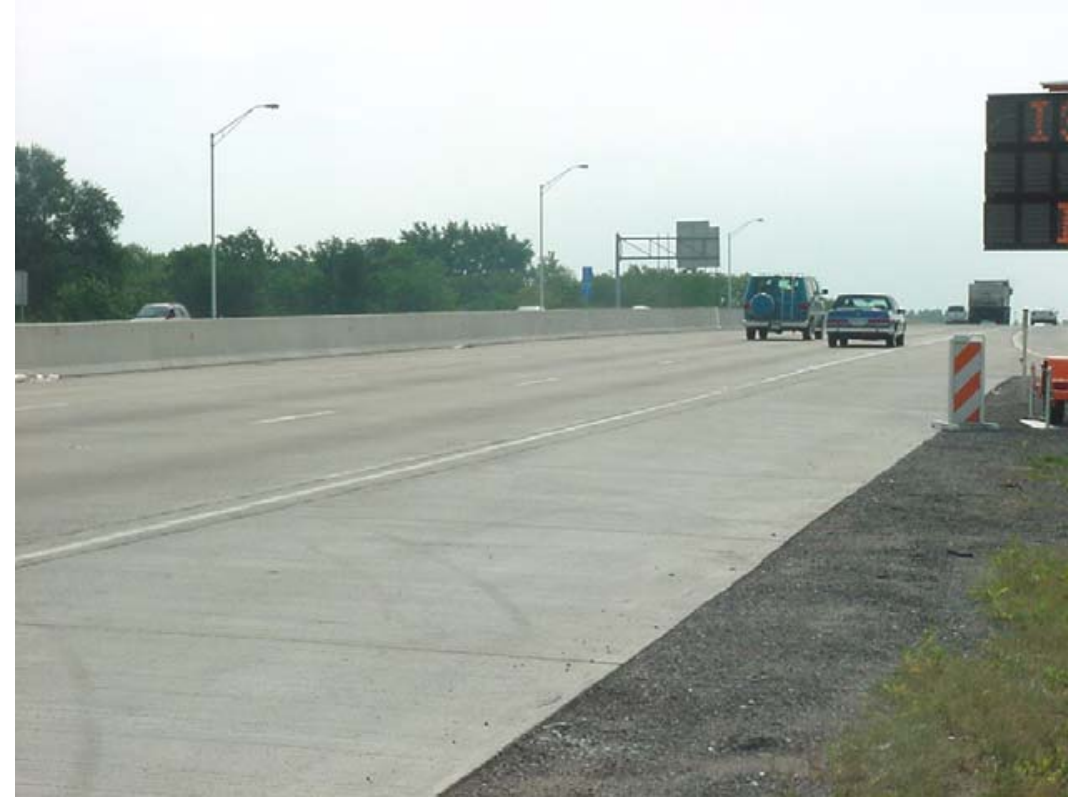

Figure 6-9 Interstate 65 Southbound at Ridge Road 


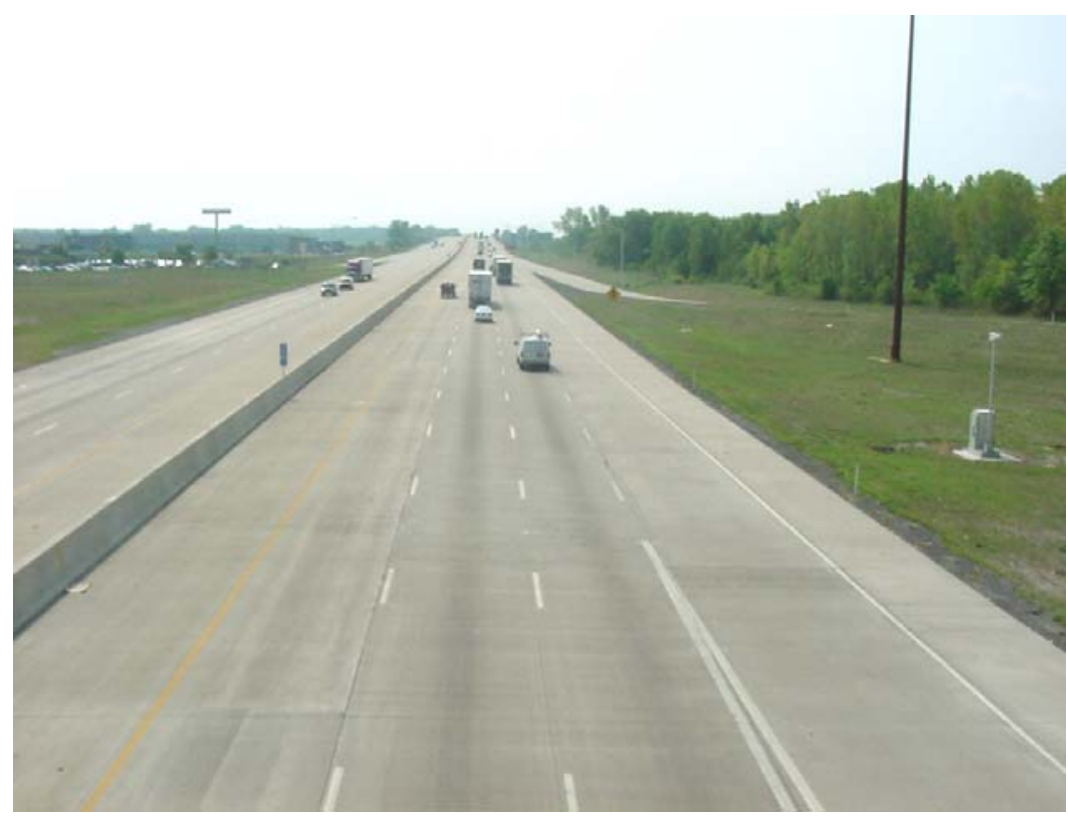

Figure 6-10 Interstate 65 Southbound at $61^{\text {st }}$ Avenue

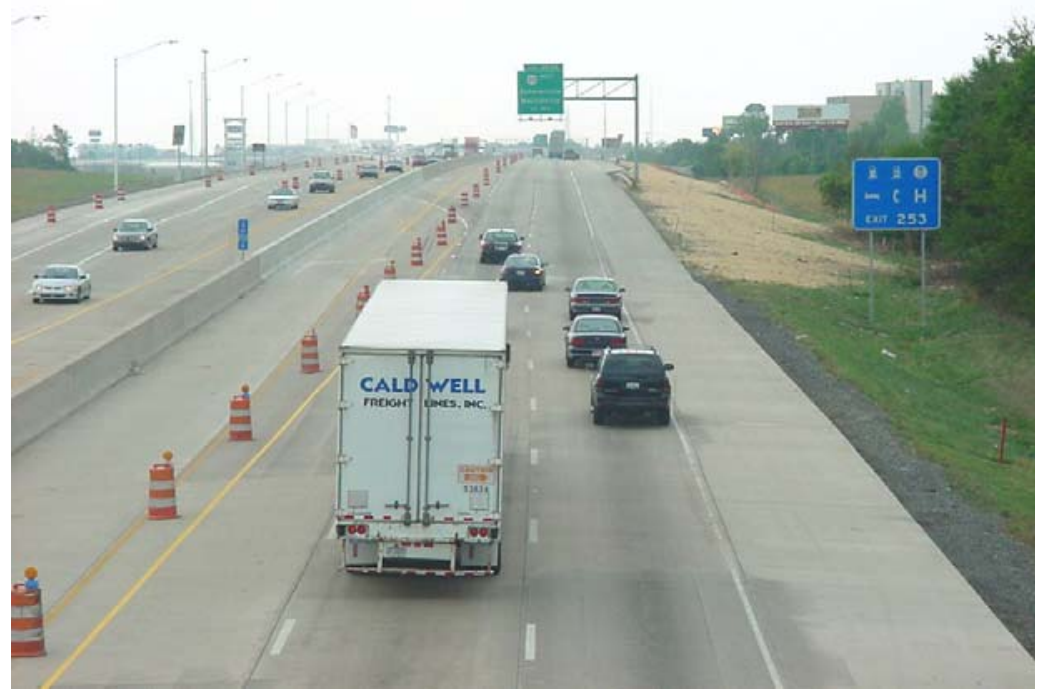

Figure 6-11 Interstate 65 Southbound at $73^{\text {rd }}$ Avenue 


\subsubsection{The Process}

While following the previously mentioned precautions at each of the speed collection locations, members of the research team collected speeds of vehicles traveling away from their location. At each location, the research team collected the speeds of approximately 300 vehicles in an effort to obtain an adequate sample size. The speeds of approximately the first 300 vehicles were obtained, with no effort to select specific vehicles during the collection process. Depending on the time of day and thus the volume of vehicles that passed the speed collection locations, the collection process typically took between ten and thirty minutes.

It was expected that the experimental work zone signs would reduce the speeds of motorists approaching and passing through the work zone. In order to test this hypothesis, speeds were collected at selected times throughout the lifetime of the signs, as can be seen in Table 6-3. It was desired to obtain the speeds of motorists before they reached work zone signs, described in Section 5.4. It was also desired to collect the speeds of motorists with the signs in place, but no message on the variable message signs. This would provide an indication of how motorists reacted to the panel signs and most likely how motorists reacted to viewing the amounts of the traffic fines that were issued in the work zone. After collecting these speeds, the research team would then display the number of tickets issued to date in the work zone and again collect speeds following the appearance of the message. Comparison of these speeds with those speeds previously collected would indicate how motorists reacted to the amount of tickets issued in the work zone. After these tasks, the research team would then update the number of tickets issued weekly and collect speeds on a bi-weekly basis. Four times throughout this process, speeds would be collected before and after changing the messages on the variable message signs. Once again, these speeds would provide an indication of how motorists reacted to the message. 
Table 6-3 Various Speed Collection Cases

\begin{tabular}{|c|c|c|c|c|}
\hline Case & Description & Date & Message on VMS & $\begin{array}{c}\text { Traffic Management } \\
\text { Phase }\end{array}$ \\
\hline \hline A & Before signage & 25-Jun-02 & None & I \\
\hline B & With Panel Signs Only & 7-Aug-02 & None & III \\
\hline C & With Panel Signs \& VMS & 7-Aug-02 & 2078 Traffic Fines & III \\
\hline D & Week 1 & 15-Aug-02 & 2150 Traffic Fines & III \\
\hline E & Week 2 & 15-Aug-02 & 2184 Traffic Fines & III \\
\hline F & Week 4 & 28-Aug-02 & 2288 Traffic Fines & III \\
\hline G & Week 5 & 4-Sep-02 & 2391 Traffic Fines & III \\
\hline H & Week 7 & 18-Sep-02 & 2459 Traffic Fines & IV \\
\hline I & Week 8 & 18-Sep-02 & 2537 Traffic Fines & IV \\
\hline J & Week 8 & $27-S e p-02$ & 2537 Traffic Fines & IV \\
\hline K & Week 9 & $27-S e p-02$ & 2591 Traffic Fines & IV \\
\hline
\end{tabular}

As seen in Table 6-3, the speed collection cases did not all occur during the same traffic management phase. In fact, no speeds were collected during several of the phases. As seen in Table 6-4, no speeds were collected during Phases I, IA, and IB. This occurred because the speed collection process was not begun until Phase II.

Table 6-4 Traffic Management Phases

\begin{tabular}{|c|c|c|}
\hline $\begin{array}{c}\text { Traffic Management } \\
\text { Phase }\end{array}$ & Start Date & End Date \\
\hline \hline I \& IA & 5-Mar-02 & 25-Apr-02 \\
\hline IB & 25-Apr-02 & 30-Apr-02 \\
\hline II & 30-Apr-02 & 8-Jul-02 \\
\hline IIA & 8-Jul-02 & 17-Jul-02 \\
\hline III & 17-Jul-02 & 21-Sep-02 \\
\hline IV & 21-Sep-02 & 31-Oct-02 \\
\hline
\end{tabular}

The traffic management phases listed in Table 6-4 and shown in Figure 6-12 through Figure 6-18, did impact the results of the speed study by influencing the way in which traffic was allowed to 
flow through the work zone. When the speed collection process was begun, traffic flowed through the work zone according to Phase II. During this phase, southbound traffic merged from three lanes to two just before reaching the exit to US 30 , as illustrated in Figure 6-14. This merging process coupled with motorists desiring to exit attempting to reach the correct lane, caused a great deal of congestion. This congestion resulted in southbound traffic flowing at speeds averaging 16.5 miles per hour during peak periods, as seen in Table 6-5. This problem was alleviated by traffic management Phases IIA through IV, which eliminated the merging process, and thus increased the average speed of traffic. 


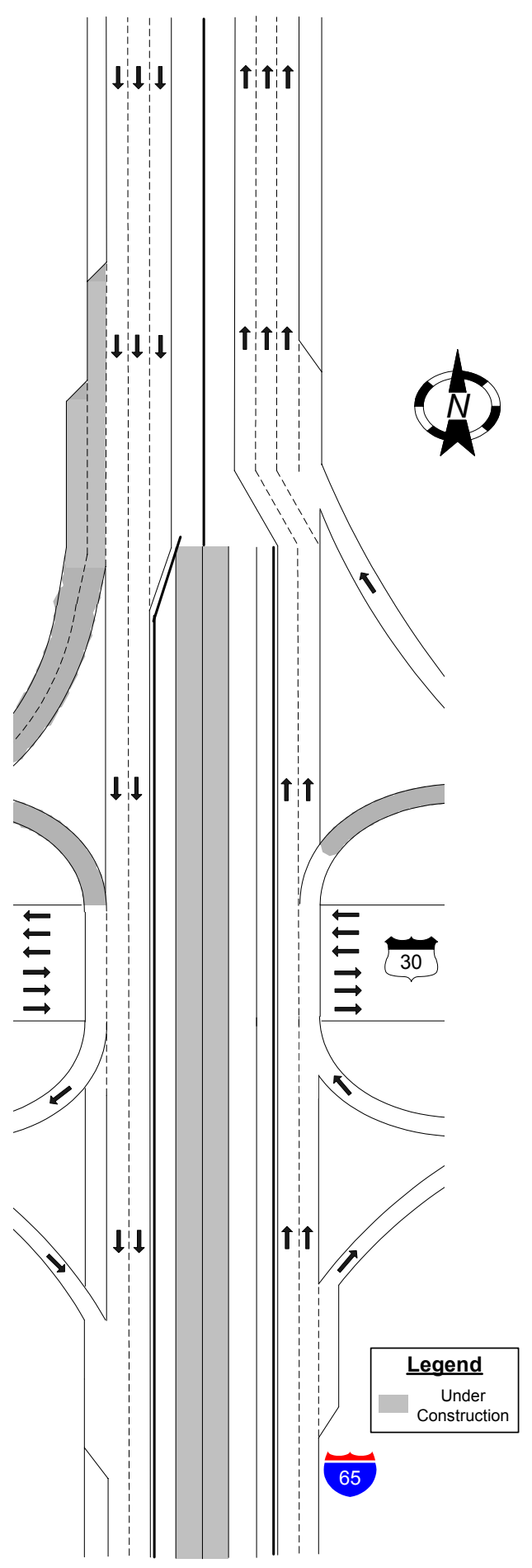

Figure 6-12 Phase I and IA 


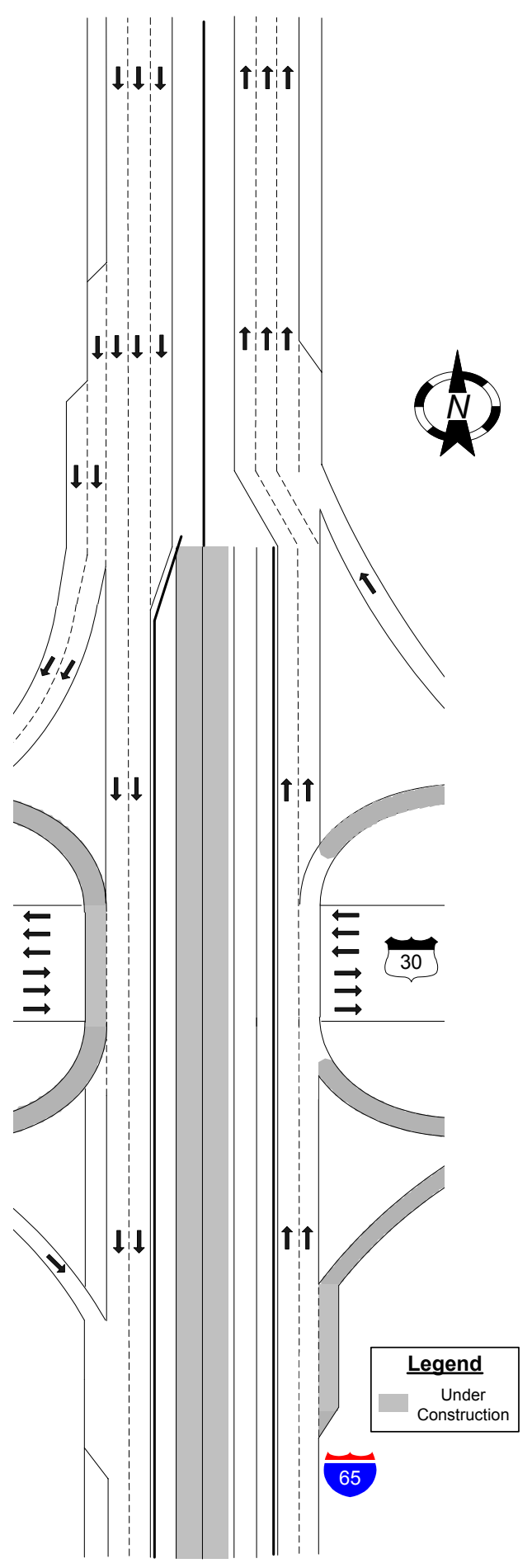

Figure 6-13 Phase IB 


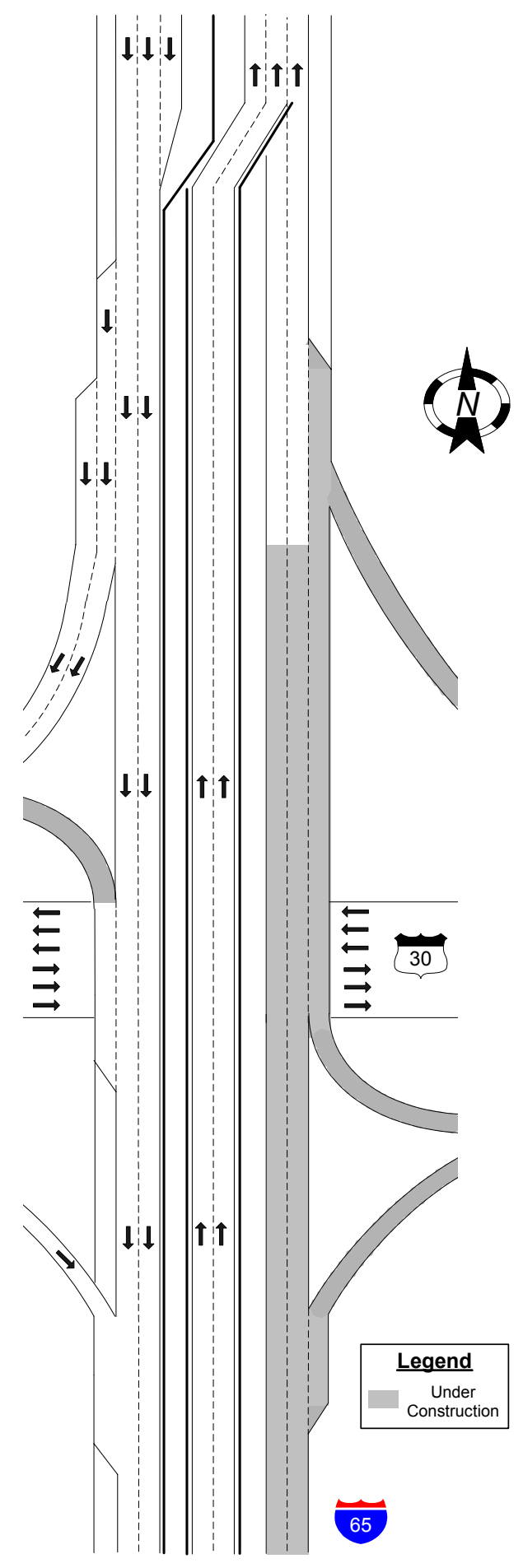

Figure 6-14 Phase II 


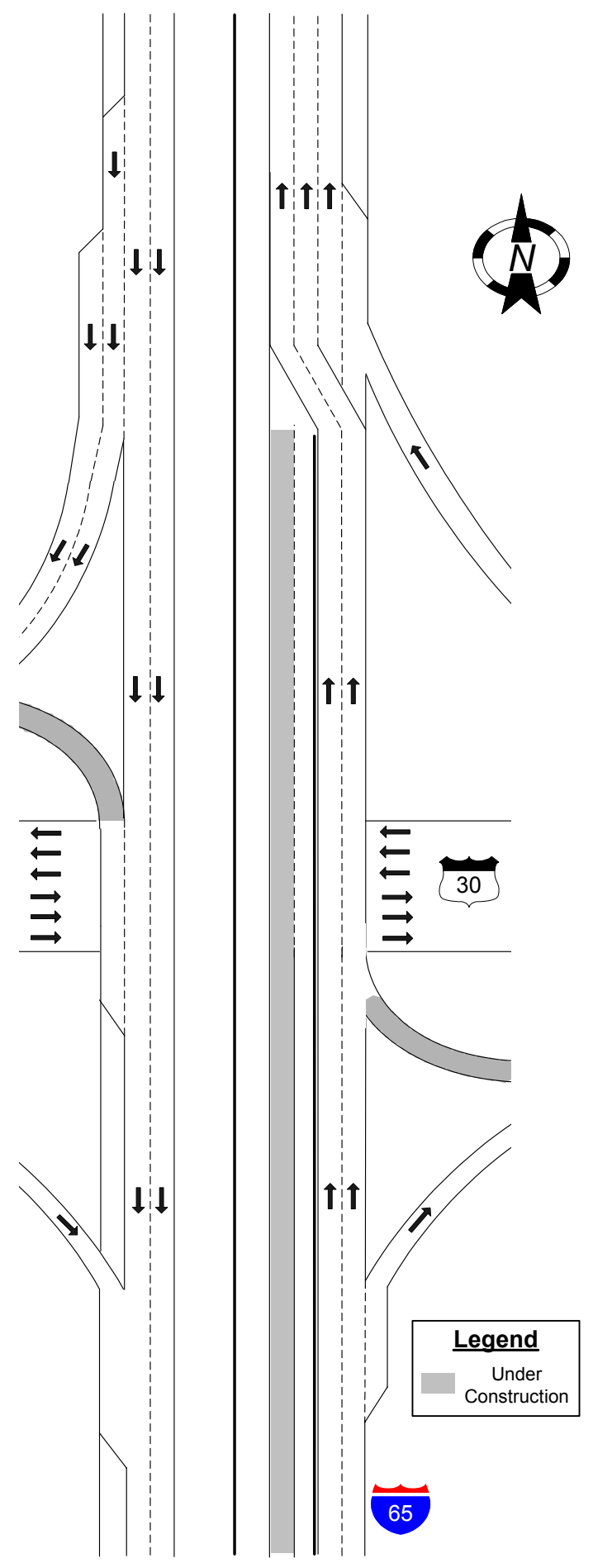

Figure 6-15 Phase IIA 


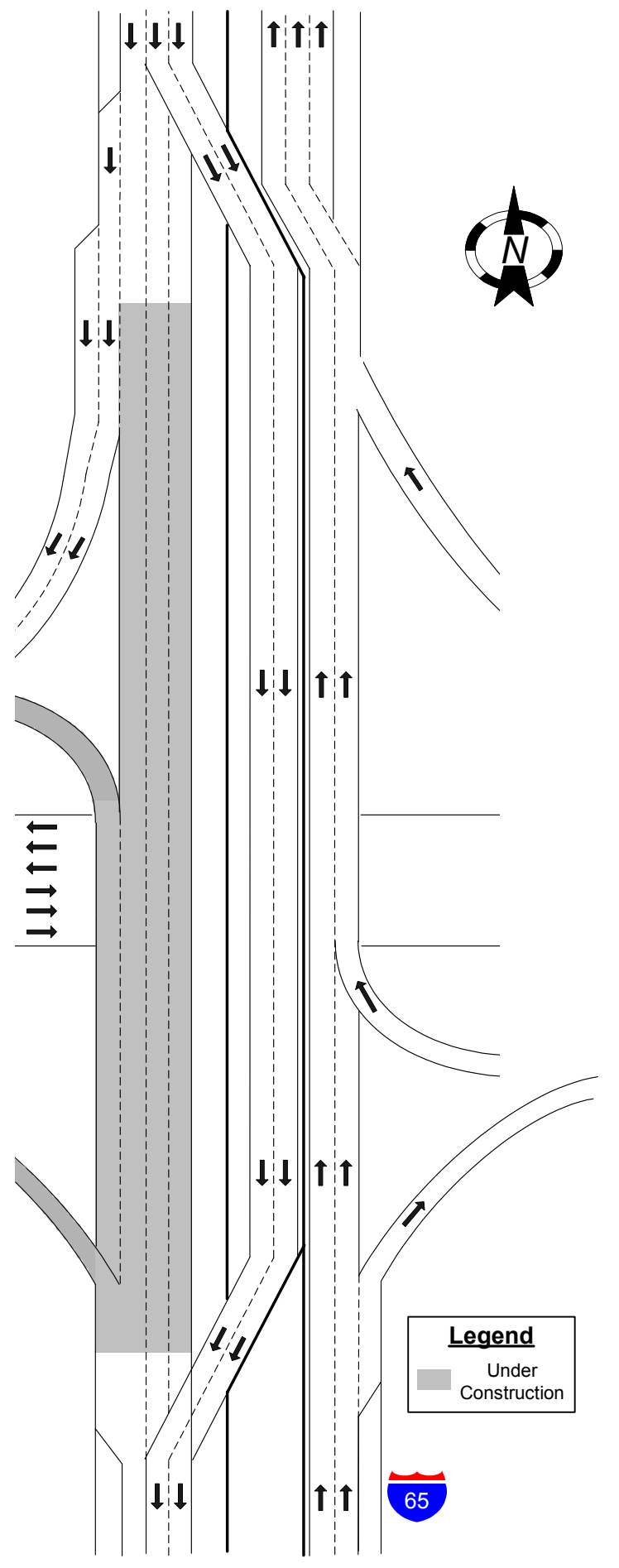

Figure 6-16 Phase III 


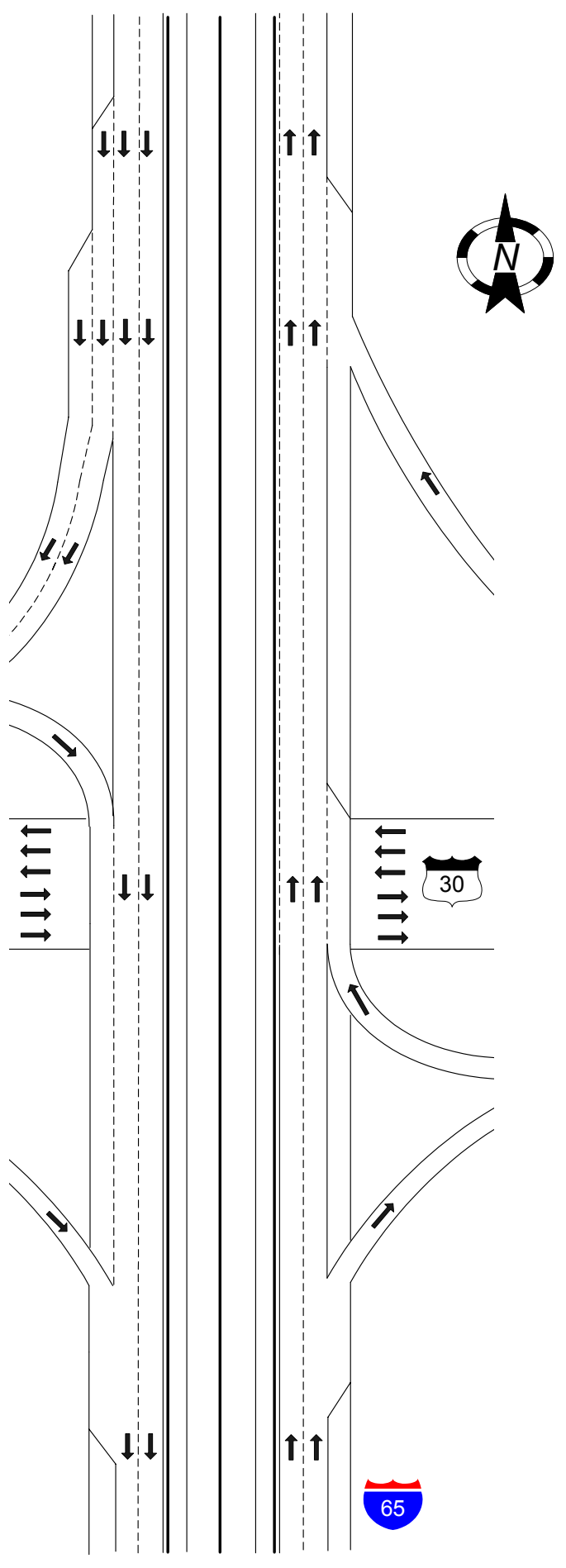

Figure 6-17 Phase IV 


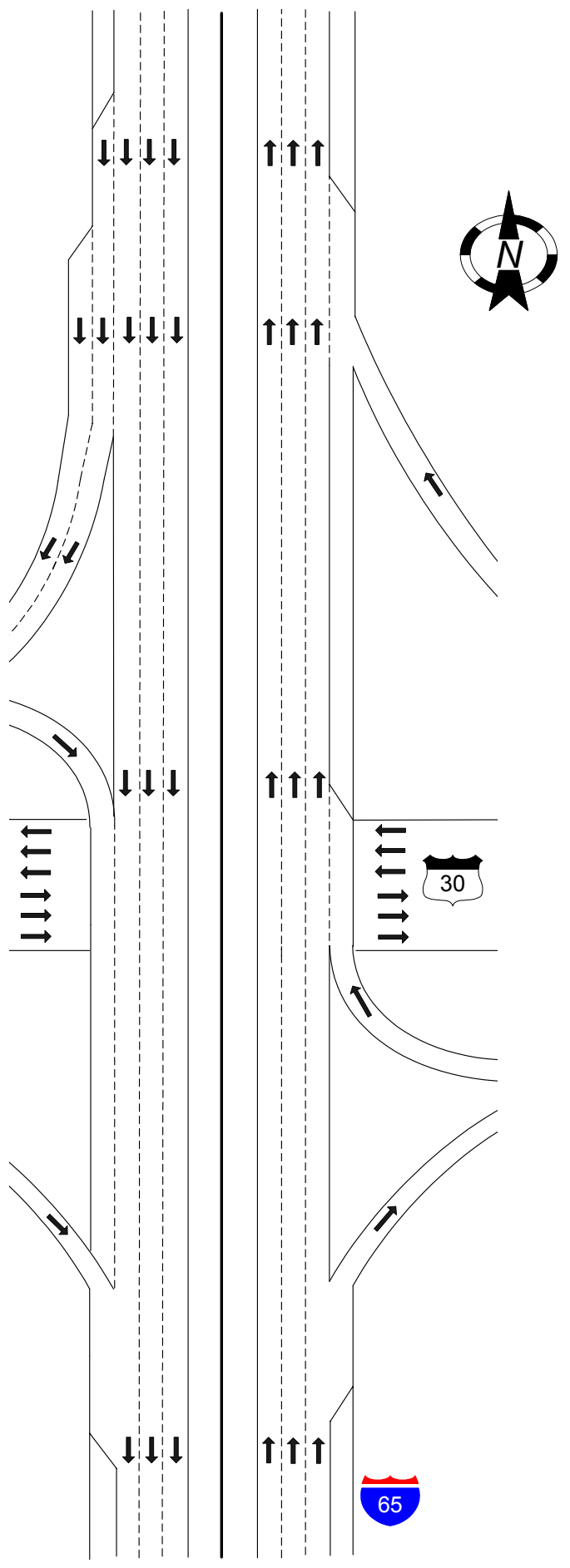

Figure 6-18 Final 


\subsubsection{Results}

\subsubsection{Averages}

As can be seen in Table 6-5, installation of the signs did not have as substantial of an impact on the speeds of motorists as the research team had originally anticipated. Table 6-5 shows that installation of the panel signs only produced a sizeable reduction (Case A vs. Case $B$ ) in the average speed at location 5-NB, which is the I-65/US 30 interchange. This reduction in the average speeds may be attributed to motorists not feeling the need to reduce their speeds until reaching the work zone. A past study has found that speed reduction will only occur when the work zone is in sight (Fors 2000).

Also found in Table 6-5 is the impact of the variable message signs. The table indicates that displaying the number of traffic fines issued to date in the work zone resulted less of a reduction in the average speed of motorists (Case $B$ vs. Case $C$ ) than the reduction associated with the panel signs (Case A vs. Case B).

Congestion played a role in the results. Table 6-5 indicates the mean speed to be extremely low (16.5 mph) for Case A at location 3-SB. This low average speed was a result of the ramp from Interstate 65 to US 30- spilling back onto the interstate and causing congested conditions. For this reason, it was not possible to determine the impact of the fixed signs at this location.

Table 6-5 Average Speed per Location: Cases A, B \& C

\begin{tabular}{|c|c|c|c|c|c|c|c|c|c|c|c|}
\hline \multirow{2}{*}{$\begin{array}{l}\text { Location } \\
\text { Code }\end{array}$} & \multirow{2}{*}{$\begin{array}{l}\text { Approx. } \\
\text { Milepost }\end{array}$} & \multirow{2}{*}{$\begin{array}{l}\text { Speed } \\
\text { Limit }\end{array}$} & \multicolumn{3}{|c|}{ Case A } & \multicolumn{3}{|c|}{ Case B } & \multicolumn{3}{|c|}{ Case C } \\
\hline & & & $\begin{array}{c}\text { Sample } \\
\text { Size }\end{array}$ & Average & Std. Dev & $\begin{array}{c}\text { Sample } \\
\text { Size }\end{array}$ & Average & Std. Dev & $\begin{array}{c}\text { Sample } \\
\text { Size }\end{array}$ & Average & Std. Dev \\
\hline 1-NB & 243.6 & 65 & 336 & 69.0 & 5.3 & 333 & 68.5 & 5.7 & 307 & 70.8 & 6.2 \\
\hline $2-N B$ & 245.3 & 65 & 274 & 67.1 & 5.3 & 342 & 67.3 & 5.6 & 312 & 67.8 & 5.4 \\
\hline $3-N B$ & 248.7 & 65 & 360 & 67.5 & 5.8 & 308 & 66.1 & 5.6 & 310 & 66.3 & 5.8 \\
\hline 4-NB & 251.3 & 45 & 366 & 65.7 & 6.1 & 305 & 63.6 & 6.3 & 327 & 63.9 & 6.7 \\
\hline $5-N B$ & 252.6 & 45 & 354 & 65.7 & 6.1 & 312 & 55.4 & 6.5 & 259 & 56.1 & 7.3 \\
\hline $6-N B$ & 253.6 & 55 & 181 & 59.2 & 5.1 & 310 & 59.3 & 4.8 & 309 & 63.3 & 6.0 \\
\hline $1-S B$ & 258.2 & 55 & N/A & N/A & N/A & $\mathrm{N} / \mathrm{A}$ & N/A & N/A & N/A & N/A & $\mathrm{N} / \mathrm{A}$ \\
\hline $2-S B$ & 255.0 & 55 & $\mathrm{~N} / \mathrm{A}$ & $\mathrm{N} / \mathrm{A}$ & $\mathrm{N} / \mathrm{A}$ & $\mathrm{N} / \mathrm{A}$ & $\mathrm{N} / \mathrm{A}$ & $\mathrm{N} / \mathrm{A}$ & N/A & N/A & $\mathrm{N} / \mathrm{A}$ \\
\hline $3-S B$ & 253.6 & 45 & 263 & 16.5 & 6.8 & 306 & 49.4 & 7.2 & 309 & 56.4 & 6.7 \\
\hline
\end{tabular}

Table 6-6, Table 6-7 and Table 6-8 show the average speeds at each collection location for Cases D thru K. Similar to the average speeds seen in Table 6-5, the average speed per location only appears to be reduced, due to the signs, at location 5-NB or at the I-65/ US 30 interchange. 
Table 6-6 Average Speed per Location: Cases D, E \& F

\begin{tabular}{|c|c|c|c|c|c|c|c|c|c|c|c|}
\hline \multirow{2}{*}{$\begin{array}{c}\text { Location } \\
\text { Code }\end{array}$} & \multirow{2}{*}{$\begin{array}{c}\text { Approx. } \\
\text { Milepost }\end{array}$} & $\begin{array}{c}\text { Speed } \\
\text { Limit }\end{array}$ & $\begin{array}{c}\text { Sample } \\
\text { Size }\end{array}$ & Average & Std. Dev & $\begin{array}{c}\text { Sample } \\
\text { Size }\end{array}$ & Average & Std. Dev & $\begin{array}{c}\text { Sample } \\
\text { Size }\end{array}$ & $\begin{array}{c}\text { Average } \\
\text { Std. Dev }\end{array}$ \\
\hline \hline 1-NB & 243.6 & 65 & 307 & 70.8 & 6.2 & 303 & 70.1 & 5.7 & 309 & 67.9 & 5.0 \\
\hline 2-NB & 245.3 & 65 & 304 & 69.1 & 5.6 & 305 & 70.3 & 6.3 & 245 & 68.0 & 5.4 \\
\hline 3-NB & 248.7 & 65 & 310 & 66.9 & 5.5 & 309 & 68.8 & 5.6 & 305 & 65.7 & 5.4 \\
\hline 4-NB & 251.3 & 45 & 310 & 63.2 & 7.4 & 307 & 65.2 & 7.1 & 305 & 62.1 & 6.2 \\
\hline 5-NB & 252.6 & 45 & 294 & 56.1 & 6.5 & 304 & 57.2 & 6.6 & 302 & 55.2 & 6.3 \\
\hline 6-NB & 253.6 & 55 & 324 & 62.2 & 5.7 & 297 & 64.7 & 6.2 & 316 & 61.2 & 5.2 \\
\hline 1-SB & 258.2 & 55 & N/A & N/A & N/A & N/A & N/A & N/A & 302 & 62.4 & 5.8 \\
\hline 2-SB & 255.0 & 55 & N/A & N/A & N/A & N/A & N/A & N/A & 289 & 62.3 & 6.5 \\
\hline 3-SB & 253.6 & 45 & 301 & 50.0 & 7.1 & 305 & 56.9 & 6.0 & 311 & 55.1 & 6.3 \\
\hline
\end{tabular}

Table 6-7 Average Speed per Location: Cases G, H \& I

\begin{tabular}{|c|c|c|c|c|c|c|c|c|c|c|c|}
\hline \multirow{2}{*}{$\begin{array}{l}\text { Location } \\
\text { Code }\end{array}$} & \multirow{2}{*}{$\begin{array}{l}\text { Approx. } \\
\text { Milepost }\end{array}$} & \multirow{2}{*}{$\begin{array}{l}\text { Speed } \\
\text { Limit }\end{array}$} & \multicolumn{3}{|c|}{ Case G } & \multicolumn{3}{|c|}{ Case H } & \multicolumn{3}{|c|}{ Case I } \\
\hline & & & $\begin{array}{c}\text { Sample } \\
\text { Size }\end{array}$ & Average & Std. Dev & $\begin{array}{c}\text { Sample } \\
\text { Size }\end{array}$ & Average & Std. Dev & $\begin{array}{c}\text { Sample } \\
\text { Size }\end{array}$ & Average & Std. Dev \\
\hline 1-NB & 243.6 & 65 & 310 & 69.5 & 6.0 & 303 & 69.6 & 5.0 & 312 & 71.0 & 6.1 \\
\hline $2-N B$ & 245.3 & 65 & 310 & 68.3 & 5.3 & 311 & 68.5 & 5.8 & 242 & 69.7 & 6.2 \\
\hline $3-N B$ & 248.7 & 65 & 314 & 65.1 & 5.2 & 311 & 66.7 & 5.9 & 315 & 66.1 & 5.4 \\
\hline 4-NB & 251.3 & 45 & 328 & 68.3 & 5.2 & 307 & 68.5 & 5.9 & 325 & 69.7 & 5.4 \\
\hline $5-N B$ & 252.6 & 45 & 298 & 53.1 & 7.2 & 229 & 55.3 & 5.7 & 305 & 55.2 & 7.2 \\
\hline 6-NB & 253.6 & 55 & 331 & 61.5 & 5.9 & 307 & 61.3 & 5.4 & 316 & 64.2 & 5.5 \\
\hline $1-S B$ & 258.2 & 55 & 322 & 61.7 & 5.5 & 304 & 58.8 & 5.3 & 302 & 58.9 & 5.5 \\
\hline $2-S B$ & 255.0 & 55 & 352 & 62.7 & 6.3 & 295 & 61.5 & 6.5 & 338 & 61.9 & 5.8 \\
\hline $3-S B$ & 253.6 & 45 & 313 & 56.4 & 6.2 & 310 & 55.7 & 5.8 & 312 & 54.4 & 7.3 \\
\hline
\end{tabular}


Table 6-8 Average Speed per Location: Cases J \& K

\begin{tabular}{|c|c|c|c|c|c|c|c|c|}
\hline \multirow{2}{*}{$\begin{array}{c}\text { Location } \\
\text { Code }\end{array}$} & \multirow{2}{*}{$\begin{array}{c}\text { Approx. } \\
\text { Milepost }\end{array}$} & Speed & \multicolumn{3}{|c|}{ Lase J } & \multicolumn{3}{c|}{ Case K } \\
\cline { 5 - 9 } & & & $\begin{array}{c}\text { Sample } \\
\text { Size }\end{array}$ & Average & Std. Dev & $\begin{array}{c}\text { Sample } \\
\text { Size }\end{array}$ & Average & Std. Dev \\
\hline \hline 1-NB & 243.6 & 65 & 318 & 70.5 & 5.5 & 311 & 70.3 & 5.8 \\
\hline 2-NB & 245.3 & 65 & 309 & 68.7 & 5.6 & 311 & 68.7 & 5.7 \\
\hline 3-NB & 248.7 & 65 & 313 & 66.6 & 5.9 & 309 & 67.1 & 5.5 \\
\hline 4-NB & 251.3 & 45 & 314 & 68.7 & 5.9 & 313 & 68.7 & 5.5 \\
\hline 5-NB & 252.6 & 45 & 291 & 56.5 & 7.0 & 331 & 56.9 & 7.3 \\
\hline 6-NB & 253.6 & 55 & 319 & 63.0 & 6.0 & 322 & 63.8 & 6.1 \\
\hline 1-SB & 258.2 & 55 & 295 & 57.7 & 5.1 & 306 & 59.0 & 5.2 \\
\hline 2-SB & 255.0 & 55 & 305 & 62.2 & 5.8 & 318 & 61.2 & 6.6 \\
\hline 3-SB & 253.6 & 45 & 316 & 55.5 & 6.1 & 317 & 53.6 & 6.2 \\
\hline
\end{tabular}

Figure 6-19and Figure 6-20 illustrate the average speed per location and per speed collection case. These figures show that the speeds of motorists are consistently above the posted speed limit during every speed collection case. Figure 6-19 also shows that as motorists traveling northbound on $1-65$ entered the work zone at location 4-NB or $93^{\text {rd }}$ Avenue, they traveled on average in excess of fifteen miles per hour over the posted work zone speed limit of 45 miles per hour in every speed collection case. As the motorists continued north to location 5-NB, their average speeds reduced in every speed collection case in which the signs were in place.

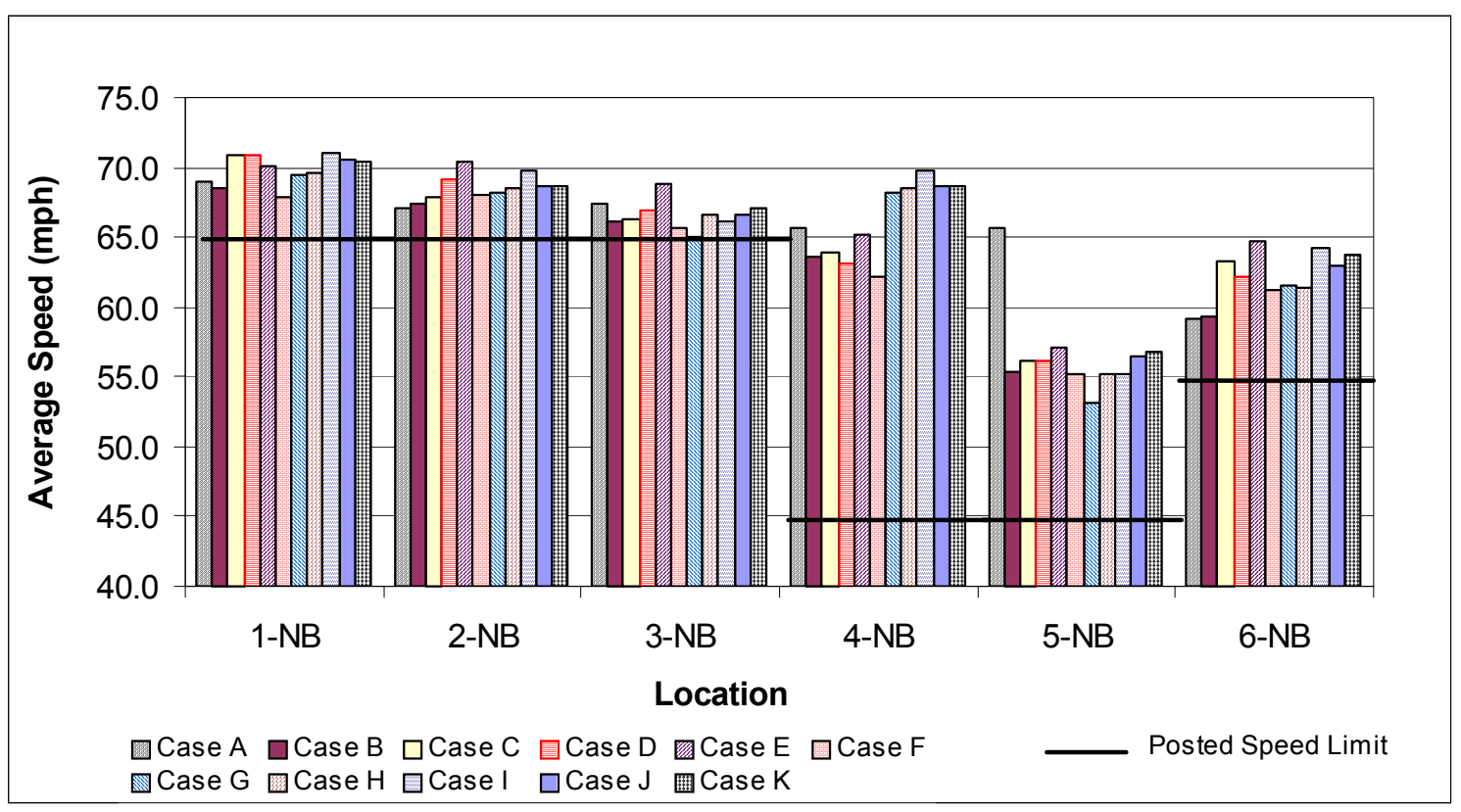

Figure 6-19 I-65 Northbound Speeds per Location and Case 


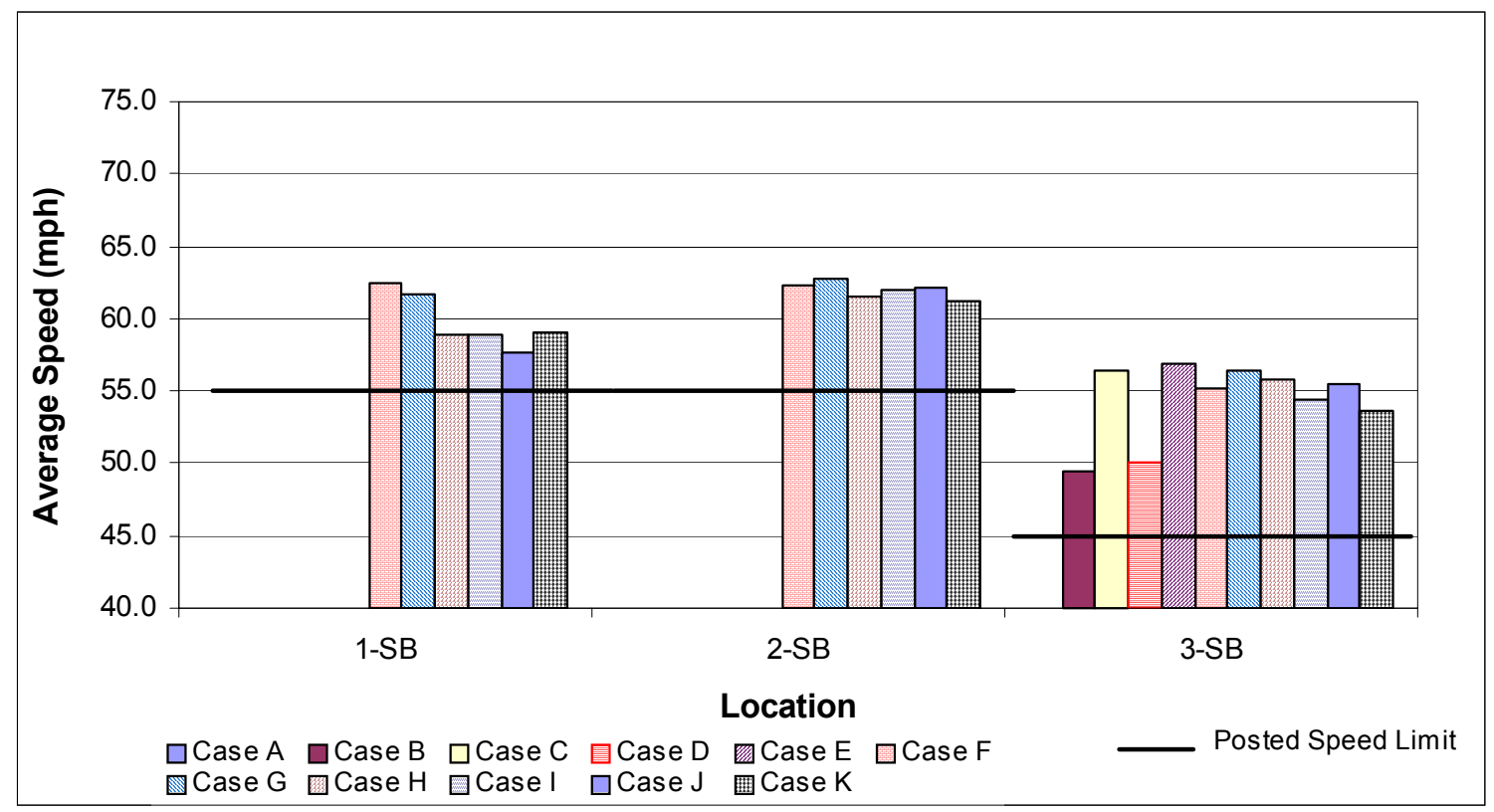

Figure 6-20 I65 Southbound Speeds per Location and Case

\subsubsection{Statistical Testing}

Although the tables and figures discussed in Section 6.2.5.1 show that the average speed of motorists reduced sizably only at the I-65/ US 30 interchange, statistical testing on the averages was necessary to determine the magnitude of the benefit of the signs. The goal of this testing was to determine if a statistically significant speed reduction occurred as a result of the installation of the fixed panel signs (Case $\mathrm{B}$ ), displaying of the number of traffic fines issued to date (Case $\mathrm{C}$ ), the updating of these traffic fines message (Case $\mathrm{C}-$ Case $\mathrm{K}$ ) or a combination of these events. If no statistically significant speed reduction was found at any of the speed collection locations, then no benefit was received from the signs.

To begin the testing, a "significant speed reduction" was defined as a speed reduction greater than five miles per hour in the average speed due to the one or more of the events described above. The threshold for this term was set at five miles per hour because any speed reduction less than this amount was assumed to be only a marginal benefit. With this in mind, the t-test was then used to determine if a significant speed reduction had occurred. To determine the outcome of the $t$-test, the $t$ statistic or $t_{o}$ was compared to the $t$ distribution. When $t_{o}$ was found to be greater than the t-distribution, the speed change was determined to be significant or greater 
than five miles per hour. This method was then used to compare Case A with each of the other cases and to compare the speed collection cases that occurred immediately prior to and immediately following the changing of the number of tickets displayed on the variable message signs.

\subsection{Impact of Fixed Panel Signs}

It was expected that the fixed signs (Figure 5-6, Figure 5-7, Figure 5-9 and Figure 5-10) would result in lower mean speeds on the approach to and in the work zone. However, no statistical evidence was found to support the hypothesis that mean speeds would be reduced on the approach to the work zone due to the introduction of the fixed panel signs(Table 6-9 Locations 2 \& 3-NB), nor from the signs remaining in place (Table 6-10 to Table 6-18, Locations 2 \& 3-NB)..

Table 6-9 Testing for Speed Change > $5 \mathrm{mph}$ : Cases A \& B

\begin{tabular}{|c|c|c|c|c|c|c|}
\hline \multirow{2}{*}{$\begin{array}{c}\text { Location } \\
\text { Code }\end{array}$} & \multicolumn{6}{|c|}{ Cases A \& B } \\
\cline { 2 - 7 } & Mean A & Mean B & $\mathbf{t}_{\mathbf{0}}$ & $\mathbf{d f}$ & $\mathbf{t}$ distribution & Conclusion \\
\hline \hline 1-NB & 69.0 & 68.5 & -10.663 & 663 & 1.647 & Not Significant \\
\hline 2-NB & 67.1 & 67.3 & -11.971 & 596 & 1.647 & Not Significant \\
\hline 3-NB & 67.5 & 66.1 & -8.262 & 654 & 1.647 & Not Significant \\
\hline 4-NB & 65.7 & 63.6 & -5.878 & 637 & 1.647 & Not Significant \\
\hline 5-NB & 65.7 & 55.4 & 10.833 & 641 & 1.647 & Significant \\
\hline 6-NB & 59.2 & 59.3 & -11.012 & 359 & 1.649 & Not Significant \\
\hline 1-SB & N/A & N/A & N/A & N/A & N/A & N/A \\
\hline 2-SB & N/A & N/A & N/A & N/A & N/A & N/A \\
\hline 3-SB & 16.5 & 49.4 & -64.324 & 562 & 1.648 & Not Significant \\
\hline
\end{tabular}


Table 6-10 Testing for Speed Change > $5 \mathrm{mph}$ : Cases A \& C

\begin{tabular}{|c|c|c|c|c|c|c|}
\hline \multirow{2}{*}{$\begin{array}{c}\text { Location } \\
\text { Code }\end{array}$} & Mean A & Mean C & $\mathbf{t}_{\mathbf{0}}$ & $\mathbf{d f}$ & t distribution & Conclusion \\
\cline { 2 - 7 } & 69.0 & 70.8 & -15.046 & 606 & 1.647 & Not Significant \\
\hline \hline 1-NB & 67.1 & 67.8 & -12.982 & 577 & 1.647 & Not Significant \\
\hline 2-NB & 67.5 & 66.3 & -8.615 & 653 & 1.647 & Not Significant \\
\hline 3-NB & 65.7 & 63.9 & -6.397 & 660 & 1.647 & Not Significant \\
\hline 4-NB & 65.7 & 56.1 & 8.258 & 494 & 1.648 & Significant \\
\hline 5-NB & 59.2 & 63.3 & -17.928 & 428 & 1.648 & Not Significant \\
\hline 6-NB & N/A & N/A & N/A & N/A & N/A & N/A \\
\hline 1-SB & N/A & N/A & N/A & N/A & N/A & N/A \\
\hline 2-SB & 16.5 & 56.4 & -79.142 & 551 & 1.648 & Not Significant \\
\hline 3-SB & & & & & \\
\hline
\end{tabular}

Table 6-11 Testing for Speed Change > $5 \mathrm{mph}$ : Cases A \& D

\begin{tabular}{|c|c|c|c|c|c|c|}
\hline \multirow{2}{*}{$\begin{array}{c}\text { Location } \\
\text { Code }\end{array}$} & Mean A & Mean D & $\mathbf{t}_{\mathbf{0}}$ & $\mathbf{d f}$ & $\mathbf{t}$ distribution & Conclusion \\
\cline { 2 - 7 } & 69.0 & 70.8 & -15.054 & 606 & 1.647 & Not Significant \\
\hline \hline 1-NB & 67.1 & 69.1 & -15.433 & 575 & 1.648 & Not Significant \\
\hline 2-NB & 67.5 & 66.9 & -10.139 & 662 & 1.647 & Not Significant \\
\hline 3-NB & 65.7 & 63.2 & -4.705 & 597 & 1.647 & Not Significant \\
\hline 4-NB & 65.7 & 56.1 & 9.355 & 609 & 1.647 & Significant \\
\hline 5-NB & 59.2 & 62.2 & -16.144 & 413 & 1.649 & Not Significant \\
\hline 6-NB & N/A & N/A & N/A & N/A & N/A & N/A \\
\hline 1-SB & N/A & N/A & N/A & N/A & N/A & N/A \\
\hline 2-SB & 16.5 & 50.0 & -65.507 & 557 & 1.648 & Not Significant \\
\hline 3-SB & & & & & \\
\hline
\end{tabular}


Table 6-12 Testing for Speed Change > $5 \mathrm{mph}$ : Cases A \& E

\begin{tabular}{|c|c|c|c|c|c|c|}
\hline \multirow{2}{*}{$\begin{array}{c}\text { Location } \\
\text { Code }\end{array}$} & Mean A & Mean E & $\mathbf{t}_{\mathbf{0}}$ & $\mathbf{d f}$ & $\mathbf{t}$ distribution & Conclusion \\
\cline { 2 - 7 } & 69.0 & 70.1 & -13.996 & 617 & 1.647 & Not Significant \\
\hline \hline 1-NB & 67.1 & 70.3 & -17.083 & 574 & 1.648 & Not Significant \\
\hline 2-NB & 67.5 & 68.8 & -14.472 & 656 & 1.647 & Not Significant \\
\hline 3-NB & 65.7 & 65.2 & -8.832 & 607 & 1.647 & Not Significant \\
\hline 4-NB & 65.7 & 57.2 & 7.144 & 622 & 1.647 & Significant \\
\hline 5-NB & 59.2 & 64.7 & -20.258 & 436 & 1.648 & Not Significant \\
\hline 6-NB & N/A & N/A & N/A & N/A & N/A & N/A \\
\hline 1-SB & N/A & N/A & N/A & N/A & N/A & N/A \\
\hline 2-SB & 16.5 & 56.9 & -83.230 & 528 & 1.648 & Not Significant \\
\hline 3-SB & & & & & & \\
\hline
\end{tabular}

Table 6-13 Testing for Speed Change $>5 \mathrm{mph}$ : Cases A \& F

\begin{tabular}{|c|c|c|c|c|c|c|}
\hline \multirow{2}{*}{$\begin{array}{c}\text { Location } \\
\text { Code }\end{array}$} & Mean A & Mean F & $\mathbf{t}_{\mathbf{0}}$ & $\mathbf{d f}$ & $\mathbf{t}_{\text {distribution }}$ & Conclusion \\
\cline { 2 - 7 } & 69.0 & 67.9 & -9.645 & 642 & 1.647 & Not Significant \\
\hline \hline 1-NB & 67.1 & 68.0 & -12.699 & 508 & 1.648 & Not Significant \\
\hline 2-NB & 67.5 & 65.7 & -7.469 & 656 & 1.647 & Not Significant \\
\hline 3-NB & 65.7 & 62.1 & -3.007 & 643 & 1.647 & Not Significant \\
\hline 4-NB & 65.7 & 55.2 & 11.414 & 629 & 1.647 & Significant \\
\hline 5-NB & 59.2 & 61.2 & -14.709 & 383 & 1.649 & Not Significant \\
\hline 6-NB & N/A & 62.4 & N/A & N/A & N/A & N/A \\
\hline 1-SB & N/A & 62.3 & N/A & N/A & N/A & N/A \\
\hline 2-SB & 16.5 & 55.1 & -79.148 & 538 & 1.648 & Not Significant \\
\hline 3-SB & & & & & & \\
\hline
\end{tabular}


Table 6-14 Testing for Speed Change > $5 \mathrm{mph}$ : Cases A \& G

\begin{tabular}{|c|c|c|c|c|c|c|}
\hline \multirow{2}{*}{$\begin{array}{c}\text { Location } \\
\text { Code }\end{array}$} & Mean A & Mean G & $\mathbf{t}_{\mathbf{0}}$ & $\mathbf{d f}$ & $\mathbf{t}$ distribution & Conclusion \\
\cline { 2 - 7 } & 69.0 & 69.5 & -12.265 & 619 & 1.647 & Not Significant \\
\hline \hline 1-NB & 67.1 & 68.3 & -14.096 & 573 & 1.648 & Not Significant \\
\hline 2-NB & 67.5 & 65.1 & -6.271 & 671 & 1.647 & Not Significant \\
\hline 3-NB & 65.7 & 68.3 & -17.646 & 690 & 1.647 & Not Significant \\
\hline 4-NB & 65.7 & 53.1 & 14.408 & 584 & 1.647 & Significant \\
\hline 5-NB & 59.2 & 61.5 & -14.688 & 421 & 1.648 & Not Significant \\
\hline 6-NB & N/A & 61.7 & N/A & N/A & N/A & N/A \\
\hline 1-SB & N/A & 62.7 & N/A & N/A & N/A & N/A \\
\hline 2-SB & 16.5 & 56.4 & -81.928 & 535 & 1.648 & Not Significant \\
\hline 3-SB & & & & &
\end{tabular}

Table 6-15 Testing for Speed Change > $5 \mathrm{mph}$ : Cases A \& H

\begin{tabular}{|c|c|c|c|c|c|c|}
\hline \multirow{2}{*}{$\begin{array}{c}\text { Location } \\
\text { Code }\end{array}$} & Mean A & Mean $\mathbf{H}$ & $\mathbf{t}_{\mathbf{0}}$ & $\mathbf{d f}$ & $\mathbf{t}$ distribution & Conclusion \\
\cline { 2 - 7 } & 69.0 & 69.6 & -13.880 & 636 & 1.647 & Not Significant \\
\hline \hline 1-NB & 67.1 & 68.5 & -14.090 & 582 & 1.647 & Not Significant \\
\hline 2-NB & 67.5 & 66.7 & -9.329 & 649 & 1.647 & Not Significant \\
\hline 3-NB & 65.7 & 68.5 & -16.833 & 656 & 1.647 & Not Significant \\
\hline 4-NB & 65.7 & 55.3 & 10.999 & 510 & 1.648 & Significant \\
\hline 5-NB & 59.2 & 61.3 & -14.714 & 397 & 1.649 & Not Significant \\
\hline 6-NB & N/A & 58.8 & N/A & N/A & N/A & N/A \\
\hline 1-SB & N/A & 61.5 & N/A & N/A & N/A & N/A \\
\hline 2-SB & 16.5 & 55.7 & -82.492 & 519 & 1.648 & Not Significant \\
\hline 3-SB & & & & & \\
\hline
\end{tabular}


Table 6-16 Testing for Speed Change > $5 \mathrm{mph}$ : Cases A \& I

\begin{tabular}{|c|c|c|c|c|c|c|}
\hline \multirow{2}{*}{$\begin{array}{c}\text { Location } \\
\text { Code }\end{array}$} & Mean A & Mean I & $\mathbf{t}_{\mathbf{0}}$ & $\mathbf{d f}$ & $\mathbf{t}$ distribution & Conclusion \\
\cline { 2 - 7 } & 69.0 & 71.0 & -15.609 & 620 & 1.647 & Not Significant \\
\hline \hline 1-NB & 67.1 & 69.7 & -14.975 & 477 & 1.648 & Not Significant \\
\hline 2-NB & 67.5 & 66.1 & -8.538 & 670 & 1.647 & Not Significant \\
\hline 3-NB & 65.7 & 69.7 & -20.668 & 689 & 1.647 & Not Significant \\
\hline 4-NB & 65.7 & 55.2 & 10.471 & 598 & 1.647 & Significant \\
\hline 5-NB & 59.2 & 64.2 & -20.382 & 404 & 1.649 & Not Significant \\
\hline 6-NB & N/A & 58.9 & N/A & N/A & N/A & N/A \\
\hline 1-SB & N/A & 61.9 & N/A & N/A & N/A & N/A \\
\hline 2-SB & 16.5 & 54.4 & -72.871 & 566 & 1.648 & Not Significant \\
\hline 3-SB & & & & & & \\
\hline
\end{tabular}

Table 6-17 Testing for Speed Change > $5 \mathrm{mph}$ : Cases A \& J

\begin{tabular}{|c|c|c|c|c|c|c|}
\hline \multirow{2}{*}{$\begin{array}{c}\text { Location } \\
\text { Code }\end{array}$} & Mean A & Mean J & $\mathbf{t}_{\mathbf{0}}$ & $\mathbf{d f}$ & $\mathbf{t}_{\text {distribution }}$ & Conclusion \\
\cline { 2 - 7 } & 69.0 & 70.5 & -15.504 & 648 & 1.647 & Not Significant \\
\hline \hline 1-NB & 67.1 & 68.7 & -14.685 & 579 & 1.647 & Not Significant \\
\hline 2-NB & 67.5 & 66.6 & -9.266 & 653 & 1.647 & Not Significant \\
\hline 3-NB & 65.7 & 68.7 & -17.355 & 667 & 1.647 & Not Significant \\
\hline 4-NB & 65.7 & 56.5 & 8.045 & 577 & 1.647 & Significant \\
\hline 5-NB & 59.2 & 63.0 & -17.483 & 429 & 1.648 & Not Significant \\
\hline 6-NB & N/A & 57.7 & N/A & N/A & N/A & N/A \\
\hline 1-SB & N/A & 62.2 & N/A & N/A & N/A & N/A \\
\hline 2-SB & 16.5 & 55.5 & -80.838 & 533 & 1.648 & Not Significant \\
\hline 3-SB & & & & & & \\
\hline
\end{tabular}


Table 6-18 Testing for Speed Change > $5 \mathrm{mph}$ : Cases A \& K

\begin{tabular}{|c|c|c|c|c|c|c|}
\hline \multirow{2}{*}{$\begin{array}{c}\text { Location } \\
\text { Code }\end{array}$} & Mean A & Mean K & $\mathbf{t}_{\mathbf{0}}$ & $\mathbf{d f}$ & t distribution & Conclusion \\
\cline { 2 - 7 } & 69.0 & 70.3 & -14.495 & 627 & 1.647 & Not Significant \\
\hline \hline 1-NB & 67.1 & 68.7 & -14.518 & 581 & 1.647 & Not Significant \\
\hline 2-NB & 67.5 & 67.1 & -10.735 & 660 & 1.647 & Not Significant \\
\hline 3-NB & 65.7 & 68.7 & -17.946 & 675 & 1.647 & Not Significant \\
\hline 4-NB & 65.7 & 56.9 & 7.506 & 643 & 1.647 & Significant \\
\hline 5-NB & 59.2 & 63.8 & -18.942 & 432 & 1.648 & Not Significant \\
\hline 6-NB & N/A & 59.0 & N/A & N/A & N/A & N/A \\
\hline 1-SB & N/A & 61.2 & N/A & N/A & N/A & N/A \\
\hline 2-SB & 16.5 & 53.6 & -77.267 & 534 & 1.648 & Not Significant \\
\hline 3-SB & & & & & & \\
\hline
\end{tabular}

Although this hypothesis could not be proved, statistical evidence was found to support the hypothesis that a statistically significant speed reduction occurred inside the work zone (Table $6-9$, Location $5-N B$ ). This statistically significant speed reduction in the immediate construction area remained in effect during all of the speed data collection cases (Table 6-19, Location 5-NB).

Table 6-19 Summary of Statistically Significant Speed Reductions (Fixed Panel Signs)

\begin{tabular}{|c|c|c|c|c|c|c|c|c|c|c|c|}
\hline \multirow{2}{*}{$\begin{array}{c}\text { Location } \\
\text { Code }\end{array}$} & Speed & \multicolumn{9}{|c|}{ Case A vs. } \\
\hline \hline & Limit & Case B & Case C & Case D & Case E & Case F & Case G & Case H & Case I & Case J & Case K \\
\hline 1-NB & 65 & & & & & & & & & & \\
\hline 2-NB & 65 & & & & & & & & & & \\
\hline 3-NB & 65 & & & & & & & & & & \\
\hline 4-NB & 45 & & & & & & & & & & \\
\hline 5-NB & 45 & $\mathrm{X}$ & $\mathrm{X}$ & $\mathrm{X}$ & $\mathrm{X}$ & $\mathrm{X}$ & $\mathrm{X}$ & $\mathrm{X}$ & $\mathrm{X}$ & $\mathrm{X}$ & $\mathrm{X}$ \\
\hline 6-NB & 55 & & & & & & & & & & \\
\hline 1-SB & 55 & & & & & & & & & & \\
\hline 2-SB & 55 & & & & & & & & & & \\
\hline 3-SB & 45 & & & & & & & & & & \\
\hline
\end{tabular}

$\mathrm{X}$ : denotes statistically significant speed reduction ( $>5 \mathrm{mph}$ )

Although a statistically significant speed reduction was only found at location 5-NB, as illustrated in Figure 6-21, the signs can be termed beneficial. The benefit from these signs results from motorists reducing their speeds in the "heart" of the work zone, which is where the construction activity occurs and where workers are present. 


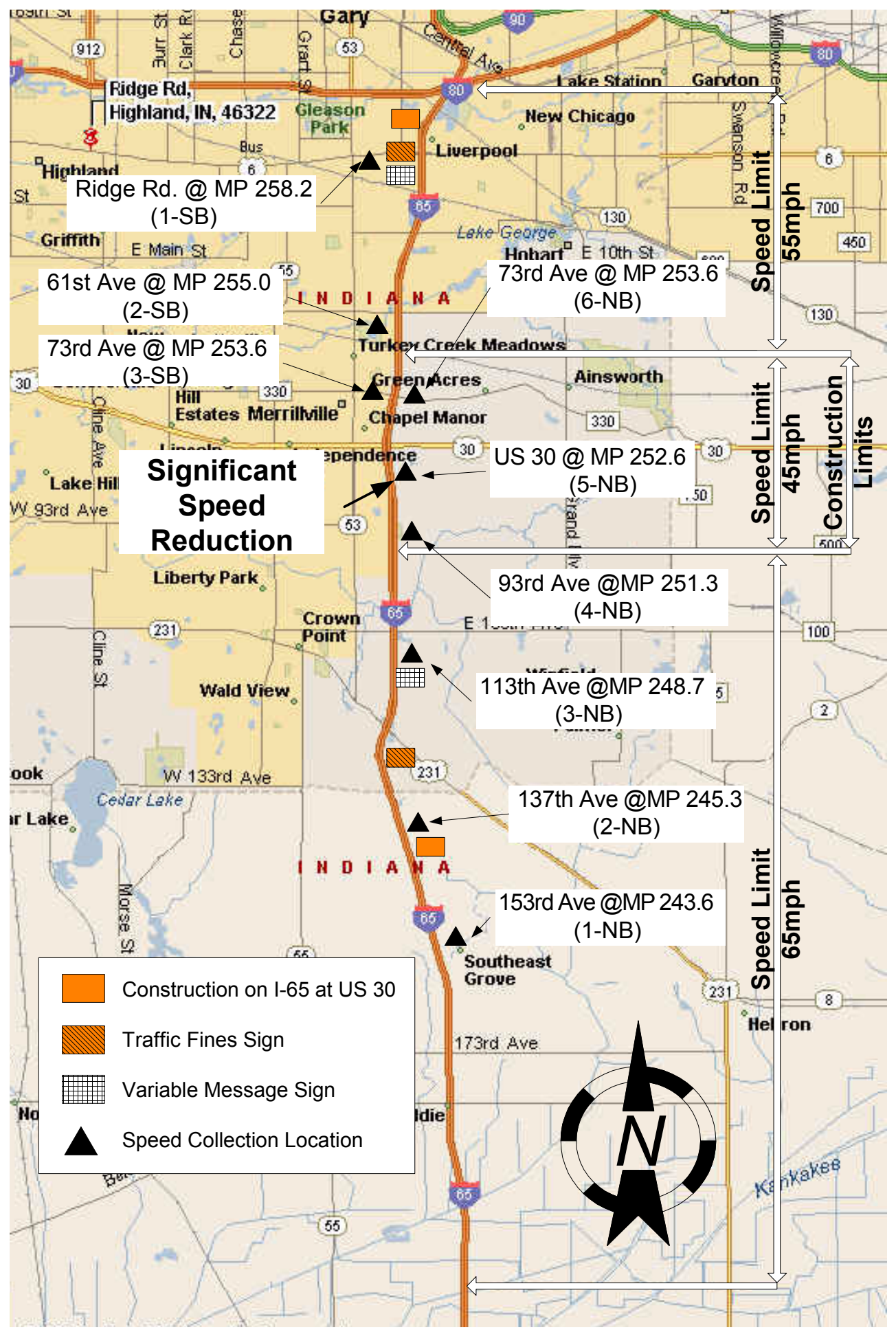

Figure 6-21 Significant Speed Reduction Location 


\subsection{Impact of Variable Message Signs}

A comparison of the mean speeds collected in Case B (Fixed panel signs only) to those obtained in each of the remaining cases (Fixed panel signs and variable message signs) was used to determine if a statistically significant speed reduction occurred at any of the speed collection locations, when the number of traffic fines issued to date was displayed on a variable message sign. This comparison indicated no statistically significant speed reductions greater than or equal to five miles per hour occurred from displaying this message (Table 6-20). Also, no evidence was found to indicate a statistically significant speed reduction greater than one mile per hour had occurred during any speed collection case as a result of the messages displayed on the variable message signs (Table 6-21).

Table 6-20 Testing for Speed Change > $5 \mathrm{mph}$ : Cases B \& C

\begin{tabular}{|c|c|c|c|c|c|c|}
\hline \multirow{2}{*}{$\begin{array}{c}\text { Location } \\
\text { Code }\end{array}$} & \multicolumn{7}{|c|}{ Cases B \& C } \\
\cline { 2 - 7 } & Mean B & Mean C & $\mathbf{t}_{\mathbf{0}}$ & $\mathbf{d f}$ & $\mathbf{t}$ distribution & Conclusion \\
\hline \hline 1-NB & 68.5 & 70.8 & -15.613 & 620 & 1.647 & Not Significant \\
\hline 2-NB & 67.3 & 67.8 & -12.785 & 649 & 1.647 & Not Significant \\
\hline 3-NB & 66.1 & 66.3 & -11.321 & 616 & 1.647 & Not Significant \\
\hline 4-NB & 63.6 & 63.9 & -10.189 & 630 & 1.647 & Not Significant \\
\hline 5-NB & 55.4 & 56.1 & -9.811 & 522 & 1.648 & Not Significant \\
\hline 6-NB & 59.3 & 63.3 & -20.662 & 587 & 1.647 & Not Significant \\
\hline 1-SB & N/A & N/A & N/A & N/A & N/A & N/A \\
\hline 2-SB & N/A & N/A & N/A & N/A & N/A & N/A \\
\hline $3-S B$ & 49.4 & 56.4 & -21.342 & 608 & 1.647 & Not Significant \\
\hline
\end{tabular}


Table 6-21 Summary of Statistically Significant Speed Reductions (Variable Message Signs)

\begin{tabular}{|c|c|c|c|c|c|c|c|c|c|c|}
\hline \multirow{2}{*}{$\begin{array}{c}\text { Location } \\
\text { Code }\end{array}$} & \multirow{2}{*}{$\begin{array}{c}\text { Speed } \\
\text { Limit }\end{array}$} & \multicolumn{9}{|c|}{ Case B vs. } \\
\hline & & Case C & Case D & Case E & Case F & Case G & Case H & Case I & Case J & Case K \\
\hline 1-NB & 65 & & & & & & & & & \\
\hline 2-NB & 65 & & & & & & & & & \\
\hline 3-NB & 65 & & & & & & & & & \\
\hline 4-NB & 45 & & & & & & & & & \\
\hline $5-N B$ & 45 & & & & & $X$ & & & & \\
\hline 6-NB & 55 & & & & & & & & & \\
\hline 1-SB & 55 & & & & & & & & & \\
\hline $2-S B$ & 55 & & & & & & & & & \\
\hline 3-SB & 45 & & & & & & & & & \\
\hline
\end{tabular}

$\mathrm{X}$ : denotes statistically significant speed reduction ( $>1 \mathrm{mph}$ )

\subsection{Impact of Updating Fine Counts on Variable Message Signs}

A third comparison of the mean speeds was performed. In this comparison, mean speeds collected immediately before the updating of the messages on the variable message signs were compared to the mean speeds collected immediately after the updating of the messages. The cases compared were: Cases D \& E, Cases H \& I, and Cases J \& K.

It was expected that the updating of the fine counts on the variable message signs (Figure 5-8) would result in lower speeds on the approach to the work zone. However, no evidence was found to indicate a statistically significant speed reduction greater than or equal to five miles per hour had occurred (Table 6-22, Table 6-23 and Table 6-24). 
Table 6-22 Testing for Speed Change > $5 \mathrm{mph}$ : Cases D \& E

\begin{tabular}{|c|c|c|c|c|c|c|}
\hline \multirow{2}{*}{$\begin{array}{c}\text { Location } \\
\text { Code }\end{array}$} & Mean D & Mean E & $\mathbf{t}_{\mathbf{0}}$ & $\mathbf{d f}$ & $\mathbf{t}$ distribution & Conclusion \\
\cline { 2 - 7 } & 70.8 & 70.1 & -8.828 & 606 & 1.647 & Not Significant \\
\hline \hline 1-NB & 69.1 & 70.3 & -12.894 & 599 & 1.647 & Not Significant \\
\hline 2-NB & 66.9 & 68.8 & -15.628 & 616 & 1.647 & Not Significant \\
\hline 3-NB & 63.2 & 65.2 & -12.110 & 614 & 1.647 & Not Significant \\
\hline $4-N B$ & 56.1 & 57.2 & -11.409 & 596 & 1.647 & Not Significant \\
\hline 5-NB & 62.2 & 64.7 & -15.768 & 604 & 1.647 & Not Significant \\
\hline 6-NB & N/A & N/A & N/A & N/A & N/A & N/A \\
\hline 1-SB & N/A & N/A & N/A & N/A & N/A & N/A \\
\hline 2-SB & 50.0 & 56.9 & -22.031 & 586 & 1.647 & Not Significant \\
\hline 3-SB & & & & & \\
\hline
\end{tabular}

Table 6-23 Testing for Speed Change > $5 \mathrm{mph}$ : Cases H \& I

\begin{tabular}{|c|c|c|c|c|c|c|}
\hline \multirow{2}{*}{$\begin{array}{c}\text { Location } \\
\text { Code }\end{array}$} & Mean H & Mean I & $\mathbf{t}_{\mathbf{0}}$ & $\mathbf{d f}$ & $\mathbf{t}$ distribution & Conclusion \\
\cline { 2 - 7 } & 69.6 & 71.0 & -14.250 & 597 & 1.647 & Not Significant \\
\hline \hline 1-NB & 68.5 & 69.7 & -12.005 & 500 & 1.648 & Not Significant \\
\hline 2-NB & 66.7 & 66.1 & -9.802 & 617 & 1.647 & Not Significant \\
\hline 3-NB & 68.5 & 69.7 & -13.727 & 615 & 1.647 & Not Significant \\
\hline 4-NB & 55.3 & 55.2 & -8.919 & 531 & 1.648 & Not Significant \\
\hline 5-NB & 61.3 & 64.2 & -17.854 & 621 & 1.647 & Not Significant \\
\hline 6-NB & 58.8 & 58.9 & -11.648 & 602 & 1.647 & Not Significant \\
\hline 1-SB & 61.5 & 61.9 & -11.013 & 594 & 1.647 & Not Significant \\
\hline 2-SB & 55.7 & 54.4 & -6.901 & 595 & 1.647 & Not Significant \\
\hline 3-SB & & & & &
\end{tabular}


Table 6-24 Testing for Speed Change > 5 mph: Cases J \& K

\begin{tabular}{|c|c|c|c|c|c|c|}
\hline \multirow{2}{*}{$\begin{array}{c}\text { Location } \\
\text { Code }\end{array}$} & Mean J & Mean K & $\mathbf{t}_{\mathbf{0}}$ & $\mathbf{d f}$ & $\mathbf{t}_{\text {distribution }}$ & Conclusion \\
\cline { 2 - 7 } & 70.5 & 70.3 & -10.756 & 622 & 1.647 & Not Significant \\
\hline \hline 1-NB & 68.7 & 68.7 & -10.937 & 618 & 1.647 & Not Significant \\
\hline 2-NB & 66.6 & 67.1 & -12.010 & 618 & 1.647 & Not Significant \\
\hline 3-NB & 68.7 & 68.7 & -10.920 & 622 & 1.647 & Not Significant \\
\hline 4-NB & 56.5 & 56.9 & -9.287 & 615 & 1.647 & Not Significant \\
\hline 5-NB & 63.0 & 63.8 & -12.047 & 639 & 1.647 & Not Significant \\
\hline 6-NB & 57.7 & 59.0 & -14.927 & 599 & 1.647 & Not Significant \\
\hline 1-SB & 62.2 & 61.2 & -8.169 & 615 & 1.647 & Not Significant \\
\hline 2-SB & 55.5 & 53.6 & -6.356 & 631 & 1.647 & Not Significant \\
\hline 3-SB & & & & & & \\
\hline
\end{tabular}

Further significance testing on these cases was conducted to determine if a statistically significant speed reduction of any amount had occurred as a result of updating the messages. The results of this testing provided no evidence that a statistically significant speed reduction greater than one mile per hour had occurred during any speed collection case as a result of the updating of the fine counts on the variable message signs (Table 6-25).

Table 6-25 Summary of Statistically Significant Speed Reductions (Updating of Fine Counts)

\begin{tabular}{|c|c|l|l|l|}
\hline $\begin{array}{c}\text { Location } \\
\text { Code }\end{array}$ & $\begin{array}{c}\text { Speed } \\
\text { Limit }\end{array}$ & Case D vs. Case E & Case H vs. Case I & Case J vs. Case K \\
\hline \hline 1-NB & 65 & & & \\
\hline 2-NB & 65 & & & \\
\hline 3-NB & 65 & & & \\
\hline 4-NB & 45 & & & \\
\hline $5-N B$ & 45 & & & \\
\hline $6-N B$ & 55 & & & \\
\hline 1-SB & 55 & & & \\
\hline 2-SB & 55 & & & \\
\hline 3-SB & 45 & & & \\
\hline
\end{tabular}

$\mathrm{X}$ : denotes statistically significant speed reduction ( $>1 \mathrm{mph}$ ) 


\subsection{Enforcement Study}

Along with the speed study conducted to evaluate the effectiveness of the work zone signs, a separate speed study was performed. This study, conducted over a two day period with the assistance of the Indiana State Police (ISP), examined the impact of police patrols in the work zone on the speeds of passing motorists.

\subsubsection{The Procedure}

To conduct this study, the test method described in Section 6.2 was slightly modified. For this study, an officer of the Indiana State Police was assigned to monitor speeds from a patrol car located at or near the beginning of the work zone, as seen in Figure 6-22. The patrol car was parked inside the median of the interstate, allowing it to be safely out of the traveled way and to remain highly visible to approaching motorists. While the state trooper remained at this location monitoring speeds, the research team collected speeds for thirty minutes from those locations described in Section 6.2 that were downstream of the trooper, as seen in Figure 6-22. Speeds would then be collected for thirty minutes at the same locations at a time when the ISP did not have a trooper patrolling in the work zone. The two sets of speeds were then compared to determine the impact of the visible patrol car on the speeds of motorists passing through the work zone.

Due to uncontrollable circumstances, several modifications were made to the test procedure. The first change dealt with the work zone patrols themselves. It was anticipated that no police officers would patrol the work zone unless they were specifically assigned by the ISP to perform patrols. Although only one trooper was assigned to the special work zone patrols at a time, they were not the only police officer in the work zone. Various other state troopers did patrol the work zone from time to time without being specifically assigned to the area. The presence of these other troopers was noted, when witnessed, and their impact on the speeds of passing motorists was determined.

The second modification to the test procedure resulted from the speeding motorists themselves. During the study, motorists occasionally passed the patrol car while greatly exceeding the work zone speed limit. In such instances, the trooper assisting with the enforcement study was forced to pursue the speeder. When such instances occurred, the research team either was notified by the trooper that the officer was leaving the stationary enforcement location or the research team witnessed the trooper leaving his location and beginning to pursue the motorist in violation of the posted speed limit. In either situation, the research team noted the time and began to measure 
speeds when no enforcement was active. Once the trooper returned to the location, the study was resumed.

To determine where the patrol car would be located, troopers who patrol the area were consulted. Since the northbound approach to the work zone provided a wide median for the trooper to safely park in, the decision was made to locate the trooper and his patrol car immediately to the south of the work zone. From this location the trooper would be visible to northbound traffic and would influence the speeds of motorists entering the work zone. This location, at mile post 251.2, would also provide the research team with three locations from which to collect speeds. These locations as well as the location of the patrol car can be seen in Figure 6-22. 


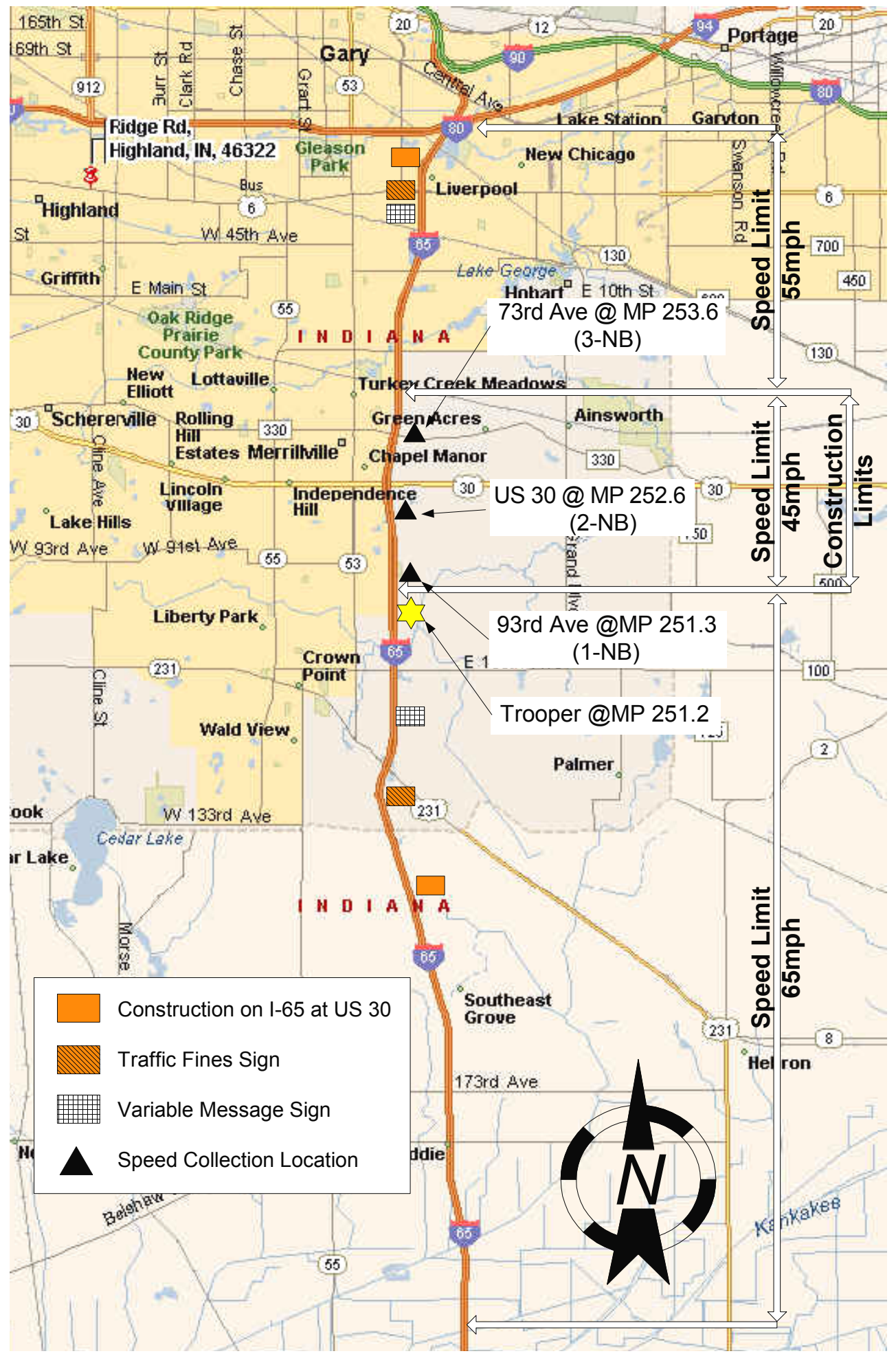

Figure 6-22 Enforcement Study Speed Collection Locations 
The southbound approach to the work zone did not provide a safe location for a patrol car to park. Lack of a safe location would cause a patrol car to be parked in a position where it would influence traffic. Parking a patrol car in such a position could also place a trooper in danger. For this reason, the decision was made not to conduct the study on the southbound approach.

\subsubsection{Results}

Speeds collected for this study make several points. The first of which is that when enforcement is present, speeds of motorists passing the location of the enforcement are dramatically lower than when the enforcement is not present. As can be seen in Table 6-26 and Figure 6-23, when a patrol car is present the average speed of passing motorists is 46.3 miles per hour. When the enforcement is not present, the average speed at that same location increases by over ten miles per hour to 56.9 miles per hour.

Table 6-26 Average Speed Per Location and Enforcement Status

\begin{tabular}{|c|c|c|c|c|c|c|c|c|}
\cline { 5 - 9 } & \multicolumn{2}{c|}{} & \multicolumn{2}{c|}{ Enforcement Active } & \multicolumn{3}{c|}{ Enforcement Inactive } \\
\hline $\begin{array}{c}\text { Location } \\
\text { Code }\end{array}$ & $\begin{array}{c}\text { Approx. } \\
\text { Mile Post }\end{array}$ & $\begin{array}{c}\text { Dist. } \\
\text { From } \\
\text { Trooper } \\
(\mathrm{mi})\end{array}$ & $\begin{array}{c}\text { Sample } \\
\text { Size }\end{array}$ & $\begin{array}{c}\text { Ave. } \\
\text { Speed } \\
(\mathbf{m p h})\end{array}$ & $\begin{array}{c}\text { Std. } \\
\text { Dev. }\end{array}$ & $\begin{array}{c}\text { Sample } \\
\text { Size }\end{array}$ & $\begin{array}{c}\text { Ave. } \\
\text { Speed } \\
(\mathbf{m p h})\end{array}$ & $\begin{array}{c}\text { Std. } \\
\text { Dev. }\end{array}$ \\
\hline \hline 1-NB & 251.3 & 0.1 & 225 & 46.3 & 4.7 & 201 & 56.9 & 7.3 \\
\hline $2-\mathrm{NB}$ & 252.6 & 1.4 & 289 & 53.0 & 5.4 & 217 & 59.4 & 6.6 \\
\hline $3-\mathrm{NB}$ & 253.6 & 2.4 & 325 & 56.3 & 5.6 & 307 & 57.7 & 5.8 \\
\hline
\end{tabular}




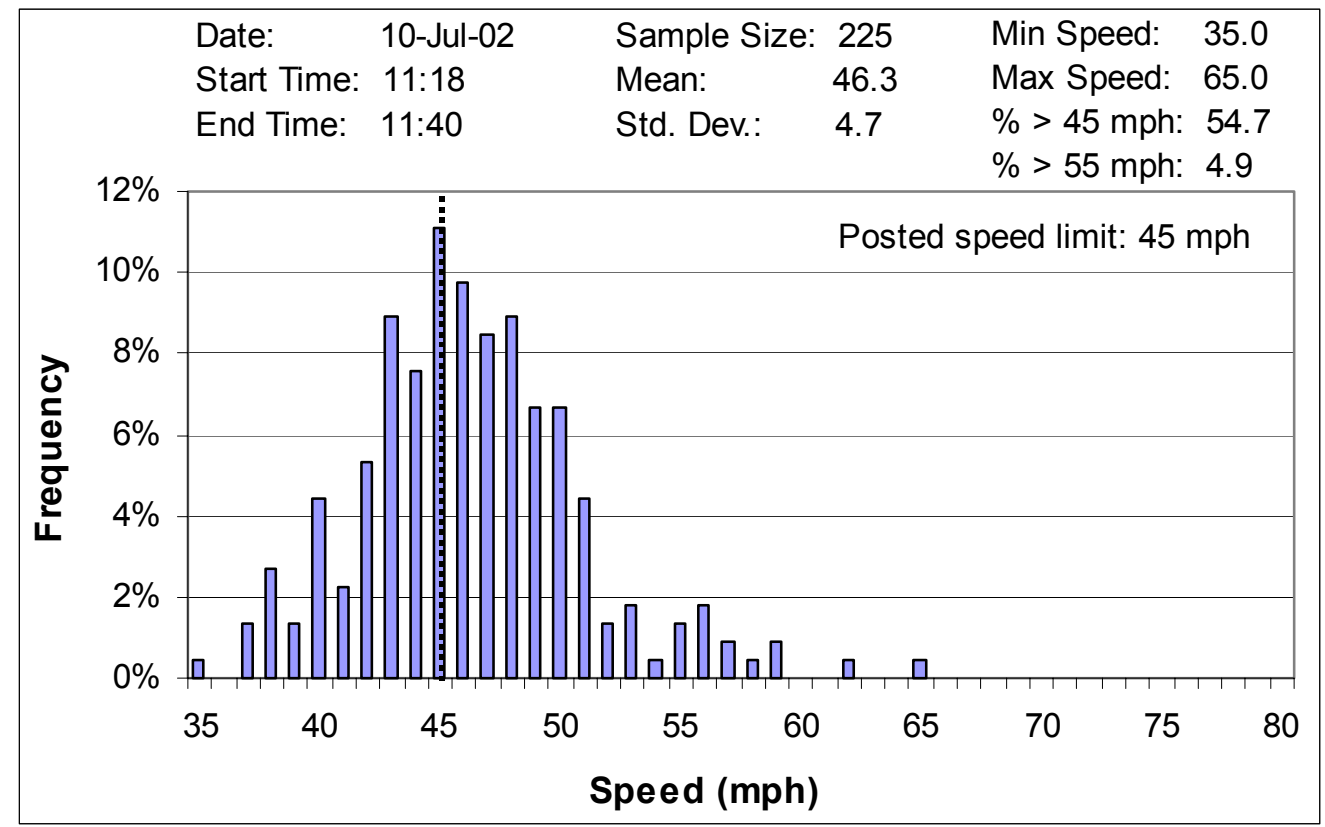

a) With Enforcement

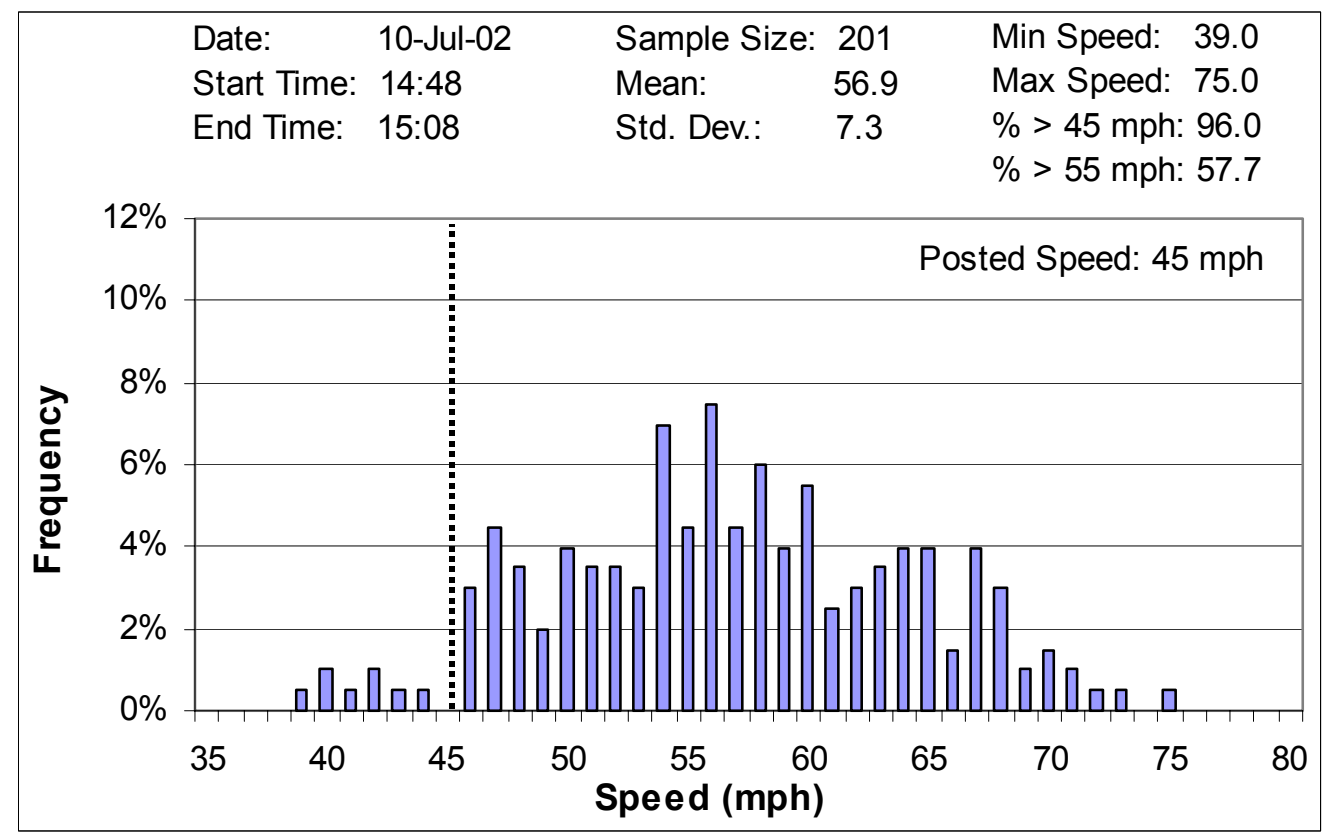

b) Without Enforcement

Figure 6-23 Speeds Adjacent to Trooper at $93^{\text {rd }}$ Ave, Trooper Location: MP 251.2Collection Location MP 251.3 
The second point that is evident from this data is that of how far downstream from the trooper the speeds are reduced. Speeds collected from the US 30 interchange, which can be seen in Table 6-26 and Figure 6-24, show that the average speed of passing motorists was found to be 6.4 miles per hour slower when enforcement was active. This suggests that impact of enforcement on passing motorists lasts for a distance of up to 1.2 miles downstream of the patrol car.

Examination of the speeds collected at the $73^{\text {rd }}$ Avenue overpass, which can be seen in Table 6-26 and Figure 6-25, suggest that the effect of enforcement on the speeds of passing motorists does not extend to a distance of 2.4 miles downstream of the patrol car. The small effective distance of the enforcement implies that for the Indiana State Police to encourage motorists to obey the posted speed limit, patrol cars must be located approximately every two miles from the beginning of a work zone to the end. Such an effort would require numerous officers and may not be feasible due to budget constraints. 


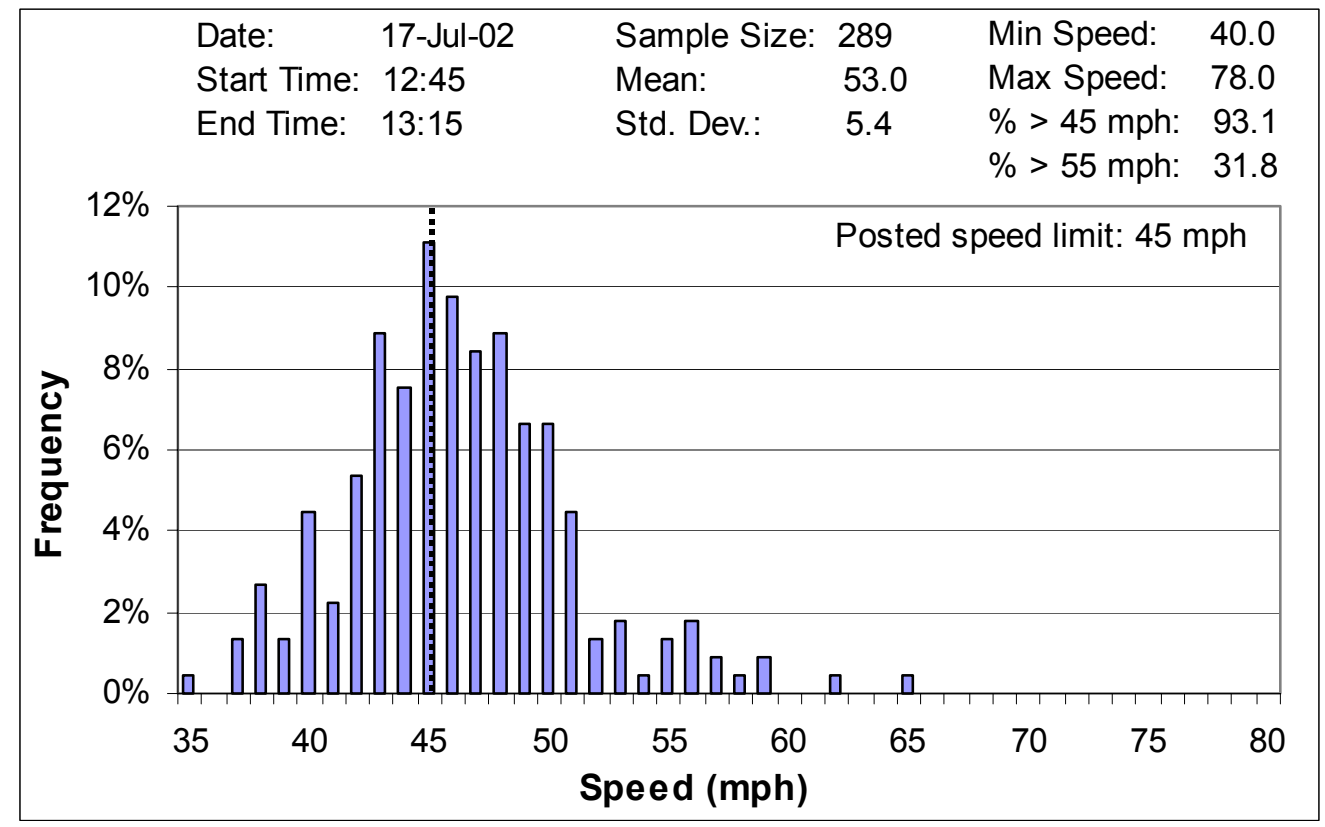

a) With Enforcement

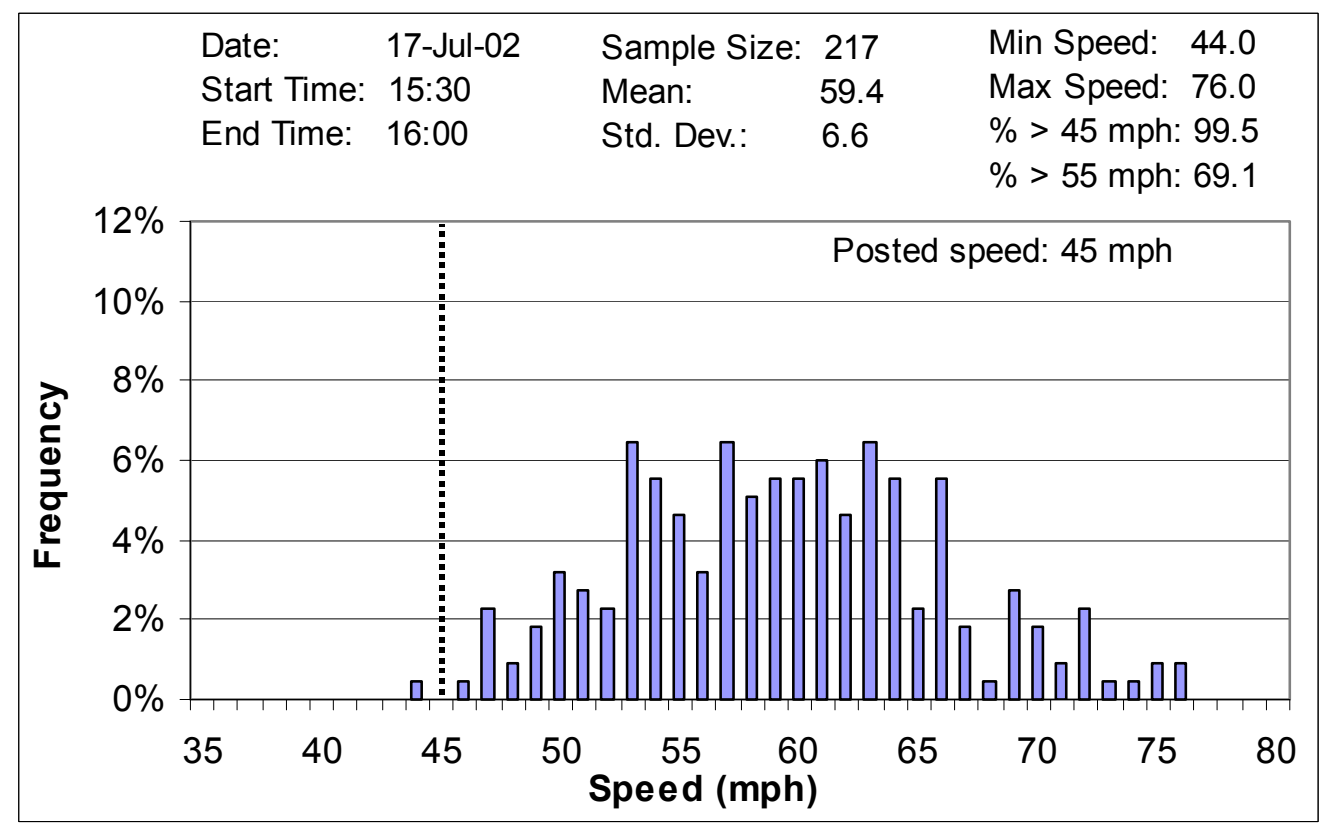

b) Without Enforcement

Figure 6-24 Downstream Speeds at US 30, Trooper Location: MP 251.2Collection Location MP 252.4 


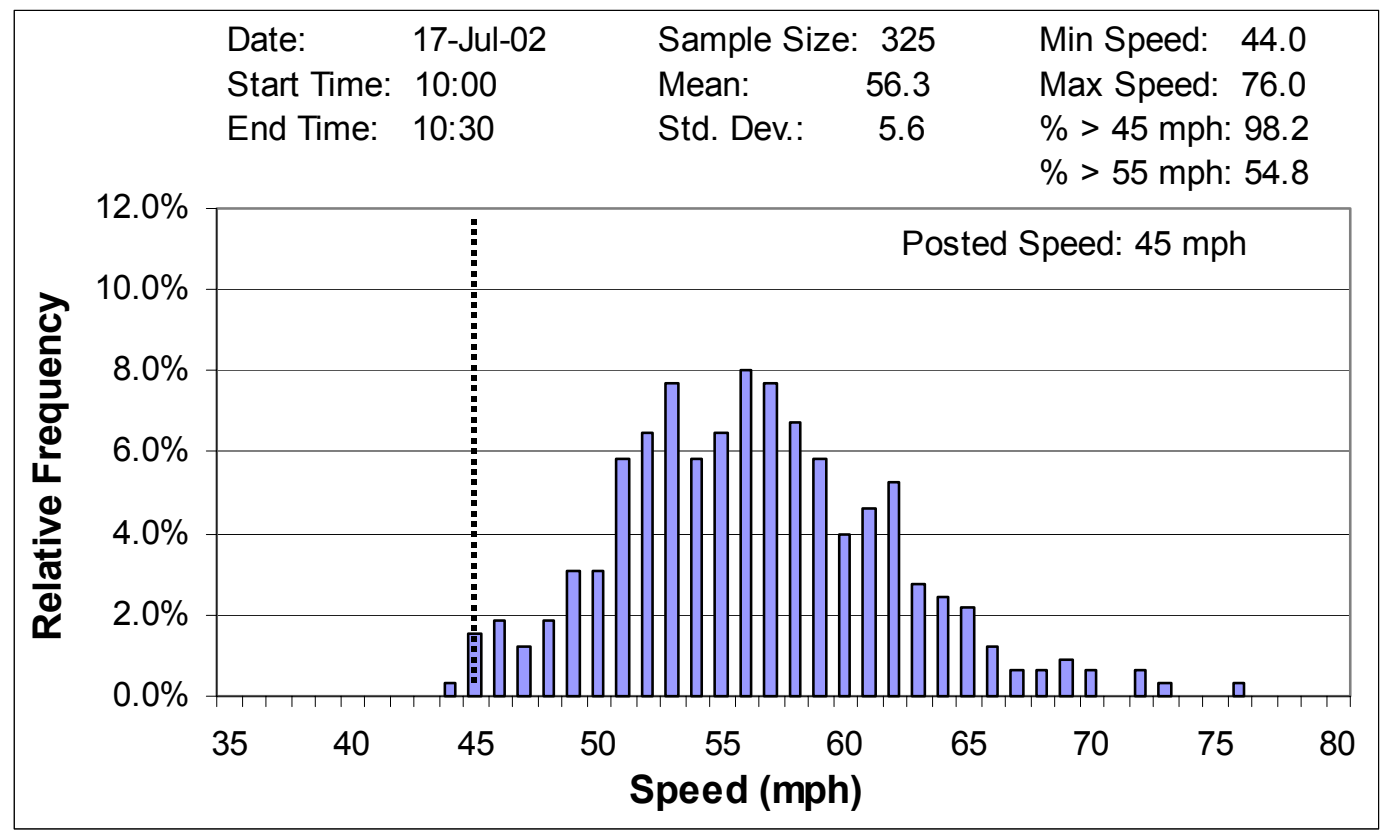

a) With Enforcement

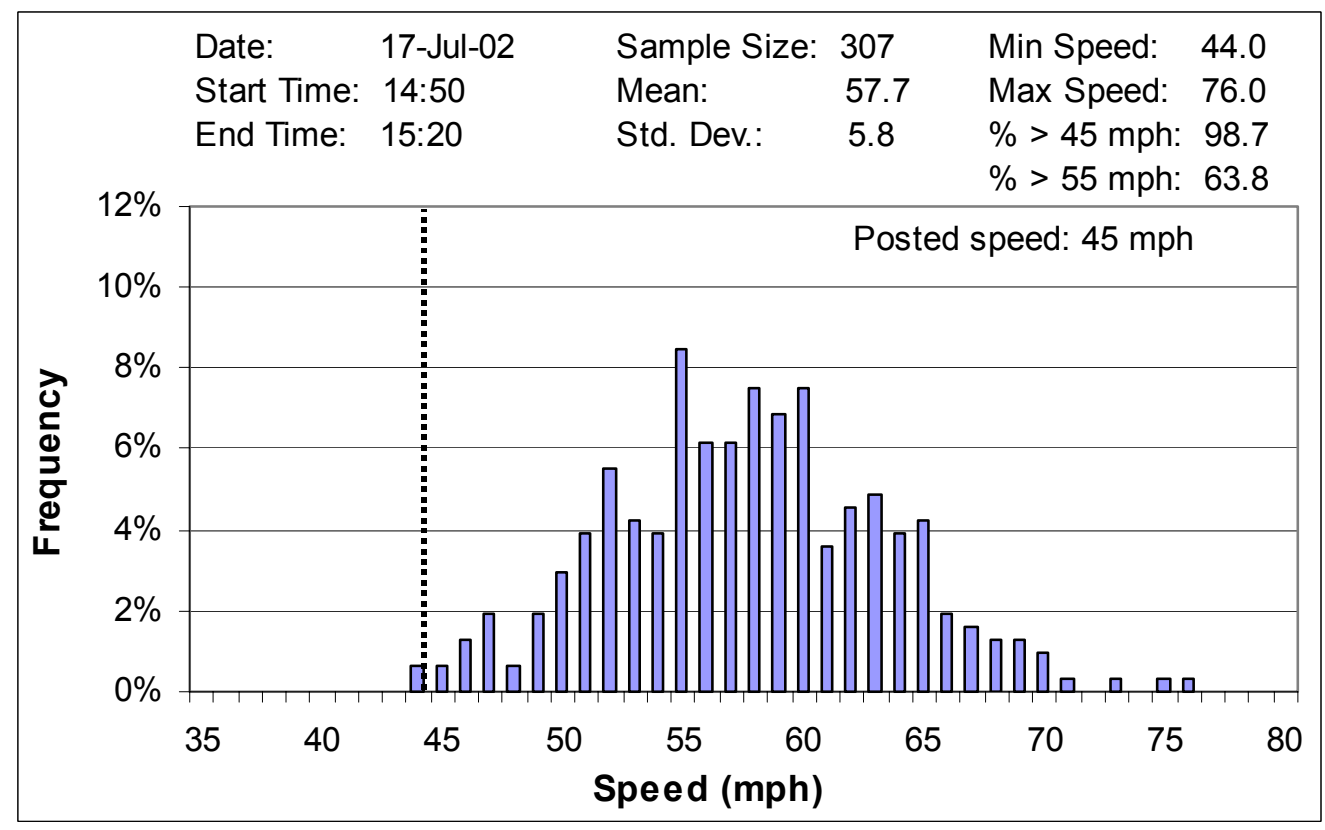

b) Without Enforcement

Figure 6-25 Downstream Speeds @ 73 ${ }^{\text {rd }}$ Ave, Trooper Location: MP 251.2Collection Location MP 253.6 


\section{4. $\quad$ Accident Analysis}

The second method used to determine the impact of the work zone signs on the safety of the work zone was to examine accident rates before and during construction. In doing so, a study area was defined, which included all of the signs, the work zone, and several miles of interstate lying beyond either the signs or the work zone itself. This study area included all of Interstate 65 from mile marker 254.0 to mile marker 259.5. All accidents occurring within this study area between April 1 and October 31 of each year were compared to each of the other year's accidents in an effort to determine if the accident rate had dropped due to the placement of the work zone signs. The number of operational lanes per direction for each year of the study period was investigated in the analysis.

While examining the accident rates for the study area for previous years, it was noted that portions of the study area had been under construction since April 1, 1998. This construction had widened the segment of Interstate 65 north of the US 30 interchange from two to three lanes per direction.

To locate a year in which no construction had taken place in the study area, the research team was forced to examine the crash records for the year of 1997. Although no construction took place in the study area in 1996, the accident rates for this year were included in the analysis because it was the first year in which INDOT required the use of a concrete barrier wall to separate oncoming lanes of traffic during construction.

Inspection of the accident rates from 1996 to 2002 showed several trends. One trend that was evident relates to the number of operational lanes per direction. As construction began in 1998, the number of operational lanes per direction was reduced from two to one per direction. This loss of a lane caused the accident rates to increase, as seen in Table 6-27 and Table 6-29. It can also be seen that as the number of operational lanes was increased back to two per direction in 2000, as seen in Table 6-28 and Table 6-30, the accident rates began to decrease. Although this decrease in the accident rates did not occur instantly, it is believed to be a result of the amount of operational lanes per direction. 
Table 6-27 Northbound Accident Rates

\begin{tabular}{|c|c|c|c|c|}
\hline Date & $\begin{array}{c}4 / 01 / 96 \text { thru } \\
10 / 31 / 96 \\
\end{array}$ & $\begin{array}{c}4 / 01 / 97 \text { thru } \\
10 / 31 / 97 \\
\end{array}$ & $\begin{array}{c}4 / 01 / 98 \text { thru } \\
10 / 31 / 98 \\
\end{array}$ & $\begin{array}{c}/ 01 / 99 \text { thru } \\
10 / 31 / 99 \\
\end{array}$ \\
\hline $\begin{array}{c}\text { Under } \\
\text { Construction? }\end{array}$ & No & No & Yes & Yes \\
\hline $\begin{array}{c}\text { \# of Operational } \\
\text { Lanes }\end{array}$ & Two & Two & One & One \\
\hline Mile Marker & \multicolumn{4}{|c|}{ Acccidents } \\
\hline 245.0 & $\overline{0}$ & 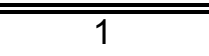 & 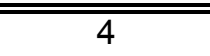 & $\overline{11}$ \\
\hline 245.5 & 3 & 0 & 0 & 2 \\
\hline 246.0 & 2 & 2 & 3 & 0 \\
\hline 246.5 & 0 & 1 & 1 & 1 \\
\hline 247.0 & 3 & 5 & 11 & 5 \\
\hline 247.5 & 0 & 1 & 1 & 0 \\
\hline 248.0 & 1 & 1 & 2 & 3 \\
\hline 248.5 & 2 & 0 & 0 & 2 \\
\hline 249.0 & 5 & 2 & 1 & 2 \\
\hline 249.5 & 1 & 0 & 1 & 0 \\
\hline 250.0 & 1 & 2 & 4 & 2 \\
\hline 250.5 & 0 & 2 & 1 & 1 \\
\hline 251.0 & 0 & 1 & 3 & 4 \\
\hline 251.5 & 0 & 0 & 1 & 0 \\
\hline 252.0 & 2 & 2 & 4 & 2 \\
\hline 252.5 & 0 & 2 & 3 & 1 \\
\hline 253.0 & 14 & 12 & 20 & 13 \\
\hline 253.5 & 2 & 0 & 1 & 0 \\
\hline 254.0 & 8 & 5 & 4 & 7 \\
\hline 254.5 & 4 & 3 & 0 & 0 \\
\hline 255.0 & 6 & 6 & 6 & 9 \\
\hline 255.5 & 0 & 0 & 0 & 0 \\
\hline 256.0 & 7 & 6 & 3 & 2 \\
\hline 256.5 & 1 & 1 & 0 & 0 \\
\hline 257.0 & 8 & 12 & 13 & 16 \\
\hline 257.5 & 1 & 0 & 1 & 1 \\
\hline 258.0 & 22 & 14 & 27 & 25 \\
\hline 258.5 & 0 & 0 & 4 & 0 \\
\hline 259.0 & 8 & 6 & 1 & 4 \\
\hline 259.5 & 4 & 8 & 10 & 11 \\
\hline
\end{tabular}


Table 6-28 Northbound Accident Rates (con't)

\begin{tabular}{|c|c|c|c|}
\hline Date & $\begin{array}{c}4 / 1 / 00 \text { thru } \\
10 / 31 / 00\end{array}$ & $\begin{array}{c}4 / 1 / 01 \text { thru } \\
10 / 31 / 01\end{array}$ & $\begin{array}{c}/ 1 / 02 \text { thru } \\
10 / 31 / 02\end{array}$ \\
\hline $\begin{array}{c}\text { Under } \\
\text { Construction? }\end{array}$ & Yes & Yes & Yes \\
\hline $\begin{array}{c}\text { \# of Operational } \\
\text { Lanes }\end{array}$ & Two & Two & Two \\
\hline Mile Marker & \multicolumn{3}{|c|}{ Accidents } \\
\hline 245.0 & 2 & 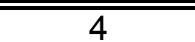 & $\overline{\overline{1}}$ \\
\hline 245.5 & 0 & 2 & 0 \\
\hline 246.0 & 1 & 0 & 4 \\
\hline 246.5 & 2 & 1 & 2 \\
\hline 247.0 & 2 & 4 & 4 \\
\hline 247.5 & 1 & 0 & 0 \\
\hline 248.0 & 2 & 2 & 3 \\
\hline 248.5 & 3 & 1 & 0 \\
\hline 249.0 & 0 & 4 & 3 \\
\hline 249.5 & 1 & 2 & 1 \\
\hline 250.0 & 3 & 0 & 2 \\
\hline 250.5 & 0 & 0 & 0 \\
\hline 251.0 & 3 & 1 & 2 \\
\hline 251.5 & 1 & 1 & 0 \\
\hline 252.0 & 1 & 5 & 6 \\
\hline 252.5 & 2 & 1 & 2 \\
\hline 253.0 & 9 & 3 & 13 \\
\hline 253.5 & 2 & 1 & 2 \\
\hline 254.0 & 10 & 3 & 3 \\
\hline 254.5 & 3 & 1 & 1 \\
\hline 255.0 & 15 & 4 & 4 \\
\hline 255.5 & 6 & 1 & 2 \\
\hline 256.0 & 5 & 8 & 2 \\
\hline 256.5 & 4 & 2 & 0 \\
\hline 257.0 & 8 & 11 & 2 \\
\hline 257.5 & 4 & 7 & 2 \\
\hline 258.0 & 16 & 17 & 3 \\
\hline 258.5 & 3 & 1 & 1 \\
\hline 259.0 & 9 & 10 & 2 \\
\hline 259.5 & 12 & 0 & 1 \\
\hline Totals: & 130 & 97 & 68 \\
\hline
\end{tabular}


Table 6-29 Southbound Accident Rates

\begin{tabular}{|c|c|c|c|c|}
\hline Date & $\begin{array}{c}\text { 4/01/96 thru } \\
10 / 31 / 96 \\
\end{array}$ & $\begin{array}{c}4 / 01 / 97 \text { thru } \\
10 / 31 / 97 \\
\end{array}$ & $\begin{array}{c}4 / 01 / 98 \text { thru } \\
10 / 31 / 98 \\
\end{array}$ & $\begin{array}{c}/ 01 / 99 \text { thru } \\
10 / 31 / 99 \\
\end{array}$ \\
\hline $\begin{array}{c}\text { Under } \\
\text { Construction? }\end{array}$ & No & No & Yes & Yes \\
\hline $\begin{array}{c}\text { \# of Operational } \\
\text { Lanes }\end{array}$ & Two & Two & One & One \\
\hline Mile Marker & \multicolumn{4}{|c|}{ Acccidents } \\
\hline 245.0 & 2 & $\overline{3}$ & 0 & $\overline{0}$ \\
\hline 245.5 & 1 & 0 & 0 & 0 \\
\hline 246.0 & 1 & 1 & 3 & 1 \\
\hline 246.5 & 0 & 1 & 0 & 0 \\
\hline 247.0 & 3 & 2 & 8 & 7 \\
\hline 247.5 & 0 & 0 & 2 & 0 \\
\hline 248.0 & 0 & 3 & 6 & 5 \\
\hline 248.5 & 1 & 1 & 1 & 0 \\
\hline 249.0 & 2 & 1 & 4 & 1 \\
\hline 249.5 & 0 & 1 & 1 & 0 \\
\hline 250.0 & 5 & 1 & 4 & 0 \\
\hline 250.5 & 1 & 0 & 1 & 2 \\
\hline 251.0 & 3 & 1 & 2 & 2 \\
\hline 251.5 & 1 & 1 & 0 & 0 \\
\hline 252.0 & 5 & 4 & 4 & 2 \\
\hline 252.5 & 1 & 1 & 1 & 0 \\
\hline 253.0 & 18 & 8 & 14 & 22 \\
\hline 253.5 & 2 & 0 & 3 & 0 \\
\hline 254.0 & 13 & 10 & 13 & 6 \\
\hline 254.5 & 2 & 0 & 1 & 0 \\
\hline 255.0 & 10 & 8 & 12 & 7 \\
\hline 255.5 & 1 & 0 & 0 & 0 \\
\hline 256.0 & 9 & 7 & 6 & 8 \\
\hline 256.5 & 0 & 0 & 0 & 0 \\
\hline 257.0 & 15 & 8 & 9 & 7 \\
\hline 257.5 & 1 & 1 & 0 & 1 \\
\hline 258.0 & 22 & 13 & 9 & 10 \\
\hline 258.5 & 1 & 2 & 1 & 1 \\
\hline 259.0 & 19 & 19 & 11 & 21 \\
\hline 259.5 & 14 & 4 & 2 & 8 \\
\hline Totals: & 153 & 101 & 118 & 111 \\
\hline
\end{tabular}


Table 6-30 Southbound Accident Rates (con't)

\begin{tabular}{|c|c|c|c|}
\hline Date & $\begin{array}{l}4 / 1 / 00 \text { thru } \\
10 / 31 / 00 \\
\end{array}$ & $\begin{array}{c}4 / 1 / 01 \text { thru } \\
10 / 31 / 01 \\
\end{array}$ & $\begin{array}{c}4 / 1 / 02 \text { thru } \\
10 / 31 / 02 \\
\end{array}$ \\
\hline $\begin{array}{c}\text { Under } \\
\text { Construction? }\end{array}$ & Yes & Yes & Yes \\
\hline $\begin{array}{c}\text { \# of Operational } \\
\text { Lanes }\end{array}$ & Two & Two & Two \\
\hline Mile Marker & \multicolumn{3}{|c|}{ Accidents } \\
\hline 245.0 & $\overline{5}$ & 1 & $\overline{0}$ \\
\hline 245.5 & 3 & 1 & 0 \\
\hline 246.0 & 4 & 2 & 2 \\
\hline 246.5 & 0 & 1 & 3 \\
\hline 247.0 & 3 & 4 & 3 \\
\hline 247.5 & 0 & 1 & 2 \\
\hline 248.0 & 2 & 3 & 3 \\
\hline 248.5 & 4 & 0 & 1 \\
\hline 249.0 & 4 & 1 & 5 \\
\hline 249.5 & 0 & 0 & 3 \\
\hline 250.0 & 0 & 5 & 2 \\
\hline 250.5 & 1 & 0 & 1 \\
\hline 251.0 & 0 & 2 & 3 \\
\hline 251.5 & 0 & 0 & 2 \\
\hline 252.0 & 1 & 1 & 4 \\
\hline 252.5 & 3 & 2 & 2 \\
\hline 253.0 & 12 & 8 & 21 \\
\hline 253.5 & 5 & 1 & 21 \\
\hline 254.0 & 8 & 2 & 7 \\
\hline 254.5 & 6 & 3 & 4 \\
\hline 255.0 & 14 & 3 & 17 \\
\hline 255.5 & 3 & 3 & 3 \\
\hline 256.0 & 7 & 8 & 2 \\
\hline 256.5 & 0 & 2 & 1 \\
\hline 257.0 & 6 & 4 & 2 \\
\hline 257.5 & 5 & 5 & 3 \\
\hline 258.0 & 11 & 11 & 1 \\
\hline 258.5 & 5 & 1 & 1 \\
\hline 259.0 & 3 & 10 & 0 \\
\hline 259.5 & 4 & 4 & 0 \\
\hline
\end{tabular}

The second trend that can be found relates to the work zone signs in place for the 2002 construction season. Table 6-28 indicates that the number of accidents on the northbound lanes of Interstate 65 has decreased in the study area from 2001 to 2002 . This decrease may be a result of the work zone signs. Table 6-30 indicates the number of accidents for the southbound 
lanes of Interstate 65 actually increased in 2002. This increase is most likely not due to the work zone signs and instead may be a result of the increase in traffic volume from 2001 to 2002.

Since 1996, less than two fatalities have occurred inside the study area from April 1 to October 31. The approximate locations of these fatalities as well as the cause of each can be seen in Table 6-31 through Table 6-34. Due to this low frequency of fatalities, it is not possible to ascertain whether or not the work zone signs reduced the number of fatalities inside the study area. 
Table 6-31 Northbound Fatalities

\begin{tabular}{|c|c|c|c|c|}
\hline Date & $\begin{array}{c}4 / 01 / 96 \text { thru } \\
10 / 31 / 96\end{array}$ & $\begin{array}{c}4 / 01 / 97 \text { thru } \\
10 / 31 / 97\end{array}$ & $\begin{array}{c}4 / 01 / 98 \text { thru } \\
10 / 31 / 98\end{array}$ & $\begin{array}{c}4 / 01 / 99 \text { thru } \\
10 / 31 / 99\end{array}$ \\
\hline $\begin{array}{c}\text { Under } \\
\text { Construction? }\end{array}$ & No & No & Yes & Yes \\
\hline $\begin{array}{l}\text { \# of Operational } \\
\text { Lanes }\end{array}$ & Two & Two & One & One \\
\hline Mile Marker & \multicolumn{4}{|c|}{ Fatalities } \\
\hline 245.0 & 0 & 0 & 0 & 0 \\
\hline 245.5 & 0 & 0 & 0 & 0 \\
\hline 246.0 & 0 & 0 & 0 & 0 \\
\hline 246.5 & 0 & 0 & 0 & 0 \\
\hline 247.0 & 0 & 0 & 0 & 0 \\
\hline 247.5 & 0 & 0 & 0 & 0 \\
\hline 248.0 & 0 & 0 & 0 & 0 \\
\hline 248.5 & 0 & 0 & 0 & 0 \\
\hline 249.0 & 0 & 0 & 0 & 0 \\
\hline 249.5 & 0 & 0 & 0 & 0 \\
\hline 250.0 & 0 & 0 & 0 & 1 \\
\hline 250.5 & 0 & 0 & 0 & 0 \\
\hline 251.0 & 0 & 0 & 0 & 0 \\
\hline 251.5 & 0 & 0 & 0 & 0 \\
\hline 252.0 & 0 & 0 & 0 & 0 \\
\hline 252.5 & 0 & 0 & 0 & 0 \\
\hline 253.0 & 0 & 0 & 0 & 0 \\
\hline 253.5 & 0 & 0 & 0 & 0 \\
\hline 254.0 & 0 & 0 & 0 & 0 \\
\hline 254.5 & 0 & 0 & 0 & 0 \\
\hline 255.0 & 0 & 0 & 0 & 0 \\
\hline 255.5 & 0 & 0 & 0 & 0 \\
\hline 256.0 & 0 & 0 & 0 & 0 \\
\hline 256.5 & 0 & 0 & 0 & 0 \\
\hline 257.0 & 0 & 0 & 0 & 0 \\
\hline 257.5 & 0 & 0 & 0 & 0 \\
\hline 258.0 & 1 & 0 & 0 & 0 \\
\hline 258.5 & 0 & 0 & 0 & 0 \\
\hline 259.0 & 0 & 0 & 0 & 0 \\
\hline 259.5 & 0 & 0 & 0 & 0 \\
\hline Totals: & $1^{A}$ & $\overline{0}$ & 0 & $1^{B}$ \\
\hline \multicolumn{5}{|l|}{ Comment: } \\
\hline $\mathrm{A}$ & \multicolumn{4}{|c|}{ Vehicle sideswiped a gaurdrail } \\
\hline$B$ & \multicolumn{4}{|c|}{$\begin{array}{l}\text { Rear end collision involving vehicle starting from a stopped } \\
\text { queue }\end{array}$} \\
\hline
\end{tabular}


Table 6-32 Northbound Fatalities (con't)

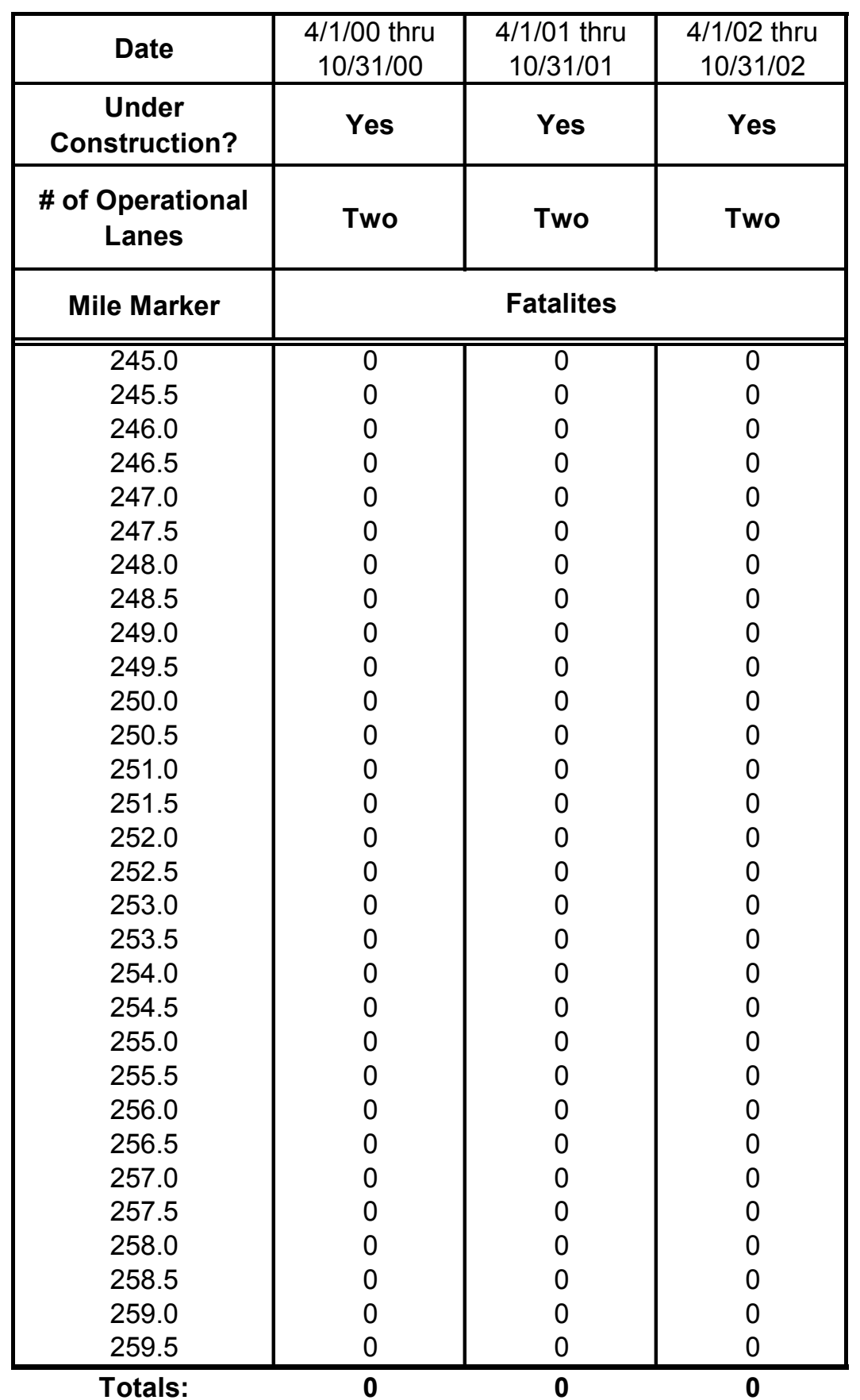


Table 6-33 Southbound Fatalities

\begin{tabular}{|c|c|c|c|c|}
\hline Date & $\begin{array}{c}\text { 4/01/96 thru } \\
10 / 31 / 96 \\
\end{array}$ & $\begin{array}{c}4 / 01 / 97 \text { thru } \\
10 / 31 / 97 \\
\end{array}$ & $\begin{array}{c}\text { 4/01/98 thru } \\
10 / 31 / 98 \\
\end{array}$ & $\begin{array}{c}/ 01 / 99 \text { thru } \\
10 / 31 / 99 \\
\end{array}$ \\
\hline $\begin{array}{c}\text { Under } \\
\text { Construction? }\end{array}$ & No & No & Yes & Yes \\
\hline $\begin{array}{c}\text { \# of Operational } \\
\text { Lanes }\end{array}$ & Two & Two & One & One \\
\hline Mile Marker & \multicolumn{4}{|c|}{ Fatalities } \\
\hline 245.0 & 0 & $\overline{0}$ & 0 & 0 \\
\hline 245.5 & 0 & 0 & 0 & 0 \\
\hline 246.0 & 0 & 0 & 0 & 0 \\
\hline 246.5 & 0 & 0 & 0 & 0 \\
\hline 247.0 & 0 & 0 & 0 & 0 \\
\hline 247.5 & 0 & 0 & 0 & 0 \\
\hline 248.0 & 0 & 0 & 0 & 0 \\
\hline 248.5 & 0 & 0 & 0 & 0 \\
\hline 249.0 & 0 & 0 & 0 & 0 \\
\hline 249.5 & 0 & 0 & 0 & 0 \\
\hline 250.0 & 0 & 0 & 0 & 0 \\
\hline 250.5 & 0 & 0 & 0 & 0 \\
\hline 251.0 & 1 & 0 & 0 & 0 \\
\hline 251.5 & 0 & 0 & 0 & 0 \\
\hline 252.0 & 0 & 0 & 0 & 0 \\
\hline 252.5 & 0 & 0 & 0 & 0 \\
\hline 253.0 & 0 & 0 & 0 & 0 \\
\hline 253.5 & 0 & 0 & 1 & 0 \\
\hline 254.0 & 0 & 0 & 0 & 0 \\
\hline 254.5 & 0 & 0 & 0 & 0 \\
\hline 255.0 & 0 & 0 & 0 & 0 \\
\hline 255.5 & 0 & 0 & 0 & 0 \\
\hline 256.0 & 0 & 1 & 0 & 0 \\
\hline 256.5 & 0 & 0 & 0 & 0 \\
\hline 257.0 & 0 & 0 & 0 & 0 \\
\hline 257.5 & 0 & 0 & 0 & 0 \\
\hline 258.0 & 0 & 0 & 0 & 0 \\
\hline 258.5 & 0 & 0 & 0 & 0 \\
\hline 259.0 & 0 & 0 & 0 & 0 \\
\hline 259.5 & 0 & 0 & 0 & 0 \\
\hline
\end{tabular}

Comment
A
Rear end collsion
B Driver crossed median and struck vehicle traveling opposite direction at a right angle
C Rear end collsion due to unordinary movement by vehicle 2 
Table 6-34 Southbound Fatalities (con't)

\begin{tabular}{|c|c|c|c|}
\hline Date & $\begin{array}{c}4 / 1 / 00 \text { thru } \\
10 / 31 / 00\end{array}$ & $\begin{array}{c}4 / 1 / 01 \text { thru } \\
10 / 31 / 01 \\
\end{array}$ & $\begin{array}{c}4 / 1 / 02 \text { thru } \\
10 / 31 / 02 \\
\end{array}$ \\
\hline $\begin{array}{c}\text { Under } \\
\text { Construction? }\end{array}$ & Yes & Yes & Yes \\
\hline $\begin{array}{c}\text { \# of Operational } \\
\text { Lanes }\end{array}$ & Two & Two & Two \\
\hline Mile Marker & \multicolumn{3}{|c|}{ Fatalities } \\
\hline 245.0 & 0 & 0 & 0 \\
\hline 245.5 & 0 & 0 & 0 \\
\hline 246.0 & 0 & 0 & 0 \\
\hline 246.5 & 0 & 0 & 0 \\
\hline 247.0 & 0 & 0 & 0 \\
\hline 247.5 & 0 & 0 & 0 \\
\hline 248.0 & 0 & 0 & 0 \\
\hline 248.5 & 0 & 0 & 0 \\
\hline 249.0 & 0 & 0 & 0 \\
\hline 249.5 & 0 & 0 & 0 \\
\hline 250.0 & 0 & 0 & 0 \\
\hline 250.5 & 0 & 0 & 0 \\
\hline 251.0 & 0 & 0 & 0 \\
\hline 251.5 & 0 & 0 & 0 \\
\hline 252.0 & 0 & 0 & 0 \\
\hline 252.5 & 0 & 0 & 0 \\
\hline 253.0 & 0 & 0 & 0 \\
\hline 253.5 & 0 & 0 & 0 \\
\hline 254.0 & 0 & 0 & 0 \\
\hline 254.5 & 0 & 0 & 0 \\
\hline 255.0 & 0 & 0 & 0 \\
\hline 255.5 & 0 & 0 & 0 \\
\hline 256.0 & 0 & 1 & 0 \\
\hline 256.5 & 0 & 0 & 0 \\
\hline 257.0 & 0 & 0 & 0 \\
\hline 257.5 & 0 & 0 & 0 \\
\hline 258.0 & 0 & 0 & 0 \\
\hline 258.5 & 0 & 0 & 0 \\
\hline 259.0 & 0 & 0 & 0 \\
\hline 259.5 & 0 & 0 & 0 \\
\hline \multicolumn{4}{|l|}{ Totals: } \\
\hline
\end{tabular}

Comment

A Semi exited work zone, lost control, struck a car parked in the shoulder 


\section{5. $\quad$ Conclusions}

The speed study indicated that the "Construction Zone Traffic Fines" sign had a statistically significant impact on the mean speeds of motorists in the "heart" of the work zone. Although this statistically significant speed reduction was only found at location 5-NB, the panel signs can be viewed as beneficial. The benefit from these signs results form motorists reducing their speeds in the "heart" of the work zone, which is where the construction activity occurs and where workers are present.

The speed study also indicated that the variable message signs displaying the number of traffic fines issued to date in the work zone, and the updating of this message, did not significantly reduce the mean speeds of motorists.

Despite the fact that the signs only reduced the speeds of motorists at the heart of the work zone, the signs were not a failure. The accident analysis described in Section 6.4 indicated that the overall safety of the work zone did improve, at least in terms of the number of accidents that occurred inside the work zone. It is believed that the reduced speeds in the "heart" of the work zone contributed to the reduced number of accidents throughout the study area. Based on the reduced accident rate alone, the main objective of the signs was achieved.

To reduce the risk of a motorist being involved in a rear end collision with another motorist who is stopped or slowly moving in a queue caused by a work zone, it is necessary to warn motorists of a work zone and to encourage them to reduce their speeds. The results of this speed study suggest that the signs used in this experimental project have little or no effect on reducing such a risk.

The results of the enforcement study discussed in this chapter may lead to a solution to this problem. These results showed that speeds of motorists were reduced up to 1.2 miles downstream of a marked, visible patrol car. This suggests that one method to reduce speeds and thus the chance of a rear end collision is to place a marked patrol car approximately one mile in advance of the anticipated back of queue. However, there is a dilemma that is associate with this method. That dilemma is locating the ever moving back of the queue. 


\section{CHAPTER 7. TRAVEL TIME STUDIES THROUGH WORK ZONES USING GLOBAL POSITIONING SYSTEMS (GPS)}

The advent of automated traffic data collection procedures has led to new alternatives for transportation officials. One of the most promising of these data collection technologies is the Global Positioning System (GPS). GPS has gained wide acceptance and has been extensively used for many applications in the transportation industry. The possibility of automatically collecting data, and obtaining key parameters such as location (latitude and longitude), speed and distance traveled, is greatly beneficial. Although Global Positioning System (GPS) can be used as effective tools for determining with high degree of accuracy points of interest, these devices have not been used for collecting traffic data during periods of construction work on interstates.

Construction work on interstates results in significant impacts on traveling conditions for motorists. The impacts tend to translate into back-up queues and lines of stopped vehicles. The mobility of the section is not appropriate if traffic congestion is encountered. The primary impact during work zones is reduced freeway capacity. Capacity reduction is the key factor in determining the queue length and the maximum delay observed in a specific interstate segment. In this chapter, three interstate workzones with differing lane restrictions in the state of Indiana have been evaluated, to link the different type of lane restrictions to the impact on traffic flow (mainly capacity and delay). In an effort to study how to improve mobility on the interstates, a Global Positioning System (GPS) was used to collect the data and to relate the traffic conditions with the construction activities taking place.

\subsection{Description of Technology}

The Global Positioning System (GPS) comprises a total of 24 satellites orbiting the earth. At a specific point in time, the GPS system requires at least four satellites for referencing locations of interest on earth. The most important principle underlying the functioning of the entire system is Trilateration. Trilateration consists of utilizing three satellites for determining the location of virtually anyplace on earth by referencing to other already known locations (Brain and Harris 2002). 
In addition to the three satellites a fourth satellite is required to incorporate the measurement of time and cancel any time measurement error. According to Daniels and Huxford (2001) "A clock at the receiver unit is needed to ensure that the signals are perfectly synchronized. Because these clocks are so expensive, it is impossible to put them in receivers. Instead, receivers use the measurements from a fourth satellite to remove clock errors."

The high degree of precision encountered when using these GPS systems is advantageous for conducting transportation studies. However, there are also errors associated with the use of this technology. Selective Availability (SA) is the original set of errors or miscalculations incorporated to the satellite signal, which limit the accuracy of the civilian receivers to about 100 meters (Sluzas, 2002). These original miscalculations in the early beginnings of the system have been cancelled in May of 2000 (Brain and Harris, 2002). An adjustment called "differential correction" improves the accuracy and minimizes the error encountered. This adjustment increases even more the accuracy of this technology and provides more advantages for its extensive utilization on travel time studies.

Miller and Karr (1998) utilized GPS as a tool for locating motor vehicle crashes. Quiroga and Bullock (1999) conducted an extensive evaluation of GPS for measuring the control delay at signalized intersections. Draijer et al. (2000) conducted an evaluation of GPS for collecting information about travel behavior. The study concluded that by using GPS it was possible to successfully monitor different kinds of travel modes such as car, public transportation, and walking. The study also showed that GPS devices were effective collecting data that could be used for determining information about travel behavior.

Only one study was found dealing with the use of GPS in work zones. Jiang and Shuo (2002) conducted an evaluation of seven interstate work zones (with a total of 29 runs) in the state of Indiana. The main goal of this evaluation was to obtain traffic characteristics that could not otherwise be obtained by using normal traffic counters such as vehicle speeds profiles and queue lengths. Researchers were able to analyze vehicle position and speed data readily by employing GPS. The study concluded that this technology was highly beneficial for recording vehicle position through work zones and for collecting traffic characteristics such as location (latitude and longitude), speed and distance traveled. However the study also indicated that there are certain obstacles to the full scale use of the technology. The GPS device is inside the probe car, and can be considered "dynamic" device because it cannot be fixed at a location. In addition, GPS devices cannot record traffic volumes. 


\subsection{Description of GPS Study}

A field study was conducted to demonstrate the effectiveness of utilizing GPS for conducting travel-time runs during construction work on interstates. By utilizing GPS the exact location of back-up queues can be easily located, helping engineers in improving mobility throughout the interstate section. In an effort to have different conditions, several locations were evaluated. The data collection was conducted in three different rural work zones on Interstate 65 in Indiana. Multiple runs were conducted at each location to analyze the impact of traveling conditions to changes in lane restrictions during construction periods on interstates. As shown in Table 7-1, the study was conducted on rural interstates with very similar characteristics.

Table 7-1 Summary of GPS data collection sites

\begin{tabular}{|c|c|c|c|c|c|}
\hline Number & $\begin{array}{c}\text { Project } \\
\text { Location }\end{array}$ & $\begin{array}{c}\text { Interstate } \\
\text { Route }\end{array}$ & $\begin{array}{c}\text { Project } \\
\text { Description }\end{array}$ & $\begin{array}{c}\text { AADT } \\
(1999)\end{array}$ & $\begin{array}{c}\text { Route } \\
\text { Number } \\
\text { Assigned }\end{array}$ \\
\hline $\mathbf{1}$ & Merrillville & I-65 & $\begin{array}{c}\text { Interchange } \\
\text { Reconstruction }\end{array}$ & 72,940 & $1,2,4 \& 5$ \\
\hline $\mathbf{2}$ & Thorntown & I-65 & $\begin{array}{c}\text { Bridge \& Lane } \\
\text { Widening }\end{array}$ & 39,440 & 3 \\
\hline $\mathbf{3}$ & Lafayette & I-65 & $\begin{array}{c}\text { Overpass } \\
\text { Construction }\end{array}$ & 40,000 & 6 \\
\hline
\end{tabular}

The study was conducted by driving through the work zone at what the driver perceived to be the traffic flow speed. Under normal conditions, the free flow speed was assumed to be equal to the posted speed limit both inside the work zone and outside the work zone limits. The data was collected by a team of two: the driver and a co-pilot who was in charge of turning on and off the GPS system. The co-pilot also had the responsibility of marking down the coordinates of the most important landmarks (construction limits, and activity area) of the work zone.

Travel time studies are typically conducted by following either the floating-car technique, or the moving-vehicle technique (Jiang and Shuo, 2002). In the floating car technique, the "driver "floats" with the traffic by attempting to safely pass as many vehicles as pass the test vehicle (Turner et al 1998). In the moving vehicle technique, the testing vehicle conducts a round trip, and parameters such as number of vehicles in the opposing lanes, number of vehicles passed, and the travel time through the section are recorded (Jiang and Shuo, 2002). 
According to Jiang and Shuo (2002), both of these techniques are only applied for highways with multi-lanes. These conditions, claim the authors, are typically not encountered on rural interstate work zones. For this study evaluation, however, a hybrid of the floating-car method and the average car was implemented. The average car is another technique, in which the test vehicle travels at what the driver perceived to be the prevailing traffic flow (Turner et al 1998). This technique was considered appropriate for the study due to the differing traveling conditions and lane restrictions encountered in the work zones analyzed.

\subsubsection{Equipment Used for Research Study}

The equipment used for this evaluation was a Garmin eMap $^{\mathrm{TM}}$. The Garmin GPS utilized is not aimed for conducting travel time studies. This unit can be considered a fairly inexpensive system ( $\$ 200$ dollar range). One of the main points of this study was to evaluate if transportation officials can use "inexpensive" GPS devices for collecting traffic data.

Data was collected by turning the device "on" and "off". This feature can somehow affect the data collection because a larger study area than the one actually required is needed in order to provide a consistent study area for different runs. The accuracy for the runs was between 4.5 to 6 $\mathrm{m}$ (15 to $30 \mathrm{ft}$ ), which is believed to be sufficient for travel time runs. The update rate or time taken for receiving a signal was not very precise. Sometimes the signal took more than 35 seconds. On average, for all the travel time runs conducted the average update rate was 22 seconds.

The output obtained from the GPS was analyzed by using MapSource ${ }^{\mathrm{TM}}$, the software package available with the GPS unit. By using this software, the "tracks" or "breadcrumb" trail showing the exact locations traveled were obtained. Each point on the "track" log gives the following information:

- Coordinates (Latitude and Longitude)

- Time \& Date

- Distance \& Time Traveled (From previous location)

- Leg Speed 


\subsubsection{Calculation of Distances}

It was considered appropriate to conduct a transformation of the distances obtained in the log from Latitude-Longitude to $\mathrm{X}, \mathrm{Y}$ (Cartesian) coordinates, in order to obtain more accurate distances. An important approximation called the flat-earth approximation was used for this purpose. This approximation states that the distances between two points of interest are very small compared to the radius of the earth. By using this approximation, points are believed to be located on a plane parallel to the surface of the earth. Therefore, the calculation is performed in the parallel plane and does not take into consideration the earth's curvature.

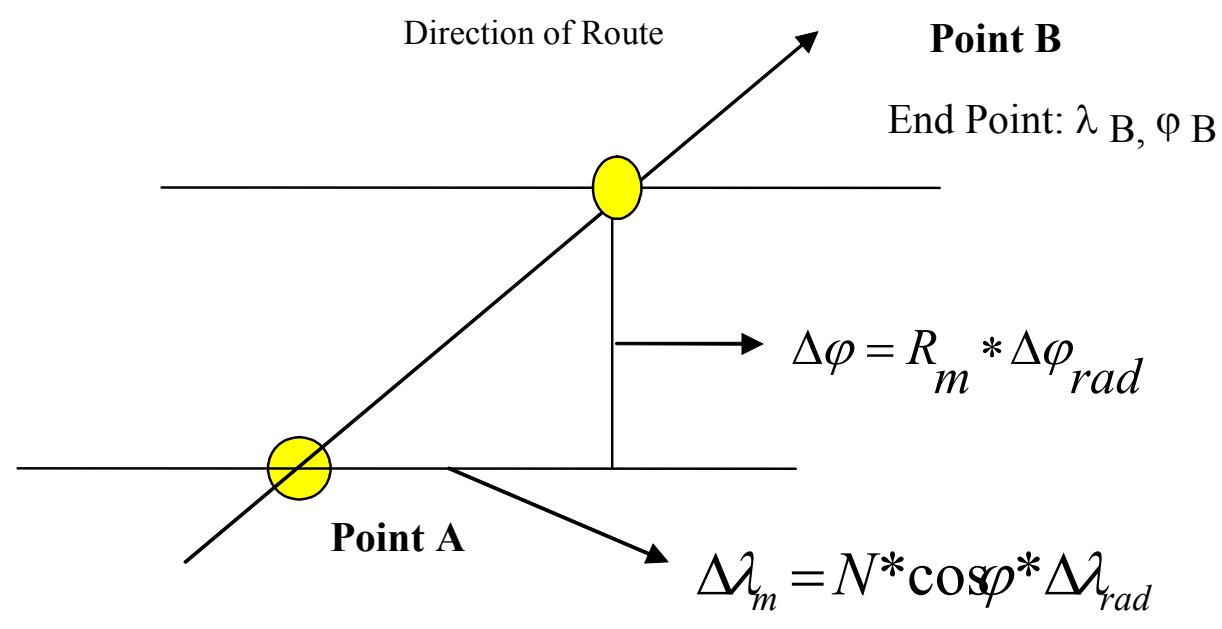

Ref Point: $\lambda_{\mathrm{A}}, \varphi \mathrm{A}$

Figure 7-1 Calculation of Distances (Source: Adapted from van Gelder (2002))

As shown in Figure 7-1, the calculation of coordinates is conducted by using principles of trigonometry and the flat-earth approximation. Assume that the direction of the route is from Point $A$ to $B$. Point $A$ and Point $B$ have their respective coordinates (latitude and longitude). The latitude and longitude angle values are changed from decimal degrees to radians. The change in angle (Point $\mathrm{B}-$ Point $\mathrm{A}$ ) is then obtained for both latitude and longitude. This change is multiplied by the Meridional Curvature "M" for the latitude and the Prime Vertical Curve "N" for the longitude. The Pythagorean Theorem is then used for calculating the change in distances. The " $\mathrm{M}$ " and "N" values diverge between those in Northern Indiana and the values found in West Lafayette. Table 7-2 presents the values used for the Meridional Curvature "M", and Prime Vertical Curve "N" during the evaluation. 
Table 7-2 Summary of M and N values (Source: van Gelder (2002))

\begin{tabular}{|c|c|c|c|c|}
\cline { 2 - 5 } \multicolumn{1}{c|}{} & \multicolumn{2}{c|}{ Northern Indiana } & \multicolumn{2}{c|}{ West Lafayette } \\
\hline & & Meters & & Meters \\
\hline $\mathrm{R}=\mathrm{M}$ & Latitude & $6.3635 \mathrm{E}+06$ & Latitude & $6.3624 \mathrm{E}+06$ \\
\hline $\mathrm{R}^{\prime}=\mathrm{N}$ & Longitude & $6.3872 \mathrm{E}+06$ & Longitude & $6.3872 \mathrm{E}+06$ \\
\hline
\end{tabular}

\section{3. $\quad$ Travel Time Routes Description}

To maintain consistency during the evaluation, projects were "subdivided" into multiple routes. Routes on the North Bound (NB) and South Bound (SB) direction for example, are considered two separate routes. A total of six routes were analyzed in this study. Multiple runs were conducted on each route. The runs were designed to represent different lane restrictions. For instance, one project consisted of an interchange reconstruction (I-65/US-30 Merrillville Project), while another project (I-65 Project near Lafayette) consisted of restricting traffic for twenty-minute periods while setting the beams for an overpass bridge.

The study area for the travel time runs was chosen to be more extensive than the actual construction limits. This allowed the data collection team:

- To investigate conditions upstream and downstream. These are locations where most of the rear-end collisions tend to occur.

- To mitigate the fact that the GPS needs to be turned on and off at every run, causing delay in the reception of the signal.

Table 7-3 presents the different projects and the corresponding routes. The milepost and coordinates (latitude and longitude) are provided for both the start and end locations of the study area. 
Table 7-3 General Route Information

\begin{tabular}{|c|c|c|c|c|c|c|c|c|c|c|}
\hline \multirow{2}{*}{$\begin{array}{l}\text { Route } \\
\text { Number }\end{array}$} & \multirow{2}{*}{$\begin{array}{c}\text { Project } \\
\text { Location } \\
\end{array}$} & \multirow{2}{*}{$\begin{array}{c}\text { Interstate } \\
\text { Route }\end{array}$} & \multirow{2}{*}{$\begin{array}{l}\text { Direction } \\
\text { of Travel } \\
\end{array}$} & \multirow{2}{*}{ Project Description } & \multicolumn{3}{|c|}{ Start Location } & \multicolumn{3}{|c|}{ End Location } \\
\hline & & & & & MP & Latitude & Longitude & MP & Latitude & Longitude \\
\hline Route \# 1 & Merrillville & $\mid-65$ & NB & $\begin{array}{c}\text { Interchange } \\
\text { Reconstruction }\end{array}$ & 245.0 & N41.36042 & W87.31856 & 259.0 & N41.56962 & W87.30065 \\
\hline Route \# 2 & Merrillville & $1-65$ & SB & $\begin{array}{c}\text { Interchange } \\
\text { Reconstruction }\end{array}$ & 259.0 & N41.56962 & W87.30065 & 245.0 & N41.36042 & W87.31856 \\
\hline Route \# 3 & Thorntown & $1-65$ & SB & $\begin{array}{c}\text { Bridge \& Lane } \\
\text { Widening }\end{array}$ & 152.0 & N40.19549 & W86.57222 & 142.0 & N40.07253 & W86.49774 \\
\hline Route \# 4 & Merrillville & I-65 & SB & $\begin{array}{c}\text { Interchange } \\
\text { Reconstruction }\end{array}$ & 259.0 & N41.56984 & W87.30020 & 247.4 & N41.39451 & W87.32378 \\
\hline Route \# 5 & Merrillville & I-65 & SB & $\begin{array}{c}\text { Interchange } \\
\text { Reconstruction }\end{array}$ & 254.7 & 41.49933 & W87.32002 & 247.0 & N41.39445 & W87.32382 \\
\hline Route \# 6 & Lafayette & $\mathrm{I}-65$ & NB & Overpass Construction & 164.0 & N40.32060 & W86.74940 & 170.9 & N40.4077 & W86.80337 \\
\hline
\end{tabular}

7.4. $\quad$ Route \# 1: I-65/US-30 Project near Merrillville, IN

7.4.1. $\quad$ Route \# 1 Description

The I-65/US-30 project consists of an interchange reconstruction and reconstruction of a segment on I-65. The reconstructed I-65 section increased the number of lanes from two to three lanes of traffic in the North Bound direction. The project was completed under a design-build delivery method. The project started in March 2002 and was completed in November 2002. The typical Annual Daily Traffic (ADT) is 73,000 vehicles per day on this segment. Previous conditions consisted of two lanes of traffic. With the high ADT of the section, it is essential to increase the number of lanes and minimize congestion conditions on I-65. In addition, the existing off-ramps on I-65 towards US-30 during peak periods create spillbacks that translate into traffic backups on I-65.

Table 7-4 presents the construction limits for this project. The interchange reconstruction project was constructed on both I-65 and US-30. The limit on the south most portion on I-65 is in the vicinity of mile marker 251.2. On the northbound portion, the limit is the beginning of the newly constructed pavement north of US-30 (Mile marker 253.9). 
Table 7-4 I-65/US-30 Project General Coordinate Information

\begin{tabular}{|l|c|c|c|c|c|c|}
\hline & \multicolumn{3}{|c|}{ Start } & \multicolumn{3}{c|}{ End } \\
\cline { 2 - 7 } & MP & Latitude & Longitude & MP & Latitude & Longitude \\
\hline Construction Limits & 251.2 & N41.44942 & W87.32165 & 253.9 & N41.48599 & W87.32111 \\
\hline SB Taper & 253.4 & N41.48030 & W87.32335 & 253.1 & N41.47654 & W87.32402 \\
\hline Construction "Point" & & N41.47065 & W87.32417 & & & \\
\hline
\end{tabular}

Figure 7-2 presents a schematic diagram of the work zone layout obtained by using the software package available with the GPS. The actual trip (dotted-line) represents the breadcrumb obtained in one of the travel time runs.

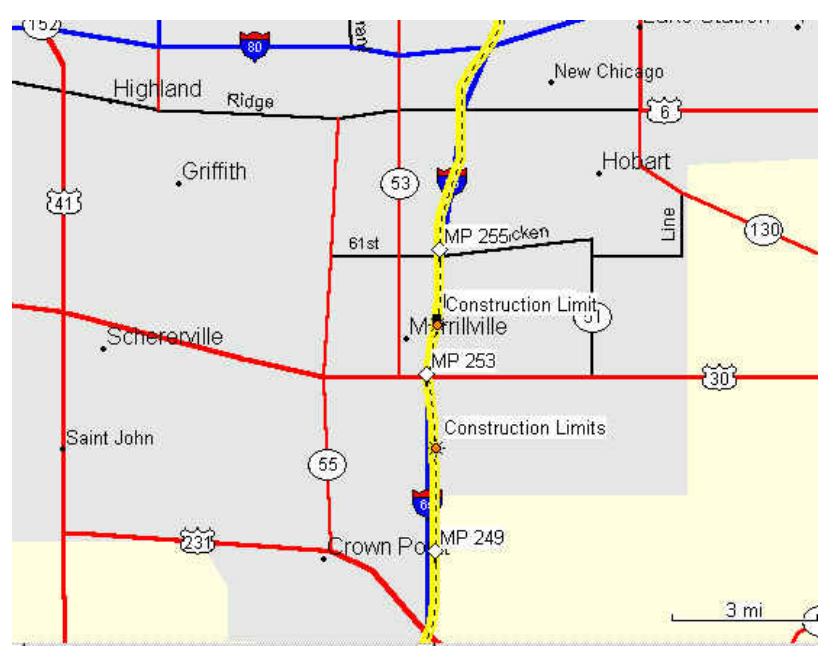

Figure 7-2 I-65/US-30 Work Zone Layout

\subsubsection{Route \# 1: Travel-Time Runs}

On Route \# 1 traffic travels on a typical two-lane median divided highway in the northbound direction. Two lanes of traffic prevail until reaching north of the US-30 interchange. After passing the interchange, three lanes of traffic are available. It was expected that because of the proximity with the I-80/94 interchange (approx. 6 miles north); the southbound direction would present more congestion than the northbound direction, due to the high volume of traffic entering I-65 from the I-80/94 interchange. Table 7-5 presents the information for the travel time runs completed for Route \# 1. 
Table 7-5 I-65/US-30 Project General Coordinate Information

\begin{tabular}{|c|c|c|c|c|c|c|c|c|c|c|}
\hline \multirow{2}{*}{$\begin{array}{l}\text { Route } \\
\text { Number }\end{array}$} & \multirow{2}{*}{ Route Code } & \multirow{2}{*}{$\begin{array}{c}\text { Direction of } \\
\text { Travel }\end{array}$} & \multirow{2}{*}{ Date } & \multirow{2}{*}{ Start Time } & \multirow{2}{*}{ End Time } & Time Elapsed & \multirow{2}{*}{$\begin{array}{c}\text { Number of } \\
\text { Observations }\end{array}$} & \multirow{2}{*}{$\begin{array}{c}\text { Min. Speed } \\
(\mathrm{mph})\end{array}$} & \multirow{2}{*}{$\begin{array}{c}\text { Max. Speed } \\
(\mathrm{mph})\end{array}$} & \multirow{2}{*}{$\frac{\text { Avg. Speed }}{(\mathrm{mph})}$} \\
\hline & & & & & & $(\min )$ & & & & \\
\hline \multirow{8}{*}{ 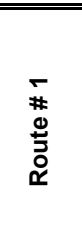 } & 1-NB-0501-01 & NB & $5 / 1 / 2002$ & $14: 18$ & $14: 33$ & $0: 14: 40$ & 53.0 & $4 \quad 46.6$ & 67.7 & 61.1 \\
\hline & 1-NB-0501-02 & NB & $5 / 1 / 2002$ & $15: 03$ & $15: 17$ & 0:13:24 & 50.0 & 50.7 & 73.5 & 64.0 \\
\hline & 1-NB-0508-03 & NB & $5 / 8 / 2002$ & $14: 39$ & $14: 50$ & $0: 11: 41$ & 42.0 & 54.4 & 76.0 & 68.1 \\
\hline & 1-NB-0508-04 & NB & $5 / 8 / 2002$ & $15: 23$ & $15: 34$ & $0: 12: 33$ & 48.0 & 52.4 & 74.2 & 66.9 \\
\hline & 1-NB-0524-05 & NB & $5 / 24 / 2002$ & $14: 39$ & $14: 53$ & $0: 14: 02$ & 58.0 & 52.0 & 69.4 & 64.1 \\
\hline & 1-NB-0524-06 & NB & $5 / 24 / 2002$ & $15: 21$ & $15: 36$ & $0: 14: 41$ & 62.0 & 33.0 & 72.5 & 64.3 \\
\hline & 1-NB-0527-07 & NB & $5 / 27 / 2002$ & $16: 09$ & $16: 22$ & 0:13:39 & 59.0 & 60.8 & 72.8 & 67.2 \\
\hline & 1-NB-0527-08 & NB & $5 / 27 / 2002$ & $19: 14$ & $19: 29$ & $0: 14: 33$ & 60.0 & 49.6 & 75.2 & 67.3 \\
\hline
\end{tabular}

In order to represent "typical" conditions several runs were conducted on various dates. The first four runs were completed on a typical weekday in the afternoon. As expected, no major traffic congestion was observed, and traffic was perceived to be traveling at speed limit (65 mph prior, and $45 \mathrm{mph}$ inside the workzone) or in some cases, at speeds higher than the posted speed limit. Two lanes of traffic were open, and traffic wanting to use the US-30 exit on I-65 was detoured to the US-231 exit (MP 247). Figure 7-3 provides a representation of the conditions encountered when conducting the runs. Figure 7-3a, shows a schematic distance-time diagram depicting a profile of the run, and the posted speed limit on the section. On the vertical axis, the major points of interest such as construction limits and actual US-30 interchange are presented. Delay was found on this route during a typical weekday. In Figure 7-3b, a speed-time diagram is presented to illustrate the locations where the traveling speed was below the threshold values. 


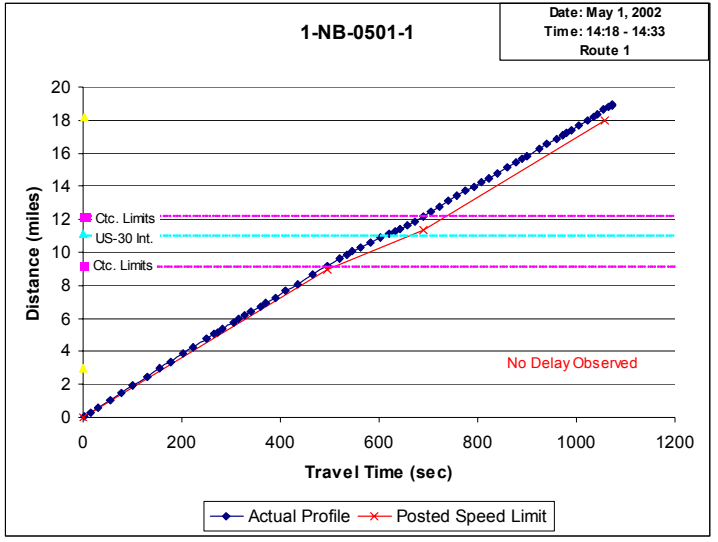

a) 1-NB-0501-1 Distance-Time Diagram

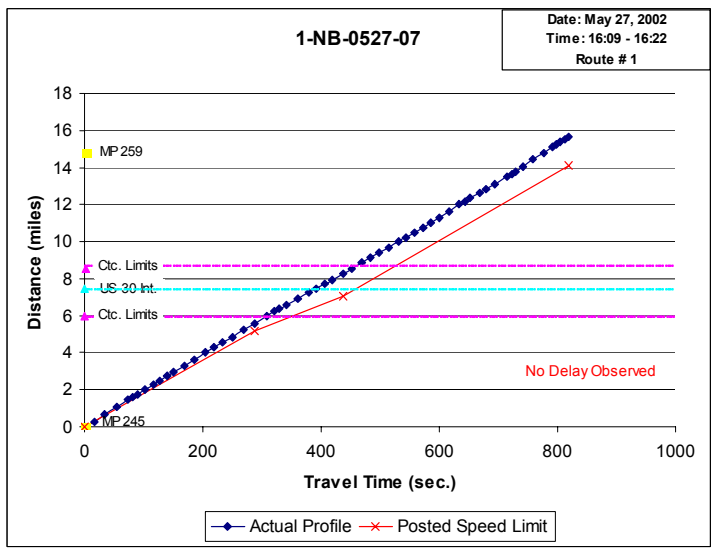

c) 1-NB-0527-01 Distance-Time Diagram

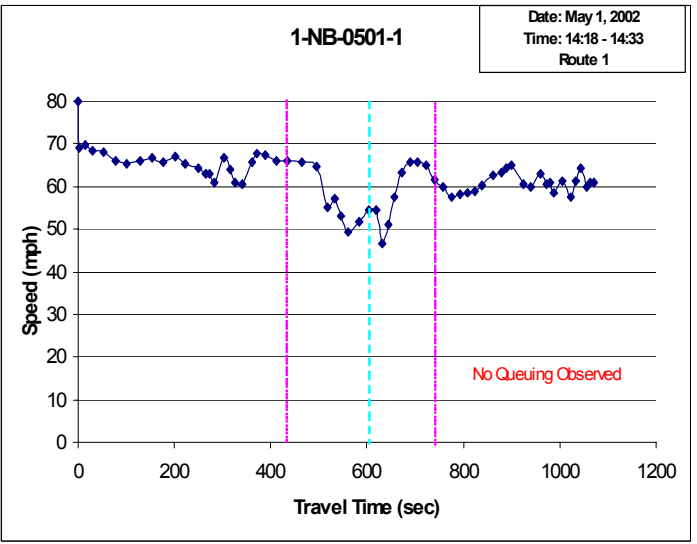

b) 1-NB-0501-1 Speed-Time Diagram

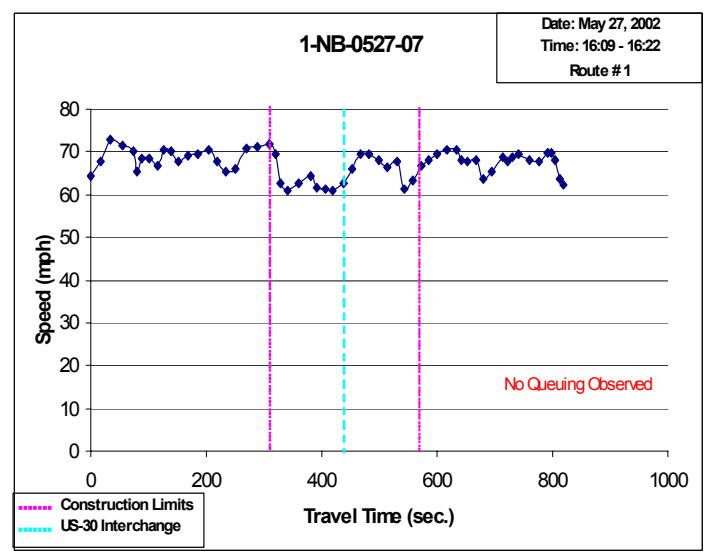

d) 1-NB-0527-1 Speed-Time Diagram

Figure 7-3 Route \# 1 (1-NB-0501-1) Conditions Observed

The conditions shown in Figure $7-3 \mathrm{c}$ did not generate any congested situations. Travel time runs were also conducted during a holiday weekend to determine if holiday traffic would result in congestion. It was expected that with the US-30 exit ramps closed in the northbound directions, traffic on a busy weekend would be slowed down, resulting in congestion. Runs were conducted on both Friday and Sunday afternoons and nights during the Memorial Day weekend (May 24 and May 27, 2002). A total of 800 miles were traversed and 24 runs were completed on these two dates. No congestion was observed, during run (1-NB-0527-07). In some cases, motorists were even traveling at speeds higher than the posted speed limit. Figure $7-3 c \& d$, present the distance-time and speed-time diagrams. Based on the findings of Route \# 1, it can be concluded 
that the capacity of the I-65 northbound segment with both lanes open is sufficient to meet adequate demand while construction is taking place.

\section{5. $\quad$ Route \# 2: I-65/US-30 Project near Merrillville, IN}

\subsubsection{Route \# 2 Description}

The I-65/US-30 project near Merrillville is the site for this route. The study area for Route \# 2 is the same as Route \# 1. The only difference is the travel direction. In this case, traffic data was collected while traveling in the southbound direction. Southbound traffic can enter I-65 from the I$80 / 94$ exit. Also, I-65 starts just prior to entering the study area. Three lanes of traffic are open to traffic prior to entering the work zone limits. As shown in Table 7-4, a taper exists on the southbound direction. (MP 253.4 to 253.1). After the taper, only two lanes of traffic are open to the public.

\subsubsection{Route \# 2 Travel Time Runs}

Table 7-6 presents the runs conducted on Route \# 2. More than twenty runs were conducted on this route. Due to similarity between the runs completed, only a total of twelve runs were analyzed. The most important findings for this route were observed on the first runs conducted, and not in the runs conducted during the Memorial Day weekend.

Table 7-6 Route \# 2 Travel Time Runs Completed

\begin{tabular}{|c|c|c|c|c|c|c|c|c|c|}
\hline \multirow{2}{*}{ Route Code } & \multirow{2}{*}{$\begin{array}{c}\text { Direction of } \\
\text { Travel }\end{array}$} & \multirow{2}{*}{ Date } & \multirow{2}{*}{ Start Time } & \multirow{2}{*}{ End Time } & Time Elapsed & \multirow{2}{*}{$\begin{array}{c}\text { Number of } \\
\text { Observations }\end{array}$} & \multirow{2}{*}{$\frac{\text { Min. Speed }}{(\mathrm{mph})}$} & \multirow{2}{*}{$\frac{\text { Max. Speed }}{(\mathrm{mph})}$} & \multirow{2}{*}{$\frac{\text { Avg. Speed }}{(\mathrm{mph})}$} \\
\hline & & & & & (min) & & & & \\
\hline 2-SB-0501-01 & $\overline{\mathrm{SSB}}$ & 5/1/2002 & 14:38 & $14: 53$ & 0 & 58.0 & 20.5 & 68.0 & 58.5 \\
\hline 2-SB-0501-02 & SB & $5 / 1 / 2002$ & $15: 21$ & $15: 36$ & $0: 14: 32$ & 56.0 & 9.5 & 74.3 & 55.9 \\
\hline 2-SB-0508-03 & SB & $5 / 8 / 2002$ & $14: 15$ & $14: 29$ & $0: 13: 28$ & 52.0 & 50.8 & 78.0 & 66.5 \\
\hline 2-SB-0508-04 & SB & $5 / 8 / 2002$ & $14: 59$ & $15: 12$ & $0: 13: 19$ & 57.0 & 57.2 & 72.7 & 65.7 \\
\hline 2-SB-0508-05 & SB & $5 / 9 / 2002$ & $15: 39$ & $15: 53$ & $0: 13: 20$ & 59.0 & 59.0 & 73.1 & 65.6 \\
\hline 2-SB-0524-06 & SB & $5 / 24 / 2002$ & $14: 58$ & $15: 12$ & $0: 13: 10$ & 57.0 & 51.2 & 91.1 & 65.4 \\
\hline 2-SB-0524-07 & SB & $5 / 24 / 2002$ & $15: 40$ & $15: 54$ & $0: 14: 35$ & 63.0 & 28.6 & 76.5 & 61.8 \\
\hline 2-SB-0524-08 & SB & $5 / 24 / 2002$ & $16: 24$ & $16: 38$ & $0: 13: 58$ & 61.0 & 20.7 & 74.6 & 61.1 \\
\hline 2-SB-0524-09 & SB & $5 / 24 / 2002$ & $17: 21$ & $17: 36$ & $0: 14: 45$ & 52.0 & 35.9 & 73.3 & 65.0 \\
\hline 2-SB-0527-10 & $\mathrm{SB}$ & $5 / 27 / 2002$ & $16: 25$ & $16: 40$ & $0: 14: 29$ & 59.0 & 45.7 & 75.7 & 66.8 \\
\hline 2-SB-0527-11 & SB & $5 / 27 / 2002$ & $18: 11$ & $18: 26$ & $0: 15: 00$ & 61.0 & 37.1 & 72.4 & 64.6 \\
\hline 2-SB-0527-12 & SB & $5 / 27 / 2002$ & $20: 10$ & $20: 26$ & $0: 15: 05$ & 60.0 & 51.7 & 71.3 & 64.8 \\
\hline
\end{tabular}

Figure 7-4 represents the conditions observed when the US-30 ramps on the southbound direction on I-65 were closed. The minimum speed for most of the runs is lower than the ones 
observed on Route \# 1, as shown in Figure 7-4. During the construction of the exit ramps, traffic slowed down significantly when drivers not familiar with the change in configuration realized that the exit was closed. As a result, traffic was backed up for several miles as presented in Figure 7-4b. In one of the runs, traffic slowed down significantly. A back-up queue was observed during this run. Based on the findings by using the GPS device, the exact location of the queue length was found to be at 1.2 miles with respect to the construction limits.

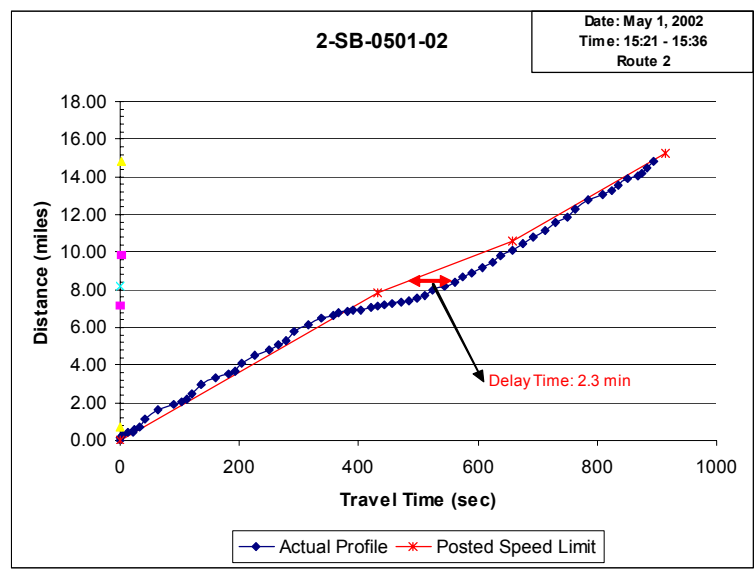

a) 2-SB-0501-02 Distance-Time Diagram

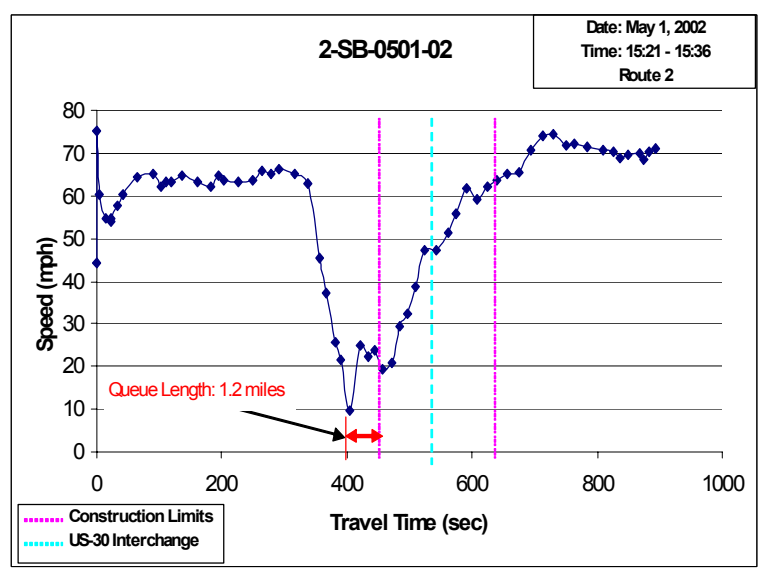

b) 2-SB-0501-02 Distance-Time Diagram

Figure 7-4 Route \# 2 (1-NB-0501-1) Conditions Observed

Runs were also conducted during the Memorial Day weekend. Worse conditions were observed on a typical weekday as documented in Figure 7-4, than during the Memorial Day weekend. As shown on Figure 7-4b delay was observed when conducting the (2-SB-0501-01) run on a typical week day. Although traffic was not completely stopped, the congestion was sufficient to generate delay which is represented by the spaces between the actual profile and the posted speed limit in Figure 7-4a. Delays and long back-up queues can also be attributed to the conditions on US-30. A common occurrence in the runs conducted on the Merrillville project, was the congestion generated by the US-30 spillbacks on I-65. Although several runs were analyzed for this route, only one set of diagrams are presented. Figure 7-4 represents the worst conditions observed throughout the evaluation.

Most of the runs conducted in the southbound direction are similar because traffic was traveling at the free flow speed prior to entering the taper. The taper consisted of double arrow message signs which may have had an impact on the way in which motorists merged to the desired lanes. 
The queuing observed was most likely generated primarily due to the ramp closure and not due to the lane reduction and taper.

\section{6. $\quad$ Route \# 3: I-65 project near Thorntown, IN}

\subsubsection{Route \# 3 Description}

The I-65 project near Thorntown, IN includes the widening of a bridge and the widening of a segment on I-65. This project is the first effort by the Indiana Department of Transportation (INDOT) to increase the number of lanes to three lanes in each direction from Indianapolis to south of the US-231 exit on I-65 (MP 247). The project started in April 2002 and it is expected to be completed by November 2002. The typical ADT is approximate 40,000 vehicles per day on this segment.

Table 7-7 presents the construction limits for this project. The limit on the southern most portion of I-65 is in the vicinity of mile marker 145 . On the northbound portion, the limit is 0.46 miles south of SR. 47 in Boone County (MP 148).

Table 7-7 I-65 near Thorntown Project General Coordinate Information

\begin{tabular}{|l|c|c|c|c|c|c|}
\hline & \multicolumn{3}{|c|}{ Start } & \multicolumn{3}{c|}{ End } \\
\cline { 2 - 7 } & MP & Latitude & Longitude & MP & Latitude & Longitude \\
\hline \hline Construction Limits & 148 & N40.15195 & W86.53674 & 145.1 & N40.11490 & W86.51412 \\
\hline Taper & 145.8 & N40.12580 & W86.51752 & 145.7 & N40.12315 & W86.51694 \\
\hline Bridge Location (Approx) & 145.4 & N40.12115 & W86.51632 & & & \\
\hline
\end{tabular}

Figure 7-5 presents a schematic diagram of the work zone layout obtained by using the software package available with the GPS. The actual trip (dotted-line) represents the breadcrumb obtained in one of the travel time runs. 


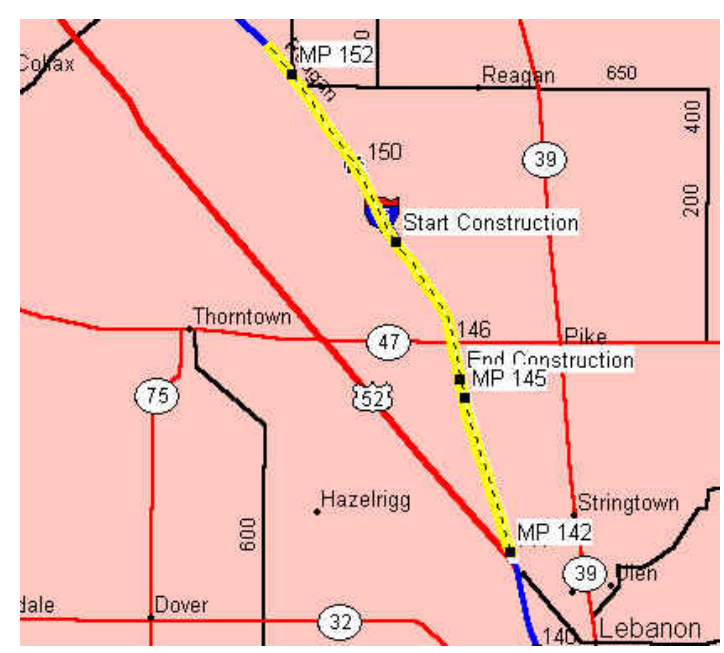

Figure 7-5 I-65 near Thorntown Work Zone Layout

7.6.2

Route \# 3: Travel-Time Runs

On Route \# 3, runs were completed only in the southbound direction. The project consisted of widening a bridge and its respective superstructure. In addition, the lanes on I-65 were also widened, and the inside shoulders of the segment were strengthened to accommodate traffic. Once this work was completed, the traffic was shifted to occupy the newly paved area so that work on the outside shoulders could commence.

The travel-time runs for this project were conducted when the inside shoulders were being constructed. This project called for a phased-construction. Two lanes of traffic had to remain open for most of the project duration with the exception of the time when concrete work was being completed on the shoulders. The runs were conducted to analyze changes in conditions, during a period of time when lane reductions were in place and the passing lane was closed. As shown in Table 7-8, four of the five runs were completed in the morning, when the preparation and setting of the reinforcement bars was in progress. The last run was conducted in the afternoon when the shoulder concrete work (a) was taking place. Due to the lane restrictions encountered, and the period of time when the closure was taking place, periods of heavy congestion were observed. 
Table 7-8 Route \# 3: Travel Time Runs Completed

\begin{tabular}{|c|c|c|c|c|c|c|c|c|c|}
\hline \multirow[t]{2}{*}{ Route Code } & \multirow{2}{*}{$\begin{array}{c}\text { Direction of } \\
\text { Travel }\end{array}$} & \multirow[t]{2}{*}{ Date } & \multirow{2}{*}{$\begin{array}{l}\text { Start } \\
\text { Time }\end{array}$} & \multirow{2}{*}{ End Time } & \multirow{2}{*}{\begin{tabular}{|c|} 
Time Elapsed \\
$(\min )$ \\
\end{tabular}} & \multirow{2}{*}{$\begin{array}{c}\text { Number of } \\
\text { Observations }\end{array}$} & \multirow{2}{*}{\begin{tabular}{|c|} 
Min. Speed \\
$(\mathrm{mph})$ \\
\end{tabular}} & \multirow{2}{*}{$\begin{array}{c}\text { Max. Speed } \\
(\mathrm{mph})\end{array}$} & \multirow{2}{*}{$\begin{array}{c}\text { Avg. Speed } \\
(\mathrm{mph})\end{array}$} \\
\hline & & & & & & & & & \\
\hline 3-SB-0515-01 & $\overline{\mathrm{SB}}$ & $5 / 15 / 2002$ & $8: 02$ & 8:09 & $\begin{array}{c}0: 07: 04 \\
\end{array}$ & 29.0 & $\begin{array}{l}17.8 \\
\end{array}$ & $\begin{array}{l}73.3 \\
\end{array}$ & $\begin{array}{l}51.7 \\
\end{array}$ \\
\hline 3-SB-0515-02 & $\mathrm{SB}$ & $5 / 15 / 2002$ & $8: 34$ & $8: 48$ & $0: 13: 35$ & 56.0 & 17.8 & 71.2 & 41.4 \\
\hline 3-SB-0515-03 & $\mathrm{SB}$ & $5 / 15 / 2002$ & $9: 10$ & $9: 23$ & $0: 12: 31$ & 52.0 & 3.7 & 76.2 & 47.4 \\
\hline 3-SB-0515-04 & $\mathrm{SB}$ & $5 / 15 / 2002$ & $9: 46$ & 9:56 & $0: 09: 32$ & 39.0 & 23.4 & 71.6 & 56.9 \\
\hline 3-SB-0515-05 & $\mathrm{SB}$ & $5 / 15 / 2002$ & $15: 12$ & $15: 36$ & $0: 24: 07$ & 83.0 & 0.0 & 71.4 & 27.6 \\
\hline
\end{tabular}

Figure 7-7 represents the distance-time and speed-time diagram for run 3-SB-0515-03. Traveling conditions were congested when the run was conducted. As shown in Figure 7-6 the actual profile or breadcrumb obtained, crosses the posted speed limit before entering the construction zone. After this, a delay is observed in the work zone. This delay occurs 3.1 miles before the location of the actual activity area, creating back-up queues, which tend to increase the likelihood of the occurrence of accidents.

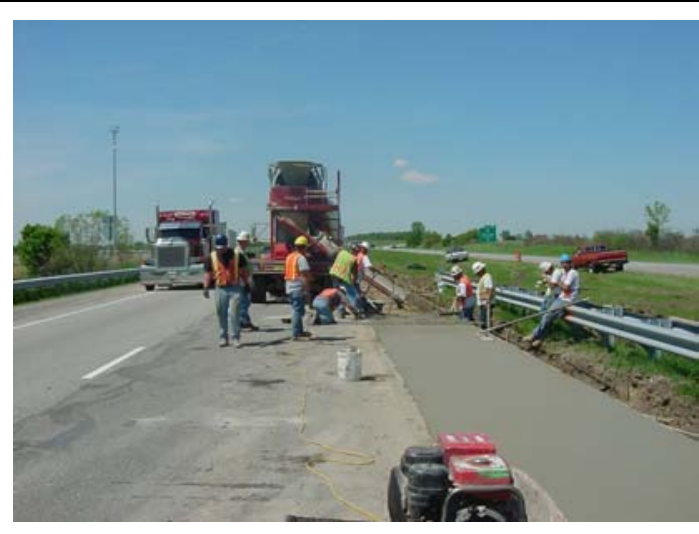

a) Shoulder Concrete Work

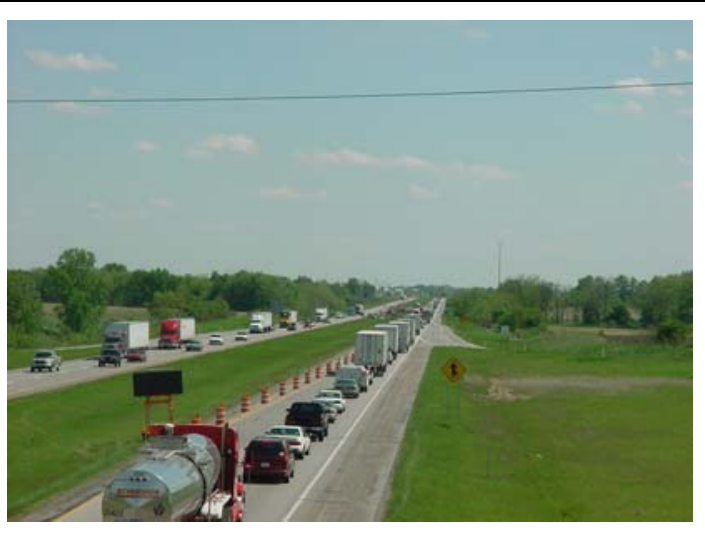

b) PM Conditions Observed

Figure 7-6 Route \# 3 Pictures

As shown in Figure 7-7, the last run performed on this route (3-SB-0515-05) took the longest time (twenty-four minutes). During this run, heavy congestion was observed (Figure 7-6b). In several cases, the observed speed of the traffic was $0 \mathrm{mph}$. Several conclusions can be drawn from this run. The segment analyzed on I-65 around 3:00 pm experiences periods of heavy congestion and different construction work activities tend to impact the speed of traveling public differently. The freeway capacity on I-65 is not sufficient to accommodate a lane restriction during the afternoon hours. It may be beneficial to conduct lane closures at nights or early in the day. A significant speed reduction was observed during periods of high construction work. The reduction in speed can be attributed to two factors: a) no protection or barrier wall existed between the activity area 
and the ongoing traffic and $b$ ) the taper generated long queues which cause vehicles to travel slowly within the activity area after passing the "merge" point.

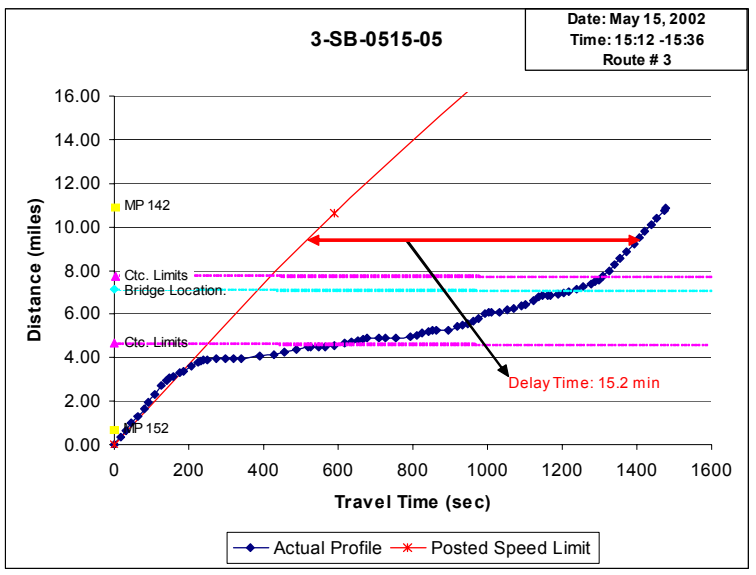

a) 3-SB-0515-05 Distance-Time Diagram

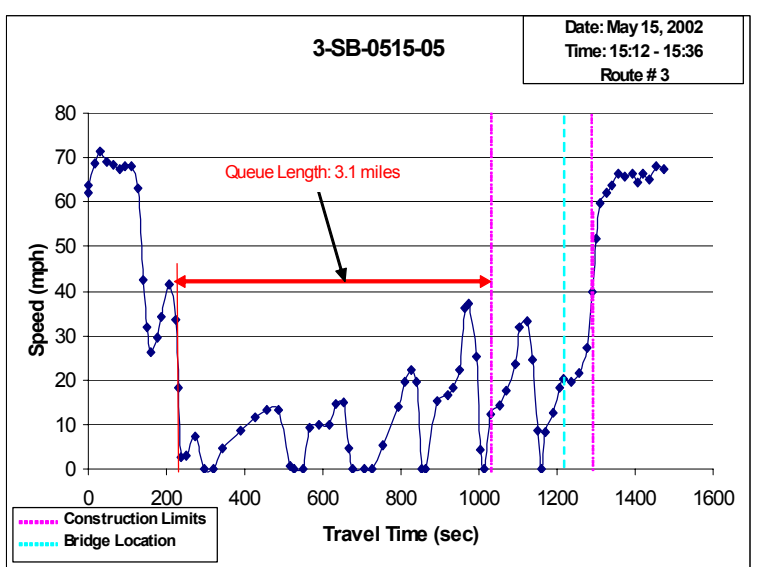

b) 3-SB-0515-05 Speed-Time Diagram

Figure 7-7 Route \# 3 (3-SB-0515-05) Conditions Observed

\section{7. $\quad$ Route \# 4: I-65/US-30 project near Merrillville, IN}

\subsubsection{Route \# 4 Description}

The project and location where Route \# 4 took place is the same as Route \# 1. The main difference between the two routes is the study area. The study area for Route \# 4 starts near milepost 259 and ends near milepost 247.

\subsubsection{Route \# 4: Travel-Time Runs}

The single run on Route \# 4 was completed in the southbound direction. Table 7-9 describes the general information of this run. 
Table 7-9 Route \# 4 Travel Time Runs Completed

\begin{tabular}{|c|c|c|c|c|c|c|c|c|c|}
\hline \multirow{2}{*}{ Route Code } & \multirow{2}{*}{$\begin{array}{c}\text { Direction of } \\
\text { Travel }\end{array}$} & \multirow{2}{*}{ Date } & \multirow{2}{*}{$\begin{array}{l}\text { Start } \\
\text { Time }\end{array}$} & \multirow{2}{*}{ End Time } & Time Elapsed & \multirow{2}{*}{$\begin{array}{c}\text { Number of } \\
\text { Observations }\end{array}$} & Min. Speed & Max. Speed & Avg. Speed \\
\hline & & & & & $(\min )$ & & (mph) & $(\mathrm{mph})$ & $(\mathrm{mph})$ \\
\hline 4-SB-0612-01 & $\mathrm{SB}$ & 12-Jun & $15: 57$ & $16: 12$ & $0: 15: 04$ & 60.0 & 1.3 & 72.0 & 51.6 \\
\hline
\end{tabular}

The minimum speed for this run was low (1.3 mph). During this run, the I-65/US-30 exit ramps were open to traffic. However, traffic congestion was observed when the run was completed. Figure 7-8 presents the typical schematics obtained for the run conducted. It is important to point out, that delay in the work zone was present after the test vehicle entered the construction zone.

Figure 7-8 shows the backup queue observed in the work zone. In the vicinity of milepost 254.1 the speed observed is close to zero. Since this speed is very small and negligible (equal to zero), it can be assumed that at this point (MP 254.1), the vehicle is joining the backup queue. A queue of 0.2 miles (MP 254.1 - MP 253.9) was observed with respect to the work zone limit. In addition, a queue of 0.7 miles was observed with respect to the actual US-30 interchange (or activity area).

Figure 7-9 provides a sample of the output generated by the Map Source ${ }^{\mathrm{TM}}$ software. Two points are of interest in this case. The first point relates to the location at which the speed of the test vehicle is $1.3 \mathrm{mph}$. This takes place near MP 254.1. The variation in speeds before entering the work zone is smaller than the one inside the work zone. Another point that may be of interest to transportation officials is the location at which the vehicles exit the queue and reach saturation flow speed again. This point is expected to be near $30 \mathrm{mph}$ on an interstate work zone. As shown in Figure 7-9, this takes place near milepost 253.3 after the US-30 interchange. This represents the point at which vehicles resume their normal traveling speed. In this case, the location was inside the work zone area and not at the limits of the work zone. 


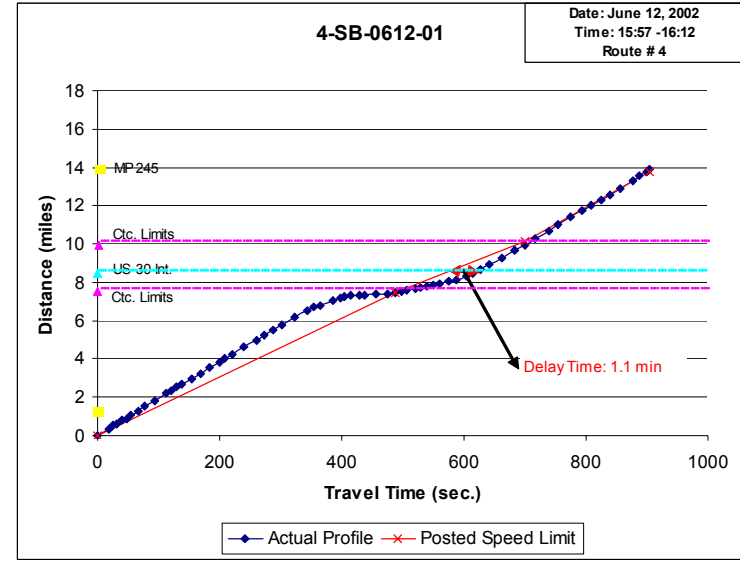

a) 4-SB-0612-01 Distance-Time Diagram

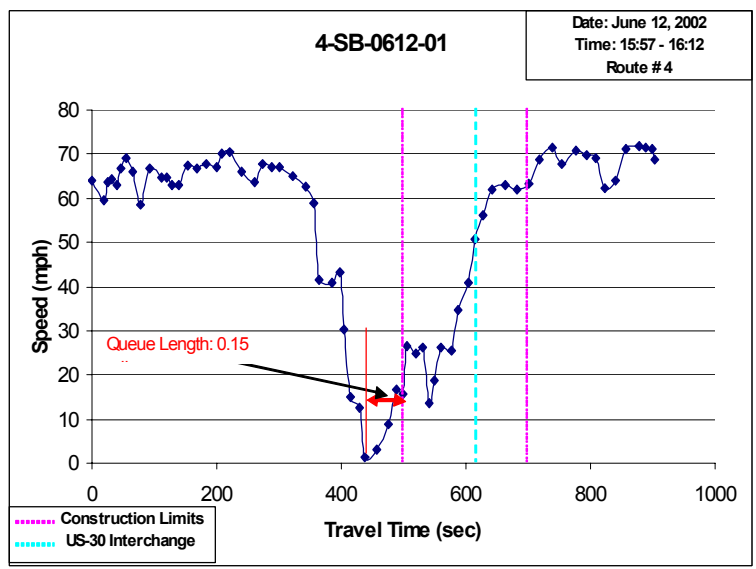

b) 4-SB-0612-01 Speed-Time Diagram

Figure 7-8 Route \# 4 (4-SB-0612-01) Conditions Observed

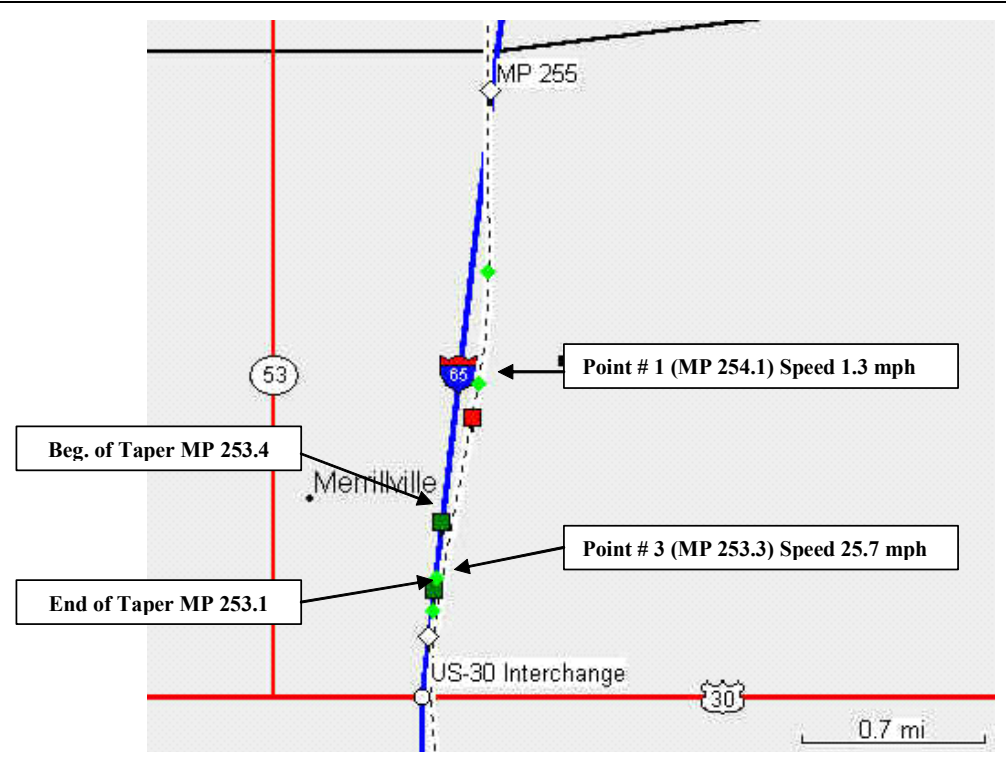

Figure 7-9 Route \# 4 (4-SB-0612-01) Detailed Observation

During this run the southbound exit ramp was open to traffic. Both eastbound and westbound US30 vehicles exited the interstate on the same ramp. The backup queue was observed up to the point where the exit ramp is located. Motorists that are not exiting on 1-65 towards US-30 increase their speed substantially. Two possible scenarios may explain the jump in speeds after the exit ramp: a) US-30 ramp generates spillbacks that impact the traffic conditions on I-65 and b) 
vehicles that remain on I-65 increase their speeds after noticing the exit ramp even tough they still remain within the construction limits. Several runs were conducted to corroborate any of these scenarios.

7.8. $\quad$ Route \# 5: I-65/US-30 project near Merrillville, IN

\subsubsection{Route \# 5 Description}

The project and location of Route \# 5 is the same as the one of Route \# 4. However, the main difference between the two routes is the study area. The study area for Route \# 4 starts near milepost 255 and ends near milepost 247.

\subsubsection{Route \# 5: Travel-Time Runs}

The single run along this route was conducted on a typical weekday in the southbound direction of I-65 near Merrillville, IN. In this particular run, the traffic conditions were the same as the ones observed in Run \# 4. Table 7-10 describes the travel-time run completed on this route.

Table 7-10 Route \# 5 Travel Time Runs Completed

\begin{tabular}{|c|c|c|c|c|c|c|c|c|c|}
\hline \multirow{2}{*}{ Route Code } & \multirow{2}{*}{$\begin{array}{c}\text { Direction of } \\
\text { Travel }\end{array}$} & \multirow{2}{*}{ Date } & \multirow{2}{*}{$\begin{array}{l}\text { Start } \\
\text { Time }\end{array}$} & \multirow{2}{*}{ End Time } & \multirow{2}{*}{\begin{tabular}{|c|} 
Time Elapsed \\
$(\mathrm{min})$ \\
\end{tabular}} & \multirow{2}{*}{$\begin{array}{c}\text { Number of } \\
\text { Observations }\end{array}$} & \multirow{2}{*}{\begin{tabular}{|c|} 
Min. Speed \\
(mph) \\
\end{tabular}} & \multirow{2}{*}{\begin{tabular}{|c|} 
Max. Speed \\
$(\mathrm{mph})$ \\
\end{tabular}} & \multirow{2}{*}{$\frac{\text { Avg. Speed }}{\text { (mph) }}$} \\
\hline & & & & & & & & & \\
\hline 5-SB-0612-01 & SB & 12-Jun & $16: 46$ & 16:56 & $0: 10: 39$ & 47.0 & 0.6 & 73.1 & 40.7 \\
\hline
\end{tabular}

Figure 7-10 presents the typical schematic obtained for all the runs conducted. As soon as the vehicle enters the study area a back-up queue is observed. At this point the test vehicle is the last to enter the work zone queue. Figure 7-10 shows that the queue length is equal to 0.5 miles (From MP 254.4 to 253.9) with respect to the work zone limit. However, the queue is much greater when it is calculated with respect to the US-30 interchange 1.4 miles.

Figure 7-11 is presented to provide a sample of the output generated by the Map Source ${ }^{\mathrm{TM}}$ software. Similar to Route \# 4, two points are of interest in this evaluation. The first location is the one at which the speed of the vehicle is $0.6 \mathrm{mph}$. The other point of interest is expected to be near $30 \mathrm{mph}$ on an interstate work zone. As shown in Figure 7-11, this takes place near milepost 253.3 after the US-30 interchange. 


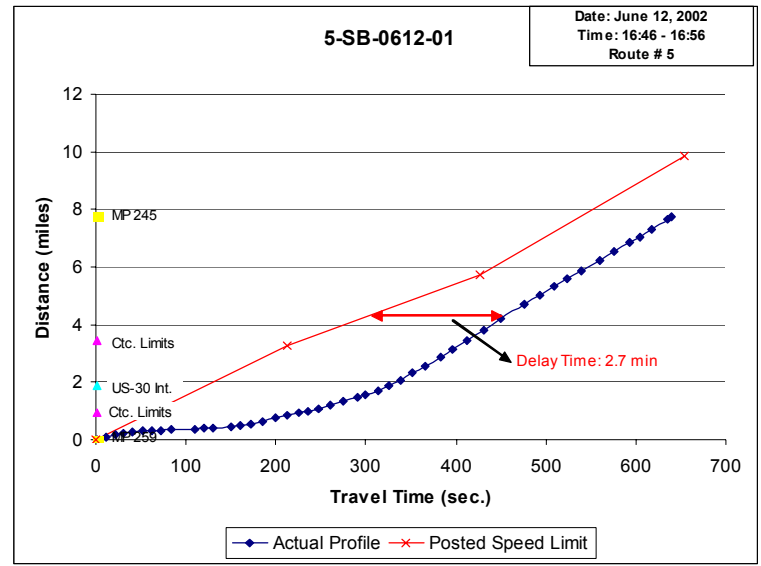

a) 5-SB-0612-01 Distance-Time Diagram

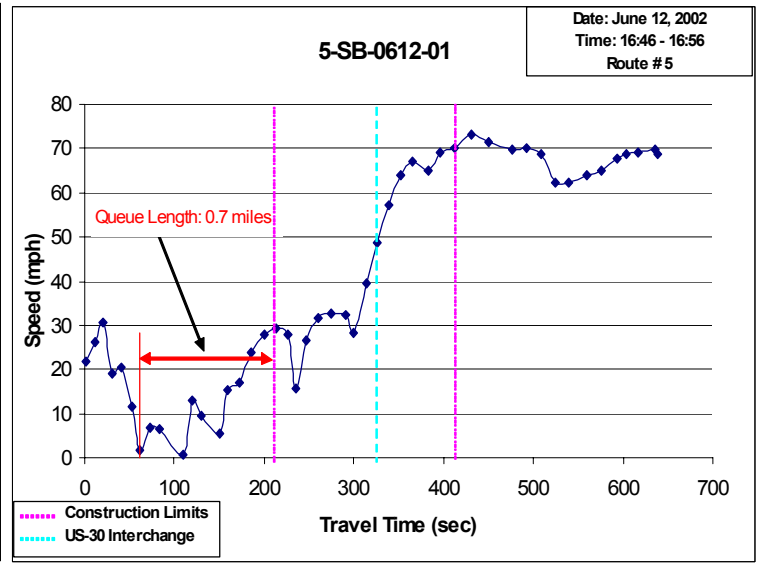

b) 5-SB-0612-01 Speed-Time Diagram

Figure 7-10 Route \# 5 (5-SB-0612-01) Conditions Observed

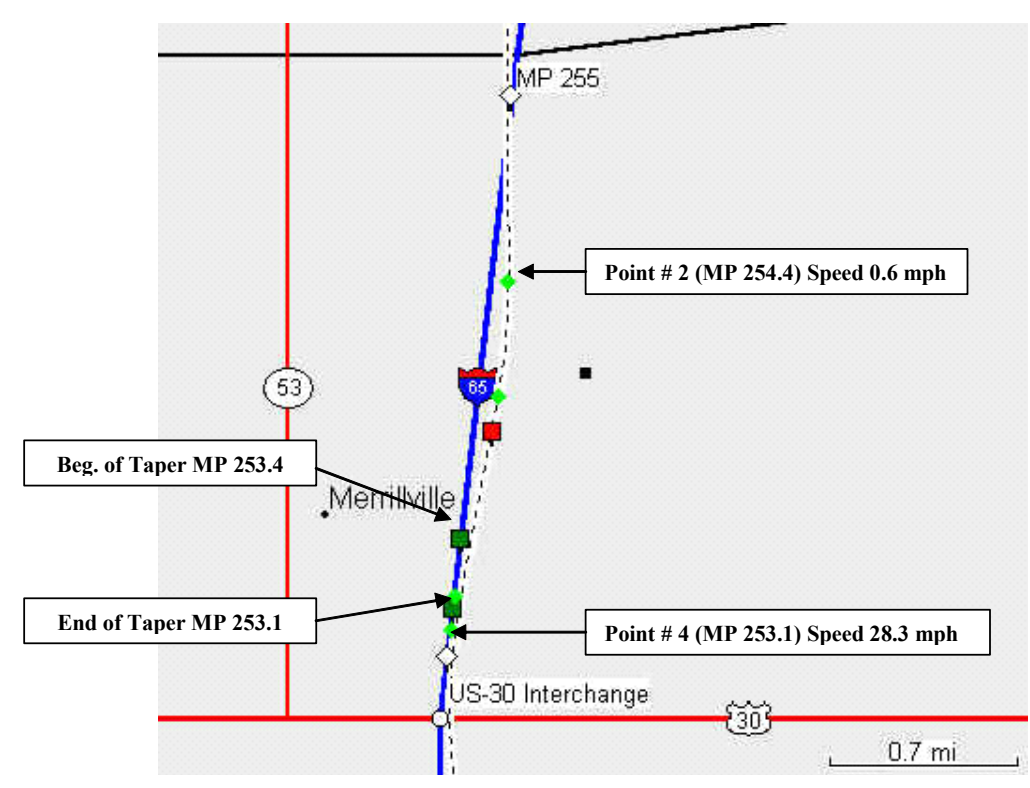

Figure 7-11 Route \# 5 (5-SB-0612-01) Detailed Observation 


\section{9. $\quad$ Route \# 6: I-65 project near Lafayette, IN}

\subsubsection{Route \# 6 Description}

The I-65 project near Lafayette, IN consisted of the construction of the McCarty Lane overpass bridge on I-65. The project started in April 2002 and was completed by October 2002. The typical ADT is approximate 40,000 vehicles per day for this section.

Table 7-11 presents the construction limits for this project. The limits of the project are MP 169.8 south and MP 170.9 north. Figure 7-12 presents the typical schematic diagram of the work zone layout.

Table 7-11 I-65 near Lafayette Project General Coordinate Information

\begin{tabular}{|c|c|c|c|c|c|c|}
\hline & \multicolumn{3}{|c|}{ Start } & \multicolumn{3}{c|}{ End } \\
\cline { 2 - 7 } & MP & Latitude & Longitude & MP & Latitude & Longitude \\
\hline Area of Study & 164.5 & N40.32060 & W86.74940 & 171 & N40.40877 & W86.80487 \\
\hline $\begin{array}{c}\text { Construction } \\
\text { Limits }\end{array}$ & 169.8 & N40.39170 & W86.79261 & 170.9 & N40.40777 & W86.80337 \\
\hline
\end{tabular}

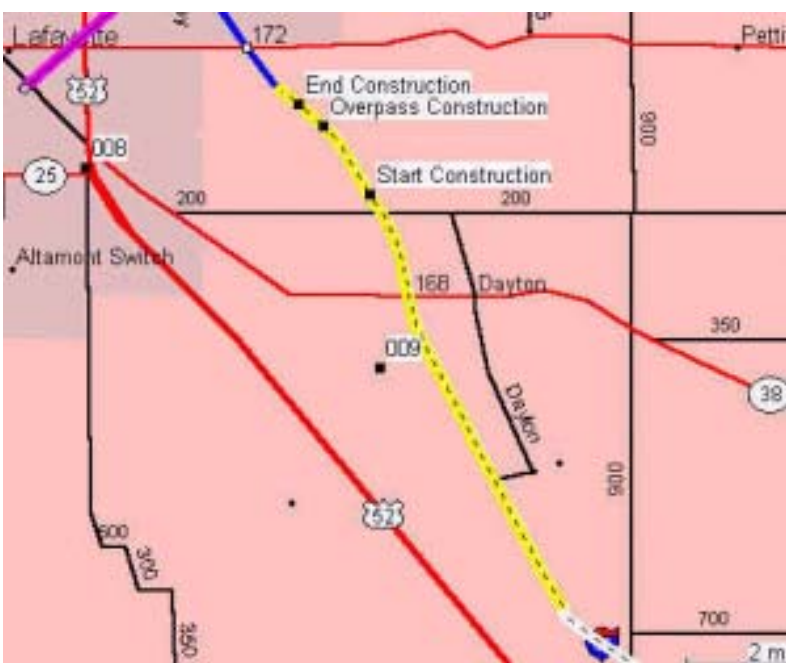

Figure 7-12 I-65 near Lafayette Work Zone Layout 


\subsubsection{Route \# 6: Travel-Time Runs}

A total of four runs were conducted on this route. All the runs took place in the evening hours on a weekday. Although most of the construction work did not have an impact on I-65, severe congestion was observed on the day of the runs. The day of the evaluation (July 2, 2002), I-65 was shutdown for three different 20-minute intervals between 18:00 to 20:00. The interstate was closed, in order to set the beams of the overpass bridge (Figure 7-13a). Severe congestion was observed after the total closure on I-65 (Figure 7-13b).

The travel-time runs for this project were conducted in an attempt to reach the work zone activity area, at the time when lanes were reopen to traffic and vehicles resume their speeds. Three beams had to be set in place for the construction of the bridge. Run 6-NB-0702-01 was conducted when the first beam was being placed.

Table 7-12 Route \# 6 Travel Time Runs Completed

\begin{tabular}{|c|c|c|c|c|c|c|c|c|c|}
\hline \multirow[t]{2}{*}{ Route Code } & \multirow{2}{*}{$\mid \begin{array}{c}\text { Direction of } \\
\text { Travel }\end{array}$} & \multirow[t]{2}{*}{ Date } & \multirow{2}{*}{$\begin{array}{l}\text { Start } \\
\text { Time }\end{array}$} & \multirow{2}{*}{ End Time } & \multirow{2}{*}{\begin{tabular}{|c|} 
Time Elapsed \\
(min)
\end{tabular}} & \multirow{2}{*}{$\begin{array}{l}\text { Number of } \\
\text { Observations }\end{array}$} & \multirow{2}{*}{$\begin{array}{c}\text { Min. Speed } \\
\text { (mph) }\end{array}$} & \multirow{2}{*}{\begin{tabular}{|c|} 
Max. Speed \\
(mph)
\end{tabular}} & \multirow{2}{*}{$\begin{array}{c}\text { Avg. Speed } \\
(\mathrm{mph}) \\
\end{array}$} \\
\hline & & & & & & & & & \\
\hline 6-NB-0702-01 & NB & $7 / 2 / 2002$ & \begin{tabular}{c|}
$18: 01$ \\
\end{tabular} & $18: 20$ & $0: 18$ & 265.0 & $\begin{array}{ll}0.0 \\
\end{array}$ & $\begin{array}{ll}73.0 \\
\end{array}$ & 28.3 \\
\hline 6-NB-0702-02 & NB & $7 / 2 / 2002$ & $18: 41$ & $18: 47$ & $0: 05$ & 24.0 & 54.5 & 74.3 & 66.7 \\
\hline 6-NB-0702-03 & NB & $7 / 2 / 2002$ & 19:12 & 19:44 & $0: 31$ & 46.0 & 0.0 & 75.1 & 35.0 \\
\hline 6-NB-0702-04 & NB & $7 / 2 / 2002$ & $20: 05$ & $20: 21$ & $0: 15$ & 50.0 & 0.0 & 75.7 & 33.5 \\
\hline
\end{tabular}

The second run (6-NB-0702-02) was conducted in between closures, and the last two runs were conducted during periods when the beams were being set.

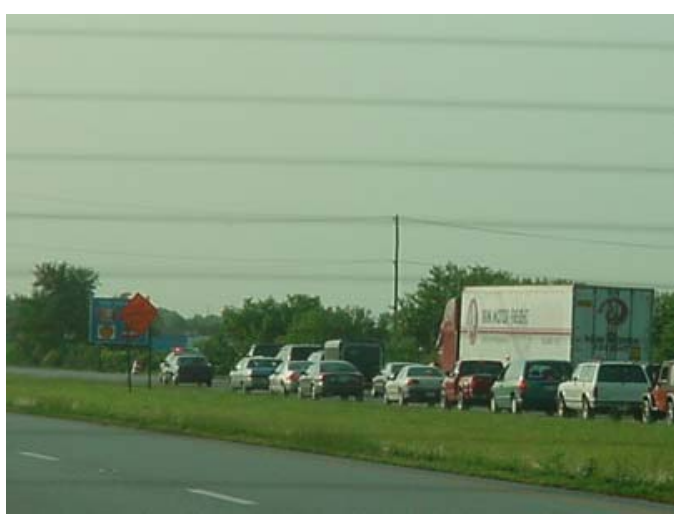

a) Total Closure of I-65

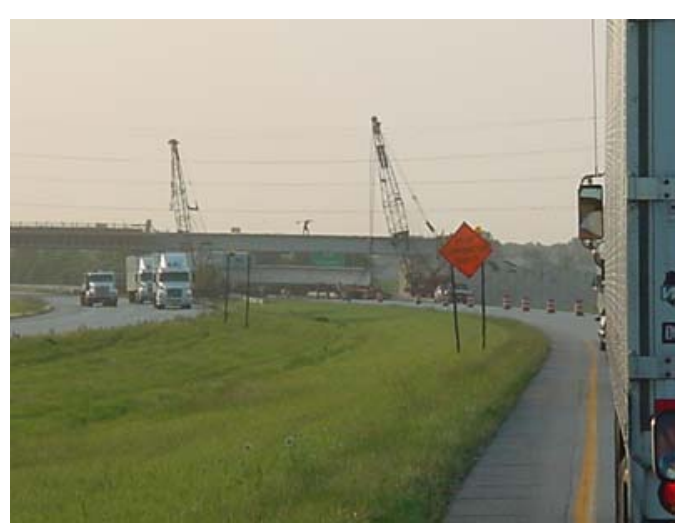

b) Congestion Observed

Figure 7-13 Route \# 3 Pictures 
The third run (6-NB-0702-03) took place when the second beam was being installed. The test vehicle came to a complete halt a few meters away from the trooper who was shutting down the interstate. In the fourth run (6-NB-0702-04) heavy congestion was observed. Longer back up queues than the ones observed during Run \# 1 were experienced.

In Figure 7-14 the work zone delay is presented. Figure 7-14b shows several locations during the evaluation when the speed of the testing vehicle was zero. In Figure 7-14b the location of the most significant speed reduction is shown. In this case, the test vehicle reached the work zone queue at a distance of 2.4 miles (MP 168.4) with respect to the overpass activity area. This queue is very significant. This particular project, revealed an important tradeoff constantly encountered by transportation officials. Runs 6-NB-0702-02 and 6-NB-0702-04 are similar since they were both conducted after I-65 was reopened. Run 6-NB-0702-02 showed no congestion and almost free flow conditions. The test vehicle was perceived to be driving at speed limit or above. In run 6NB-0702-04 however, long queues and heavy congestion was observed. No lane closures were in effect during this run.
A back-up queue of 2.4 miles is fairly significant. The queue observed in Run \# 4 can create hazardous conditions for motorists. Motorists were not informed of the construction activity or the lane restrictions. There were no signs in advance (a few miles) of the work zone. The terrain at which this closure was in place was fairly flat. However, around MP 168 there are some long tangents and vertical curves which can increase the probability of accidents. The GPS evaluation of traffic runs on Route \# 6 indicated that signs are required at least two to three miles in advance of the work zone, in order to inform motorists to expect "slowed down" traffic ahead when lane closures are in effect. 


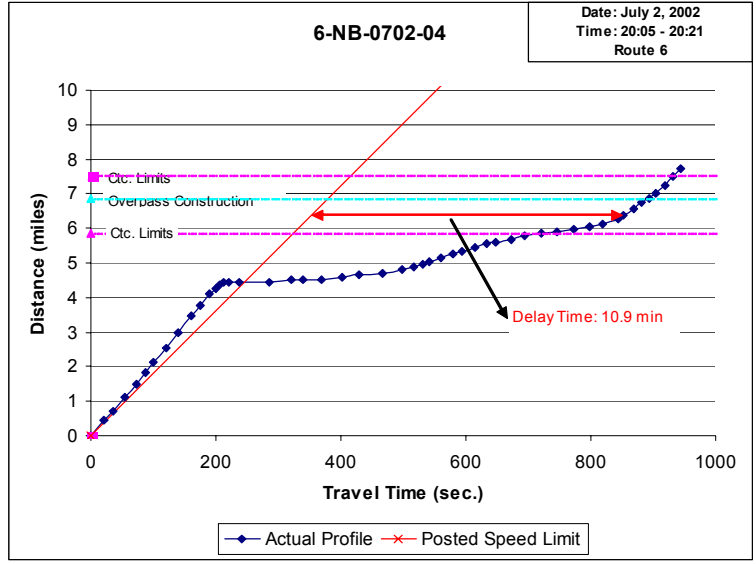

a) 6-NB-0702-04 Distance-Time Diagram

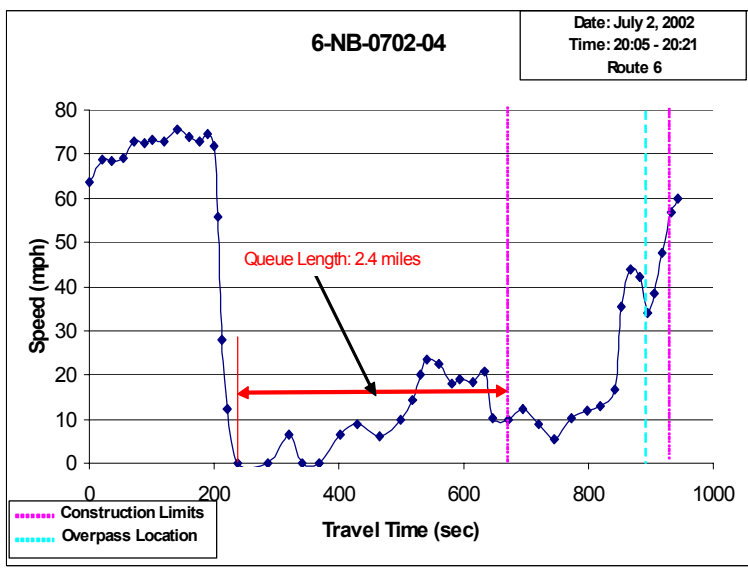

b) 6-NB-0702-04 Speed-Time Diagram

Figure 7-14 Route \# 6 (6-NB-0702-04) Conditions Observed

7.10. Evaluation of GPS System as a traffic collection device

The primary purpose for using GPS to conduct travel time runs during periods of construction work on interstates was to link the construction activities taking place with the impact on traffic flow. With the use of the GPS system, the mobility of the segment can be measured. Based on the evaluation performed the following advantages and challenges were identified:

\subsection{1.}

Advantages

The Global Positioning System (GPS) is an easy-to-use tool that can be used by any transportation agency to collect data with ease. The particular system used in this evaluation has shown that an expensive apparatus is not required to collect data. The Garmin ${ }^{\top \mathrm{M}}$ device used in this study was simple and sufficient to conduct the study. The software available with the GPS proved to be satisfactory for obtaining maps and layouts of the area of study.

By using this device, the most important landmarks of the work zone were obtained. Locations such as construction limits, activity area, tapers and sign location were recorded by using the GPS. The information obtained using the GPS provides a snapshot of the traveling conditions on a particular date and time. This is greatly beneficial in order to maintain a log of different back-up queue locations within a work zone. This information can be used in future construction projects 
to estimate the exact location of queues that occur when different construction activities are in progress along the highway. This is particularly important for long-term work zones that are in effect for more than one construction season.

\subsubsection{Challenges}

In this project, an algorithm was not developed to connect the GPS to a laptop computer. Therefore, the time that it took for the device to turn On and Off was a significant drawback. A greater study area than the one required was necessary to conduct the evaluation. By having to turn the GPS every time, the research team was not able to determine precisely in the field at what point the GPS had commenced collecting data. Another disadvantage was the inconsistency of the satellite signal reception. Most of the GPS manufacturers claim that their units can receive a signal in a specified interval. However, often this is not the case. The average update rate for this evaluation was 22 seconds, which is fairly high.

Another challenge when using this technology is the work required to be performed after the data is collected in the field. The calculations were performed using an spreadsheet program such as Microsoft Excel, to obtain the travel-time graphs and the change in coordinates from latitude/longitude coordinates to Cartesian.

Using a GPS to collect traffic data is a two-person task. One person to drive the car and the other to collect data by turning on/off the device and noting the coordinates of landmarks. It would be greatly beneficial if this task were fully automated so that only one person would be required to collect the data.

The GPS system is a dynamic device, which travels inside the test vehicle. This feature is considered to be a significant obstacle as a traffic data collection device. It can be inferred, that relying solely on the driver's perceived traveling conditions is not beneficial for conducting travel time studies. The data collection procedure becomes a subjective effort, which does not provide a good sample, unless the same driver performs the entire evaluation under similar conditions.

\subsection{1. $\quad$ Conclusions and Recommendations}

The GPS system is an effective device for documenting and referencing points of interest in work zones. GPS can be used as a proactive approach to estimate the expected conditions during construction periods in work zones. A short signal reception is considered essential to conduct an 
effective evaluation. In this project, an "inexpensive" unit was used and the unit was effective in collecting the landmarks and the location of significant queuing within the work zone.

Based on the findings, if a rural interstate with a typical ADT of 40,000 vehicles per day is closed for a total of twenty minutes or more, two-mile queues can be expected to occur. Hence, appropriate signs must be deployed in an effort to inform motorists of the roadwork ahead and to prevent rear end collisions which are the most typical accidents ahead of the work zone.

The lane restriction analyzed in the project near Thorntown showed that if no wall barrier is used traffic tends to slow down significantly. The absence of a barrier wall is very unsafe to workers and must be avoided at all times. The data collected on the US-30 interstate reconstruction project showed that traveling conditions were not affected in any direction as long as two lanes of traffic were open at all times. This project was severely affected when there was congestion on US-30 and the congestion spilled back onto I-65. The change in traffic conditions affects motorists after a newly completed exit is open to traffic.

Table 7-13 presents a summary of findings of the travel time studies by using Global Positioning Systems in work zones. Each of the projects analyzed had a different type of restriction. The maximum queue and the maximum travel time for each of the projects analyzed are also presented in this table. The importance of these findings is the relationship between the queuing found in the work zone and its vicinity, and the restriction that was observed when conducting the runs.

Table 7-13 Summary of Findings of Travel Time Studies

\begin{tabular}{|c|c|c|c|l|c|c|}
\cline { 4 - 7 } Project & $\begin{array}{c}\text { ADT } \\
(1999)\end{array}$ & Dir. & $\begin{array}{c}\text { Number of } \\
\text { Runs }\end{array}$ & \multicolumn{1}{c|}{ Type of Restriction } & $\begin{array}{c}\text { Queue } \\
\text { Observed (miles) }\end{array}$ & $\begin{array}{c}\text { Travel Time } \\
(\mathrm{minutes})\end{array}$ \\
\hline Thorntown & 39,440 & SB & 5 & Passing Lane Closure & 3.1 & 24.1 \\
\hline Lafayette & 40,000 & NB & 4 & Total Closure & 2.4 & 31.2 \\
\hline Merrilville & 72,940 & NB & 15 & Two Lanes Open & None & 14.4 \\
\cline { 3 - 7 } & & SB & 15 & Three to Two Lanes & 1.5 & 25.0 \\
\hline
\end{tabular}

Recommendations include equipping construction engineers in charge of long-term construction projects with GPS devices, to document the major locations of back-up queue incidents. It would be greatly beneficial to create a database of different characteristics of work zones according to the construction activities taking place (i.e. lane closure, lane restriction, total closure, etc). With such database, engineers will be able to document and reference the typical conditions encountered after a specific activity has taken place. 
Another recommendation includes equipping police officers patrolling work zones with GPS. Although not the topic of this evaluation, it is strongly believed that by providing troopers with a GPS device will be beneficial to document location of crashes and maintain an automated database.

The use of GPS device provides construction engineers with a proactive tool for dealing with lane restrictions. The information stored from previous projects can be accessed, and results can be obtained after linking the information available with the conditions of the construction activities taking place. Information about lane restrictions can be assessed based on documented data that confirms what queuing levels can be expected, and how they will vary according to the time of day, day of the week, etc.

By maintaining this information, the location of the signs in advance of the work zone can also be verified. As explained in Section 7.9, twenty-minute closures translate into two-mile back-up queues. By collecting more data from different projects with different geographical characteristics and traffic volume, the GPS tool provides the engineers with a preliminary tool for corroborating the placement of the signs in advance of a work zone.

Equipping engineers with a Global Positioning System device has some challenges. The most significant disadvantage is the cost of each unit if a certain level of accuracy is desired. In addition, the time required to perform the runs and analyze the data collected is highly labor intensive. 


\title{
CHAPTER 8. EVALUATION OF TWO LANE OPEN POLICY
}

\begin{abstract}
8.1. $\quad$ Introduction
Transportation officials are faced with the task of minimizing changes in road conditions during interstate work zones. Changes that take place during construction periods tend to confuse the traveling public. In addition, because of the modifications in road configuration the likelihood of accidents is increased. Capacity is the most severely impacted factor during interstate construction. It is important to find procedures to maintain appropriate levels of capacity that simulate those of normal conditions. An option available to minimize the impact on capacity is to maintain the same number of travel lanes while construction is taking place.
\end{abstract}

An objective of this research project is to evaluate if two lanes of traffic can be maintained open at all times during construction work. The main goal is to determine the feasibility of implementing this approach on rural interstates in the state of Indiana. In this chapter, different procedures for determining lane closures by other Departments of Transportations are discussed. An evaluation of implementing these procedures in the state of Indiana is presented. In addition, the economic model for determining the feasibility of maintaining two lanes open is presented and evaluated by using a case study.

\section{2. $\quad$ Options Available for Consideration}

During the construction of a project, the preferred alternative for both motorists and officials is to maintain the same number of travel lanes. By implementing this alternative, delays will be kept to a minimum, and the changes in traveling conditions will be insignificant. However, this approach is not always possible. When rural interstates are considered only two lanes of traffic are available in each direction. In many cases, during construction periods lane restrictions and closures are required in order to ensure safety for both motorists and workers. The restriction of lanes on rural interstates translates into delays and subsequently drivers' frustration. 
After determining the number of lanes that will remain open, the next step is to determine how to improve safety throughout the work zone. The Indiana Department of Transportation (INDOT) has been employing temporary concrete jersey barriers since 1996 on every long-term interstate construction project. By utilizing these barriers, the work zone is "enclosed" from the passing traffic in an attempt to improve the safety of workers. When these barriers are installed head-tohead operations are no longer possible. Head-to-head operations involve shifting traffic to the opposing side when construction is being performed on the other side. The separation of traffic is conducted with tubular markers and channelizers.

If lane closures are required, then officials have to decide the timing and location of the closures. Factors such as peak periods of traffic, time of day (daytime vs. nighttime) and day of the week (weekday vs. weekend) are considered. Location (milepost), exits and surrounding towns and traffic volumes (typically ADTs) must be incorporated before making the decision. Lane closures can be short-term (less than 24 hours) or long-term (more than 24 hours). Total lane closures for extended period of times (weekends or nightly closures) can also be evaluated. However, this alternative is not feasible on rural interstates, because often there are insufficient routes to detour traffic. On the other hand, this approach can be conducted on urban interstates with high possibility of success. (Nam et al. 1999)

Several alternatives exist for accommodating traffic when lane closures are needed. The most common approach is to incorporate median crossovers to shift traffic to one direction. By doing so, one lane will be open in each direction and construction can take place in the closed lanes. Another option is to strengthen the shoulders. Traffic can be shifted to the strengthened shoulder and in most cases this is sufficient to adequately serve the demand. A third alternative includes utilizing temporary structures such as bridges for mitigating the impact of reduced number of lanes.

If two lanes of traffic cannot be maintained at all times, then Intelligent Transportation Systems (ITS) can be used. Traffic management systems such as the ones described in Chapter 3 are an option to inform motorists of the changes in traveling conditions for improving mobility.

\section{3. $\quad$ Current Practices}

Departments of Transportation in Florida and Ohio have started policies for conducting lane closure analysis. The Ohio Department of Transportation (ODOT) for example, has different procedures for determining the permitted lane closure periods on the Interstate system. These 
procedures are determined on a district-by-district basis with no common procedure used throughout the state (Pfenning 2002). District One which includes Lima, $\mathrm{OH}$ has developed a procedure for calculating periods of time on Interstate 75 when lane restrictions are not permitted.

The procedure involves collecting traffic data on the interstate by using inductive loops and comparing it to an already specified value. According to (Pfenning 2002), the threshold value for capacity has been determined to be 1250 passenger cars/per hour /per lane for District 1 . The threshold capacity value is highly dependent on the location and the type of interstate (rural vs. urban). The results obtained from the procedure, provide contractors and transportation officials with periods of time when the interstate cannot be restricted. These periods are divided according to time of the day, day of the week and season of the year. The results of this procedure are posted on a website (http://www.dot.state.oh.us/dist1/planning/WorkZone/WorkZones.htm).

In an effort to complete a standardized procedure to be used throughout the state, ODOT is in the process of formalizing a lane closure method. This approach called the "Partial Lane Closure Method (PLCM)" consists of determining the closure times by using the Highway Capacity Manual to calculate the wok zone capacity values. Terrain and truck percentage are incorporated into the calculation. If the volume of an interstate section (obtained by Average Daily Traffic, Automatic Traffic Recorder (ATR) station counts) exceeds the capacity of the work zone then no lane closures are permitted (Young 2002).

According to Young (2002), the PLCM is a "quick-method" that can be used to obtain preliminary results. Further calculations can be performed by using traffic software such as QUEWZ, Symchro, Corsim, etc. If the PLCM and the analysis performed by using traffic software specify that lane closure periods are required, then approval by a work zone committee from the ODOT Central Office is needed. The Ohio Department of Transportation strives for maintaining two lanes open when feasible if the directional ADT is greater than 20,000 vehicles per day. When a work zone is located on an interstate segment with volume above this threshold value, then the "Part Width Construction" approach is implemented.

Florida is another state with lane closure policies in effect. Florida Department of Transportation (FDOT) has been implementing this lane closure policy since 1995 (FHWA Best Practice Policy 2002). The policy states that: "On the Interstate, maintain the existing number of through travel lanes in the work area; in no case less than two lanes". A sample of the procedure used for calculating the "Lane Closure Analysis" can be found in Appendix A. This procedure considers 
not only lane closures on interstates but also urban and rural roads and highways. The procedure is based on volume (ADTs) of the section and the peak/non-peak periods.

In Florida, the conditions of the traffic lanes during the construction operations must be maintained equal to existing traveling conditions. No long-term lane restrictions are permitted in the state. If lane restrictions are necessary, special approval from the District Secretary is required (Adams 2002). Short-term lane restrictions are permitted as long as the contractor assures that the lanes will be reopened within 24 hours. This is particularly important in the case of hurricane evacuations, which tend to occur during the construction season. Lane restrictions at night are also permitted in Florida.

Neither Ohio nor Florida have conducted economic evaluations of implementing their lane closure policies to evaluate the costs and benefits associated with enforcing this policy. Many factors need to be considered in such an analysis. The percentage of trucks traveling through the work zone (i.e. the truck factor) is an important factor that must also be considered in the calculations. The procedure developed in Florida does not work well for roads with a truck factor greater than 8 percent (Adams 2002). Florida DOT is in the process of revisiting this procedure in an effort to incorporate this important factor.

\subsection{Example of Lane Closure Analysis Procedure}

An example of lane closure analysis presented herein is based on the procedure currently used by the Florida Department of Transportation (FDOT). As shown in Table 8-1, six evaluations based on three projects were conducted in Indiana by using the FDOT procedure. Both northbound and southbound directions were considered.

Table 8-1 List of Projects Analyzed

\begin{tabular}{|c|c|c|c|c|c|c|c|}
\hline & & 1 & 2 & 3 & 4 & 5 & 6 \\
\hline \multirow{4}{*}{ 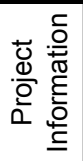 } & Location & Merrilville & Merrilville & W. Lafayette & W. Lafayette & Ft. Wayne & Ft. Wayne \\
\hline & Interstate & I-65 & I-65 & $\mathrm{I}-65$ & \begin{tabular}{|l|}
$\mathrm{I}-65$ \\
\end{tabular} & I-69 & I-69 \\
\hline & Number of Lanes & 2 & 3 & 2 & 2 & 2 & 2 \\
\hline & \begin{tabular}{|l} 
Direction \\
\end{tabular} & NB & SB & NB & SB & NB & SB \\
\hline \multirow{4}{*}{ 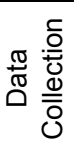 } & Date & $11 / 1 / 2001$ & $11 / 1 / 2001$ & $6 / 22 / 2000$ & $6 / 22 / 2000$ & $6 / 18 / 2000$ & $6 / 18 / 2000$ \\
\hline & Type of Station & W.I.M & W.I.M & ATR & ATR & ATR & ATR \\
\hline & Location (MP) & 253.7 & 253.7 & 175.8 & 175.8 & 106.9 & 106.9 \\
\hline & Typical ADT & 70,000 & 70,000 & 40,000 & 40,000 & 47,000 & 47,000 \\
\hline
\end{tabular}


The data was collected by using Weigh-in-Motion (WIM) and Automatic Traffic Recorder (ATR) stations. The following assumptions were made:

- The Seasonal Adjustment Factors (SAF) were based on Indiana Department of Transportation values (INDOT 2002)

- Remaining Traffic Factor for the projects is $100 \%$ i.e., no detour routes exist for the projects analyzed.

- The width of travel lanes and lateral clearance are 3.6 meters (12 feet) and 1.2 meters (4 feet) respectively.

The capacity of the work zone section is the most significant factor in the calculation, because the reduction of capacity results into delays and lines of halted vehicles. According to Krammes and Lopez (1994) the capacity for freeway work zones was determined to be 1600 vehicles per hour per lane (vphpl). This number has been obtained based on results on rural and urban interstates in Texas; therefore, one must proceed with caution when utilizing this value in Indiana's work zones. Due to the high dependency of the results on the capacity value, sensitivity analysis was conducted in an effort to determine the periods of time when lane closures are not permitted. Two different work zone capacity values were used. For case \# 1 (Table 8-2 and Figure 8-1) the capacity value was determined to be 1600 vphpl and for case \# 2 (Table 8-3 and Figure 8-2) the capacity was $1400 \mathrm{vphpl}$. The values were chosen to corroborate the values found in Texas, and investigate their impact in Indiana's work zones.

Table 8-2 Sensitivity Analysis Case 1 (Capacity = 1600 vphpl)

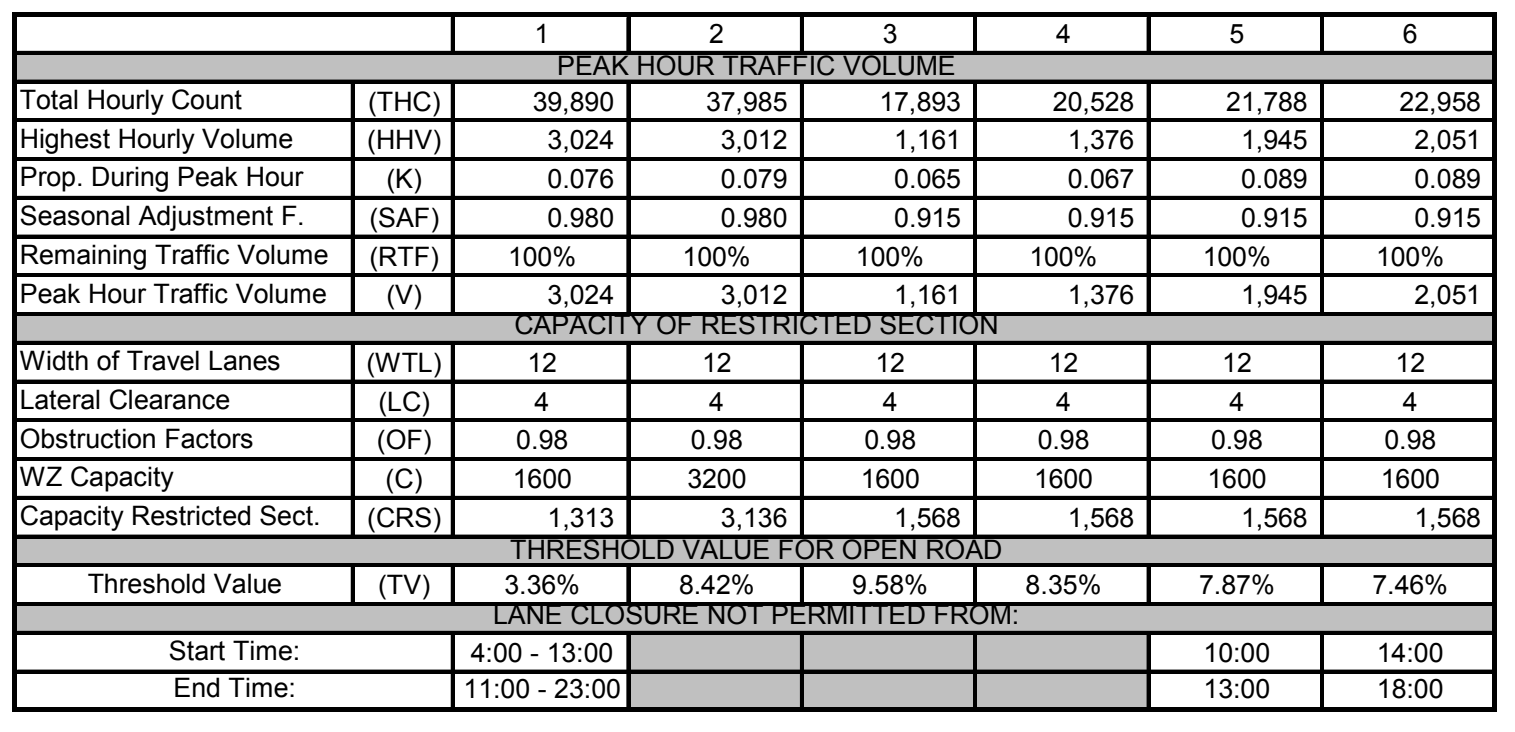


Table 8-2 shows the procedure followed for obtaining the closure periods for case \# 1. Figure 8-1 illustrates these results. Based on the evaluation conducted on the I-65/US-30 project (Evaluations \# $1 \&$ 2) the northbound direction cannot be restricted during certain periods of the day, whereas the southbound direction can be restricted. The northbound section can only be restricted during the 11:00-13:00 period. However, it is important to clarify, that the northbound direction carries only two lanes of traffic. The southbound direction on the other hand, carries three lanes of traffic. With the ADT of approximately 35,000 vehicles per day along this direction, the configuration in the northbound direction of only two lanes is not sufficient to allow for periods of lane restrictions.

Evaluations were also conducted on the I-65/SR-25 project near Lafayette. As shown in Table 8-2 \& Figure 8-1, lane restrictions are possible at any time on this interstate segment.

Evaluations $5 \& 6$ were conducted on the I-69 project near Forth Wayne. The results obtained showed that the flow of traffic along this direction is greater than the work zone capacity during periods of the day. Closures are not permitted during the 10:00-13:00 period for the southbound direction and during the evening hours (From 14:00 to 18:00) for the northbound direction.

Table 8-3 Sensitivity Analysis Case 2 (Capacity = 1400 vphpl)

\begin{tabular}{|c|c|c|c|c|c|c|c|}
\hline & & 1 & 2 & 3 & 4 & 5 & 6 \\
\hline \multicolumn{8}{|c|}{ PEAK HOUR TRAFFIC VOLUME } \\
\hline Total Hourly Count & (THC) & 39,890 & 37,985 & 17,893 & 20,528 & 21,788 & 22,958 \\
\hline Highest Hourly Volume & $(\mathrm{HHV})$ & 3,024 & 3,012 & 1,161 & 1,376 & 1,945 & 2,051 \\
\hline Prop. During Peak Hour & $(\mathrm{K})$ & 0.076 & 0.079 & 0.065 & 0.067 & 0.089 & 0.089 \\
\hline Seasonal Adjustment F. & $(\mathrm{SAF})$ & 0.980 & 0.980 & 0.915 & 0.915 & 0.915 & 0.915 \\
\hline Remaining Traffic Volume & (RTF) & $100 \%$ & $100 \%$ & $100 \%$ & $100 \%$ & $100 \%$ & $100 \%$ \\
\hline Peak Hour Traffic Volume & $(\mathrm{V})$ & 3,024 & 3,012 & 1,161 & 1,376 & 1,945 & 2,051 \\
\hline \multicolumn{8}{|c|}{ CAPACITY OF RESTRICTED SECTIONN } \\
\hline Width of Travel Lanes & (WTL) & 12 & 12 & 12 & 12 & 12 & 12 \\
\hline Lateral Clearance & $(\mathrm{LC})$ & 4 & 4 & 4 & 4 & 4 & 4 \\
\hline Obstruction Factors & (OF) & 0.98 & 0.98 & 0.98 & 0.98 & 0.98 & 0.98 \\
\hline WZ Capacity & (C) & 1400 & 2800 & 1400 & 1400 & 1400 & 1400 \\
\hline Capacity Restricted Sect. & (CRS) & 1,372 & 2,744 & 1,372 & 1,372 & 1,372 & 1,372 \\
\hline \multicolumn{8}{|c|}{ THRESHOLD VALUE FOR OPEN ROAD } \\
\hline Threshold Value & (TV) & $3.51 \%$ & $7.37 \%$ & $8.38 \%$ & $7.30 \%$ & $6.88 \%$ & $6.53 \%$ \\
\hline \multicolumn{8}{|c|}{ LANE CLOSURE NOTPERIMITTED FROM: } \\
\hline Start Time: & & 4:00 - 13:00 & $15: 00$ & & & 11:00 & $12: 00$ \\
\hline End Time: & & 11:00 - 23:00 & 17:00 & & & 18:00 & $20: 00$ \\
\hline
\end{tabular}

Figure 8-2 and Table 8-3 present the results obtained for case \# 2. In this case the work zone capacity value was determined to be 1400 vphpl. Evaluation \# 1 \& 2 indicated that no significant changes were observed in the northbound direction compared to Case 1 where the capacity was 1600 vphpl. However, the southbound direction showed periods of time when traffic on the 
interstate cannot be restricted. Based on the evaluations, lane closures are not permitted during the 15:00 PM to 17:00 PM period. The I-65 project near Lafayette on I-65 showed no periods when the lane closures are prohibited, i.e, the capacity of I-65 is sufficient to accommodate demand even when one lane of traffic is not serviceable. The evaluations conducted on the I69/US-24 project near Ft Wayne showed a significant impact when the capacity is reduced from 1600 vphpl to 1400 vphpl. In the northbound direction, I-69 cannot be restricted from 11:00 AM to 18:00 PM. In the southbound direction the interstate cannot be closed from 12:00 PM to 20:00 PM. 


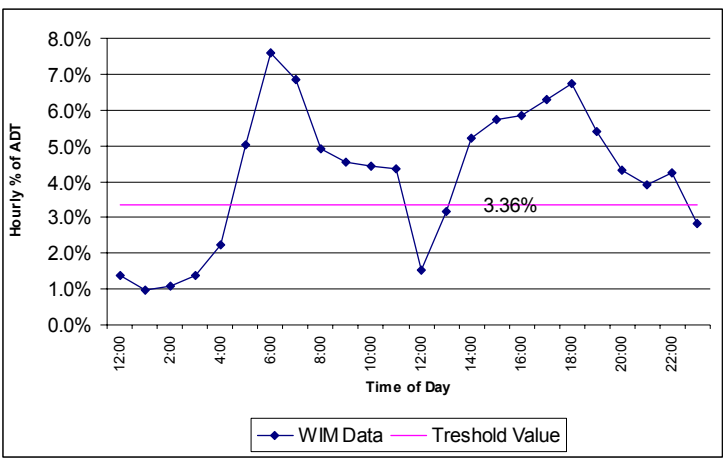

a) Evaluation \# 1- US-30 NB

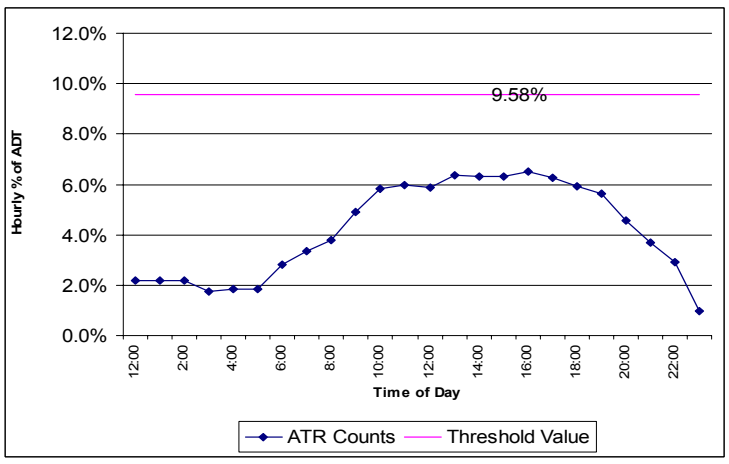

c) Evaluation \# 3- SR-25 NB

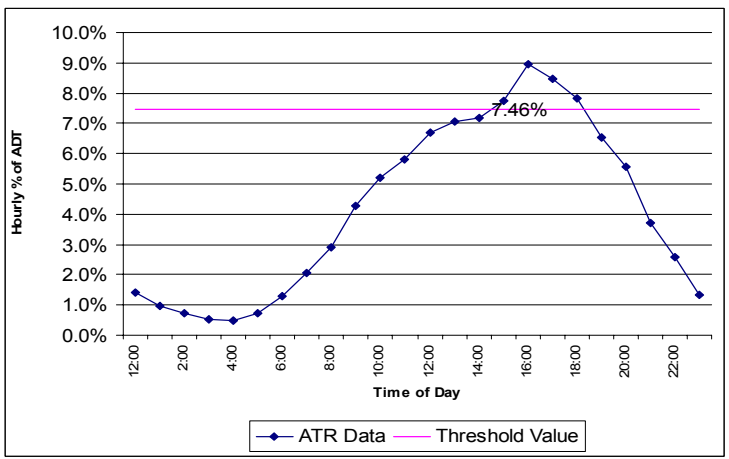

e) Evaluation \# 5- US-24 NB

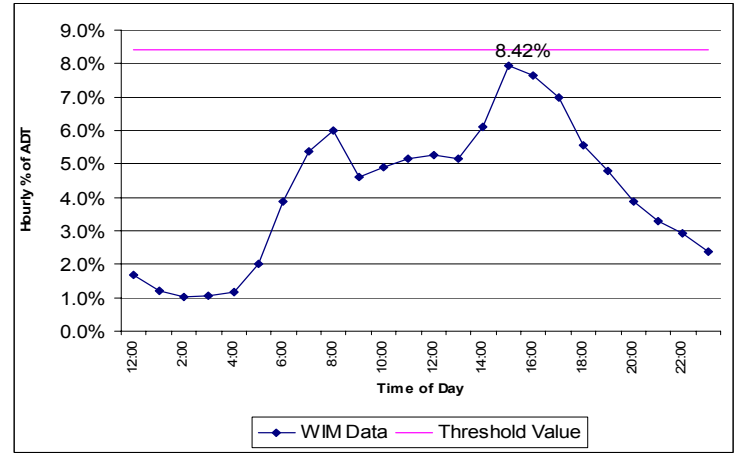

b) Evaluation \# 2-US-30 SB

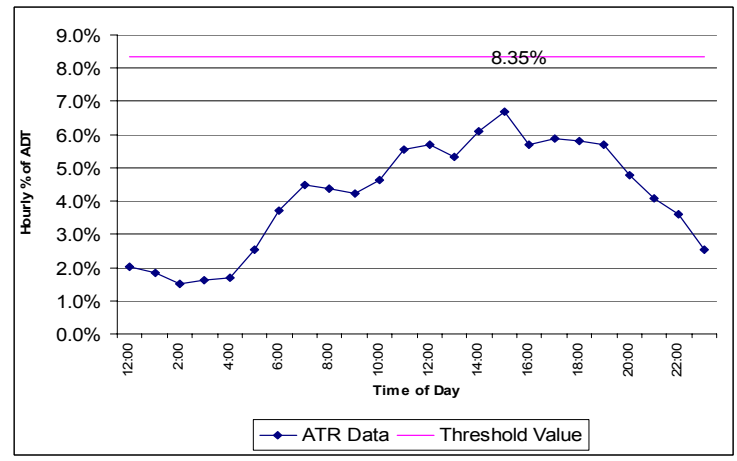

d) Evaluation \# 4- SR-25 SB

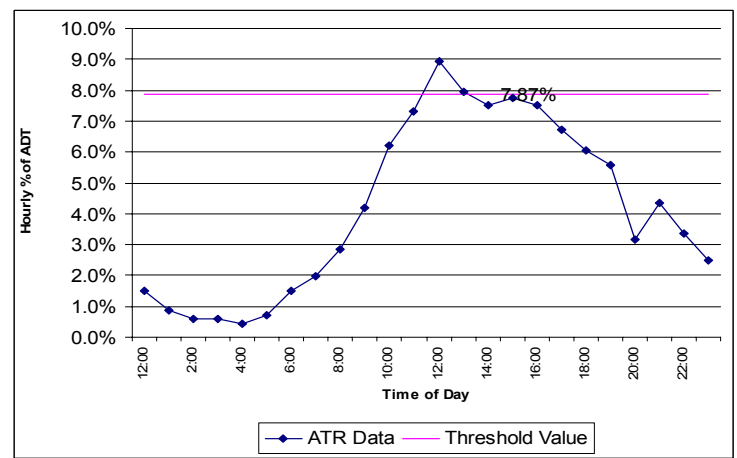

f) Evaluation \# 6-US-24 SB

Figure 8-1 Case \# 1: Work zone Capacity = 1600 vphpl

This analysis showed that when the directional ADT of a section of interstate is greater than 20,000 , there are periods when lane restrictions are prohibited. The I-69 project near Ft Wayne 


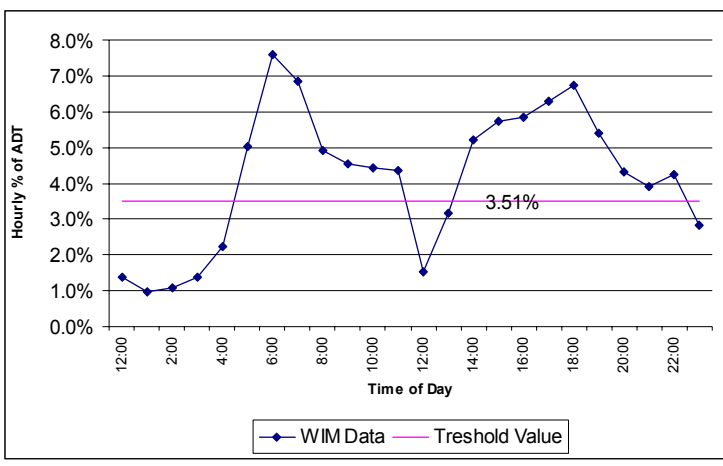

a) Evaluation \# 1- US-30 NB

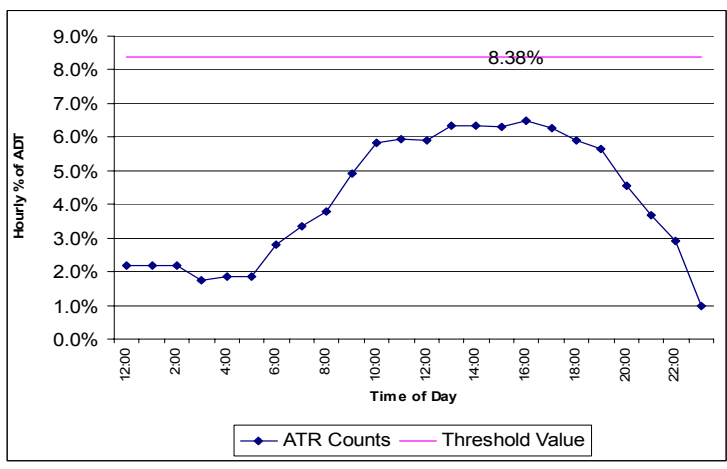

c) Evaluation \# 3- SR-25 NB

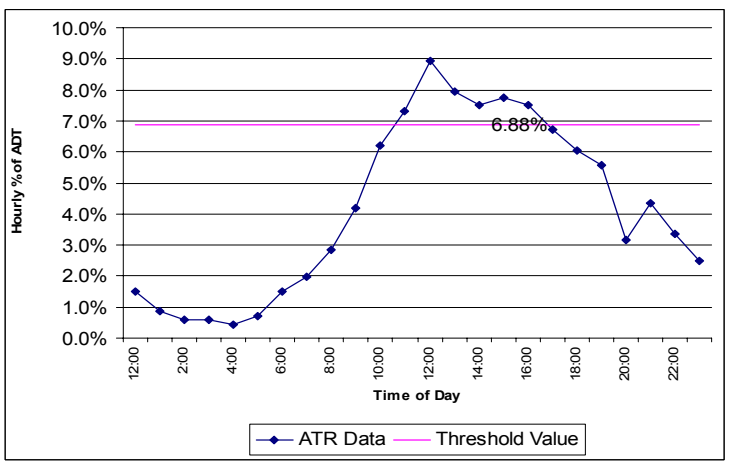

e) Evaluation \# 5- US-24 NB

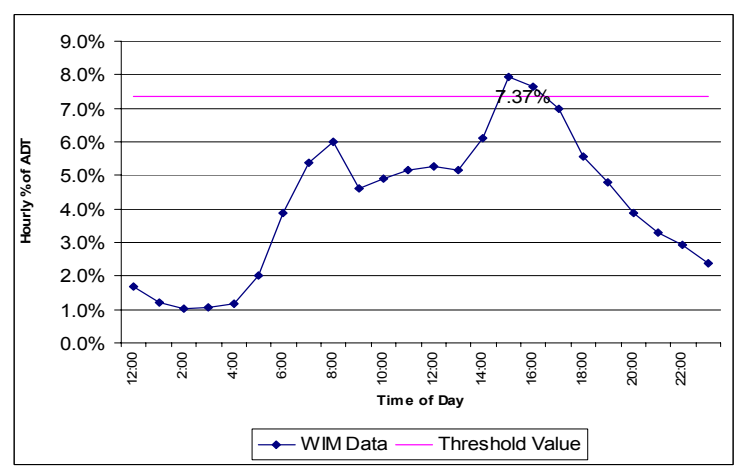

b) Evaluation \# 2-US-30 SB

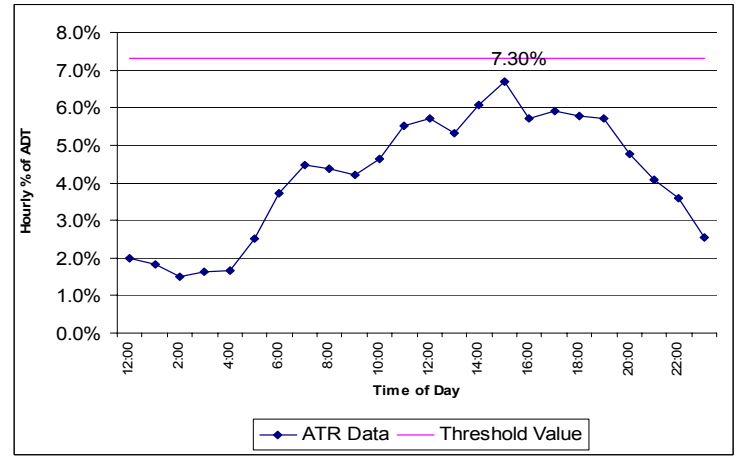

d) Evaluation \# 4- SR-25 SB

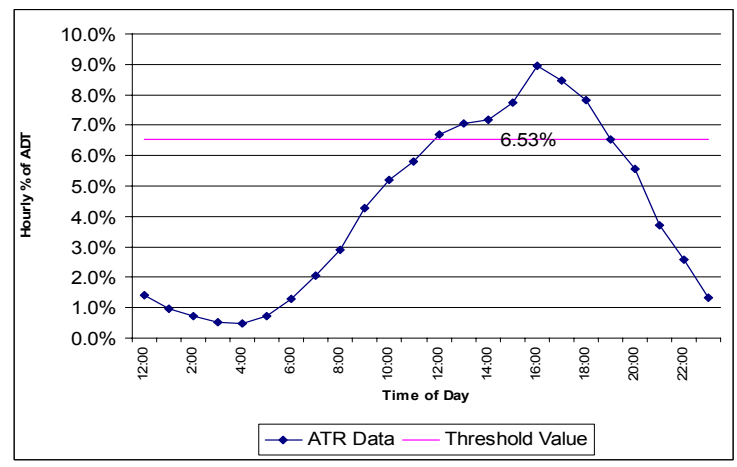

f) Evaluation \# 6-US-24 SB

Figure 8-2 Case \# 2: Work zone Capacity = 1400 vphpl

(directional ADT of 23,500) showed periods when lane closures are prohibited. A reduction of 200 vphpl in the work zone capacity translates into periods of lane restrictions which are doubled from 4 to 8 hours, as evidenced in the southbound direction. The project on 1-65 near Lafayette $(20,000$ directional ADT) showed no periods when lane restrictions are prohibited. However, conditions on I-65 south of Lafayette during construction near Lebanon in 2002 have shown different results. Extensive periods of queue were observed during this project when a lane was 
closed. The FDOT procedure provides a rough calculation of the lane closure analysis. Nevertheless, it is important to determine more precisely, the threshold value of capacity when periods of lane closure begin.

\subsection{Economic Model}

In Indiana, rural interstates typically consist of two-lane median divided highways. Hence, maintaining two lanes of traffic during construction on interstates can be difficult. A tradeoff between the benefits and costs associated by keeping two lanes open must be addressed. $A$ simple but comprehensive model is needed to provide the initial basis for determining if maintaining two lanes open is a feasible solution.

The economic model presented herein was developed in terms of the costs of (a) shoulder strengthening, (b) use of temporary structures, (c) fatalities and (d) accidents. Two parameters, Parameter $A$ and Parameter $B$ compose the model. Parameter $A$ is defined as the costs required for additional construction. Parameter $B$, on the other hand, is defined as the increase in additional costs for motorists when traveling in a work zone.

\subsection{Economic Model: Parameter A}

Each parameter is divided into two components. Parameter A includes: (1) the costs associated with strengthening the shoulders and (2) the costs of employing a temporary structure (in many cases, temporary bridges).

\subsubsection{Parameter A: Shoulder Strengthening}

Typically, rural interstates with two traffic lanes in each direction consist of shoulders: one inside and the other outside. The inside shoulder is located next to the passing lane. The outside shoulder, wider than the inside shoulder, is located next to the driving lane. The shoulders, especially the outside, are only used for emergency incidents. In general, both shoulders are not originally designed nor constructed with sufficient structural capacity to accommodate traffic. There are some advantages to strengthening the shoulders:

Capacity: Long lines of halted vehicles are encountered when a lane restriction is taking place. Lane restrictions generate queues upstream of the work zone. If shoulders are strengthened, then traffic can be shifted to the shoulder, thereby maintaining the same number of lanes (two) 
during construction. By "enclosing" the work zone, the construction activity area is safer for both motorists and the traveling public. The changes to driving conditions are minimal thus minimizing the likelihood of the occurrence of accidents.

Maintenance: During future periods of maintenance operations, the strengthened segment will be available to accommodate traffic independent of the activities taken place. The disruptions are reduced because the interstate segment is "prepared" to handle the traffic. Also, traffic can be shifted or the configuration of the lanes can be changed as necessary.

However there are also some obstacles to strengthening the shoulders:

Restrictions: While the shoulders are strengthened, lane restrictions have to be implemented. Most of these restrictions are conducted at night during periods of lower traffic volume. In many cases, it is possible to consider strengthening of the shoulders as a sub task within the scope of a project. In such cases, the strengthening is conducted prior to the actual start of the project construction, in an effort to have the conditions prepared for motorists traveling through the work zone.

Temporary vs. Total Solution: Strengthened shoulders are considered a temporary solution. However, based on the design of the asphalt the solution can be permanent. The costs associated with traffic maintenance be included. If the temporary solution is chosen, then the segment does not adequately maintain all traffic. Additional signage and enforcement must be included to inform motorists that the driving lane is not adequately prepared to carry truck traffic, for example.

An estimate was prepared in an effort to estimate the cost associated with strengthening the shoulder for a typical rural interstate segment. It was assumed that full depth Hot Mix Asphalt would be used (QC/QA). The unit costs for the takeoff were averages from INDOT's unit price summary report. Table 8-4 presents a breakdown of the calculation and the total cost ( $\$ /$ Mile) used in the model $(\$ 356,713)$. 
Table 8-4 Total Cost* of Strengthening Shoulder / Mile

\begin{tabular}{|c|c|c|}
\hline \multicolumn{3}{|c|}{ TOTAL COST } \\
\hline Removal & $\$$ & 17,556 \\
\hline Excavation & $\$$ & 26,462 \\
\hline QC/QA HMA Surface & $\$$ & 20,180 \\
\hline QC/QA HMA Intermediate & $\$$ & 173,333 \\
\hline QC/QA HMA Base & $\$$ & 119,182 \\
\hline Marking & $\$$ & 2,957 \\
\hline TOTAL (\$/mile) & $\$$ & 356,713 \\
\hline
\end{tabular}

${ }^{*}$ Assuming Mobilization/Demobilization and Maintenance of Traffic costs are included in project

\subsubsection{Parameter A: Temporary Structures}

The second component of Parameter A is temporary structures. In order to provide two lanes of traffic during construction work on interstates, temporary structures can be used. Bridges are the most common temporary structures used on interstate reconstruction and rehabilitation projects.

Modular steel bridges have been extensively used as a solution for replacing old and damaged bridges. Temporary bridge structures when originally developed where intended primarily for military purposes. The Bailey bridge, the most popular design of modular bridges, was developed during World War II based on a conceptual idea of Sir Donald Bailey (World Highways 2001), and was an extensively used solution for constructing bridges in need of repair and bridges damaged during military operations. The biggest advantage of these bridges was their ease of erection, because they could be assembled by soldiers by using only hand tools.

These bridges have been redeveloped and improved for other uses including vehicular, pedestrian and even wetland bridges. According to Shaker and Greenwald (1994) "In the 1970's, Bailey's patent expired and two British companies, Acrow® Ltd. And Mabey \& Johnson, Ltd. produced an enhanced version of the original". Although the original design of the Bailey bridge still remains the same, advances in both materials and erection processes have led to important improvements. Newer and stronger materials have made possible longer and stronger spans which results in an even greater variety of applications for these bridges.

Temporary bridges as they exist today are constructed to meet the load standards specified by the American Association of State Highway and Transportation Officials (AASHTO). Several 
loading categories can be complied by using different bridge configurations. For interstate bridges with an expected heavy truck traffic volume, the most adequate design loading category according to prevalent standards is the AASHTO HS25. The most common material for construction of modular bridges is steel. It is the preferred alternative, because this material can be hot-dipped galvanized minimizing the environmental impact (weathering) on the structure. In addition, steel requires minimal maintenance, and can be adapted to site specific conditions by using minimal labor.

Temporary bridges are fabricated in the "shop", and are constructed according to specifications given by the client. The modular bridges can be installed, uninstalled and stored with ease; therefore the same bridge can be used several times with little or no change to the superstructure. The structure is adjustable to different conditions and it can be easily adapted to different needs. For example, when installed, the bridge can be designed with an upper layer of asphalt in one deployment, and on the next it can be designed with a thin epoxy coating. These bridge modules are also compatible with each other and can be used in series to reach a greater span if required.

There are many advantages offered by the use of temporary bridges:

Different Applications: Modular bridges can be used on interstate projects as solutions for several applications including: temporary, permanent and structures for incident management. Temporary bridges are the scope of this evaluation; they represent the utilization of bridges only when construction activity is underway. When the construction period is over, the bridge will be removed. Due to their extended life design, modular bridges can become a permanent solution. Incident management bridges represent deployments of modular structures after an unpredictable incident such as collapse of bridges. Incident management is one of the reasons why several Departments of Transportation have several bridges stored at different locations.

Faster Erection Time: Due to the simple design and assembly process, the time required to install modular bridges is minimal and the process is less labor-intensive when compared to permanent reinforced bridges. These bridges can be constructed in hours or days compared to weeks or months for typical permanent bridges on interstates (Shaker and Greenwald 1994). Temporary bridges can be constructed by using a crew of 5 laborers and a supervisor (foreman) with minimal equipment.

Ready to Install: Once unloaded from the trucks the bridges are ready to be assembled. The repetitiveness of the process increases the productivity of the workers involved in the assembly. 
The standardization of the launching and crane lift-in tasks makes the process fairly simple and shortens the learning curve for the labor crew.

Minimal Disruptions: The benefits for the owner (DOT), the contractor and the motorist when a modular bridge is used in a work zone are significant. For the owner, using a temporary bridge means reduced traffic disruptions. By maintaining normal traveling conditions the possibility of accident occurrences is minimized. The contractors reap the benefits of having the work zone enclosed and not being disrupted by the ongoing traffic. When traveling conditions are maintained throughout work zones, fewer delays and frustrations due to heavy congestion will be experienced by the traveling motorists.

Completion Time: By employing temporary structures the overall construction period for interstate projects is shortened. According to Goodwin (1997): "Using a temporary bridge reduced the estimated project duration from three to two years and made the work zone safer, the quality of the finished repair better, and the total cost of the project significantly lower." Separating and enclosing the work zone by maintaining two lanes open at all times, has been proven to be a very effective and practical solution for improving traffic mobility and safety.

However there are also some obstacles that should be considered when selecting a temporary structure:

Substructure vs. Superstructure: One of the most important challenges of these technologies, is the high dependence on the work performed by others. The superstructure is easily constructed using a highly repetitive process. However, the substructure is treated as a separate component and it must be fully completed before installation of the modular bridges. Depending on the length of the span, the bridge requires piles or abutments. In many cases, the piles are skewed to fit the existing conditions. Typical 30' span bridges on highway requires two pipe pile caps. However, exceptions exist when the span of the bridges does not require the use of piles.

Additional Construction: In addition of the substructure construction required, approaches for the temporary bridges must also be constructed. The cost of connecting the bridge to the existing traveling lanes can be high, because the interstate needs to be constructed to connect to the bridge. A layer of pavement or asphalt is also required on top of the metal decks to minimize the changes in the surface roughness for the drivers.

Total Cost: Temporary bridges do alleviate the recurring problem of capacity on interstates. However, there is a high cost associated with the installation of the modular bridges and not the 
superstructure itself. The additional construction (mainly foundation, approaches, etc) required to start routing traffic through the bridge account for the most expensive scopes of work in a project. It is difficult to factor in the additional construction cost for the approaches and foundations.

The cost of the superstructure can be obtained from the vendors of the bridges. However the costs of the substructure and the costs of the road approaches that tie into the bridge are site specific and project specific. The Florida Department of Transportation used an estimate of $\$ 400$ 500 per LF of temporary bridge assuming a $30 \mathrm{ft}$ span (Bhuvasorakul 2002). North Carolina DOT has installed three temporary bridges on I-85 in Durham. The costs per bridges were approximately $\$ 750,000$ depending on the span of the bridge (Parks 2002). These costs did not include the costs of the approaches but they did include the cost of the superstructure. The total cost of the temporary bridges used for this economic model will be taken from the values used by North Carolina DOT on the I-85 project in Durham. The project in Durham, NC simulates the typical conditions encountered in the state of Indiana for both volume of traffic and interstate configuration (four-lane median divided highway).

\subsection{Economic Model: Parameter B}

Parameter A can be considered to be the costs of maintaining two lanes open by additional construction, while Parameter $B$ is associated with the benefits of implementing this policy. Parameter $B$ is the estimated additional cost of accidents during the work zone period, and is divided into two main components, namely (1) the costs of fatalities and (2) the costs of accidents.

\subsubsection{Parameter B: Cost of Fatalities}

In an effort to provide a comprehensive evaluation of undertaking a certain project, most public policy initiatives include in their analysis the costs associated with fatalities and injuries. The Value of Statistical Life (VSL) is the term used in the literature to define the costs associated with a fatality. In the transportation sector, the Federal Highway Administration (FHWA) is the agency in charge of recommending the VSL value that should be used for investment analysis.

FHWA has issued several memoranda updating the VSL value to be used by Departments of Transportation. The most recent document is the Revised Departmental Guidance: "Treatment of Value of Life and Injuries in Preparing Economic Evaluations (FHWA 2002)". According to the Memorandum, in 1993 a prior version of the Memorandum was issued. At that time, based on the 
findings, a proposed a value of $\$ 2.5$ million was recommended. These values were recommended to be adjusted periodically using the Gross Domestic Product implicit price deflator. The value was first updated to $\$ 2.7$ million in 1996. In January 2002, FHWA proposed an updated value of $\$ 3.0$ Million dollars. Table 8-5 presents the values as they have been modified throughout the years. For the economic model, the VSL value used is the $\$ 3.0$ Million dollars, as specified by the 2002 FHWA Memorandum.

Table 8-5 Cost of Fatalities according to FHWA

\begin{tabular}{|c|cr|}
\hline $\begin{array}{c}\text { FHWA } \\
\text { Memorandum } \\
\text { Year }\end{array}$ & \multicolumn{2}{|c|}{$\begin{array}{c}\text { Cost } \\
(1,000,000)\end{array}$} \\
\hline 1983 & $\$$ & 2.5 \\
\hline 1996 & $\$$ & 2.7 \\
\hline 2002 & $\$$ & 3.0 \\
\hline
\end{tabular}

\subsubsection{Parameter B: Cost of Accidents}

The values presented in Table 8-6 were taken directly from Figure 50-2A of INDOTs Design Manual. The values show the accident cost per accident, based on the location of the incident. The value of $\$ 74,000$ which describes the cost associated with an accident on an interstate rural route will be used in the model.

Table 8-6 Accident Cost per Accident

(Source: INDOT Design Manual Fig. 50-2A)

\begin{tabular}{cc}
\hline Accident Type & Fatal Injury/ \\
& Property Damage Only (\$) \\
Interstate Rural Route & $74,000 / 3,000$ \\
Interstate Urban Routes & $51,000 / 3,000$ \\
\hline
\end{tabular}




\subsection{Economic Model Formulation}

Equation 8-1 and Equation 8-2 present the proposed model. Parameter A (Equation 8-1) is composed of the costs associated with additional construction. The main components are the costs for strengthening the shoulder multiplied by the number of miles of the proposed segment. The second component denotes the use of temporary bridges. The cost of the temporary bridges is multiplied by the number of bridges planned, if any. The cost of the bridges must also include the cost of the approaches since this cost can sometimes be high.

Equation 8-1- Economic Model: Parameter A

$$
\begin{gathered}
\text { A = Component } 1+\text { Component } 2 \\
\text { Where: } \\
\text { Component } 1=\text { Cost of Shoulder Strengthening } \\
\text { Component } 2=\text { Cost of Temporary Bridges } \\
A=\left[\frac{\text { Cost_of_Shoulder_Strength }}{\text { Number_of_Miles }} * \text { Miles }\right]+[\text { Cost_of_Temp._Bridges } * \text { Number }]
\end{gathered}
$$

Parameter B is presented in Equation 8-2. The factor $(\lambda)$ represents the increment rate for accidents that can be expected during interstate work zones as evidenced in the 16 projects analyzed in the state of Indiana. The INDOT Report (Huebschman et al. 2002) presents the calculation of $(\lambda)$. According to the findings this value is equal to 0.275 (i.e., accidents during construction on interstate projects are expected to increase by 27.5 percent). The factor $(\lambda)$ is used to multiply both the number of accidents and the number of fatalities. The number of fatalities typically does not increase by twenty seven and one half percent. However, it was considered appropriate to assume that the rate of increase in fatalities will be equal to the accident rate increase to account for the misfortune of having a fatality on an interstate work zone. 


\section{Equation 8-2- Economic Model: Parameter B}

$$
\begin{aligned}
& A=\text { Component } 1+\text { Component } 2 \\
& \text { Where: } \\
& \text { Component } 1 \text { = Cost of Accident } \\
& \text { Component } 2 \text { = Cost of Fatalities } \\
& B=\left[\begin{array}{l}
\left.\left\{(1+\lambda) *\left(\frac{\sum_{i=0}^{n} \text { Accidents / year }}{n}\right)-\left(\frac{\left.\sum_{i=0}^{n} \text { Accidents / year }\right)}{n}\right)\right\} * \frac{\operatorname{Cost}(\$)}{\text { Accident }}+\right] \\
\left\{(1+\lambda) *\left(\frac{\sum_{i=0}^{n} \text { Fatals / year }}{n}\right)-\left(\frac{\left.\sum_{i=0}^{n} \text { Fatals / year }\right)}{n}\right)\right\} * \frac{\operatorname{Cost}(\$)}{\text { Fatal }}
\end{array}\right] \\
& \text { where } n=\text { number of years }
\end{aligned}
$$

The estimated costs to be used in the model are presented in Table 8-7 These values must be updated periodically and modified to account for different project characteristics.

Table 8-7 Summary of Costs for Economic Model

\begin{tabular}{|l|c|cr|}
\hline \multicolumn{1}{|c|}{ Description } & Unit & \multicolumn{2}{c|}{ Cost (\$) } \\
\hline \hline & & \multicolumn{2}{|c|}{} \\
\hline Cost of Fatalities & Ea. & \$ $3,000,000$ \\
\hline Cost of Accidents & Ea. & $\$$ & 74,000 \\
\hline Cost of Shoulder Strenghtening & Mile & $\$$ & 356,713 \\
\hline Cost of Temporary Bridge & Ea. & $\$ 750,000$ \\
\hline
\end{tabular}




\subsubsection{Economic Model Procedure}

The following presents a step-by-step procedure to implement the economic model in a particular project:

Parameter A:

Determine project limits

Calculate number of miles to perform shoulder strengthening

Determine if temporary bridges are necessary

By using Equation 8-1 and the costs presented in Table 8-7 calculate the value of Parameter A

\section{B. Parameter B:}

1. Collect accident data for prior years for the location of the project. More than two years worth of data is preferable.

2. Calculate number of accidents per year and divide by the number of years of observation (n). This value is called the average number of accidents.

3. Multiply the value of $(1+\lambda)$ by the average number of accidents. The value obtained is the projected number of accidents.

4. Subtract from the projected number of accidents the average number of accidents.

5. Multiply the result obtained in Step 4 by the cost per accident presented in Table 8-7 as shown in Equation 8-2.

6. Collect fatalities data for prior years for the location of the project. More than two years worth of data is preferable.

7. Calculate number of fatalities per year and divide by the number of years of observation (n). This value is called the average number of fatalities.

8. Multiply the value of $(1+\lambda)$ by the average number of fatalities. The value obtained is the projected number of fatalities.

9. Subtract from the projected number of fatalities the average number of fatalities.

10. Multiply the result obtained in Step 9 by the cost per fatalities presented in Table 8-7 as shown in Equation 8-2.

11. Parameter B is the sum of the values obtained in Step 5 and Step 10. 
$B=\left[\begin{array}{l}\left.\left\{(1+\lambda) *\left(\frac{\sum_{i=0}^{n} \text { Accidents / year }}{n}\right)-\left(\frac{\sum_{i=0}^{n} \text { Accidents / year }}{n}\right)\right\} * \frac{\operatorname{Cost}(\$)}{\text { Accident }}+\right] \\ \left\{(1+\lambda) *\left(\frac{\sum_{i=0}^{n} \text { Fatals } / \text { year }}{n}\right)-\left(\frac{\left.\sum_{i=0}^{n} \text { Fatals } / \text { year }\right)}{n}\right)\right\} * \frac{\operatorname{Cost}(\$)}{\text { Fatal }}\end{array}\right]$

\section{Ratio Comparison:}

The value of Parameter B (step B-11) must be divided by the value of Parameter A (step A-4). Then the following must be considered:

- If $B / A>1 \rightarrow$ then two lanes should be maintained open

- If $B / A<1 \rightarrow$ then the model does not justify the policy of keeping two lanes open

- If $B / A=1 \rightarrow$ then additional evaluation must be considered

\subsubsection{Economic Model Validation}

Table 8-8 presents a list of rural interstate work zone projects conducted in the state of Indiana during the 1996-2001 period. The table shows the project limits, construction dates and the estimated ADT for each project. Based on the actual project configuration, and the types of lane restrictions implemented, Project \# 3 was chosen to validate the model. Project \# 3 was located on I-65 near the Tippecanoe/White county border. Construction started in February 1998 and was completed in August 1999. The typical ADT for this section is 33,000 vehicles per day. The limits of the project are defined as follows: construction started 1.7 miles north of SR-43 (MP 179.6) and ended one mile north of the rest area in Tippecanoe \& White counties (MP 197.8). The difference between the Milepost limits defined in Table 8-8 and the description given above is the study area for the accident data collection process. The limits for all the projects were extended a total of five miles with respect to the construction limits in an effort to provide a consistent study area for all the projects analyzed. 
Table 8-8 Interstate Projects Analyzed

\begin{tabular}{|c|c|c|c|c|c|c|c|}
\hline & & & \multicolumn{3}{|c|}{ Construction Limits } & \multicolumn{2}{|c|}{ Project Dates } \\
\hline Zone & Site & AADT & From MP & To MP & \# Miles & Start Date & End Date \\
\hline 1 & $1-65$ & 45,840 & 169.9 & 180.6 & 10.7 & 21-Apr-00 & 25-May-01 \\
\hline 2 & $1-65$ & 42,940 & 71.2 & 85.6 & 14.4 & 16-Mar-97 & 12-Aug-97 \\
\hline 3 & $1-65$ & 32,987 & 174.6 & 202.8 & 28.2 & 23-Feb-98 & 31-Aug-99 \\
\hline 4 & $1-65$ & 26,050 & 198.2 & 222.5 & 24.3 & 10-Apr-96 & 19-Dec-97 \\
\hline 6 & $1-65$ & 72,940 & 241.9 & 258.6 & 16.7 & 9-Feb-98 & 2-Aug-99 \\
\hline 7 & $1-65$ & 45,840 & 159.5 & 177.7 & 18.2 & 24-Mar-97 & 7-Jul-97 \\
\hline 8 & $1-69$ & 40,120 & 1.9 & 17.8 & 15.9 & 27-Mar-98 & 16-Jul-98 \\
\hline 9 & $1-69$ & 30,570 & 36.9 & 81.6 & 44.7 & 1-Sep-98 & 18-Nov-98 \\
\hline 10 & $1-69$ & 26,559 & 74.9 & 90.7 & 15.8 & 17-Mar-97 & 4-Nov-97 \\
\hline 11 & $1-69$ & 22,230 & 140.6 & 162.1 & 21.5 & 1-Nov-96 & 5-Nov-97 \\
\hline 12 & $1-69$ & 22,236 & 133.9 & 154.1 & 20.2 & 6-Mar-98 & 24-Nov-98 \\
\hline 13 & I-69 & 19,890 & 143.9 & 162.0 & 18.1 & 22-Feb-99 & 10-Sep-99 \\
\hline 14 & $1-70$ & 24,830 & 0.0 & 12.1 & 12.1 & 18-Aug-97 & 19-Nov-97 \\
\hline 15 & $1-70$ & 24,830 & 0.0 & 13.6 & 13.6 & 24-Mar-99 & 19-Jul-99 \\
\hline 16 & $1-70$ & 36,320 & 145.0 & 159.4 & 14.4 & 13-Мау-97 & 28-Apr-98 \\
\hline
\end{tabular}

Data was subdivided into two periods: before construction (PRE) which represents the historical data, and during construction (CON). The period of analysis of accident and fatalities for the historical data was February 1996 to August 1997. The construction period started in February 1998 and ended in August 1999. All the data obtained was segmented for each direction (northbound (NB) and southbound (SB)).

Starting in Table 8-9 to Table 8-13 the validation of the economic model is presented. Table 8-9 shows the calculation of the estimated additional construction cost (Parameter A). The project consisted of resurfacing 1-65. Due to the scope of work of the project, no temporary bridges were required for this project. However, it was assumed that shoulder strengthening was required for the entire length of the project. 
Table 8-9- Model Validation: Parameter A

\begin{tabular}{|c|l|c|c|c|}
\cline { 3 - 5 } \multicolumn{2}{c|}{} & \multicolumn{3}{c|}{ ADDITIONAL COST } \\
\hline $\begin{array}{c}\text { ESTIMATED } \\
\text { ADDITIONAL } \\
\begin{array}{c}\text { CONSTRUCTION } \\
\text { COST (A) }\end{array}\end{array}$ & Direction & NB & SB & NB + SB \\
\cline { 2 - 5 } & $\begin{array}{l}\text { Number of Miles to be } \\
\text { Strengthened }\end{array}$ & 18.2 & 18.2 & 36 \\
\cline { 2 - 5 } & Number of Bridges & 0 & 0 & 0 \\
\cline { 2 - 5 } & VALUE OF A $(\$ 1,000)$ & 6,492 & 6,492 & 12,984 \\
\hline
\end{tabular}

In Table 8-10 Component 1 required for the calculation of Parameter B is presented. The historical data is presented in the first column. In the second column, the historical data was multiplied by the $(1+\lambda)$ value in order to obtain the projected number of accidents and fatalities on the segment during the construction phase. In the last column, the actual number of accidents and fatalities obtained from the Indiana State Police records are presented. The numbers of accidents and fatalities were multiplied by their respective costs from Table 8-7.

Table 8-10- Model Validation- Parameter B (Part 1)

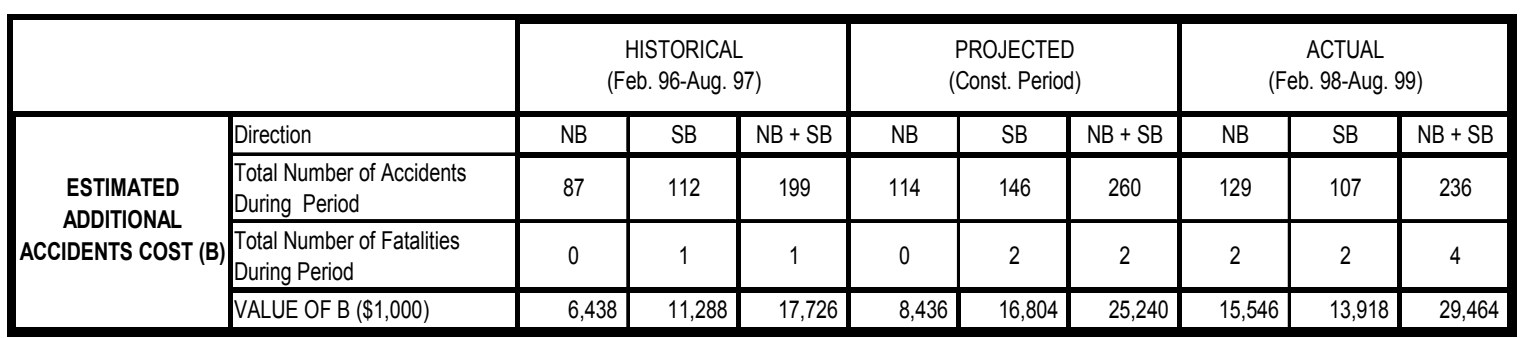

Table 8-11 shows the final calculation of Parameter B. Costs were calculated for both projected and actual by using the values in Table 8-7. The difference between the projected and the historical costs are presented in the first column. The difference between the actual and the historical is presented in column two. 
Table 8-11- Model Validation- Parameter B (Part 2)

\begin{tabular}{|c|c|c|c|c|c|c|c|}
\hline & & ADDITION & PROJEC & ED COST & ADDITI & - ACTU & - COST \\
\hline & Direction & NB & SB & $\mathrm{NB}+\mathrm{SB}$ & NB & SB & $\mathrm{NB}+\mathrm{SB}$ \\
\hline ESTIMATED & $\begin{array}{l}\text { Total Number of Accidents } \\
\text { During Period }\end{array}$ & 27 & 34 & 61 & 42 & 0 & 42 \\
\hline ACCIDENTS COST (B) & $\begin{array}{l}\text { Total Number of Fatalities } \\
\text { During Period }\end{array}$ & 0 & 1 & 1 & 2 & 1 & 3 \\
\hline & VALUE OF B $(\$ 1,000)$ & 1,998 & 5,516 & 7,514 & 9,108 & 3,000 & 12,108 \\
\hline
\end{tabular}

Table 8-12 shows the results of the economic model. The additional construction cost was divided by the value of the additional cost of accidents and fatalities. Keeping two lanes open is not justified for the project since the ratio of B/A is less than 1.

Table 8-12- Model Validation- Projected Results

\begin{tabular}{|c|c|r|r|r|}
\cline { 2 - 4 } \multicolumn{2}{c|}{} & \multicolumn{1}{c|}{ NB } & \multicolumn{1}{c|}{ SB } & NB + SB \\
\hline \multirow{2}{*}{$\begin{array}{c}\text { PROJECTED } \\
\text { RESULTS }\end{array}$} & VALUE OF A $(\$ 1,000)$ & 6,492 & 6,492 & 12,984 \\
\cline { 2 - 5 } & VALUE OF B $(\$ 1,000)$ & 1,998 & 5,516 & 7,514 \\
\cline { 2 - 5 } & B/A & 0.31 & 0.85 & 0.58 \\
\hline
\end{tabular}

Table 8-13 shows the calculations performed when the actual number of accidents and fatalities are considered. The project did not warrant keeping two lanes open because the ratio of (NB + $\mathrm{SB}$ ) is less than 1. For that project INDOT did not maintain two lanes open.

Table 8-13- Model Validation: Actual Results

\begin{tabular}{|c|c|r|r|r|}
\cline { 2 - 4 } \multicolumn{2}{c|}{} & \multicolumn{1}{c|}{ NB } & \multicolumn{1}{c|}{ SB } & NB + SB \\
\hline \multirow{3}{*}{ ACtUAL RESULTS } & VALUE OF A $(\$ 1,000)$ & 6,492 & 6,492 & 12,984 \\
\cline { 2 - 5 } & VALUE OF B $(\$ 1,000)$ & 9,108 & 3,000 & 12,108 \\
\cline { 2 - 5 } & B/A & 1.40 & 0.46 & 0.93 \\
\hline
\end{tabular}

\section{9. $\quad$ Conclusions}

The possibility of maintaining two lanes open during work zones on interstates to minimize the changes in traveling conditions is critical for both motorists and transportation officials. The main 
objective is to maintain the same number of travel lanes open when feasible during periods of work on interstates. A procedure is required to determine the segments of interstate where closures are permitted. Several states (including Florida and Ohio) have developed standardized guidelines to determine when to maintain the number of traveling lanes open. It is important that such procedure be developed in Indiana, in an effort to provide contractors with a formal procedure to follow when determining the lane restriction periods.

A review of current practices regarding implementation of lane closures was presented in this chapter. A sample of the Lane Closure Analysis procedure from the Florida Department of Transportation is presented in Appendix A. An example using the procedure developed by the Florida DOT was presented. The critical threshold value for maintaining two lanes open was found to be 20,000 directional ADT.

An economic model was developed in terms of the costs of (a) shoulder strengthening, (b) use of temporary structures, (c) fatalities and (d) accidents. Parameter A and Parameter B can be used to describe the model. Parameter $A$ is defined as the costs required for additional construction. Parameter $\mathrm{B}$, on the other hand, is defined as the increase in additional costs for motorists when traveling a work zone. The model is intended to be use as a preliminary tool to determine when to maintain two lanes open. The model was validated by using the I-65 project in the state of Indiana.

In order to determine the feasibility of maintaining two lanes open, INDOT should determine (1) if the 20,000 directional ADT threshold value is exceeded, and (2) if the B / A of the economic model is greater than 1. By utilizing these two procedures, INDOT will have two separate tools to perform a preliminary estimate of determining the feasibility of maintaining two lanes open, and the period of time when the 2-lane open policy has to be in effect. 


\title{
CHAPTER 9. BUILDING FOR THE FUTURE
}

\begin{abstract}
9.1. $\quad$ Introduction
As the highway infrastructure (especially bridges), is reaching its design life, Departments of Transportation (DOTs) are performing less new construction and more rehabilitation and/or reconstruction of existing highway facilities. Transportation officials are faced with the challenge of minimizing changes in travel conditions during work zones. Construction activities conducted are often unexpected by motorists and tend to increase the probability of accident occurrences. Traffic conditions in a work zone are disrupted by lane reductions, speed reductions, changes in roadway geometrics, additional signage, etc. In addition, freeway work zone capacity is severely impacted during regular construction operations on interstates.
\end{abstract}

Transportation officials must strive to provide road users with minimal changes as to simulate those of normal interstate conditions. The goal must be to develop and implement a set of guidelines and strategies to minimize the impact of work zones on capacity. An alternative is to conduct a multilane closure strategy, which involves shifting traffic during different stages of a long-term work zone project. This approach can significantly increase work-zone capacity. Implementing this type of operations has been referred to "Building for the Future". This approach includes reconstructing interstates to meet future demand. The immediate benefits of carrying out this approach is a reduction in the number of traffic disruptions in future years, a reduction in delays for motorists, and a reduction in the impact during future maintenance projects by keeping at least a minimum of two lanes open at all times.

The purpose of this chapter is to provide an evaluation of an interstate reconstruction project conducted in Des Moines, lowa. The information presented herein consists of findings based on literature review, discussion with DOT officials, conversations with representatives of the prime contractor, and information gathered from the contract documents of the project. 


\subsection{Case Study: I-35/80 Reconstruction Project near Des Moines, IA}

In an effort to increase the capacity of a heavily traveled urban interstate, the lowa Department of Transportation (lowa DOT) completed the I-35/80 reconstruction project. The project, located on the northeastern side of Des Moines, covered 12 miles of work on Interstate 35 in the vicinity of Interstate 80 . The average daily traffic for this section was approximately 70,000 vehicles per day. The project consisted of adding additional 2-lanes to an existing urban 4-lane median divided highway. The normal speed limit posted on I-35 is $65 \mathrm{mph}$. The speed limit throughout the work zone was reduced to $55 \mathrm{mph}$.

Due to the location and size of this reconstruction project, all four traffic lanes were required to be open during the entire project with ramp access. The project started in 1989 and was completed in November 2000. Work was broken down by construction seasons and it was completed in nine seasons. The latest portion of work, which is the project analyzed in this chapter, included the reconstruction of 2.5 miles of interstate, twelve bridges and reconstruction of two interchanges.

See Figure 9-1.

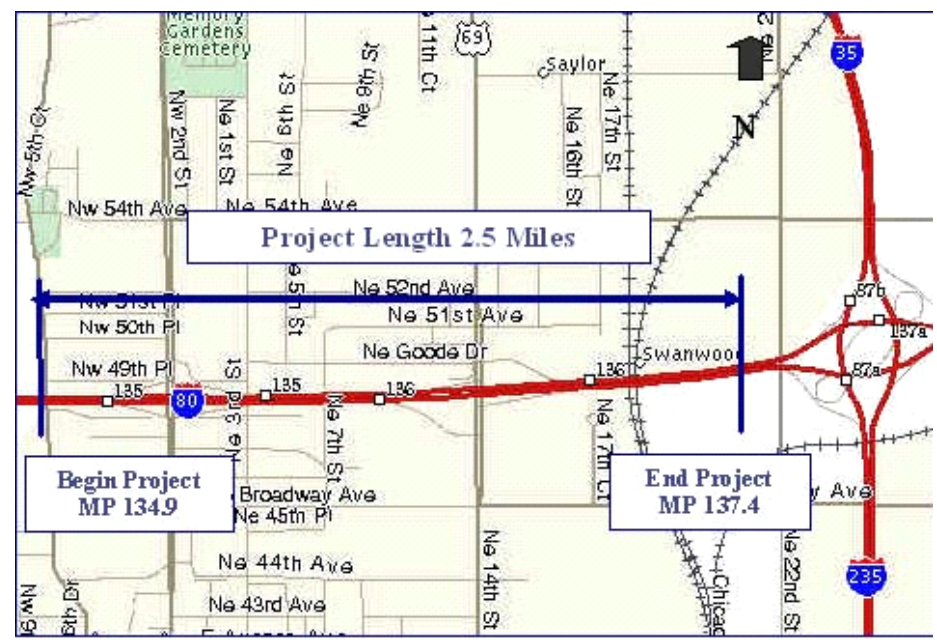

Figure 9-1 Location of I-35/80 Reconstruction Project

The average daily traffic for this particular segment in 1999 was 62,900 vehicles per day and it is expected to increase to 84,300 vehicles per day by 2019 . In order to add two-lanes of traffic to improve capacity without disrupting flow and mobility, a series of steps and project staging was necessary. The project was "subdivided" into four subprojects: Subproject \# 1 comprised the full strengthening of the outside shoulders. Subproject \# 2 involved the construction and completion of median bridges. Subproject \# 3 involved the construction and completion of median lanes and 
utilities, and Subproject \# 4 consisted of the construction and completion of the outside lanes. Figure 9-2 presents an overview of the four projects.

\subsection{Subproject \# 1}

This first subproject consisted of full-depth strengthening of both outside shoulders to handle traffic. This project was completed during the 1998 construction season. The project was awarded to the Des Moines Asphalt and Paving Company for $\$ 1.3$ million. The goal was to strengthen the shoulders for minimizing the need of added enforcement and additional signage for maintaining heavier vehicles on a dedicated lane. All construction activities that required lane reductions were conducted at night. The contractor for this project was required to open all 4lanes of traffic at 6:00 am to avoid traffic disruption.

\section{4. $\quad$ Subproject \# 2}

Subproject \# 2 consisted of the construction and completion of median bridges. The project was completed during the 98-99 winter season. The contract for this project was awarded to various contractors for a total price of $\$ 3.8$ million. This project can be further subdivided into stage $1 \mathrm{~A}$. During this stage the normal traffic operations are not affected. Traffic is maintained on existing Eastbound (EB)/ Westbound (WB) lanes. Construction operations in this stage included the construction and completion of median bridges. 


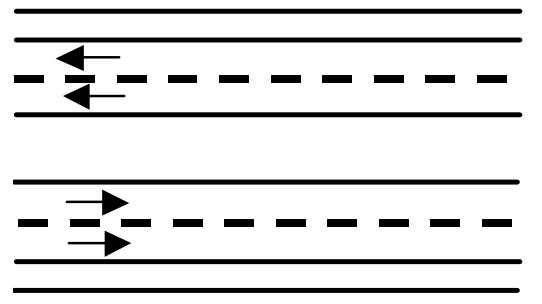

a) I-35/80 Original Configuration
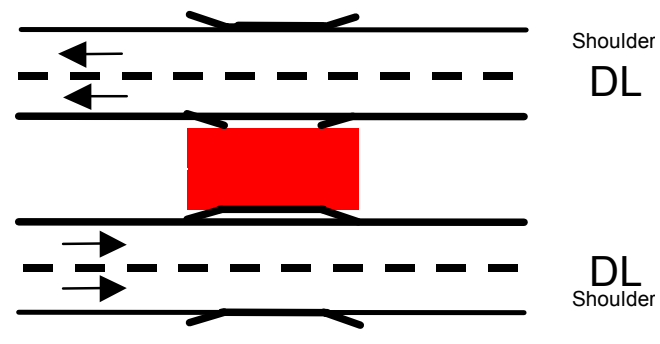

c) Project \# 2: Median Bridges Construction
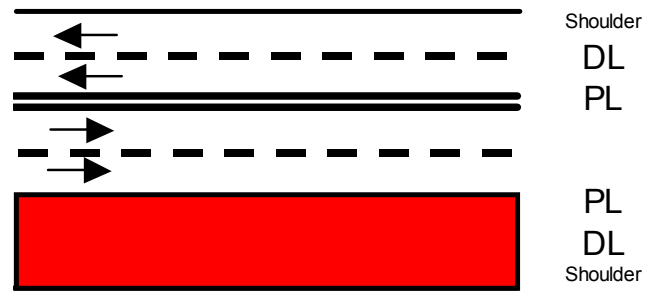

e) Project \# 4: Stages 1 A, B \& C Eastbound Construction

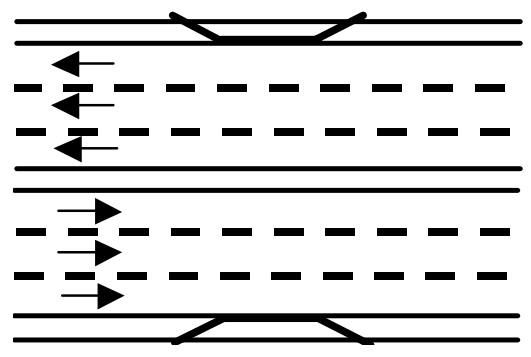
Shoulder
$\mathrm{DL}$
DL
PL
$\mathrm{PL}$
DL
$\mathrm{DL}$

g) Project \# 4: Stage 3 A \& B-Final Lane Configuration

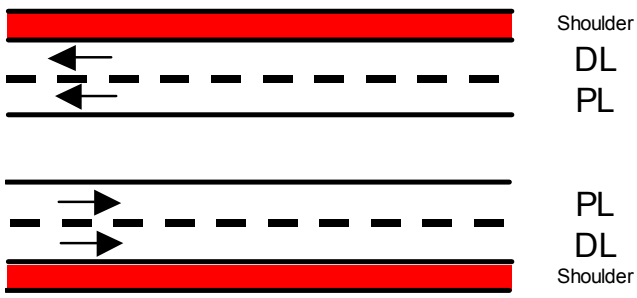

b) Project \# 1: Shoulder Strengthening

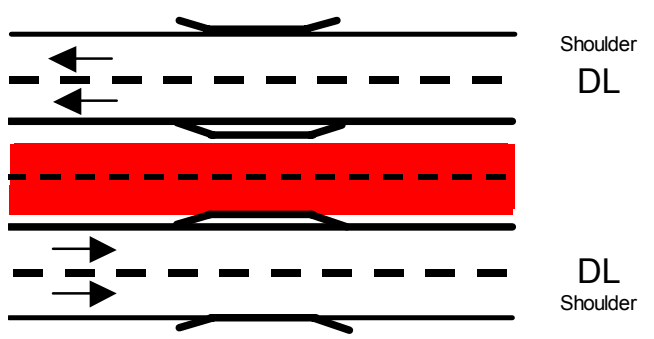

d) Project \# 3: Median Lanes Construction

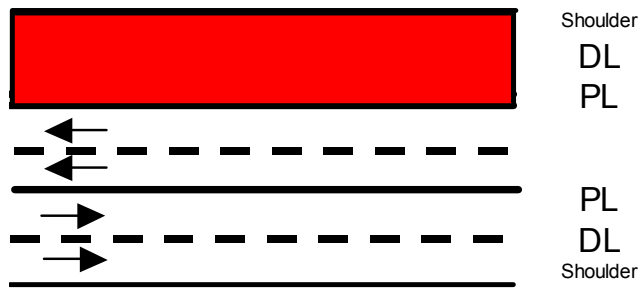

f) Project \# 4: Stages 2 A, B \& C

Westbound Construction

\begin{tabular}{|cl|}
\hline \multicolumn{1}{|c|}{ LEGEND } \\
$\square$ & Work Zone Area \\
DL & Driving Lane \\
PL & Passing Lane \\
\hline
\end{tabular}

h) Legend

Figure 9-2 Overview of Project Work Zone Location and Staging 
In order to maintain traffic in existing lanes while building segments of the median bridges, existing bridge lanes were reduced to $28 \mathrm{ft}$ from the $30 \mathrm{ft}$ original configuration (Figure 9-3 \& Figure 9-4). Grading and paving of median on-ramp access was also required.

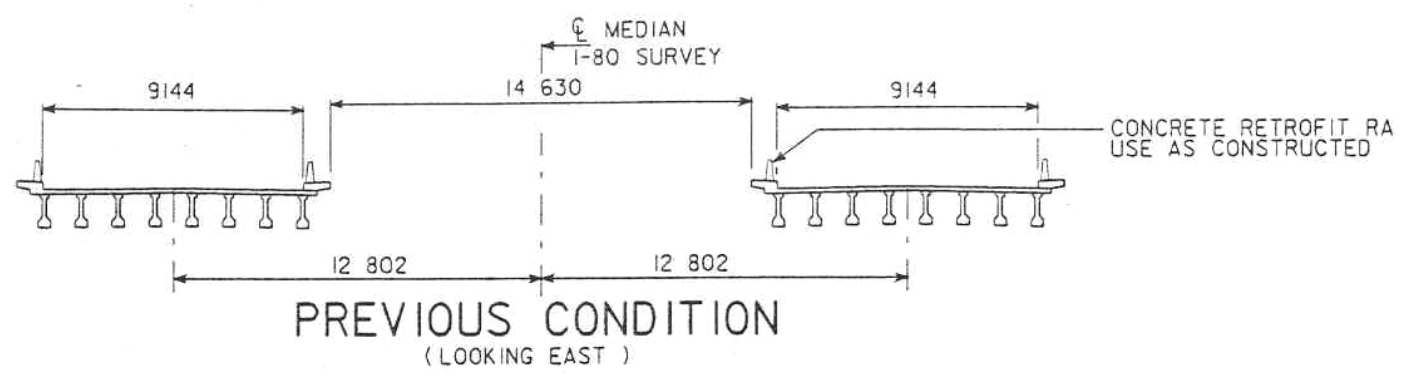

Figure 9-3 Project \# 2: Stage 1A Previous Bridge Dimensions

(Source: lowa DOT (2001a))

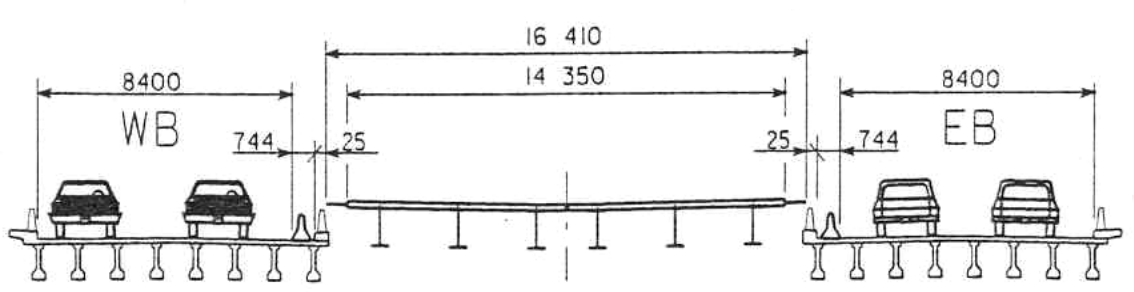

Figure 9-4 Project \# 2: Reduction of Bridge Dimensions during Stage 1A

(Source: lowa DOT (2001a))

\section{5. $\quad$ Subproject \# 3}

Subproject \# 3 consisted of the construction and completion of the median lanes. The Cedar Valley Corporation was awarded the contract for this $\$ 13.5$ million dollar project. The project started in April 1999 and was completed in November 1999. All the activities conducted on this subproject were dependent on the completion of the shoulder strengthening of subproject \# 1. This subproject was further subdivided into two different stages of work: Stages 1A, and 1B. Each one of these stages will be further analyzed by describing the traffic and construction operations During stage $1 \mathrm{~A}$, existing traffic on both directions was shifted to the already strengthened shoulders completed in subproject \# 1. The median and the existing passing lanes were enclosed as the work zone area. The key construction operations in this stage consisted of grading and 
paving of the entire median section. See Figure 9-5. In addition, minor grading and paving works were performed. These works included patching and extension of box culverts, as well as grading and paving portions of the I-35/80 on-and-off ramps on both EB/WB approaches.

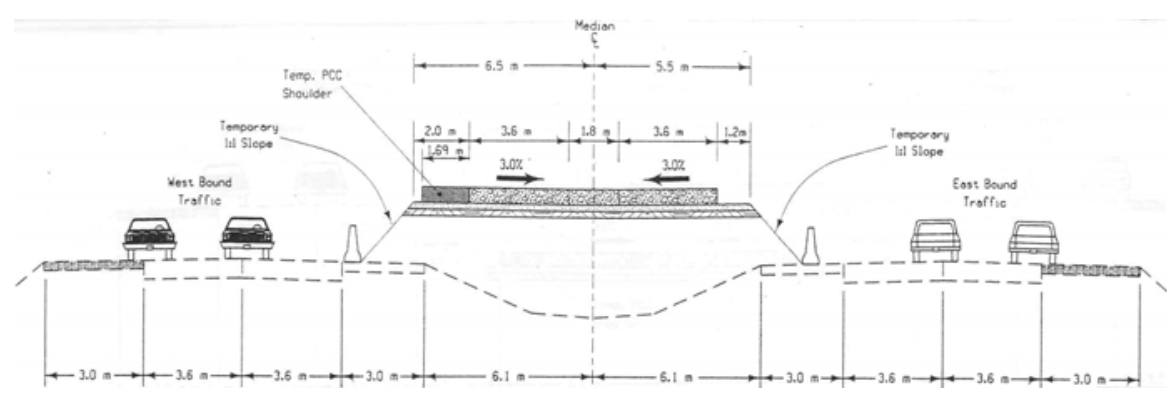

Figure 9-5 Project \# 2: Grading and Paving of Median Section

(Source: lowa DOT (2001a))

In stage $1 \mathrm{~B}$, the traffic in the eastbound (EB) direction was shifted to the completed median section (Figure 9-5). The westbound (WB) traffic remained on existing WB lanes. Due to the placement of traffic on existing median, no access was available to SB I-235. Traffic was detoured to primary roadways. Major construction operations performed included temporary pavement for on-and-off ramps on the eastbound approach.

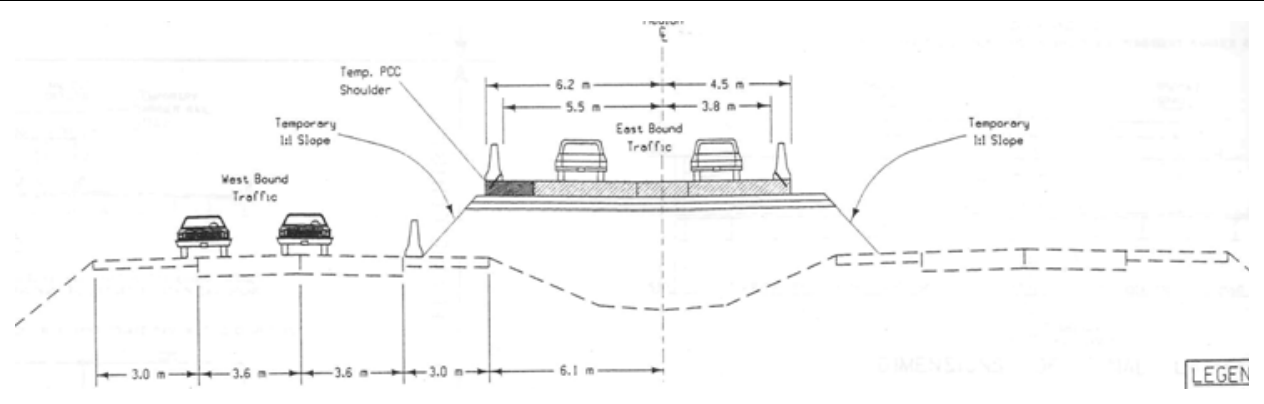

Figure 9-6 Project \# 3: Final Placement of Traffic on Stage 1C

(Source: lowa DOT (2001a))

\section{6. $\quad$ Subproject \# 4}

Subproject \# 4 consisted of the construction and completion of the outside lanes and bridges. The Cedar Valley Corporation was also awarded the contract for this project. Total cost of the project was approximately $\$ 37.9$ million. The project was awarded in January 2000 and construction 
started in March 2000. The project was completed by November 2000, a year ahead of schedule. Similar to subproject \# 3, this subproject was subdivided into different stages of work. Stages $1 \mathrm{~A}$, $B$ and $C$ related to construction activities conducted on the eastbound lanes. Stages $2 A, B, C$ and D comprehended activities on the westbound lanes. Stages $3 \mathrm{~A}$ and $\mathrm{B}$ consisted of the final placement of traffic.

During Stage $1 \mathrm{~A}$, the eastbound traffic was maintained on the median lanes. Westbound traffic remained on existing WB lanes. Construction operations on this stage included temporary pavement for on-and off ramps along the eastbound direction. During Stage 1B eastbound traffic remained on the median lanes. The reconstruction of bridges completed in this stage, involved the removal of the existing bridge and the construction of new bridges. In addition, grading and paving operations were also conducted during this stage. Table 9-1 presents a summary of these grading and paving operations conducted on the EB direction.

Table 9-1 Project \# 4: Summary of Pavement Grading and Replacing Operations for Stages 1B \& 2B

\begin{tabular}{|c|c|c|c|}
\hline & \multicolumn{2}{|c|}{ Milepost (approx.) } & $\begin{array}{c}\text { Distance } \\
\text { Paved (mi) }\end{array}$ \\
\cline { 2 - 4 } & Start & End & 0.5 \\
\hline \hline \multirow{3}{*}{ STAGES } & 134.9 & 135.4 & 0.4 \\
\cline { 2 - 4 } 1B \& 2B & 136.1 & 136.4 & 0.3 \\
\cline { 2 - 4 } & 137.2 & 137.3 & 0.0 \\
\cline { 2 - 4 } & 137.3 & 137.4 & 0.1 \\
\hline \multicolumn{2}{|c|}{ Total Distance } & 0.9 \\
\hline
\end{tabular}

Table 9-2 Project \# 4: Summary of Paving and Grading Operations for Stages 1C \& 2C

\begin{tabular}{|c|c|c|c|}
\hline & \multicolumn{2}{|c|}{ Milepost (approx.) } & Distance \\
\cline { 2 - 4 } & Start & End & Paved(mi) \\
\hline \hline & 135.4 & 135.7 & 0.3 \\
\cline { 2 - 4 } & 135.7 & 135.9 & 0.2 \\
\cline { 2 - 4 } STAGES & 136.0 & 136.1 & 0.2 \\
\cline { 2 - 4 } 1C \& 2C & 136.4 & 136.7 & 0.3 \\
\cline { 2 - 4 } & 136.8 & 137.0 & 0.2 \\
\cline { 2 - 4 } & 137.0 & 137.2 & 0.2 \\
\cline { 2 - 4 } & \multicolumn{2}{|c|}{ Total Distance } & 1.4 \\
\hline \multirow{2}{*}{}
\end{tabular}


During stage $1 \mathrm{C}$, eastbound traffic was still maintained on the median lanes. During this stage, remaining bridges along the mainline on the eastbound approach are reconstructed. In addition, more grading and paving work is completed. Table 9-2 shows a detailed summary of these operations, which were conducted throughout this stage along the eastbound direction.

The I-35/80 reconstruction project included total reconstruction of two interchanges: a) I-35/80 with $2^{\text {nd }}$ Street and b) I-35/80 with $14^{\text {th }}$ street. One of the interchanges consisted of interstate I$35 / 80$ with $14^{\text {th }}$ street. This interchange located near Milepost 136 , consisted of two continuous welded steel girder bridges with an approximate length of $243 \mathrm{ft}$. Both bridge decks were in need of reconstruction. Problems had been encountered with commercial vehicles traveling along this route and hitting the overpass due to a height restriction limit. Consequently, bridges over $14^{\text {th }}$ street, which also serves as State Route 69 , were raised to minimize the number of accidents. In Figure 9-7a, an aerial photograph of the interchange before construction is presented. In Figure $9-7 b$, the interchange configuration after the project was completed is presented. As it can be seen, the interchange was reconstructed to a partial cloverleaf layout. 


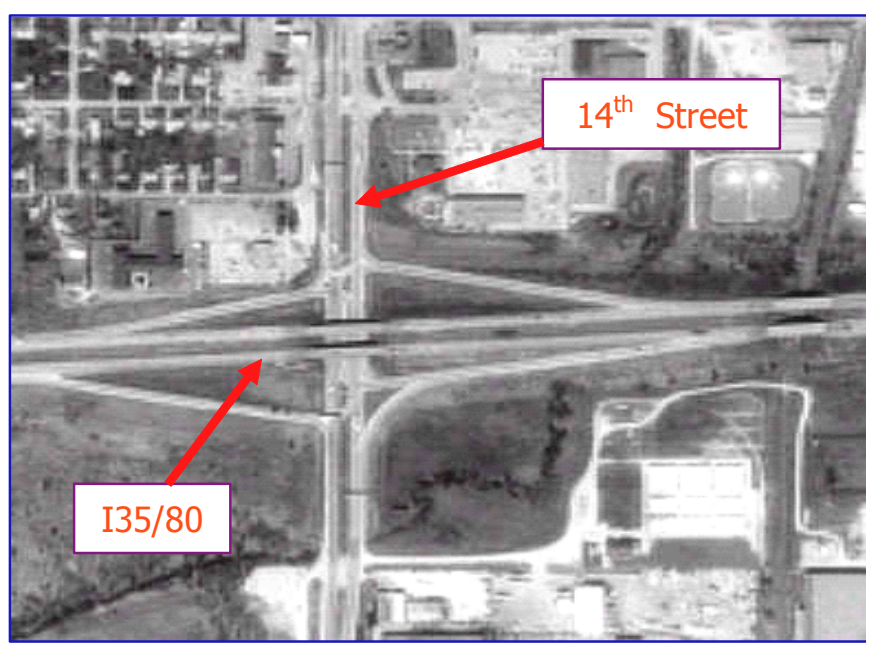

a) Before Construction

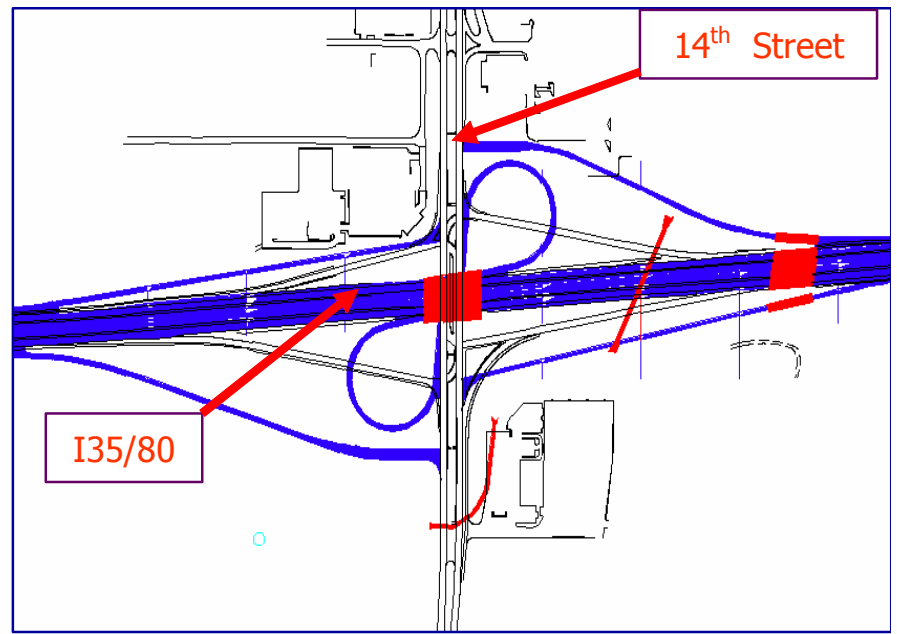

b) After Construction (Source: Iowa DOT(2001b))

Figure 9-7 14th Street Interchange

The cost of completing both of these steel bridges (Figure 9-8) was $\$ 1.36$ million dollars. According to quantity takeoff numbers provided by the lowa DOT officials, 551 cubic yards of concrete and approximate 440, $000 \mathrm{lbs}$ of structural steel were utilized. One important construction issue encountered during the construction of this interchange, was the median bridge reinforcement bars. These bars (2-ft long) had been left sticking out, and it was considered not to be safe for the traveling public. Couplers were required for tying the rebar of the median 
with the outside bridges. These mechanical connectors were used for reinforcing bar splices and proved to be very effective and safer for motorists.

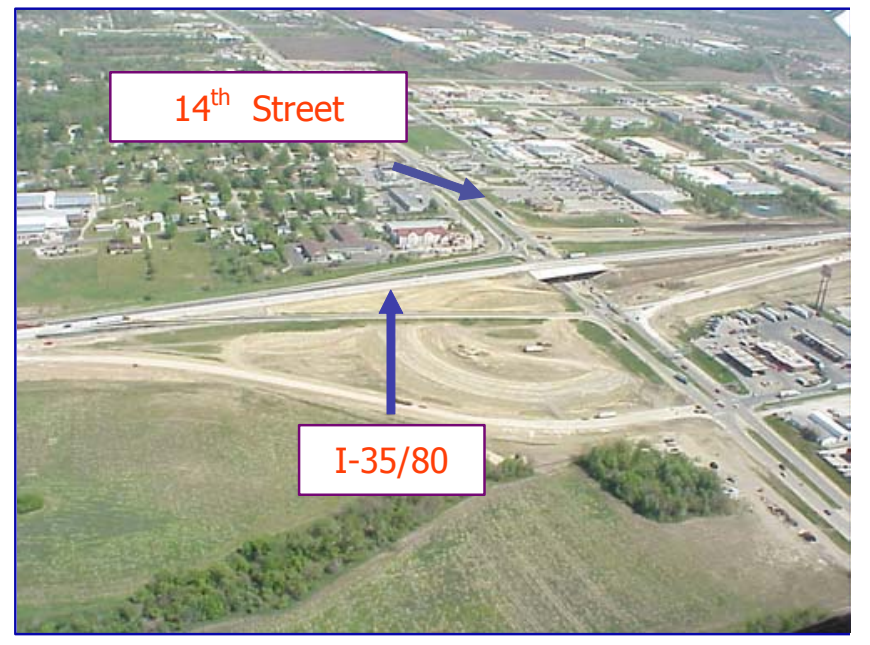

a) I-35/80 and $14^{\text {th }}$ Street Interchange (Source: lowa DOT(2001b))

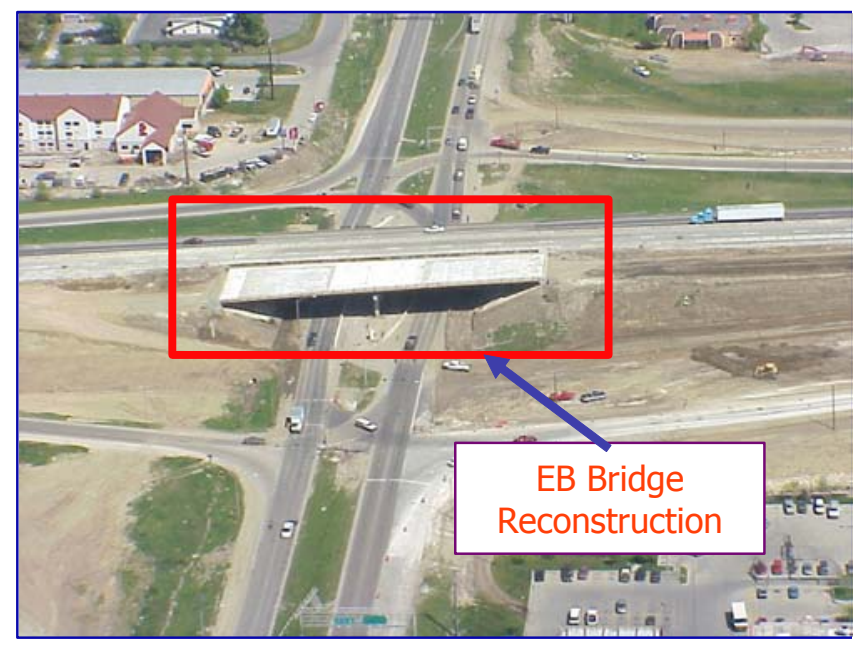

b) New I-35/80-Eastbound Bridge (Source: lowa DOT(2001b))

Figure 9-8 14th Street Interchange - Bridge Reconstruction

In preparation for stages 2 and after, construction work commenced on the westbound exit ramp bridges. Finally, the eastbound detour on-and-off ramps were removed.

During stage $2 A$, WB traffic was placed on median pavement and eastbound traffic was placed on the completed EB lanes. Temporary pavement was placed for on-and-off westbound ramps 
along two of the exit ramps. Stage $2 \mathrm{~B}$, consisted of construction of the bridge at $3^{\text {rd }}$ street (MP 136). Grading and paving for the same distances presented in Stage 1B (Table 9-1) are completed but in the opposing direction (westbound direction).

Figure 9-9 Project \# 4: Final Placement of Traffic Stage 3B

(Source: lowa DOT (2001a))

Stage 2C followed the same traffic operations for Stage 2A. Construction of bridges was continued along the mainline. Grading and paving operations were completed for the same distances as in stage 1C (Table 9-2) but in the other direction. At the end of this stage, the I-235 NB I-35/80 WB was reopened to traffic.

The final stages of the project ( $3 \mathrm{~A}$ and $3 \mathrm{~B}$ ) correspond to the placement of traffic on the permanent lanes. Throughout stage $3 \mathrm{~A}$ eastbound traffic and westbound traffic used the two outer lanes. The traffic was shifted $15 \mathrm{ft}$ to the left so the barrier rails could be constructed. During this stage the reminder of grading and paving operations were completed in order to tie-in MP 137.4 with existing lanes. The construction of permanent barrier railing in the median was also completed in this stage. Stage $3 \mathrm{~B}$ is the final stage of the project. All three lanes were open to normal traffic operations (Figure 9-9). No construction activities were performed in this stage and the project was successfully completed in November 2000.

\subsection{Summary}

Table 9-3 presents a summary of the project. The stages of work are divided into work performed on traffic lanes and bridgework. For example, subproject \# 4: Stage 1A had work performed on both traffic lanes and bridges. The traffic lanes work consisted mainly of reconstruction (grading and paving) and the bridgework consisted of reconstruction (removal of existing and construction of new bridge). To better understand the staging of the project, Figure 9-10 is presented. This figure shows the typical scopes of work performed during the entire period of the project. This figure shows, the timeframe required for completing the bridges on the I-35/14th Street 
interchange. As it can be seen, this process involved three construction periods and several modifications and shifting of traffic on the interstate.

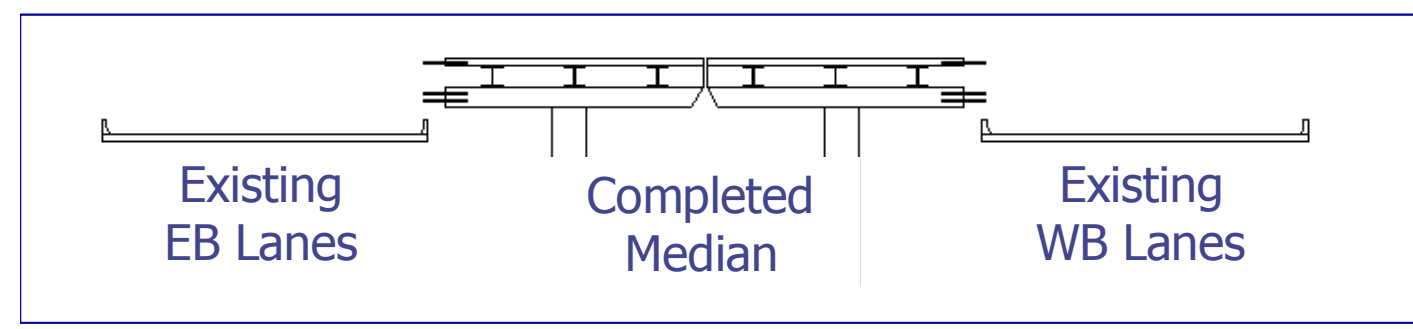

Winter 1998/ Spring 1999: Median bridges

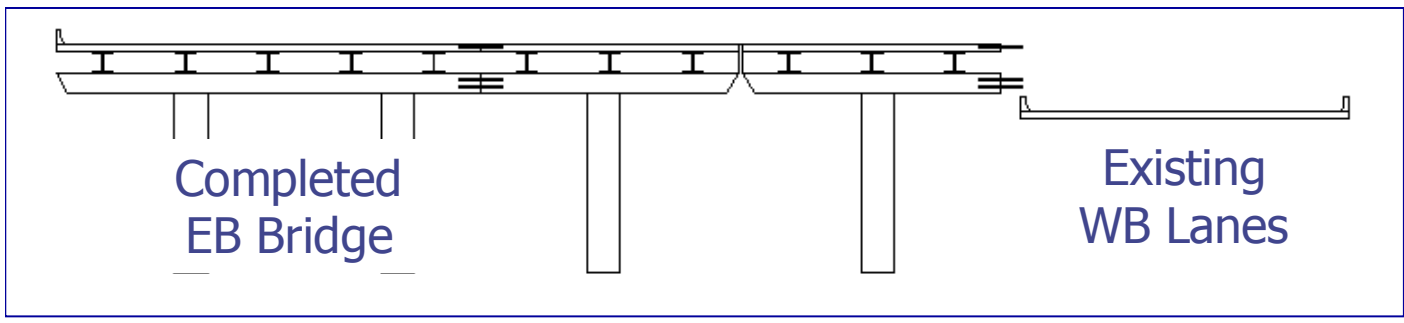

Spring 2000: EB Construction

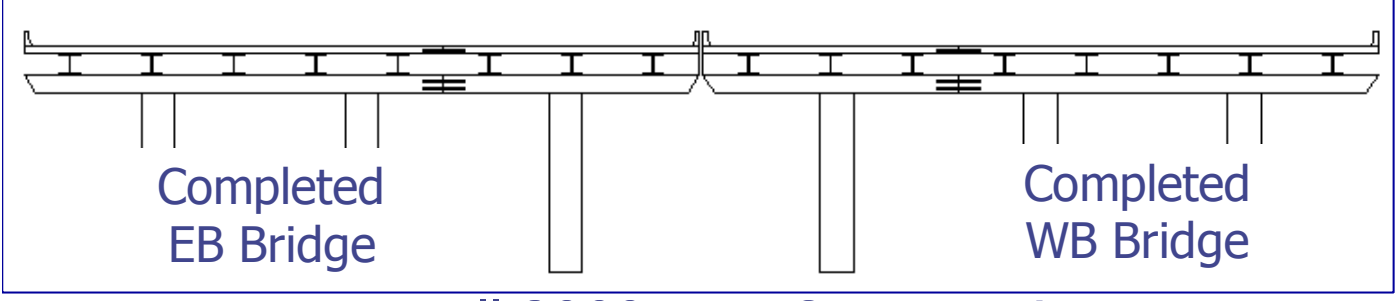

Fall 2000: WB Construction

Figure 9-10 Project Staging (Source: lowa DOT (2001c))

By implementing this multilane closure strategy the lowa DOT has completed a project where two additional lanes have been added. The total cost of the project described herein was $\$ 56.5$ million. To meet future demand of capacity and mobility, the Department of Transportation designed the distribution of lanes in such a manner that if required an additional 2-lanes can be added for a total of 8-lanes, without any additional construction. The only requirement will be shifting the pavement markings.

The lowa DOT and the Cedar Valley Corporation received the 2001 Excellence in Concrete Paving Award for traffic management and traffic safety from the American Concrete Pavement 
Association (ACPA) (http://www.pavement.com). The I-35/80 project in Des Moines exemplifies a new approach implemented recently by some transportation agencies. Typically, shoulders are not constructed with sufficient structural capacity to resist normal traffic. It is beneficial to spend the upfront cost in strengthening the shoulders to address capacity issues as well as to minimize the delays in future maintenance projects. Agencies can maintain normal traffic operations by avoiding lane closures if shoulders have already been strengthened. These modifications represent greater benefits for motorists during work zone operations as well as during normal traffic operations.

Table 9-3 Interstate 1-35/80 Project Summary

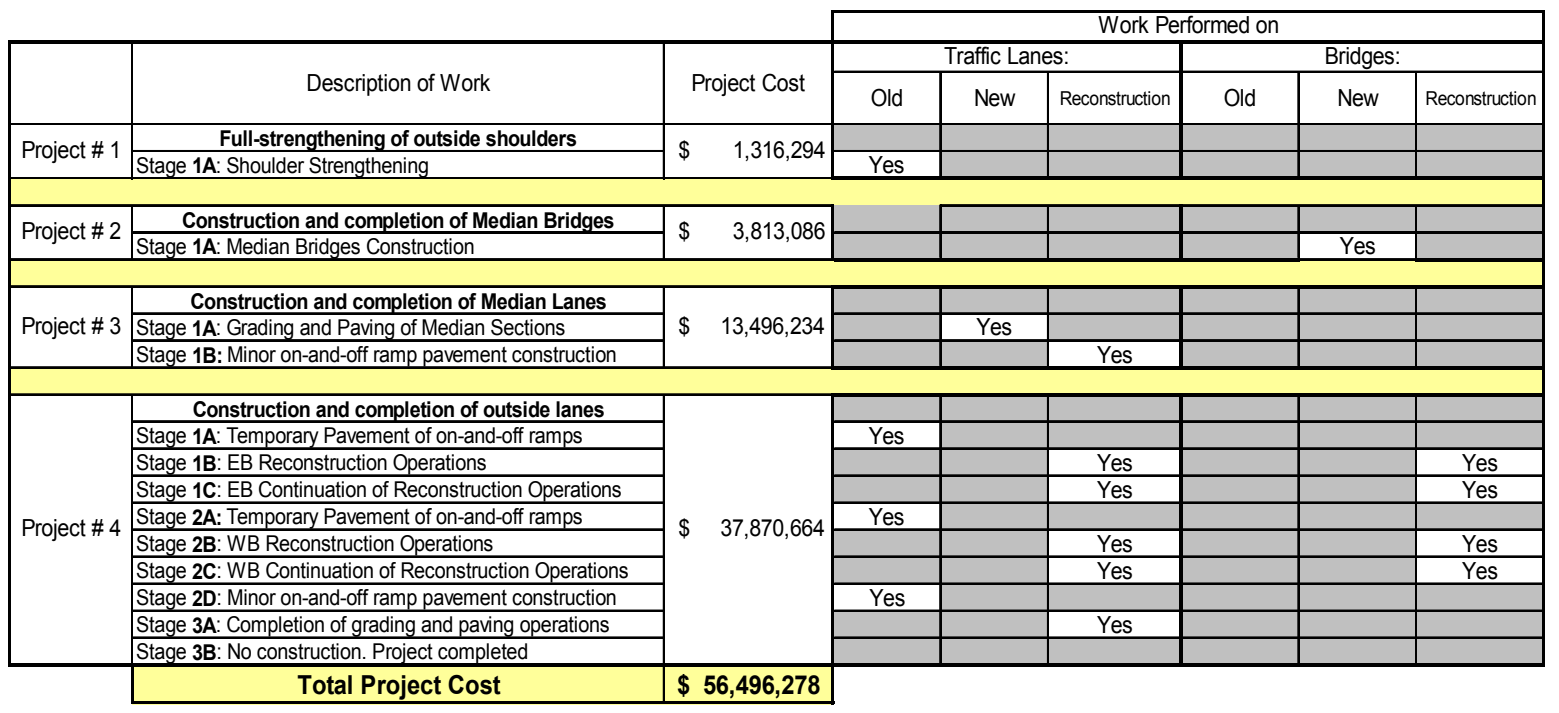

\section{8. $\quad$ Application for Indiana Projects}

The case study presented in this chapter, provides several findings which can be used to successfully complete similar projects in the state of Indiana. The project in lowa was conducted through several seasons in the winter 1998- fall 2000 period. The importance of breaking down tasks in order to lessen the impact in traveling conditions for the public is critical. This project was conducted during three construction seasons, and the staging of both traffic and construction activities was developed accordingly. One of the most important attributes of this project was the maintenance of two traffic lanes open at all times. 
By maintaining the same number of lanes, motorists are less confused because changes in traveling conditions are kept to a minimum. In addition, the capacity of the interstate segment is adequate to meet the existing and future demand. Benefits associated with reducing the impact on capacity during the different constructions seasons are immediate. If capacity is adequate to meet demand, less congestion will generate thus minimizing the likelihood of accident occurrences (in particular rear end crashes) which are common occurrence during work zones. The lowa reconstruction project was constructed in a segment of interstate with a typical ADT of 63,000 vehicles per day. It was therefore imperative to maintain the traffic lanes fully operational. Based on information provided by the engineers involved in the project, during the entire construction project no fatalities were associated with the work zone.

The most important construction processes worth analyzing are the activities associated with the bridge construction. In this case, the use of mechanical couplers as devices to tie-in the rebar within bridges that were constructed in separate periods was very beneficial. The staging associated with the construction was also instrumental in improving the safety for both motorists and construction workers. The high number (twelve) of bridges and the interchanges (two) require extensive coordination between the construction and traffic maintenance activities. Figure 9-10 can be used as a guideline to develop the staging process for bridge construction.

Strengthening the shoulders prior to commencement of the actual project was proven to be beneficial. Project \# 1 as described in the case study, presented includes the shoulder strengthening part of the project. Traffic was shifted to the outer lanes while work was being performed in the median. The work zone area was enclosed, and by strengthening the shoulders serviceability of the interstate segment under construction was maintained throughout the project life. The total cost for this part of the project was $\$ 1.3$ Million and provides clear benefits to the construction project.

The Building for the Future Approach as described herein exemplifies long term benefits to Departments of Transportation. Strengthening the shoulders and constructing additional lanes of traffic to accommodate future demand represents a proactive approach. Benefits are clear for both motorists and the Departments of Transportation. Disruptions during maintenance operations will be reduced. Interstates are constructed to accommodate traffic and if necessary by shifting it to the strengthened shoulder, maintenance operations can be completed with minimal impact on motorists. Additional lanes of traffic will provide sufficient capacity to accommodate demand and minimize the number of inconveniences to the public. Based on funds 
availability, if the Building for the Future Approach is implemented, then the state of Indiana will be prepared for the increase in the volume of traffic on rural interstates 


\section{CHAPTER 10. CONCLUSIONS AND RECOMMENDATIONS}

\section{1. $\quad$ Conclusions}

A review of current work zone practices in neighboring states and abroad was presented. The review of consisted of analyzing the practices of five Midwestern states (Indiana, Illinois, Michigan, Kentucky and Ohio) as well as current European work zone practices. The review indicated that: 1) INDOT lags behind other Departments of Transportation because it lacks a formal queue prediction method, and 2) the funding of work zone special patrols has been consistently used throughout the other states analyzed.

An extensive evaluation of several traffic management technologies that are currently available was presented. The systems analyzed have been designed to inform the traveling public of the changing conditions during periods of construction work on interstates. These technologies have been proven effective as dissemination tools for informing motorists of the conditions that lie ahead. However, these systems were not found to be associated with an improvement of safety on interstate work zones. The spacing between sensors and the limitation in communications influences the information that is being displayed to motorists. The benefits of these systems can sometimes be outweighed by their costs if such systems are not deployed appropriately.

Data from sixteen (16) interstate projects in the state of Indiana were analyzed in an effort to quantify the increment of these occurrences during periods of work. Data was analyzed for the period of construction and the same period one year prior to the construction period when construction was not taking place. As presented in this report, the findings of this analysis showed the accident rate increases by twenty seven and one half percent $(27.5 \%)$ when construction is present. The high consistency of the regression value $(0.995)$ obtained showed high confidence on the results obtained.

To inform drivers well in advance of the work zone of the construction activities taking place, a pilot project was initiated in the I-65/US-30 interchange reconstruction project near Merrillville, IN. Deployment of the experimental signs consisted of fixed panel signs and Variable Message Signs (VMS) prior to entering the work zone. The panel signs used included a combination of signs 
presently used by INDOT. The VMS displayed the number of traffic citations issued to date in the work zone.

A speed study with the goal of determining the effectiveness of the experimental signs deployed for the I-65/US-30 interchange reconstruction project near Merrillville, IN has been presented. The experimental signs consisted of fixed panel signs and Variable Message Signs (VMS) prior to entering the work zone. The panel signs consisted of a combination of signs presently used by INDOT. The VMS displayed the number of traffic citations issued to date in the work zone. The results of the speed study indicated that the installation of the panel signs had significant reduction (greater than $5 \mathrm{mph}$ ) only at the US-30 interchange. This speed reduction was associated with the installation of the fixed panel signs, rather than with the installation of the Variable Message Signs displaying the number of tickets. The results also indicated that displaying the number of tickets issued to date did not have a significant impact on the average speeds of motorists throughout the study area.

An enforcement study that was conducted in the I-65/US-30 work zone indicated that a significant reduction (greater than $5 \mathrm{mph}$ ) in the average speed occurred on I-65 adjacent to the trooper. This significant speed reduction remained in effect 1.2 miles downstream of the trooper, but was not present 2.4 miles downstream of the trooper. These results indicate that the benefits associated with allocating funds to support work zone special patrols in the state of Indiana are well spent.

A travel time study conducted using a GPS showed the benefits of utilizing such systems to document and reference conditions throughout the life of the work zone. The benefits of using GPS systems include the possibility of linking a type of lane restriction to its impact on traffic flow and use this knowledge in future construction seasons.

An economic model to determine the feasibility of maintaining two lanes open at all times during work zones was developed in terms of the costs of shoulder strengthening, temporary bridges, accidents and fatalities. The model provides INDOT with a preliminary tool for deciding if two lanes open should be maintained in a particular project. The model was validated by using one interstate project on I-65 in the state of Indiana. 


\subsection{Recommendations for Future Work}

Panel signs similar to those shown in Figure 5-7 were found to be effective at reducing speeds in the heart of the work zone. These signs should continue to be used in work zones. However, variable message signs similar to those shown in Figure 5-8 were not found to be effective at reducing speed, anywhere. Consequently, their use to reduce speeds can not be justified. More research is needed to determine the effectiveness and the criteria of messages to be displayed on the Variable Message Signs (VMS) in work zones.

Recommendations also include conducting regular monitoring of speeds in work zones as they relate to law enforcement visibility. Additionally, studies to evaluate the effectiveness of equipping construction engineers with Global Positioning Systems (GPS) to create a database to link the conditions encountered with the construction activities needs to be conducted. The study can also include equipping police officers with Global Positioning Systems to assist in more accurate location of accidents in work zones.

Future work should involve implementation of the economic model developed, in more work zone projects to determine its effectiveness and flaws. Incorporating differing conditions in the model such as urban vs. rural, vicinity to on/off ramps, etc will provide a model more applicable to different interstate projects. 
LIST OF REFERENCES 


\section{LIST OF REFERENCES}

Acrow Corporation of America (2002) "Company Literature" < http://www.acrowusa.com/> (September 20, 2002)

Adams, C (2002). Design Engineer, Florida DOT. Telephone Conversation. September 18, 2002

American Association of State Highway and Transportation Officials, A Policy on Geometric Design of Highways and Streets, AASHTO, Washington, D.C., 1994.Transportation Research Board. Highway Capacity Manual. Transportation Research Board Special Report 209, 3rd ed. Washington D.C.: TRB, 1997.

American Traffic Safety Services Association "Work Zone Statistics Reveal Record High Number of Fatalities" ATSSA 2001. <http://wzsafety.tamu.edu/press/atssa10-12-01.pdf> (August 12, 2002)

ASTI Transportation Systems (2001) "Computerized Highway Information Processing System (CHIPS ${ }^{\mathrm{TM}}$ ) Company Home Page" < http://www.asti-trans.com> (December, 2001)

Bailey Bridges, Inc (2002) "Company Literature" < http://www.baileybridge.com> (October 31, 2002)

Bhuvasorakul, J (2002) Structures Design Office, Florida DOT. Personal Communication. September 25, 2002

Brain, M and Harris, T (2002) "How Global Positioning Systems (GPS) Receivers Work" <http://www.howstuffworks.com/GPS> (July 9, 2002)

Braxton, M. Telephone Conversation. Office of Traffic Engineering, Work Zones, Ohio Department of Transportation. October 2001 
Cornett, S. Telephone Conversation. Director, Division of Traffic, Kentucky Transportation Cabinet. October 2001

Daniels, R and Huxford, R (2001) “Using Global Positioning Systems (GPS): How it Works, Limitation and Some Guidelines for Operation" Publication \# 00-06-015 Washington State, Olympia, WA January 16, 2001

Draijer, G, Kalfs, N and Perdok, J (2000).“Global Positioning System as Data Collection Method for Travel Research". Transportation Research Record, \#1719, TRB, National Research Council, Washington, DC, pp. 147-153,2000.

Dudek, Conrad L. and Stephen H. Richards, 1982. "Traffic Capacity Through Urban Freeway Work Zones in Texas", Transportation Research Record 869, p.14-18.

Dumke, L and Doyle, T (2001) "Intelligent Transportation Systems in Work Zones: Levering the Internet and Wireless Communications" "ITS America 2001" 11th Annual Meeting \& Exposition Intelligent Transportation Society of America June 4-7, 2001 Miami Beach Convention Center, Miami, Florida

Federal Highway Administration. FHWA 2001. "Work Zone Safety Facts". <http://safety.fhwa.dot.gov/programs/wsz.htm> (August 12, 2002))

FHWA (2002) "Revised Departmental Guidance: "Treatment of Value of Life and Injuries in Preparing Economic Evaluations "<http://ostpxweb.dot.gov/VS: background.htm> (November 4, 2002)

FHWA/Best Practice Policy (2002) <http://ops.fhwa.dot.gov/wz/wzguidbk/Documents/hp-fl5.htm> (September 16,2002)

Fors, C. (2000) "Work Zone Ahead: Reduce Speed," Roads and Bridges, Scranton Gillette Communications, Inc., Vol. 38, No. 1, pp. 58-61, January, 2000.

Foundation for Traffic Safety-AAA (2002) "Controlling Road Rage: A Literature Review and Pilot Study." <http://www.aaafoundation.org/resources> (May 23, 2002) 
Garber, N.J. and Ming Zhao, 2001. "Distribution and Characteristics of Crashes at Different Locations within Work Zones in Virginia", Transportation Research Board 2002 Annual Meeting

Goodwin, K. (1997) "RoboCrane Construction of Bridges". Transportation Research Record, Issue No. 1575, TRB, National Research Council, Washington, DC, pp. 42-46,1997.

Grossklaus, J. Telephone Conversation. Construction Technology Division, Michigan Department of Transportation. October 2001

Hall, J. W. and Lorenz, V. M. (1989). "Characteristics of Construction Zone Accidents," Transportation Research Record 1230, Transportation Research Board of the National Research Council, $20-27$.

Hauser, E and Massey, A (2001) "Best ITS Management Practices and Technologies for Ohio" Ohio Department of Transportation Columbus, OH Final Report FHWA/HWY-01/2002

ITS Decision (2002)"ITS Decision Report: Variable Message Signs" ITS Decision <http://www.path.berkeley.edu/ leap/> (May 23, 2002)

lowaDOT (2002a) “I-35/80 Reconstruction Project Contract Documents” March 2002

lowaDOT (2002b) "Personal Communication with Mark Borttle (Office of Construction)" February 2002

lowaDOT (2002c) "Personal Communication with Deanna Mayfield(Construction Engineer)" March 2002

Indiana Department of Transportation (2002). County Flow Maps.

$<$ http://www.ai.org/dot/roadway/counties.htm> (November 2001)

Jiang, Y and Shuo, L (2002) "Measuring and Analyzing Vehicle Position and Speed Data at Work Zones by Using Global Positioning Systems". ITE Journal. March 2002 Page 48-53 
Kamyab, A Et. Al. (2000) "Evaluation of Speed Reduction Techniques at Work Zones." Proceedings of Mid-Continent Transportation 2000 Symposium, Ames, lowa, lowa State University. May 15-16, 2000, 189-192

Manual on Uniform Traffic Control (2001) FHWA, <http://mutcd.fhwa.dot.gov> (April 1, 2002)

Mabey Bridge \& Shore, Inc (2002) "Company Literature" < http://www.mabey.com> (October 31, 2002)

May, Adolf D., Traffic Flow Fundamentals, Prentice-Hall, Inc., Englewood Cliffs, New Jersey, 1990.

Middleton, D and Parker, R (2000) "Initial Evaluation of Selected Detectors to Replace Inductive Loops on Freeways", Research Report 1439-7. Texas Transportation Institute, College Station, TX

Miller, J. and Karr D. (1998)."Experimental Application of Global Positioning System to Locate Motor Vehicle Crashes: Impact on Time and Accuracy". Transportation Research Record, \#1625, TRB, National Research Council, Washington, DC, pp. 41-49,1998

Minnesota Guidestar (1996) "Test of Monitoring of Urban Vehicle Operations Using Non-Intrusive Technologies Volume 5, Task Three Report: Extended Field Tests" Minnesota Department of Transportation Minnesota Guidestar, St. Paul, MN, and SRF Consulting Group, Minneapolis, MN

MwSWZDI (2000) “Midwest States Smart Work Zone Deployment Initiative” Year One Report. <http://www.matc.unl.edu/research/MwSWZDI> (September 10, 2001)

Nam, D., J. Lee, P. Dunston and F. Mannering (1999). "Analysis of the impacts of freeway reconstruction closures in urban areas," Transportation Research Record 1654, Transportation Research Board of the National Research Council, 161-170

North Carolina DOT (2002) "I-95 Smartzone Application in Fayetteville, NC." (North Carolina DOT))

Parks, R (2002). Construction Engineer North Carolina DOT. Telephone Conversation. November 5, 2002 
PDP Associates (2001) "Company Literature" <http://www.pdpassociates.com> (November, 2001)

Quiroga, C. and Bullock, D (1999) "Measuring Control Delay at Signalized Intersections" Journal of Transportation Engineering, ASCE, Vol. 125, No. 4, pp. 271-280, July/August, 1999

Register (2002) "Real-Time Traffic Control System" ITS America, Long Beach, CA " "ITS America 2002" 12th Annual Meeting \& Exposition Intelligent Transportation Society of America April 29-May 2, 2002 Long Beach, California

Pfenning, E (2002). District One, Planning Ohio DOT. Telephone Conversation. September 7 , 2002

Schoenherr, J. Telephone Conversation. Bureau of Operations, Illinois Department of Transportation. October 2001.

Shaker, SM and Greenwald, JH (1994) "Modular Evolution" Civil Engineering. Vol. 64 No. 5 ASCE, 64-67

Sesny, R (2001) Telephone Conversation. Manager, Regulations and Control Section Pennsylvania Department of Transportation. September 3, 2001

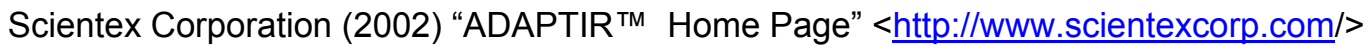
(January, 2002)

Steinke, D et. al (2000) "Methods and Procedures to Reduce Motorist Delays in European Work Zones" FHWA (Publication No. FHWA-PL-01-001) Washington, D.C

Teed, N. and Lund, A. K. (1993) "The Effect of Laser Speed-Measuring Devices on Speed Limit Law Enforcement in Charleston, South Carolina," Accident Analysis and Prevention, Pergamon Press, Vol. 25, No. 4, pp. 459-463, April, 1993.

Trafcon (2001) "Work Zone Alert and Information Radio (WIZARD) Company Literature" <http://www.trafcon.com/wizard.html> (December, 2001) 
Turner, D (1999) "What's a Work Zone?" Turner-Fairbanks Highway Research Center, McLean, VA < http://www.tfhrc.gov/pubrds/mayjun99/workzone.htm> (June 11, 2001)

United Rentals (2001) "Automated Information Management System (A.I.M.S.) Company Literature" <http://www.unitedrentals.com/> (November, 2001)

Van Gelder, B (2002) “Fundamentals of GPS for GIS” Indiana GIS Conference 2002. Indianapolis, IN March 2002.

World Highways (2001) "Keeping the Traffic Moving" Journal of World Highways/Routes Du Monde Vol. 10 No. 9 Route One Publishing, England. 100-101

Young, J (2002). Office of Traffic Engineering Ohio DOT. Telephone Conversation. October 15, 2002

Zwahlen, H (2001) "Evaluation of A Real-Time Travel Prediction System in a Freeway Construction Work Zone" Final Report March 2001, submitted to the Ohio Department of Transportation (ODOT). Columbus, $\mathrm{OH}$ 
APPENDIX 


\section{APPENDIX A. FLORIDA}

\subsubsection{Lane Closure Analysis}

The lane closure analysis is a process used by designers to calculate the peak hour traffic volume and the restricted capacity for open road and signalized intersections. The analysis will determine if a lane closure should or should not be allowed and the time of day or night a lane closure could occur without excessive travel delay.

For all projects under reconstruction, the existing number of lanes shall remain open to traffic when construction is not active.

For construction on Limited Access facilities, the Traffic Control Plan will keep the existing number of traffic lanes open at all times throughout the duration of the construction project.

No lane closures in excess of one work day shall be permitted on Limited Access construction where only two traveled lanes in one direction exist. If it becomes necessary to have a long-term lane closure on a four lane Interstate, sufficient documentation shall be provided to the District Secretary for her/his approval.

Exhibit 10-A includes the lane closure analysis work sheets and two sample analyses. The sample Lane Closure Work Sheet (Exhibit 10-A, Sheet 3 of 11) has been cross-referenced to the Lane Closure Symbols and Definitions sheets (Exhibit 10-A, Sheets 1 \& 2 of 11) with circled numbers. The circled numbers correspond to the numbers of the symbols and definitions. The symbols and definitions sheets show the designer where to find the necessary information to fill out the lane closure work sheet.

Fill out the top part of the lane closure work sheet and complete the formulas to calculate the hourly percentage of traffic at which a lane closure will be permitted (see Exhibit 10-A, Sheets 6 $\& 8$ of 11). Transfer these percentages to the graph on the Lane Closures 24 Hour Counts sheet (Exhibit 10-A, Sheet 5 of 11). Draw a line across the graph representing the percentage for both open road and signalized intersections (see Exhibit 10-A, Sheets $7 \& 9$ of 11). Plot the hourly percentages (hourly volume divided by total volume) on the graph. Any hourly percentage extending above the restricted capacity percentage lines for open road or signalized intersections indicated lane closure problems The bottom of the graph gives times for AM and PM. By coordinating the lane closure problem areas to the time of day, a designer knows when to restrict lane closure.

Many of Florida's roadways have directional peak hour traffic volumes, with inbound morning traffic, and outbound afternoon traffic. Doing a composite lane closure analysis would in many cases require night work. However, if a separate lane closure analysis is calculated for inbound and outbound separately, a lane closure may be allowed and the contractor could work in daylight hours, (See Exhibit 10-A, Sheets $10 \& 11$ of 11). 


\section{Exhibit 10-A Lane Closures \\ Sheet 1 of 11}

\section{Symbols and Definitions}

1. $\quad$ ATC $=$ Actual Traffic Counts. Use current traffic counts. Traffic counts can be obtained from the Office of Planning, or you may need to get traffic counts done. The designer needs hourly traffic volumes with a total traffic volume for a 24 -hour period (see Exhibit 10-A, Sheet 7 of 11).

2. $\quad$ P/D = Peak Traffic to Daily Traffic Ratio. Highest hourly volume divided by the total 24hour volume. Convert the percentage to a decimal on the Lane Closure Worksheet (see Exhibit 10-A, Sheet 7 of 11).

3. $\quad \mathbf{D}=$ Directional Distribution of peak hour traffic on multilaned roads. This factor does not apply to a two-lane roadway converted to two-way, one-lane. The directional distribution can be obtained from the Office of Planning.

4. $\quad$ PSCF $=$ Peak Season Conversion Factor. Many counties in Florida have a significant variance in seasonal traffic. The designer should use the PSCF for the week in which the actual traffic count was conducted. The Office of Planning has tables showing Peak Season Conversion Factors for every county in Florida. (See sample table of values on Exhibit 10-A, Sheet 4 of 11).

5. $\quad$ RTF $=$ Remaining Traffic Factor is the percentage of traffic that will not be diverted onto other facilities during a lane closure. Convert the percentage to a decimal on the Lane Closure Worksheet. This is an estimate that the designer must make on his own, or with help from the Office of Planning. Range: $0 \%$ for all traffic diverted to $100 \%$ for none diverted.

6. $\quad \mathbf{G} / \mathbf{C}=$ Ratio of Green to Cycle Time. This factor is to be applied when lane closure is through or within $600 \mathrm{ft}$. of a signalized intersection. The Office of Traffic Engineering has timing cycles for all traffic signals.

7. $\quad \mathbf{V}=$ Peak Hour Traffic Volume. The designer calculates the peak hour traffic volume by multiplying the actual traffic count, times peak to daily traffic ratio, times directional factor, times peak seasonal factor, times remaining traffic factor. This calculation will give the designer the expected traffic volume of a roadway at the anticipated time of a lane closure. 


\section{Exhibit 10-A Lane Closures, Sheet 2 of 11 \\ Symbols and Definitions (Continued)}

8. $\quad \mathbf{C}=$ Capacity of a $2 \mathrm{~L}, 4 \mathrm{~L}$ or $6 \mathrm{~L}$ roadway with one lane closed, and the remaining lane(s) unrestricted by lateral obstructions. The capacity of a $4 \mathrm{~L}$ or $6 \mathrm{~L}$ roadway is based on lane closure in only one direction (see Lane Closure Capacity Table on Exhibit 10-A, Sheet 3 of 11).

9. $\quad \mathbf{R C}=$ Restricting Capacity of the above facilities by site specific limitations detailed in the Traffic Control Plans (TCP) which apply to travel lane width, lateral clearance and the work zone factor. The work zone factor only applies to two lane roadways (see the tables on Exhibit 10-A, Sheet 4 of 11 to obtain the Obstruction Factor and Work Zone Factor).

10. OF = Obstruction Factor which reduces the capacity of the remaining travel lane(s) by restricting one or both of the following components: Travel lane width less than $12 \mathrm{ft}$. and lateral clearance less than $6 \mathrm{ft}$. (see TCP and Obstruction Factor Table in Exhibit 10-A, Sheet 4 of 11).

11. $\mathbf{W Z F}=$ Work Zone Factor $(\mathrm{WZF})$ is directly proportional to the work zone length (WZL). The capacity is reduced by restricting traffic movement to a single lane while opposing traffic queues. The WZF and WZL only apply to a two lane roadway converted to two way, one lane (see the Work Zone Factor Table on Exhibit 10-A, Sheet 4 of 11).

12. TLW = Travel Lane Width is used to determine the obstruction factor (see TCP and the Obstruction Factor Table on Exhibit 10-A, Sheet 4 of 11).

13. $\quad \mathbf{L C}=$ Lateral Clearance is the distance from the edge of the travel lane to the obstruction. The lateral clearance is used to determine the obstruction factor (see MOT plans and Obstruction Factor Table on Exhibit 10-A, Sheet 4 of 11). 
Exhibit 10-A, Lane Closures, Sheet 3 of 11

LANE CLOSURE WORK SHEET

FINANCIAL PRODUCT ID

FAP

NO:

COUNTY:

DESIGNER:

NO. EXISTING LANES:

SCOPE

OF

WORK:

Calculate the peak hour traffic volume (V)

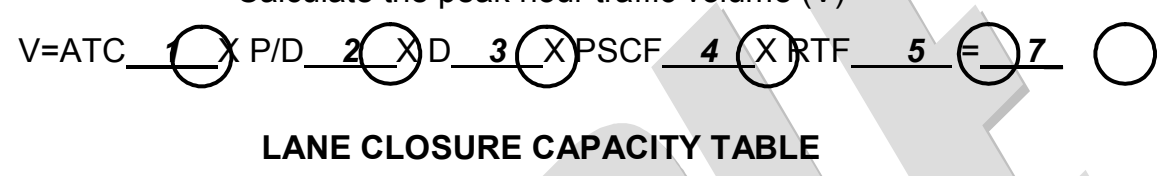

Capacity (C) of an Existing 2-Lane - Converted to 2-Way, 1-Lane $=1400 \mathrm{VPH}$

Capacity (C) of an Existing 4-Lane - Converted to 1-Way, 1-Lane $=1800 \mathrm{VPH}$

Capacity (C) of an Existing 6-Lane - Converted to 1-Way, 2-Lane $=3600 \mathrm{VPH}$

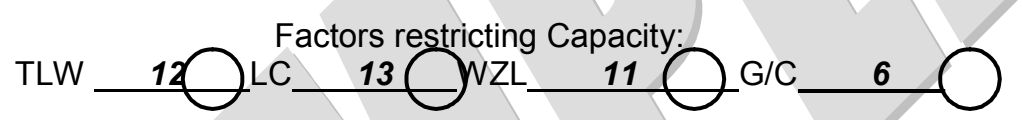

Calculate the Restricted Capacity $(\mathrm{RC})$ at the Lane Closure Site by multiplying the appropriate $2 \mathrm{~L}$, $4 \mathrm{~L}$, or $6 \mathrm{~L}$ Capacity (C) from the Table above by the Obstruction Factor (OF) and the Work Zone Factor (WZF). If the Lane Closure is through or within $600 \mathrm{ft}$. of a signalized intersection, multiply the RC by the G/C Ratio.

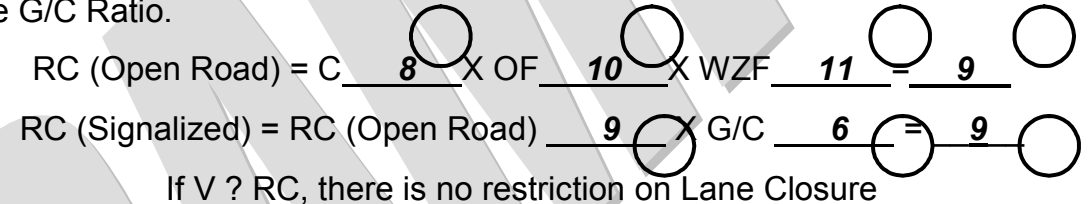

If $\mathrm{V}>\mathrm{RC}$, calculate the hourly percentage of ADT at which Lane Closure will be permitted

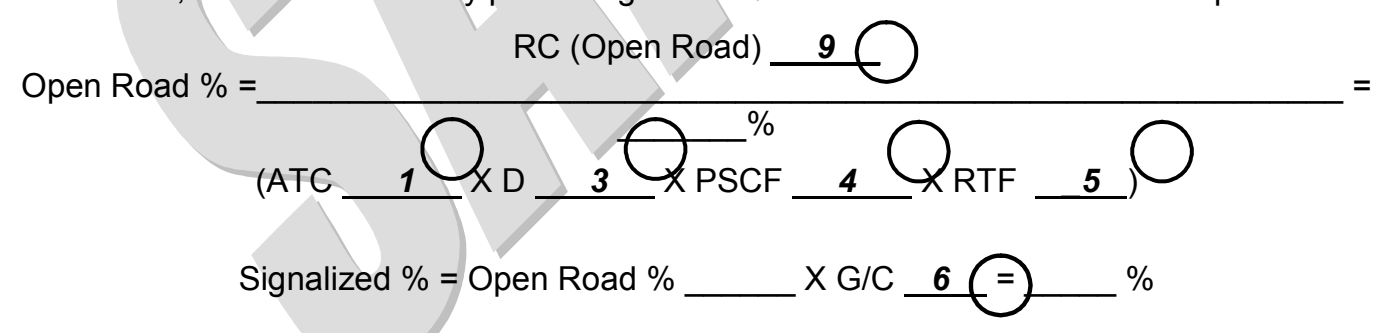

Plot 24 hour traffic to determine when Lane Closure permitted. (See Exhibit 10-A, Sheet 5 of 11)

NOTE: For Existing 2-Lane Roadways, $D=1.00$.

Work Zone Factor (WZF) applies only to 2-Lane Roadways.

For RTF $\quad<\quad 1.00, \quad$ briefly describe alternate route 
Exhibit 10-A, Lane Closures, Sheet 4 of 11

Lane Closures - Capacity Adjustment Factors

Peak Season Conversion Factor (PSCF) Sample

1998 Peak Season Factor Category Report for Tropic County

\begin{tabular}{|c|c|c|c|c|c|c|c|}
\hline WK & Dates & SF & PSCF & WK & Dates & SF & PSCF \\
\hline 9 & $02 / 22-02 / 28 / 98$ & 1.14 & 1.48 & 15 & $04 / 05-04 / 11 / 98$ & 0.86 & 1.12 \\
\hline 10 & $03 / 01-03 / 07 / 98$ & 1.04 & 1.35 & 16 & $04 / 12-04 / 18 / 98$ & 0.87 & 1.13 \\
\hline 11 & $03 / 08-03 / 14 / 98$ & 0.94 & 1.22 & 17 & $04 / 19-04 / 25 / 98$ & 0.90 & 1.17 \\
\hline 12 & $03 / 15-03 / 21 / 98$ & 0.83 & 1.08 & 18 & $04 / 26-05 / 02 / 98$ & 0.93 & 1.21 \\
\hline 13 & $03 / 22-03 / 28 / 98$ & 0.84 & 1.09 & 19 & $05 / 03-05 / 09 / 98$ & 0.96 & 1.25 \\
\hline 14 & $03 / 29-04 / 04 / 98$ & 0.85 & 1.11 & 20 & $05 / 10-05 / 16 / 98$ & 0.99 & 1.29 \\
\hline
\end{tabular}

Obstruction Factors (OF)

\begin{tabular}{|c|c|c|c|c|}
\hline \multirow{2}{*}{$\begin{array}{c}\text { Lateral Clearance } \\
\text { (LC) (feet) }\end{array}$} & \multicolumn{4}{|c|}{ Travel Lane Width (TLW) (feet) } \\
\cline { 2 - 5 } & $\mathbf{1 2}$ & $\mathbf{1 1}$ & $\mathbf{1 0}$ & $\mathbf{9}$ \\
\hline 6 & 1.00 & 0.96 & 0.90 & 0.80 \\
4 & 0.98 & 0.94 & 0.87 & 0.77 \\
2 & 0.94 & 0.90 & 0.83 & 0.72 \\
0.0 & 0.86 & 0.82 & 0.75 & 0.65 \\
\hline
\end{tabular}

Work Zone Factors (WZF)

\begin{tabular}{|c|c|c|c|c|c|}
\hline WZL (ft.) & WZF & WZL (ft.) & WZF & WZL (ft.) & WZF \\
\hline 200 & 0.98 & 2200 & 0.81 & 4200 & 0.64 \\
400 & 0.97 & 2400 & 0.80 & 4400 & 0.63 \\
600 & 0.95 & 2600 & 0.78 & 4600 & 0.61 \\
800 & 0.93 & 2800 & 0.76 & 4800 & 0.59 \\
1000 & 0.92 & 3000 & 0.74 & 5000 & 0.57 \\
1200 & 0.90 & 3200 & 0.73 & 5200 & 0.56 \\
1400 & 0.88 & 3400 & 0.71 & 5400 & 0.54 \\
1600 & 0.86 & 3600 & 0.69 & 5600 & 0.53 \\
1800 & 0.85 & 3800 & 0.68 & 5800 & 0.51 \\
2000 & 0.83 & 4000 & 0.66 & 6000 & 0.50 \\
\hline
\end{tabular}

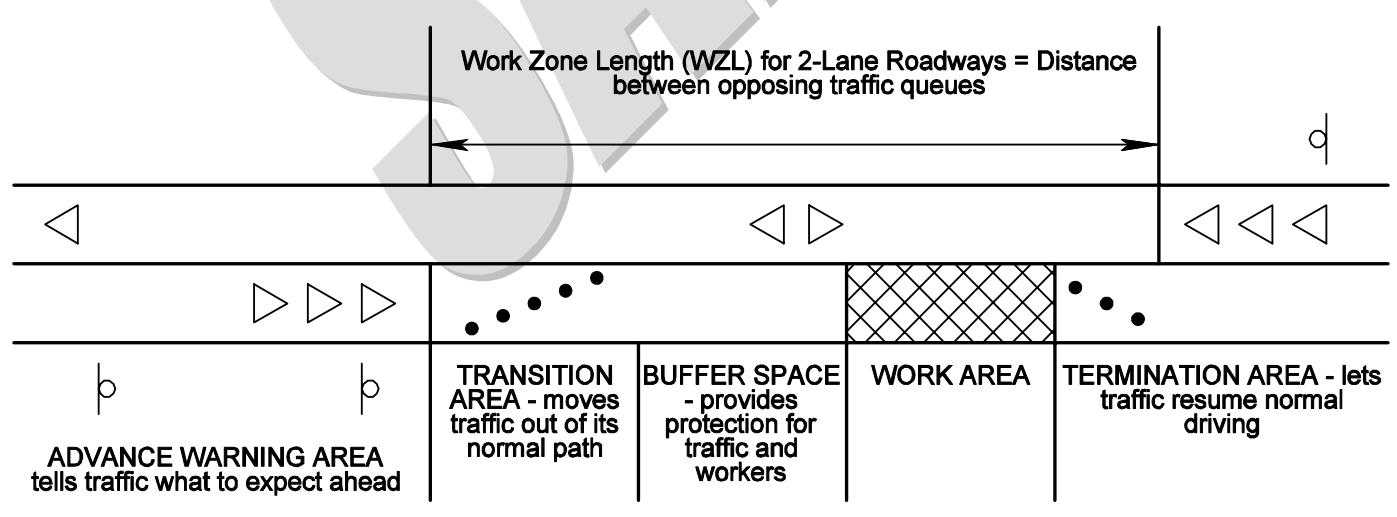


Exhibit 10-A, Lane Closures, Sheet 5 of 11

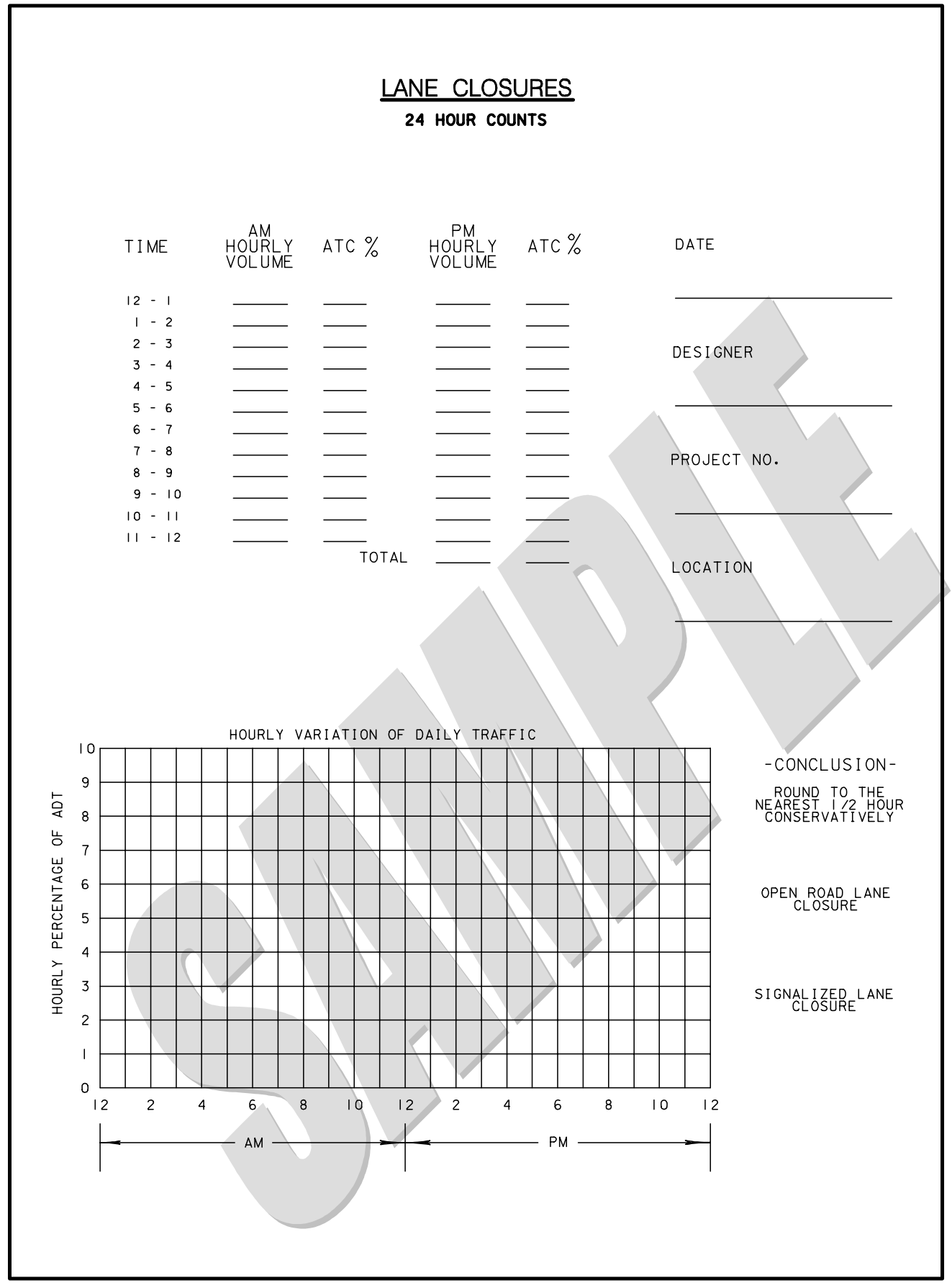




\section{Exhibit 10-A, Lane Closures, Sheet 6 of 11}

LANE CLOSURE WORKSHEET

FINANCIAL PRODUCT ID: 123456-7-89-10

COUNTY: Tropic

NO. EXISTING LANES: 2
FAP NO.: $N A$

DESIGNER: Yates

SCOPE OF WORK: Widen and Resurface

\section{Calculate the peak hour traffic volume $(\mathrm{V})$ \\ $V=A T C \underline{15000} \times$ P/D $\underline{0.083} \times D \underline{N A} \times$ PSCF $\underline{1.17} \times$ RTF $\underline{0.75}=\underline{1092}$ \\ LANE CLOSURE CAPACITY TABLE \\ Capacity (C) of an Existing 2-Lane - Converted to 2-way, 1-Lane $=1400 \mathrm{VPH}$ \\ Capacity (C) of an Existing 4-Lane - Converted to 1-way, 1-Lane $=1800 \mathrm{VPH}$ \\ Capacity (C) of an Existing 6-Lane - Converted to 1-way, 2-Lane $=3600 \mathrm{VPH}$}

$$
\text { TLW } 10 \text { Factors restricting Capacity: }
$$

Calculate the Restricted Capacity $(\mathrm{RC})$ at the Lane Closure Site by multiplying the appropriate $2 \mathrm{~L}$, $4 \mathrm{~L}$, or $6 \mathrm{~L}$ Capacity $(\mathrm{C})$ from the table above by the Obstruction Factor (OF) and the Work Zone Factor (WZF). If the Lane Closure is through or within $600 \mathrm{ft}$. of a signalized intersection, multiply the RC by the G/C Ratio.

$$
\begin{aligned}
& \text { RC (Open Road) = C } 1400 \times \text { OF } \quad 0.87 \times \text { WZF } \quad 0.82=\underline{999} \\
& \mathrm{RC}(\text { Signalized })=\mathrm{RC}(\text { Open Road) } 999 \times \mathrm{G} / \mathrm{C} \quad 0.64=639
\end{aligned}
$$

If $\mathrm{V}$ ? $\mathrm{RC}$, there is no restriction on Lane Closure

If $\mathrm{V}>\mathrm{RC}$, calculate the hourly percentage of ADT at which Lane Closure will be permitted

Open Road \% $=\frac{\operatorname{RC}\left(\text { Open Road) } \frac{999}{\%}\right.}{(\text { ATC } \underline{15000} \times D \underline{1.00} \times \text { PSCF } \underline{1.17} \times \text { RTF } \underline{\mathbf{0 . 7 5}})}=\underline{\mathbf{7 . 5 9}}$

Signalized $\%=$ Open Road $\% \underline{7.59} \times$ G/C $\underline{0.64}=\underline{4.86} \%$

Plot 24 hour traffic to determine when Lane Closure permitted. (See Exhibit 10-A, Sheet 7 of 11)

NOTE: For Existing 2-Lane Roadways, $D=1.00$.

Work Zone Factor (WZF) applies only to 2-Lane Roadways.

For RTF < 1.00 , briefly describe alternate route: $25 \%$ of existing traffic diverted on Bullard

Blvd., north on Newhall Lane, then east on Xanders Expressway.


Exhibit 10-A, Lane Closures, Sheet 7 of 11

\author{
LANE CLOSURES
}

24 HOUR COUNTS

\begin{tabular}{|c|c|c|c|c|c|c|}
\hline \multirow[t]{2}{*}{ TIME } & $\begin{array}{l}\text { AM } \\
\text { HOURLY } \\
\text { VOLUME }\end{array}$ & ATC $\%$ & $\begin{array}{l}P M \\
\text { HOURLY } \\
\text { VOLUUME }\end{array}$ & ATC $\%$ & \multicolumn{2}{|r|}{ DATE } \\
\hline & 160 & 1.1 & 960 & 6.4 & & APR 19,1998 \\
\hline $1-2$ & 990 & 0.6 & 830 & 5.5 & & \\
\hline $2-3$ & 30 & 0.2 & 810 & 5.4 & & DES I GNER \\
\hline $\begin{array}{l}3-4 \\
4-5\end{array}$ & $\frac{25}{30}$ & $\frac{0.2}{0.2}$ & $\frac{1080}{1190}$ & $\frac{7.2}{7.9}$ & $P / D$ & $\vee A T E G$ \\
\hline $\begin{array}{l}4-5 \\
5-6\end{array}$ & 130 & $\frac{0.9}{0.9}$ & 1240 & $\frac{1.7}{8.3}$ & $=.083$ & \\
\hline $6-7$ & 525 & 3.5 & 930 & 6.2 & & \\
\hline $7-8$ & 1135 & 7.6 & 680 & 4.5 & & PROJFCT NO \\
\hline $8-9$ & 910 & $\frac{6.1}{5.9}$ & 530 & 3.5 & & PRUJEC I NU. \\
\hline $9-10$ & 870 & 5.8 & 425 & 2.8 & & $12345-6789$ \\
\hline $\begin{array}{l}10-11 \\
11-12\end{array}$ & 960 & $\frac{3.4}{6.4}$ & 270 & $\frac{2.1}{1.8}$ & & \\
\hline & & TOTAL & 15,000 & 100 & & LOCATION \\
\hline & & & & & & BUCK LAKE RD。 \\
\hline
\end{tabular}

HOURLY VARIATION OF DAILY TRAFFIC

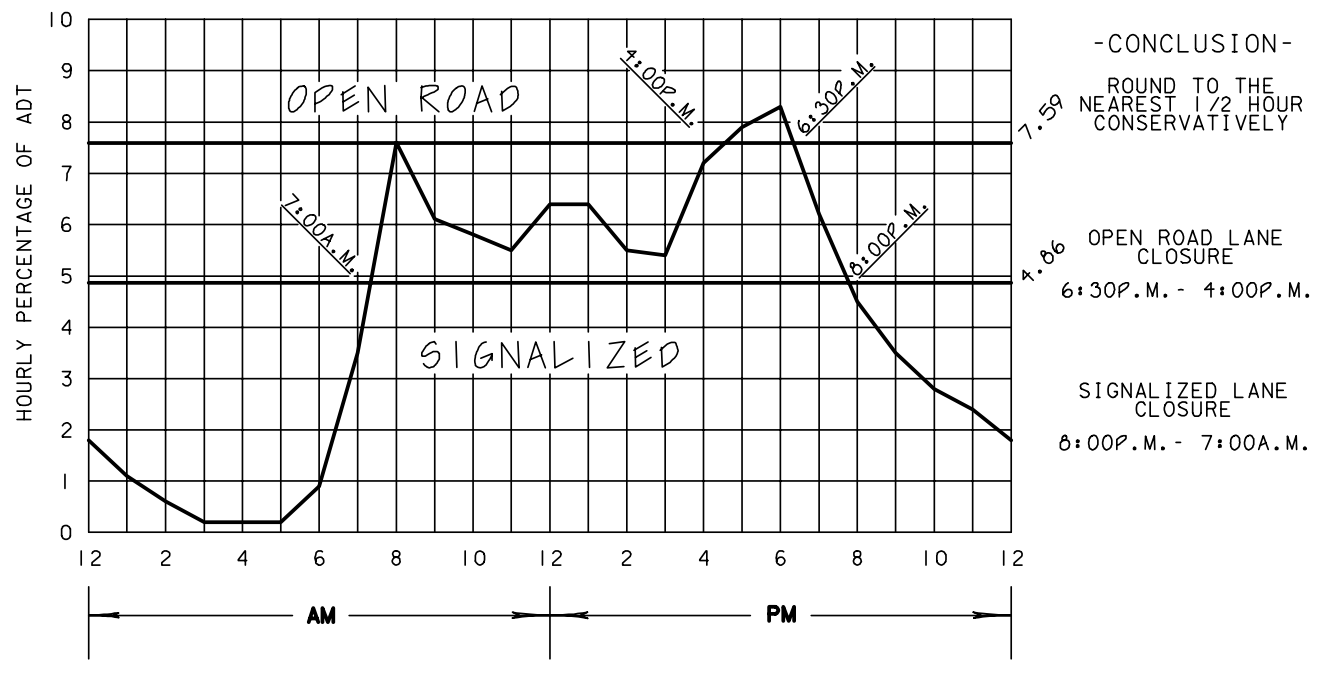




\section{Exhibit 10-A, Lane Closures, Sheet 8 of 11}

\section{LANE CLOSURE WORKSHEET}

FINANCIAL PRODUCT ID: 123456-7-89-10

COUNTY: Tropic

NO. EXISTING LANES: 2
FAP NO.: NA

DESIGNER: Giddens

SCOPE OF WORK: Resurface

\section{Calculate the peak hour traffic volume $(\mathrm{V})$ \\ $\mathrm{V}=\mathrm{ATC} \underline{\mathbf{3 0 0 0 0}} \times \mathrm{P} / \mathrm{D} \underline{\mathbf{0 . 0 8 3}} \times \mathrm{D} \underline{\mathbf{0 . 5 5}} \times \mathrm{PSCF} \underline{\mathbf{1 . 1 7}} \times \mathrm{RTF} \underline{\mathbf{1 . 0 0}}=\underline{1602}$ \\ LANE CLOSURE CAPACITY TABLE \\ Capacity (C) of an Existing 2-Lane - Converted to 2-way, 1-Lane $=1400 \mathrm{VPH}$ \\ Capacity (C) of an Existing 4-Lane - Converted to 1-way, 1-Lane $=1800 \mathrm{VPH}$ \\ Capacity (C) of an Existing 6-Lane - Converted to 1-way, 2-Lane $=3600 \mathrm{VPH}$

$$
\begin{aligned}
& \text { Factors restricting Capacity: } \\
& \text { TLW } 11 \text { LC } \quad 6 \text { WZL NA for } 4 L \text { G/C } \quad 0.74
\end{aligned}
$$

Calculate the Restricted Capacity $(\mathrm{RC})$ at the Lane Closure Site by multiplying the appropriate $2 \mathrm{~L}$, $4 \mathrm{~L}$, or $6 \mathrm{~L}$ Capacity (C) from the table above by the Obstruction Factor (OF) and the Work Zone Factor (WZF). If the Lane Closure is through or within $600 \mathrm{ft}$. of a signalized intersection, multiply the $R C$ by the $G / C$ Ratio.

$\mathrm{RC}($ Open Road) $=\mathrm{C} \underline{1800} \times \mathrm{OF} \underline{0.96} \times \mathrm{WZF} \underline{1.00}=\underline{1728}$

$\mathrm{RC}($ Signalized $)=\mathrm{RC}($ Open Road) $\underline{\mathbf{1 7 2 8}} \times \mathrm{G} / \mathrm{C} \underline{\mathbf{0 . 7 4}}=\underline{\mathbf{1 2 7 9}}$

If $\mathrm{V}$ ? $\mathrm{RC}$, there is no restriction on Lane Closure

If $\mathrm{V}>\mathrm{RC}$, calculate the hourly percentage of ADT at which Lane Closure will be permitted

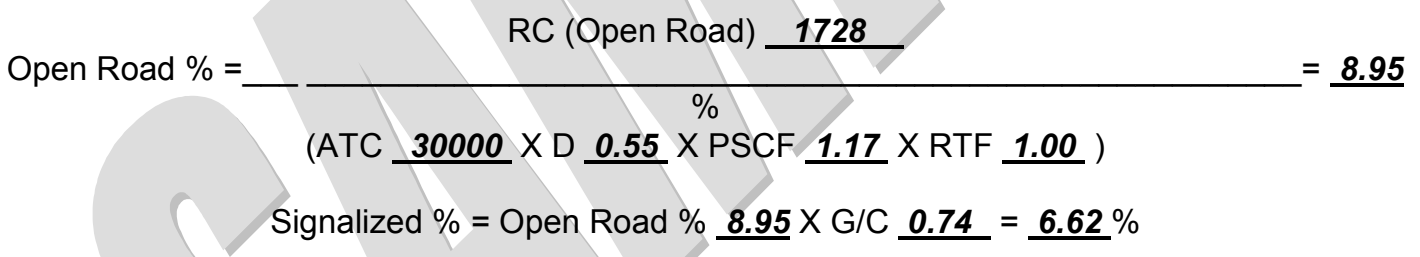

Plot 24 hour traffic to determine when Lane Closure permitted. (See Exhibit 10-A, Sheet 9 of 11)

NOTE: For Existing 2-Lane Roadways, $D=1.00$.

Work Zone Factor (WZF) applies only to 2-Lane Roadways.

For $\mathrm{RTF}<1.00$, briefly describe alternate route: $\mathbf{N A}$ 
Exhibit 10-A, Lane Closures, Sheet 9 of 11

LANE CLOSURES

24 HOUR COUNTS

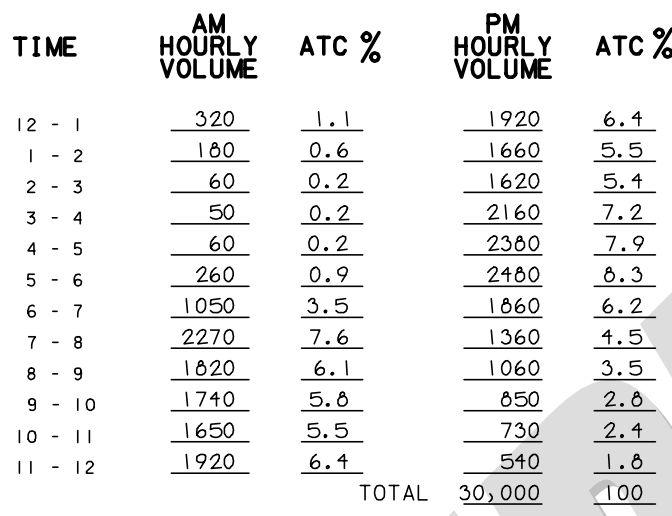

DATE

APR 19,1998

DESIGNER

GIDDENS

PROJECT NO.

$12345-6789$

LOCATION

BUCK LAKE RD。

HOURLY VARIATION OF DAILY TRAFFIC

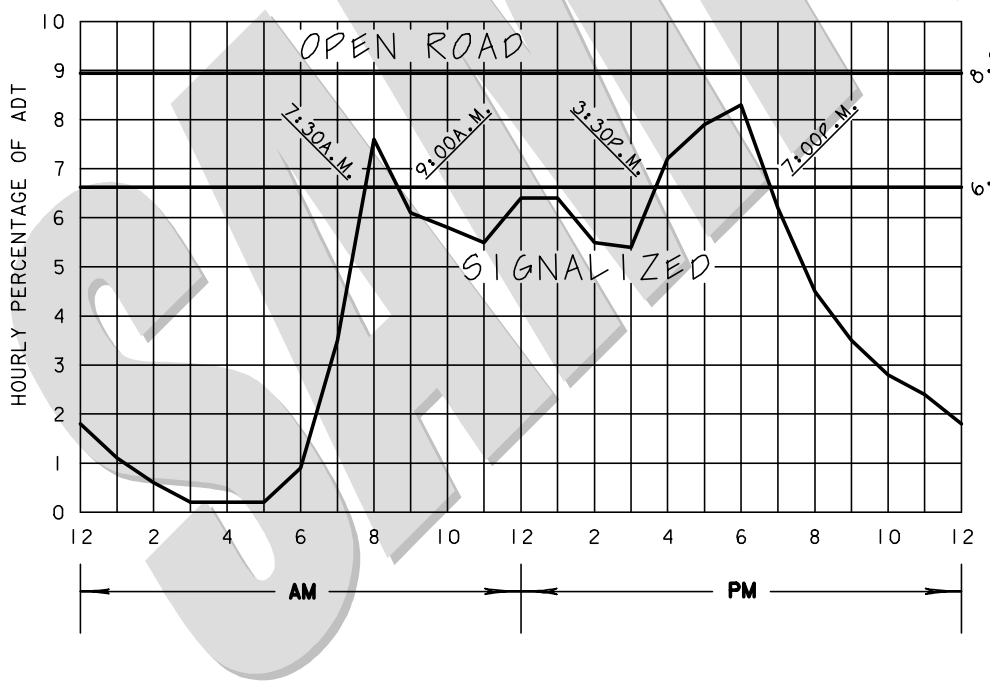

- CONCLUSION-

ROUND TO THE CONSERVATIVELY $6^{2}$

OPEN ROAD LANE

NO

RESTRICTION

SI GNAL I ZED LANE
CLOSURE

9:00A.M. - 3:30P.M.

7:0OP.M. - 7:30A.M. 
Exhibit 10-A, Lane Closures, Sheet 10 of 11

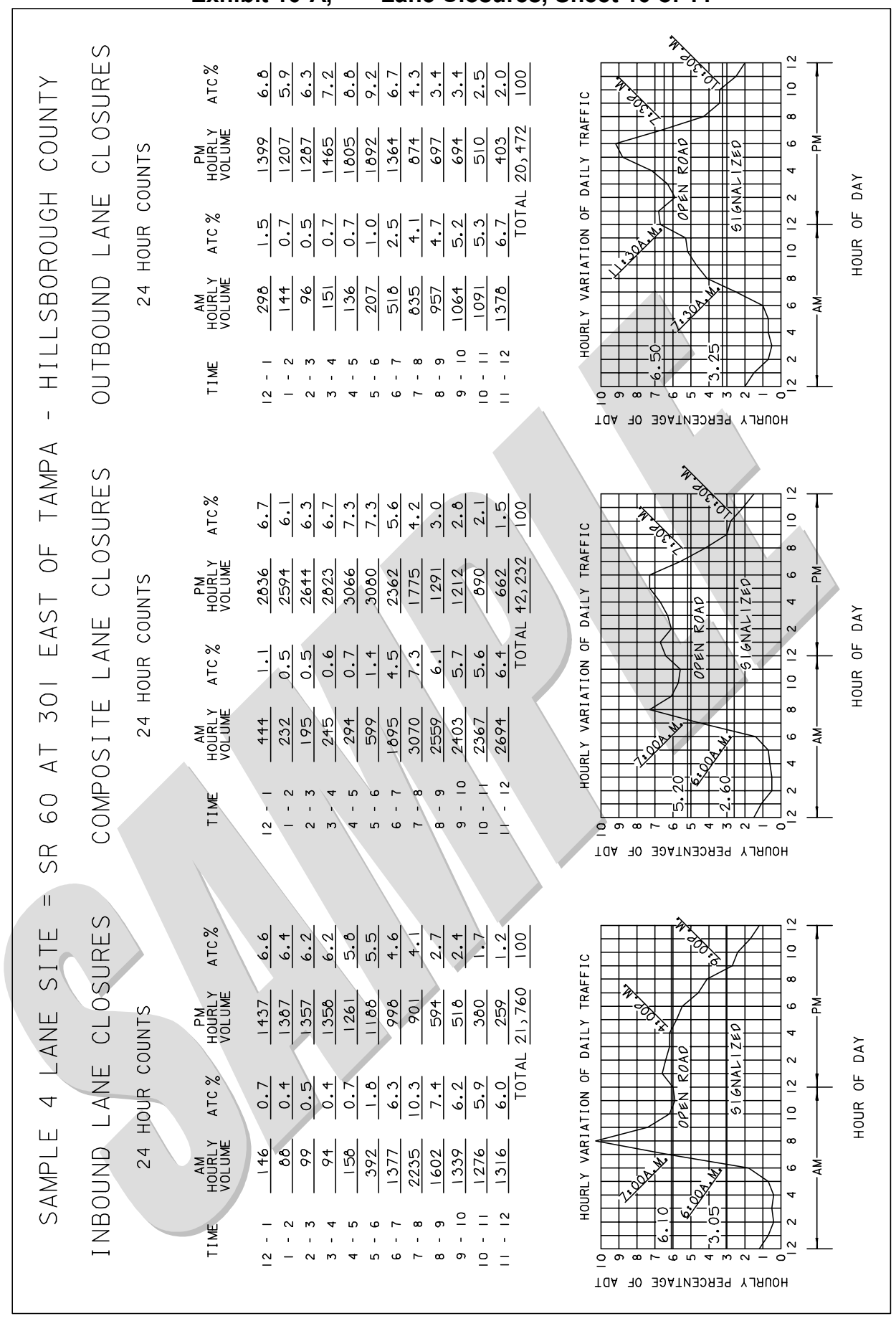


Exhibit 10-A, Lane Closures, Sheet 11 of 11

\begin{tabular}{|c|c|c|c|}
\hline \multicolumn{4}{|c|}{$\begin{array}{c}\text { LANE CLOSURE WORKSHEET SUMMARY } \\
\text { LANE SAMPLE WITH SIGNIFICANT AM-PM PEAKS } \\
\text { SAMPLES = INBOUND (WB), COMPOSITE (EB \& WB), OUTBOUND (EB) } \\
\text { SITE = SR } 60 @ \text { US } 301 \text { EAST OF TAMPA, HILLSBOROUGH CO. }\end{array}$} \\
\hline COMPONENT & INBOUND & COMPOSITE & OUTBOUND \\
\hline ADT & 21,760 & 42,232 & 20,472 \\
\hline$P / D$ & 0.103 & 0.073 & 0.092 \\
\hline$D$ & 1.00 & 0.60 & 1.00 \\
\hline PSCF & 1.17 & 1.17 & 1.17 \\
\hline RTF & 1.00 & 1.00 & 1.00 \\
\hline V & 2622 & 2164 & 2203 \\
\hline TLW & 12 & 12 & 12 \\
\hline LC & 0 & 0 & 0 \\
\hline C & 1800 & 1800 & 1800 \\
\hline OF & 0.86 & 0.86 & 0.86 \\
\hline RC (OPEN ROAD) & 1548 & 1548 & 1548 \\
\hline $\mathrm{G} / \mathrm{C}$ & 0.50 & 0.50 & 0.50 \\
\hline RC (SIGNAL) & 774 & 774 & 774 \\
\hline$\%$ OPEN ROAD & 6.10 & 5.20 & 6.50 \\
\hline$\%$ SIGNAL & 3.05 & 2.60 & 3.25 \\
\hline LANE CLOSURE & 7:00 AM & 7:00 AM & 11:30 AM \\
\hline (OPEN ROAD) & 4.00 PM & 7:30 PM & 7:30 PM \\
\hline LANE CLOSURE & 6:00 AM. & 6:00 AM & 7:30 AM \\
\hline (SIGNAL) & 9:00 PM. & 10:30 PM & 10:30 PM \\
\hline
\end{tabular}

